GEORGE ALFREDO LONGHITANO

VANTS PARA SENSORIAMENTO REMOTO: APLICABILIDADE NA AVALIAÇÃO E MONITORAMENTO DE IMPACTOS AMBIENTAIS CAUSADOS POR ACIDENTES COM CARGAS PERIGOSAS 
GEORGE ALFREDO LONGHITANO

\title{
VANTS PARA SENSORIAMENTO REMOTO: APLICABILIDADE NA AVALIAÇÃO E MONITORAMENTO DE IMPACTOS AMBIENTAIS CAUSADOS POR ACIDENTES COM CARGAS PERIGOSAS
}

\author{
Dissertação apresentada à Escola \\ Politécnica da Universidade de São Paulo, \\ para obtenção do título de Mestre em \\ Engenharia. \\ Área de Concentração: Engenharia de \\ Transportes - Geoprocessamento \\ Orientador: Prof. Dr. José Alberto \\ Quintanilha
}

São Paulo 
GEORGE ALFREDO LONGHITANO

\title{
VANTS PARA SENSORIAMENTO REMOTO: APLICABILIDADE NA AVALIAÇÃO E MONITORAMENTO DE IMPACTOS AMBIENTAIS CAUSADOS POR ACIDENTES COM CARGAS PERIGOSAS
}

\author{
Dissertação apresentada à Escola \\ Politécnica da Universidade de São Paulo, \\ para obtenção do título de Mestre em \\ Engenharia. \\ Área de Concentração: Engenharia de \\ Transportes - Geoprocessamento \\ Orientador: Prof. Dr. José Alberto \\ Quintanilha
}

São Paulo 
Este exemplar foi revisado e alterado em relação à versão original, sob responsabilidade única do autor e com a anuência de seu orientador.

São Paulo, de outubro de 2010.

Assinatura do autor

Assinatura do orientador

FICHA CATALOGRÁFICA

Longhitano, George Alfredo

VANTs para sensoriamento remoto: aplicabilidade na avaliação e monitoramento de impactos ambientais causados por acidentes com cargas perigosas / G.A. Longhitano. -- ed.rev. -São Paulo, 2010.

$148 \mathrm{p}$.

Dissertação (Mestrado) - Escola Politécnica da Universidade de São Paulo. Departamento de Engenharia de Transportes.

1. Sensoriamento remoto 2. Impactos ambientais 3. Trans portes I. Universidade de São Paulo. Escola Politécnica. Departamento de Engenharia de Transportes II. t. 
Dedicado aos mens pais, João e Clarice. 


\section{AGRADECIMENTOS}

Ao Prof. Dr. José Alberto Quintanilha, pela orientação, confiança e amizade.

À minha família que sempre me apoiou em todos os aspectos.

Aos colegas da pós-graduação e do Laboratório de Geoprocessamento que participaram desta jornada, pela amizade, transmissão de conhecimentos e incentivo nos estudos.

Ao técnico Marco Antônio Lainha do Setor de Operação de Emergências da CETESB, ao Adriano Kancelkis da AGX Tecnologia, ao Giovani Amianti da Xmobots e à BTX - geologia e meio ambiente pelo atendimento sempre solícito e pelas inúmeras informações prestadas, sem as quais a pesquisa não poderia ser realizada. 


\section{RESUMO}

A maior parte de desastres químicos no estado de São Paulo é gerada por acidentes com transporte rodoviário de cargas perigosas (cerca de 40\%). A coleta de informações ambientais das áreas atingidas depende de vistoria emergencial que muitas vezes traz riscos e dificuldades às equipes de atendimento envolvidas. objetivo principal da pesquisa foi verificar a aplicabilidade de sensoriamento remoto por VANTs para auxílio na avaliação e monitoramento de impactos ambientais causados por acidentes envolvendo transportes de cargas perigosas em rodovias. Para isso, foram caracterizados os principais projetos de sensoriamento remoto por VANTs existentes e em desenvolvimento e identificadas evoluções e tendências de aplicações, em especial, civis, com maior detalhamento dos projetos brasileiros.

Identificaram-se os benefícios que a tecnologia pode oferecer para a aplicação desejada. Definiu-se a parametrização técnica de VANTs mais adequados para viabilizar a aplicação em análise. Foi indicado um VANT da classe Mini ou Close Range. Foram identificados os cenários ambientais possíveis em situações emergenciais pós acidentes com transporte rodoviário de cargas perigosas. A partir das informações levantadas, estudou-se a viabilidade técnica, econômica e legal da aplicação por meio de hipóteses e deduções. Os resultados mostram que imagens aéreas podem auxiliar as equipes a avaliarem remotamente a situação ambiental, de forma mais rápida e segura e com geração de melhores informações. Além disso, a tecnologia pode trazer vantagens econômicas para os responsáveis pelo acidente. Conclui-se que atualmente as plataformas VANTs e sensores passíveis de serem transportados por elas são aplicáveis e podem servir adequadamente de tecnologia para sensoriamento remoto, com foco para o uso proposto. Porém, faz-se a ressalva que do ponto de vista legal, atualmente há restrições para a atividade de VANTs no Brasil que podem inviabilizar a utilização em foco.

Palavras-chave: VANT. Sensoriamento remoto. Avaliação de impactos ambientais. Transporte rodoviário. Acidentes químicos. Cargas perigosas. 


\begin{abstract}
The most part of chemical disaster in the São Paulo state is generated by accidents involving hazardous cargo highway transportation (40\%). The acquisition of environmental information in these areas depends of an emergency survey that often brings risks and difficulties for care teams involved. The main objective of the research was to verify the applicability of UAV remote sensing to assist evaluation and monitoring environmental impacts caused by accidents involving hazardous materials transport on highways. The major UAV remote sensing projects existing were characterized and trends of applications were identified. Brazilian and civil projects were detailed. The benefits offered by technology for desired applications were identified and a technique parameterization of adequate UAVs, for application under considerations, was defined. A Mini or Close Range UAV was appointed. The possible environmental scenarios in post emergency situations, involving accidents caused by road transportation of dangerous cargoes, were identified. From the information gathered, technical feasibility, economic and legal aspects were studied, through assumptions and deductions The results show that aerial images can help teams remotely assess the environmental situations, generating better, faster and safer information. Moreover, technology can bring economic advantages to those responsible for the accidents. We conclude that currently, UAV platforms and sensors are applicable and constitute an adequate remote sense technology for its intended use. However, there are legal restrictions for the UAV activity in Brazil that can derail its utilization.
\end{abstract}

Keywords: UAV. Remote sensing. Evaluation of environmental impacts. Highway transportation. Chemical accidents. Hazardous cargoes. 


\section{LISTA DE FIGURAS}

Figura 2.1.1-1: Representação de Componentes de um Sistema VANT. Adaptado de NASA (2006).

Figura 2.1.2-1: Ataque aéreo realizado por balões. Rússia - 1880 (FITEC, 2005)

Figura 2.1.2-2: $\mathrm{Na}$ esquerda, pipa de Batut e à direita, pipa de Lawrence. Fonte: Professional Aerial Photographers Association - Disponível em http://www.papainternational.org/history.html.

Figura 2.1.2-3: Fotografia aérea de São Francisco após o terremoto de 1906 obtida por câmera panorâmica acoplada a pipas. (Biblioteca do Congresso Norte Americano, 2009)

Figura 2.1.2-4: OQ-1 - O primeiro VANT rádio controlado. (HARDGRAVE, 2005 apud MEDEIROS, 2007)

Figura 2.1.2-5: Exemplos de VANTs militares. Adaptado de DoD (2003) e Armada (2004)

Figura 2.1.2-6: Evolução de VANTs militares nos EUA. Adaptado de http://www.sdauvsi.org/pdfs/uavdod_103101.pdf

Figura 2.1.2-7: Perfil de fundos anuais (em milhões de dólares) do Departamento de Defesa - DOD dos EUA em VANTs. (DOD, 2003).

Figura 2.1.2-8: Características do VANT UCAV-N da Pioneers UAV's Inc. (DOD, 2003)

Figura 2.1.2-9: Protótipo do VANT Denel Bateleur. Adaptado de http://www.defesanet.com.br/fab1/bataleur.htm

Figura 2.1.2-10: Diagnóstico dos Participantes da AUVSI's Unmanned Systems North America 2008.2 Adaptado de http://symposium.auvsi.org/show/a_demographics.php

Figura 2.1.2-11: Aeromodelo Rádio-controlado utilizado por Przybilla (1979) para obtenção de fotografias aéreas. (EINSEINBEISS, 2004)

Figura 2.1.3-1: Foto aérea de Praia das Fontes, em Beberibe-CE obtida por pipa. (http://www.altoretrato.com.br/pt-br/empinando_fotografias)

Figura 2.1.3-2: Exemplos de dirigíveis para obtenção de imagens aéreas do Projeto Aurora e Hi-Shots, respectivamente. (GALVEZ, 2003) e (http://hi-shots.biz)

Figura 2.1.3-3: RMAX da Yamaha. (NASA, 2006)

Figura 2.1.3-4: VANTs baseados em helimodelos no mundo. (MARTINS, 2008)

Figura 2.1.3-5: Altair e Altus em vôo, respectivamente. (NASA, 2006)

Figura 2.1.3-6: Aeronave Aerosonde. (NASA, 2006)

Figura 2.1.3-7: Aeronave Pegasus. Asas cobertas por painéis de captação de energia solar. (http://www.pegasus4europe.com/ 
Figura 2.1.3-8: Exemplos de MAVs. (DOD, 2003)

Figura 2.1.3-9: Exemplos de VANTs de lançamento manual. (ARMADA, 2004).

Figura 2.1.3-10: Capacidades chaves exigidas em missões com VANTs. Adaptado de Nasa (2006)

Figura 2.1.3-11: Imagem obtida por VANT construído na UFSM para monitoramento agrícola. (MEDEIROS et al., 2007)

Figura 2.1.3-12: Modelo 3D do terreno obtido por sensor laser embarcado em VANT(EISENBEISS, 2004)

Figura 2.1.3-13: À esquerda, SAR embarcado no VANT Raven, e à direita, fotografia aérea e imagem do radar de uma área com reservatório. (O YOUNG, 2007)

Figura 2.1.3-14: Imagens SAR provenientes do IAI Elta EL/M-2055. Na imagem podem ser identificados aviões. (ARMADA 2004)

Figura 2.1.3-15: Aeronave ACAUÃ. (CTA, 2005).

Figura 2.1.3-16: Projeto AqVS. VANT de pequeno porte da UFMG (ISCOLD, 2007 apud ALVES NETO, 2008).

Figura 2.1.3-17: Apoena 1000(Catálogo Apoena Series - Xmobots, 2009).

Figura 2.1.3-18: Aeronave acoplada a veículo para decolagem, torre de rastreamento e estação de comando, respectivamente (AGX TECNLOGIA. ORG. LONGHITANO, 2006)

Figura 2.1.3-19: Imagem obtida a $200 \mathrm{~m}$ de altura com distância focal de $50 \mathrm{~mm}$ - (a área recoberta é de aproximadamente $0,53 \mathrm{ha}$, com pixel de $2,57 \mathrm{~cm}$ em solo). (AGX TECNLOGIA. ORG. LONGHITANO, 2006)

Figura 2.1.3-20: VANT FITuav. (FITEC, 2005).

Figura 2.1.3-21: FS-01 - Watchdog da Flight Solutions. Imagem gentilmente cedida (FLIGHT SOLUTIONS, 2009)

Figura 2.1.3-22: Exemplo de Imagem aérea obtida pelo FS-01 Imagem gentilmente cedida (FLIGHT SOLUTIONS, 2009)

Figura 2.1.3-23: VANT Carcará. Santos Lab, 2009

Figura 2.1.3-24: Aeronave Heron em teste pela polícia federal no Paraná. (http://www.parana-online.com.br/editoria/cidades/news/384669/)

Figura 2.1.3-25: Aeronave Hermes 450. (FREITAS e COTTET, 2010)

Figura 2.2-1: Número de atendimentos emergenciais realizados pela CETESB a acidentes com transporte rodoviário de carga perigosa - 1983 a 2004. (TEIXEIRA, 2005)

Figura 2.2-2: Distribuição regional dos acidentes com transporte rodoviário de cargas perigosas no Estado de São Paulo - 1978 a 2004. (TEIXEIRA, 2005)

Figura 2.2-3: Distribuição horária dos acidentes com transporte rodoviário de cargas perigosas no Estado de São Paulo - 1978 a 2004. (TEIXEIRA, 2005) 
Figura 2.2-4: Aspectos ambientais suscetíveis a impactos causados por acidentes químicos

Figura 2.2-5: Exemplos de acidentes com transporte de cargas perigosas por rodovias. (VASCONCELLOS e LAINHA, 2006) e (CETESB, 2009)

Figura 2.2-6: Neutralização de área atingida por acidente (CETESB, 2009)

Figura 2.2-7: Destombamento de veículo em acidente com amônia anidra. (VASCONCELLOS e LAINHA, 2006)

Figura 2.2-8: Contenção de substância derramada com barreiras e recolhimento (CETESB, 2009)

Figura 2.3-1: Uso do sensoriamento remoto para avaliação de impactos ambientais causados por desastres, no caso um tsunami. (LUCHIARI e MORATO, 2009)

Figura 2.3-2: Imagem gerada pelo UAVSAR após terremoto no Haiti - falha geológica que gerou o abalo (seta preta) e a cidade de Porto Príncipe (seta amarela). (NASA, 2010)

Figura 2.3-3: Litoral da Louisiana com faixa imageada pelo UAVSAR em junho de 2010 - manchas de óleo em preto. (NASA, 2010)

Figura 2.3-4: Caminhão de Combustível Tombado em imagem aérea. (JENSEN e COWEN, 1999 apud JENSEN, 2009).

Figura 3-1: Procedimentos Metodológicos da Pesquisa

Figura 4.1.13-1: Resolução espacial e temporal de dados de sensoriamento remoto para diversas aplicações. (JENSEN, 2009).

Figura 4.2.1.4-1: Imagem obtida a cerca de $600 \mathrm{~m}$ com área recoberta de 15,09 ha (pixel corresponde a $13,76 \times 13,76 \mathrm{~cm}$ em solo). (AGX TECNOLOGIA org LONGHITANO, 2006)

Figura 4.2.1.4-2: Ampliação do retângulo demarcado na Figura 4.2.1.3-1. (AGX TECNOLOGIA org LONGHITANO, 2006)

Figura 4.2.1.8-1: Mosaico da área teste 1- Pixel da imagem original corresponde a cerca de $13 \times 13 \mathrm{~cm}$ em solo (LONGHITANO, 2006).

Figura 4.2.1.8-2: Classificação por máxima verossimilhança da área 1 . (LONGHITANO, 2006).

Figura 4.2.1.8-3: Mosaico da área teste 2- Pixel da imagem original corresponde a cerca de $13 \times 13 \mathrm{~cm}$ em solo. (LONGHITANO, 2006).

Figura 4.2.1.8-4: Classificação por segmentação da área 2. (LONGHITANO, 2006).

Figura 4.2.2.8-5: Resultado da segmentação da imagem da área 3. (LONGHITANO, 2006).

Figura 4.2.2.8-6: Classificação por segmentação - área 3. (LONGHITANO, 2006).

Figura 4.2.4.1.2-1: Comparação entre áreas cobertas por diferentes câmeras Adaptado de RUY et al., 2005 


\section{LISTA DE TABELAS}

Tabela 2.1.2-1: Áreas potenciais de emprego de VANTs no setor civil e aplicações ligadas a sensoriamento remoto (em vermelho). Adaptado de Nasa (2006).

Tabela 2.1.3-1: Categorias de VANTs definidas pela UVS-International

Tabela 2.2-1: Distribuição dos acidentes químicos por atividade no Estado de São Paulo - 1978 a maio de 2009. (CETESB, 2009)

Tabela 2.2-2: Distribuição das classes de risco dos produtos perigosos transportados nos acidentes atendidos pela CETESB entre 2003 e maio de 2009 (CETESB, 2009)

Tabela 2.2-3: Tipos predominantes de contaminação que os acidentes entre 2005 e maio de 2009 ocasionaram ao meio ambiente (CETESB, 2009)

Tabela 4.2.4.1.2-1: Tamanho de pixel e área imageada para diferentes alturas de vôo Distância focal de 28mm. (AGX TECNOLOGIA org LONGHITANO, 2010)

Tabela 4.2.4.3-1: Custos para aquisição de aerofotografias/imagens de alta resolução junho de 2010 


\section{SUMÁRIO}

1 INTRODUÇÃO

1.1 APRESENTAÇÃO E JUSTIFICATIVA

1.2 OBJETIVOS 3

1.3 ESTRUTURA DO TRABALHO 4

2 REVISÃO BIBLIOGRÁFICA E FUNDAMENTAÇÃO 6 TEÓRICA

2.1. VANTS E SENSORIAMENTO REMOTO 6

2.1.1 Definições 6

2.1.2 Histórico dos VANTs para Sensoriamento Remoto 8

2.1.3 Tecnologias, Capacidades e Exemplos de Sistemas Aéreos Não Tripulados para Sensoriamento Remoto

2.2 AVALIAÇÃO E MONITORAMENTO DE IMPACTOS AMBIENTAIS EM ACIDENTES COM TRANSPORTE DE 42 CARGAS PERIGOSAS EM RODOVIAS

2.3 SENSORIAMENTO REMOTO PARA AVALIAÇÃO DE IMPACTOS AMBIENTAIS EM EMERGÊNCIAS

3 METODOLOGIA

3.1 HIPÓTESES DE MELHORIAS NA AVALIAÇÃO E MONITORAMENTO DE IMPACTOS AMBIENTAIS ATRAVÉS DO USO DE VANTS

4 RESULTADOS E DISCUSSÃO

4.1 PARÂMETROS TÉCNICOS DE VANTS PARA A APLICAÇÃO

4.1.1 Plataforma VANT

4.1.2 Alcance 
$\begin{array}{ll}\text { 4.1.4 Altura do vôo } & 73\end{array}$

$\begin{array}{ll}\text { 4.1.5 Classe de VANT } & 74\end{array}$

$\begin{array}{ll}\text { 4.1.6 Decolagem e aterrissagem } & 75\end{array}$

4.1.7 Operações programadas e autônomas 75

4.1.8 Transmissão e armazenamento de dados 75

$\begin{array}{ll}\text { 4.1.9 Condições de tempo } & 76\end{array}$

$\begin{array}{ll}\text { 4.1.10 Segurança } & 76\end{array}$

4.1.11 Tempo para provimento de informações 76

$\begin{array}{ll}\text { 4.1.12 Capacitação profissional } & 77\end{array}$

$\begin{array}{ll}\text { 4.1.13 Sensores a serem embarcados } & 77\end{array}$

4.1.14 Modelo de VANT adequado à aplicação 80

4.2 VIABILIDADE DA APLICAÇÃO 81

$\begin{array}{ll}\text { 4.2.1 Viabilidade Técnica } & 81\end{array}$

4.2.1.1 Acionamento 82

4.2.1.2 Transporte para o local do acidente 84

4.2.1.3 Avaliação da ocorrência no local 85

4.2.1.4 Geração de informações para avaliação imediata da 90 ocorrência

4.2.1.5 Redução do tempo da avaliação ambiental 96

4.2.1.6 Segurança das equipes de avaliação 97

4.2.1.7 Monitoramento ambiental das áreas afetadas 98

4.2.1.8 Documentação da avaliação e do monitoramento de 100

$\begin{array}{lr}\text { 4.2.2 Viabilidade legal } & 109\end{array}$

$\begin{array}{ll}\text { 4.2.3 Viabilidade econômica } & 111\end{array}$

4.2.4 Comparação entre VANTs e outras plataformas de 114

$\begin{array}{ll}\text { 4.2.4.1 Parâmetros técnicos } & 114\end{array}$ 
4.2.5 Viabilidade do uso da tecnologia em acidentes com transporte de cargas perigosas em ferrovias e dutos

5 CONCLUSÕES

5.1 LEVANTAMENTO E CARACTERIZAÇÃO DE VANTS

5.2 EVOLUÇÕES E TENDÊNCIAS DE APLICAÇÕES DE VANTS

5.3 PARÂMETROS TÉCNICOS DE VANTS PARA A APLICAÇÃO

5.4 VIABILIDADE TÉCNICA, LEGAL E ECONÔMICA

6 CONSIDERAÇÕES FINAIS

Anexo A - Questionário - Levantamento de VANTs para Sensoriamento Remoto 


\section{INTRODUÇÃO}

\subsection{APRESENTAÇÃO E JUSTIFICATIVA}

O conceito de construir aeronaves não tripuladas para aplicações diversas surgiu, inicialmente, de necessidades militares, visando a execução de missões aéreas que ofereciam risco à vida humana.

Com o avanço tecnológico nos setores de processamento de dados e miniaturização de componentes eletrônicos ocorridos nas últimas duas décadas, diversas aplicações militares de Veículos Aéreos Não-Tripulados - VANTs (Unmanned Aerial Vehicles - UAV foram desenvolvidas ao redor do mundo, havendo constante crescimento do número de projetos atualmente (ARMADA, 2004).

Mais recentemente, usos científicos e civis têm sido desenvolvidos, nos quais os veículos aéreos desprovidos de tripulação podem apresentar vantagens técnicas e econômicas em relação a diferentes campos de atuação.

$\mathrm{Na}$ maioria das aplicações desenvolvidas, os VANTs têm sido concebidos como plataformas para embarcar sensores remotos para obtenção de imagens e dados da superfície terrestre.

Embora ocorra aumento do número de projetos de VANTs voltados para aplicação civil, esta ainda pode ser considerada recente e incipiente, principalmente no cenário brasileiro.

Deste modo, há carência de estudos que apresentem o estágio atual do desenvolvimento do sensoriamento remoto por VANTs.

As principais vantagens do sensoriamento remoto por VANTs, em relação ao aerotransportado por aeronaves tripuladas e ao orbital, podem ser: a redução dos custos de obtenção de imagens/fotografias aéreas; a maior flexibilidade de resolução temporal para aquisição de imagens de alta resolução espacial; possibilidade de execução de missões em condições adversas sem o risco de vida 
para o piloto e operador da câmara aerofotogramétrica; menor necessidade de gastos de treinamento de pilotos e; a maior facilidade e velocidade de incorporação de novas tecnologias.

Portanto, entende-se que há diversos potenciais de aplicação (BLAND et al., 2004) e existem poucos estudos sobre o tema no Brasil.

Considerando-se o exposto anteriormente, ressaltam-se dentre os potenciais de aplicação da tecnologia de sensoriamento remoto por VANTs: a detecção, monitoramento, caracterização e mapeamento de eventos, processos e alterações de rápido desenvolvimento, como é o caso de acidentes em transporte de cargas perigosas em rodovias.

Em estudos ambientais, o sensoriamento remoto é reconhecidamente uma ferramenta muito útil (FLORENZANO, 2002), inclusive de avaliação de impactos. É possível detectar, localizar e determinar a extensão de contaminações em solos, drenagens, na vegetação, assim como o grau de alteração provocado pelo impacto e, posteriormente, monitorar as áreas atingidas. Entretanto, não é utilizado normalmente em avaliação de impactos de desastres ambientais em pequenas e médias áreas (inferiores a $10 \mathrm{ha}$ ), devido à indisponibilidade de imagens de alta resolução em datas e horários específicos e, quando disponíveis, ao custo relativamente elevado destas.

O transporte de produtos dos setores químicos, petroquímico, de refino de petróleo, e outros produtos perigosos é realizado no Brasil, em sua maior parte, cerca de 70\%, por rodovias (ALVES et al., 2009).

Produto perigoso, segundo a Norma NFPA (2002), é qualquer substância (sólido, líquido ou gás) que quando exposta é capaz de provocar riscos às pessoas, ao meio ambiente e à propriedade.

Em todas as operações que envolvem produtos perigosos há probabilidade de ocorrência de acidentes, entretanto, as atividades de transporte são as mais suscetíveis, pois há muitos fatores externos e que fogem ao controle dos responsáveis pelo transporte que podem ocasionar os acidentes, independente de avanços e melhorias na prevenção destes.

Para exemplificar a situação, no estado de São Paulo, a maior parte (40,5\% do total) dos acidentes ambientais atendidos entre 1978 e 2008 pela CETESB - Companhia de Tecnologia de Saneamento Ambiental do Estado de São Paulo (CETESB, 2009), 
foi provocada por transporte rodoviário de cargas perigosas.

Estes acidentes podem causar diversos impactos ambientais, como por exemplo, contaminação do solo, águas superficiais e subterrâneas, impactos à fauna e vegetação, prejuízos ao patrimônio público e privado e às atividades econômicas, como a agropecuária. Podem até ocasionar danos à saúde e bem estar do homem.

Em função disto, deve haver uma avaliação dos impactos ambientais para o planejamento de medidas de controle, mitigação e compensação dos impactos e de recuperação e monitoramento ambiental das áreas atingidas.

As áreas e objetos atingidos (solos, vegetação, corpos hídricos, etc) devem ser identificados e os impactos ambientais diretos e indiretos avaliados. Também deve ser realizado o diagnóstico ambiental do local do acidente e seu entorno para auxiliar o planejamento das ações e gestão e a previsão de novos impactos ou, ainda, do comportamento dos impactos identificados. Estes procedimentos devem ser realizados em campo de forma emergencial, rapidamente. A coleta de informações ambientais nestes casos depende de vistoria expedita que muitas vezes traz riscos e dificuldades às equipes envolvidas para observação e acesso à área, dependendo da complexidade ambiental da área e da magnitude do acidente. Imagens aéreas obtidas destas áreas, desde que rapidamente, poderiam auxiliar a estas equipes avaliarem remotamente a situação ambiental, de forma mais rápida e segura e com possibilidade de geração de melhores informações.

Deste modo, a avaliação de impactos ambientais ocasionados por acidentes em transporte de cargas perigosas trata-se de um bom campo para que seja realizado um estudo de aplicabilidade de imagens da superfície terrestre geradas por VANTs, verificando-se a eficácia operacional.

Considerando-se que há este potencial de aplicação, cabe avaliar, além da viabilidade técnica e econômica da atividade, também as questões legais que podem restringir o uso dos VANTs.

\subsection{OBJETIVOS}

A presente pesquisa tem com como objetivo inicial apresentar e caracterizar os 
principais projetos de sensoriamento remoto por VANTs existentes e em desenvolvimento e identificar as evoluções e tendências de aplicações, em especial, civis, com maior detalhamento dos projetos brasileiros.

O objetivo inicial deve, desta forma, gerar subsídios para o objetivo principal da pesquisa que é verificar a aplicabilidade de sensoriamento remoto por VANTs para auxílio na avaliação e monitoramento de impactos ambientais causados por acidentes envolvendo transportes de cargas perigosas em rodovias. Devem ser identificados quais os benefícios que esta aplicação pode oferecer, bem como quais as restrições técnicas, econômicas e legais.

Atrelado ao objetivo principal, a pesquisa visa, como um objetivo secundário, a parametrização técnica de VANTs mais adequados para viabilizar a aplicação em análise. Deste modo, permite-se também a comparação técnico-econômica com outros métodos de obtenção de dados de sensoriamento remoto.

Pretende-se, por fim, a partir destes objetivos, concluir se, atualmente ou no futuro as plataformas VANTs e sensores passíveis de serem transportados por elas podem servir adequadamente de tecnologia para sensoriamento remoto, com foco para a aplicação em avaliação de impactos ambientais ocasionados por acidentes com transporte de cargas perigosas em rodovias. Também se espera definir se a técnica pode ser usada para acidentes causados pelo transporte ferroviário e por dutos de cargas perigosas.

\subsection{ESTRUTURA DO TRABALHO}

Após este capítulo introdutório, é apresentada a revisão bibliográfica e a fundamentação teórica da pesquisa. O capítulo foi dividido em três temas expressos pelos itens: "2.1 VANTs para Sensoriamento Remoto", que trata do histórico de desenvolvimento da tecnologia, com descrição dos principais equipamentos existentes e projetos em desenvolvimento; "2.2 Avaliação de Impactos Ambientais em Acidentes com Transporte de Cargas Perigosas em Rodovias", onde é abordado o atendimento emergencial e a avaliação de impactos ambientais ocasionados por acidentes com transporte de cargas perigosas em rodovias, e "2.3 Sensoriamento 
Remoto para Avaliação de Impactos em Desastres Ambientais" que apresenta o uso de sensoriamento remoto por VANTs em desastres e acidentes ambientais, em específico.

O capítulo 3 apresenta a metodologia adotada para execução da pesquisa. O levantamento de aspectos que podem ser beneficiados na avaliação e monitoramento de impactos ambientais através do uso de VANTs é abordado também neste capítulo.

Os parâmetros técnicos de VANTs definidos para a aplicação e os resultados da verificação da aplicabilidade destes em avaliação e monitoramento de impactos ambientais causados por acidentes com cargas perigosas são apresentados no capítulo 4.

Ainda neste capítulo, é realizada uma comparação dos aspectos de viabilidade técnica, econômica e legal da tecnologia de sensoriamento remoto por VANTs em relação a outros métodos de obtenção de imagens da superfície terrestre.

Em seguida (capítulo 5), são feitas as conclusões sobre os resultados obtidos, com base nos objetivos definidos, juntamente com as considerações finais da pesquisa. 


\section{REVISÃO BIBLIOGRÁFICA E FUNDAMENTAÇÃO TEÓRICA}

Neste capítulo são abordados os diferentes temas envolvidos na pesquisa.

Inicialmente é apresentado o histórico dos VANTs para sensoriamento remoto assim como os projetos de desenvolvimento de aeronaves não tripuladas em andamento, sendo enfocados sistemas de uso civil.

Informações relevantes das aeronaves são apresentadas, como medidas, autonomia de vôo em tempo e distância, velocidade, altura, capacidade de carga, sistema de vôo, sistemas de segurança e forma de decolagem e pouso. Os sistemas sensores dos VANTs também são descritos. Esta caracterização priorizou o maior detalhamento dos VANTs brasileiros.

As possíveis alterações ambientais que os principais produtos perigosos podem proporcionar ao meio ambiente, em função de suas características químicas e físicas, também foram pesquisadas e são tratadas.

A revisão bibliográfica aborda também os métodos e procedimentos de avaliação de impactos ambientais envolvidos em atendimento a emergências com acidentes de transporte de cargas perigosas ao longo de rodovias e o uso de sensoriamento remoto em avaliação e monitoramento de impactos ambientais.

\subsection{VANTS E SENSORIAMENTO REMOTO}

\subsubsection{Definições}

As informações sobre certa área da superfície terrestre podem ser obtidas diretamente em campo ou indiretamente através de produtos do sensoriamento remoto, que consiste na "utilização conjunta de modernos sensores, equipamentos, aeronaves, espaçonaves etc, com objetivo de estudar o ambiente terrestre através 
do registro e da análise das interações entre a radiação eletromagnética e as substâncias componentes do planeta Terra em suas mais diversas manifestações" (NOVO, 1989).

Através do sensoriamento remoto pode-se obter informações novas, assemelhandose ao levantamento diretamente em campo, entretanto, tem-se a possibilidade de amostrar áreas mais rapidamente.

A distância do sensor em relação à superfície da Terra é variável e é classificada em 3 níveis de altitude: orbital (sensores a bordo de satélites artificiais), aéreo (sensores a bordo de aeronaves) e o de campo/laboratório (sensores implantados em estruturas terrestres) (FLORENZANO, 2002). Naturalmente, devido às características dos VANTs, no presente estudo será destacado o nível aéreo.

VANT é abreviação de Veículo Aéreo Não Tripulado, sendo a nomenclatura em português para UAV - Unmanned Aerial Vehicle ou Unmanned Airbone Vehicle (IEEE, 2009). Destaca-se que a palavra Uninhabited (não habitado) é encontrada substituindo a Unmanned em algumas situações. O termo drone também tem sido aplicado, principalmente nos Estados Unidos, para se referir a veículos aéreos não tripulados que envolvem normalmente emprego mais acentuado da robótica e apresentam maior autonomia na operação.

Segundo o relatório do $D o D$ (Departamento de Defesa dos EUA) denominado Unmanned Aerial Vehicle Roadmap 2002 - 2027, que é um dos principais e mais completos documentos sobre o estado da arte da tecnologia, UAVs são:

Veículos aéreos que não carregam operador humano, utilizam forças
aerodinâmicas para se elevar, podem voar autonomamente ou ser pilotados
remotamente, podem ser descartáveis ou recuperáveis e podem transportar
cargas bélicas ou não bélicas. Excluem-se desta definição, veículos
balísticos e semi-balísticos como mísseis de cruzeiro, e projéteis.(DOD,
2003) Outras expressões, embora menos utilizadas, podem ser mencionadas, como Remotely Operated Aircraft - ROA (Aeronave Operada Remotamente), Remote Piloted Vehicle - RPV (Veículo Pilotado Remotamente), Airborne Remotely Operated Device - AROD (Dispositivo Aéreo Remotamente Operado). Estas são específicas para aeronaves que são pilotadas remotamente.

Mais recentemente surgiram os termos UAS - Unmmaned Aerial Systems e UAVS Unmanned Aerial Vehicles Systems que visam, adotando-se a palavra systems (sistemas), apresentar uma nomenclatura mais adequada, expressando um conceito que abrange os outros componentes, sejam de hardware ou software, além do 
veículo aéreo, como a estação de comando, o sensor, a telemetria, a navegação, etc. O DoD e a FAA - Federal Aviation Administration dos EUA, por exemplo, adotam a expressão UAS.

A Figura 2.1.1-1 mostra a representação de componentes constituintes de um típico SANT (Sistema Aéreo Não Tripulado) ou UAS.

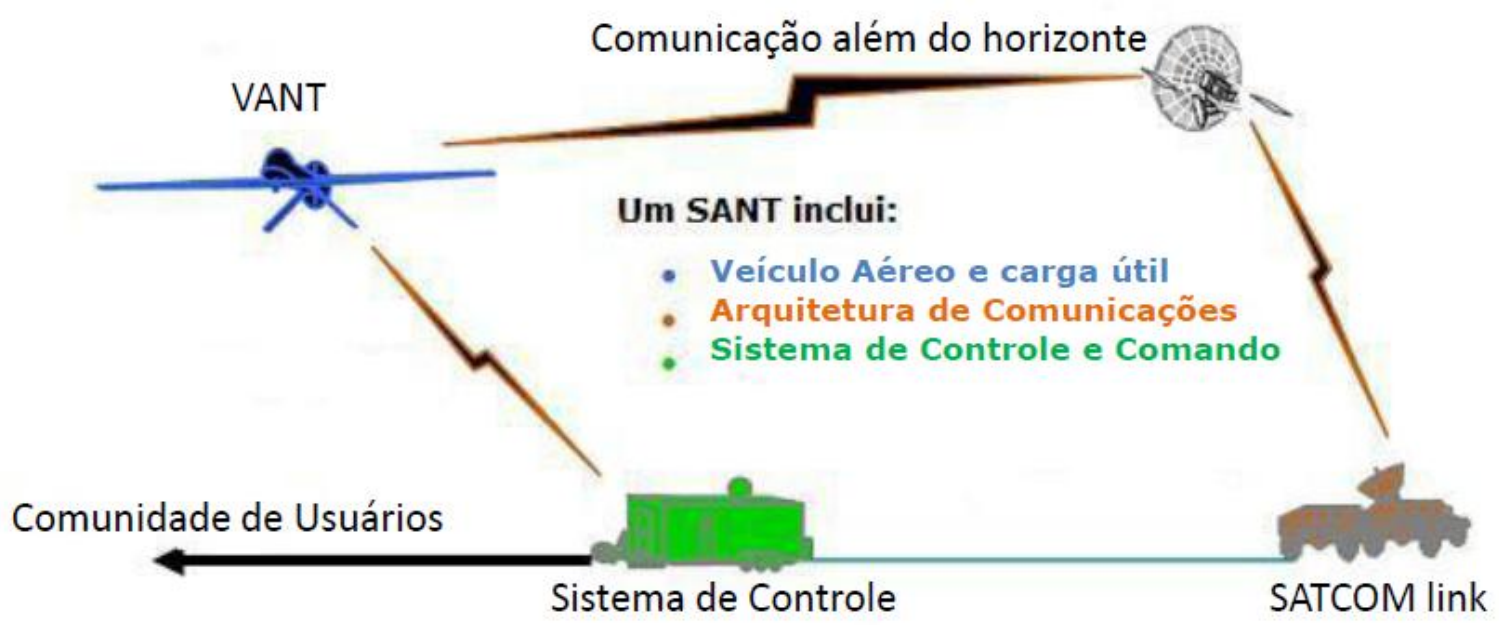

Figura 2.1.1-1: Representação de Componentes de um Sistema VANT. Adaptado de NASA (2006).

Embora existam diferentes terminologias, conforme apresentado, nota-se que a bibliografia internacional continua a adotar como termo predominante o UAV e na prática acaba muitas não distinguindo os termos em suas definições. No Brasil, o termo VANT é certamente o mais difundido e comum, sendo o adotado na presente pesquisa.

\subsubsection{Histórico dos VANTs para Sensoriamento Remoto}

A idéia de construção de artefatos voadores não tripulados é antiga e até mesmo anterior aos vôos tripulados. Um dos primeiros registros é do padre brasileiro Bartolomeu Lourenço de Gusmão que projetou e construiu um balão de ar quente e o demonstrou em 1709 em Lisboa, Portugal, sob a presença do rei João Quinto e de toda a corte portuguesa (BRANDÃO, 2007). Em um balão cativo tripulado, mais tarde, em 1858, o francês Gaspard Felix Tournachon obteria a primeira fotografia aérea conhecida e patentearia o que hoje conhecemos como aerolevantamento, 
sendo um pioneiro do sensoriamento remoto.

Balões cativos são utilizados até hoje como forma de obtenção de imagens e fotografias aéreas, mas em relação a veículos aéreos não tripulados mais leves que o ar, destacam-se os projetos que se utilizam de dirigível como plataforma para embarcar sensores, conforme será abordado posteriormente.

Antes mesmo dos balões, as pipas já existiam e estas também podem ser consideradas Veículos Aéreos Não Tripulados. As primeiras aplicações registradas de VANTs foram com balões e pipas.

Há documentos que relatam que em 22 de Agosto de 1849, os Austríacos teriam enviado cerca de 200 balões não-tripulados carregados com bombas temporizadas à cidade de Veneza na Itália. Na época, a região era dominada pela Áustria (ALVES NETO, 2008).

A ilustração russa de 1880 a seguir demonstra um ataque aéreo realizado através de balões cativos não tripulados (FITEC, 2005).

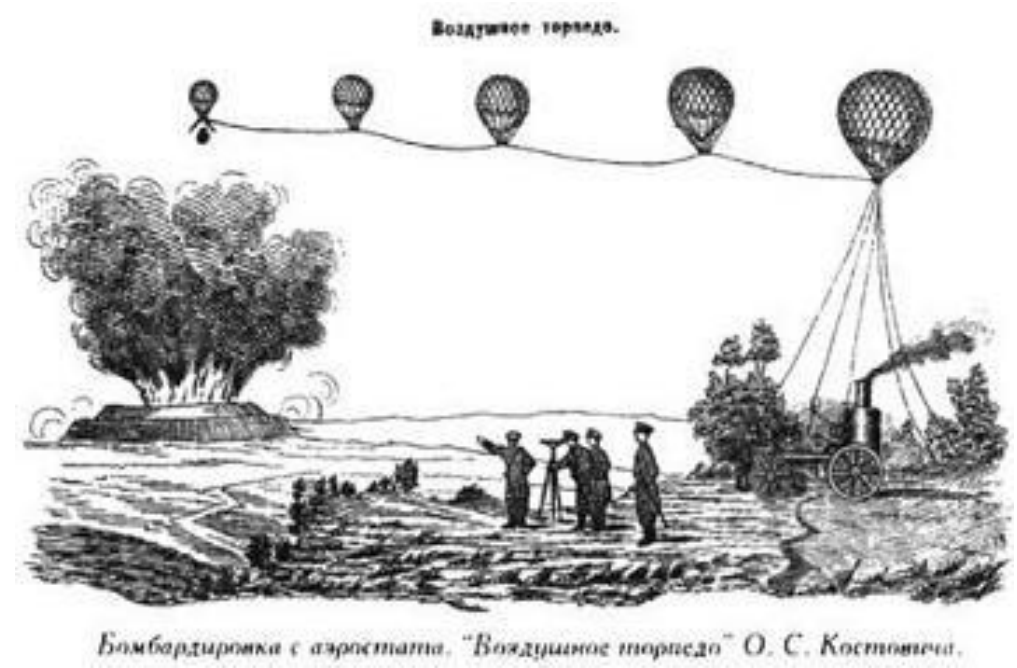

Figura 2.1.2-1: Ataque aéreo realizado por balões. Rússia - 1880 (FITEC, 2005)

Em 1883, Douglas Archibald instalou um anemômetro a um fio em uma pipa para medir o vento em diferentes altitudes e em 1888, na França, Arthur Batut acoplou uma câmera fotográfica também em uma pipa, obtendo as primeiras aerofotografias por VANT de que se tem registro (PUSCOV, 2002 apud MEDEIROS, 2007).

Batut publicou o livro "A Fotografia Aérea por Pipas" em 1890 onde visionava aplicações para exploradores, arqueólogos, agrônomos e forças militares.

George R. Lawrence, foi um dos adeptos desta técnica de fotografia aérea por pipa e em 1906 utilizou-se de um conjunto de 17 pipas de uma só vez, à qual chamava 
de Aeronave Cativa, para obter imagens de São Francisco nos EUA para registrar os escombros da cidade após o terremoto ocorrido em 18 de abril de 1906 (BAKER, 1994 apud JENSEN, 2009). Trata-se, provavelmente do pioneiro em utilizar imagens aéreas para avaliar impactos pós-desastre.

A Figura 2.1.2-2 apresenta as pipas de Batut e Lawrence e a Figura 2.1.2-3, uma fotografia aérea oblíqua obtida por Lawrence de São Francisco em 1906.
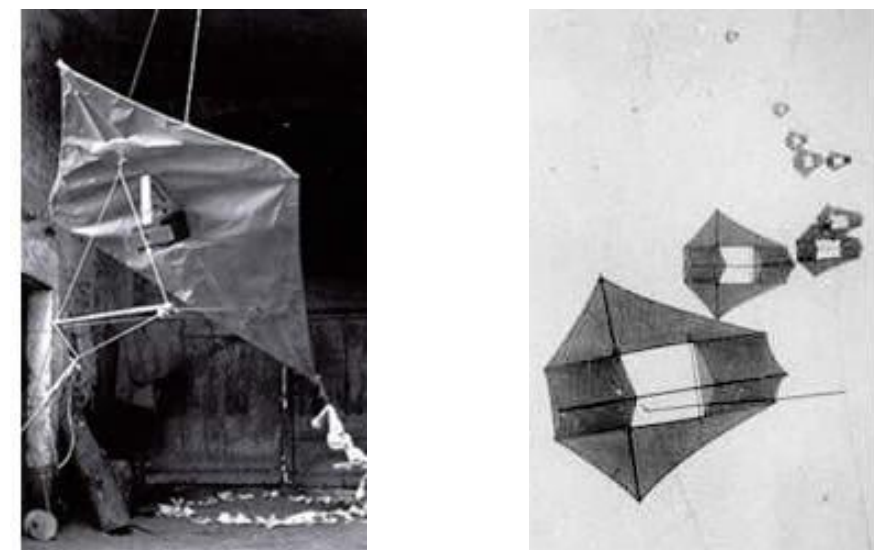

Figura 2.1.2-2: Na esquerda, pipa de Batut e à direita, pipa de Lawrence. Fonte: Professional Aerial Photographers Association - Disponível em http://www.papainternational.org/history.html.

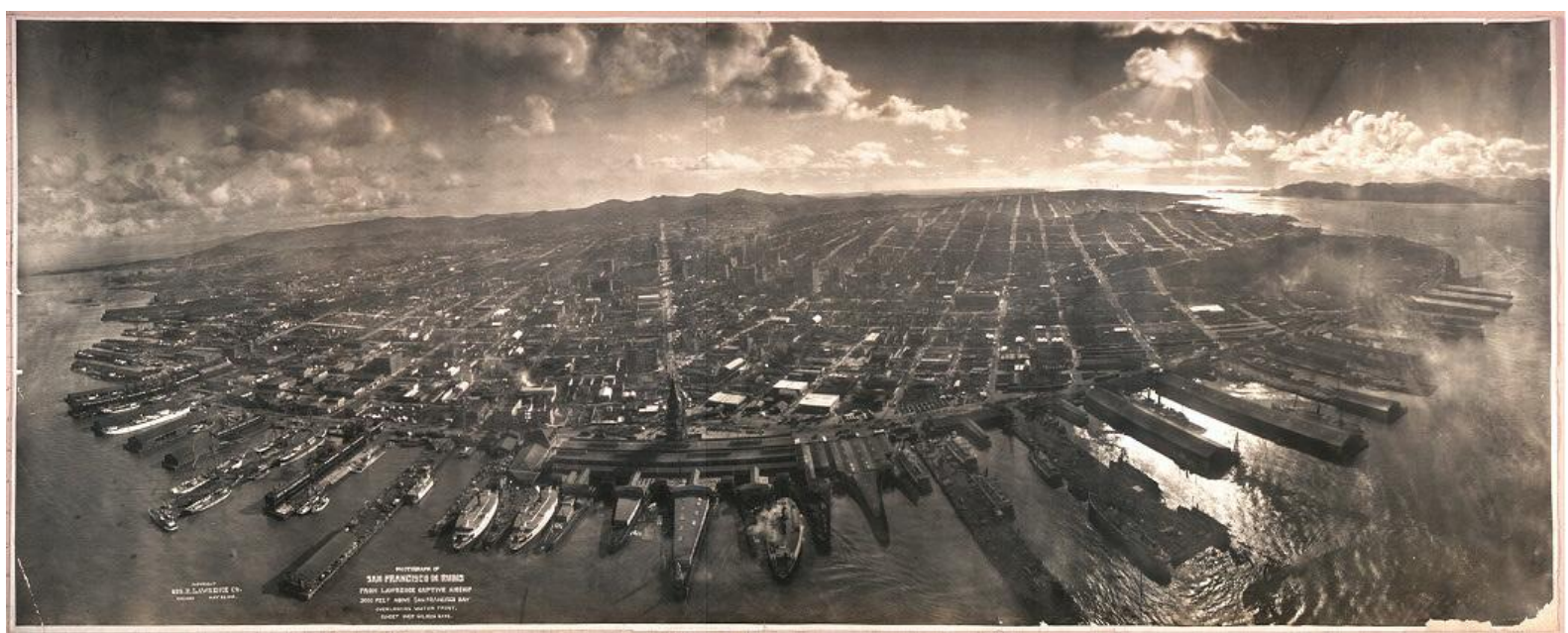

Figura 2.1.2-3: Fotografia aérea de São Francisco após o terremoto de 1906 obtida por câmera panorâmica acoplada a pipas. (Biblioteca do Congresso Norte Americano, 2009)

Outra forma pouco explorada devido às limitações e dificuldades operacionais óbvias é a de obtenção de fotografias aéreas com foguetes. Constam projetos e experiências antes mesmo da invenção do avião. Amadee Denisse em 1888, Ludwig Rahrman em 1891 e Alfred Maul em 1903 foram alguns dos proponentes desta forma de obtenção de imagens aéreas (JENSEN, 2009).

Com o advento e aprimoramento da aviação, no final do século XIX e início do 
século XX, começaram a ser desenvolvidos os primeiros projetos de aeronaves de asas fixas não tripuladas.

Neste campo, os objetivos militares dominaram e motivaram os maiores avanços. Assim como no próprio início da aerofotogrametria e do sensoriamento remoto de forma geral, o uso militar motivou intensamente também o desenvolvimento das primeiras plataformas de sensoriamento remoto por VANTs (IEEE, 2009).

A aquisição de informações privilegiadas do território inimigo de forma rápida e muitas vezes sem ser notada impulsionou o desenvolvimento do sensoriamento remoto como um todo.

O Sperry's Aerial Torpedo foi construído no ano de 1916 por Lawrence e Elmer Sperry (CAMACHO e YUHAS, 2004 apud ALVES NETO, 2008). Utilizava dois sistemas giroscópicos e é considerado um dos primeiros UAVs e um dos precursores dos mísseis-guiados modernos.

Em 1935, foi desenvolvido por Reginald Denny o $R P-1$, o primeiro VANT rádio controlado (MEDEIROS, 2007). Após sucessivos aperfeiçoamentos, o exército dos EUA encomendou 53 unidades do modelo, que foi rebatizado de OQ-1, em 1939.

Também desenvolvido no período entre guerras, o $D H .82 B$ Queen Bee foi outro dos primeiros VANTs rádio-controlados e foi construído com o propósito de servir de alvo para missões de treinamento de atiradores antiaéreos da Real Marinha Britânica.

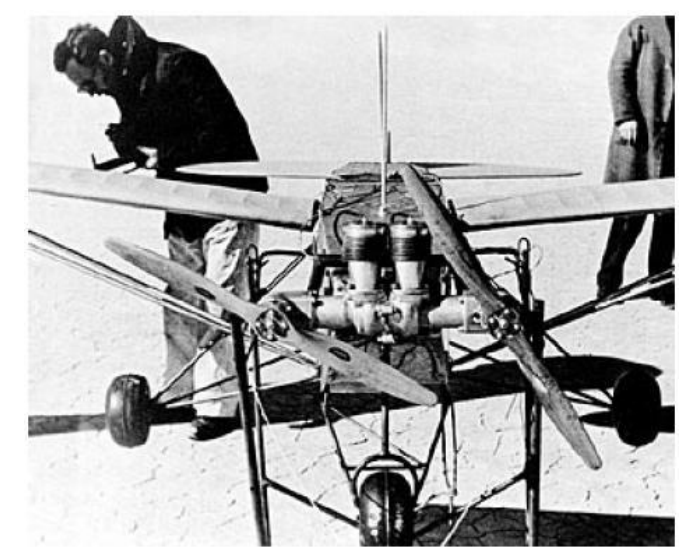

Figura 2.1.2-4: OQ-1 - O primeiro VANT rádio controlado. (HARDGRAVE, 2005 apud MEDEIROS, 2007)

A partir do OQ-1, foram feitos diversos aprimoramentos, até o RP-15 (OQ-6A) de 1945. Este projeto tratou-se de um marco e a partir da década de 1950 foram destinados mais recursos para desenvolvimento de VANTs pelo governo dos EUA. Durante a Guerra Fria, na Guerra do Vietnã, foram utilizados alguns dos primeiros 
VANTs com sucesso. Alguns dos VANTs desenvolvidos e utilizados na época foram o AQM-34 Ryan Firebee, o D-21 e o Lightning Bug (NASA, 2006).

Durante a década de 1970, conhecida como início da área moderna dos VANTs, nos Estados Unidos e em Israel, os designers começaram a experimentar projetos com VANTs mais baratos e menores. Tratava-se de aeromodelos que embarcavam pequenas câmeras de vídeo que transmitiam imagens em tempo real.

Uma das missões mais famosas realizadas por VANTs ocorreu na Guerra do Líbano, quando Israel utilizou um para reconhecimento e identificação de baterias antiaéreas Sírias. Firebee 1241 e Scout são exemplos de VANTs desenvolvidos por Israel.

Outras operações que podem ser citadas ocorreram durante a Guerra do Golfo, o conflito na Bósnia-Herzegovina e, mais recentemente e com uso intensivo, no Afeganistão e no Iraque.

Aos poucos, o interesse e número de projetos de desenvolvimento de VANTs na área militar foram crescendo, mesmo ocorrendo diversos avanços na aerofotogrametria em aeronaves tripuladas e, a partir da década de 1960, com o advento do sensoriamento remoto orbital, por satélites.

O sensoriamento remoto de nível orbital pode depender da órbita dos satélites e das condições atmosféricas da área em que se pretende imagear para a aquisição de boas imagens.

A aerofotogrametria convencional, que foi a primeira forma de aquisição de imagens aéreas para uso militar, desde a $1^{\text {a }}$ Guerra Mundial, tem sido amplamente vigiada por sistemas de vigilância do espaço aéreo das nações, sendo desta forma uma atividade que envolve a necessidade de grandes montantes de investimento para que as aeronaves sejam invisíveis (tecnologia Stealth) a estes tipos de sistemas. Mesmo com esta tecnologia, são oferecidos riscos aos tripulantes destas aeronaves. O sensoriamento remoto por VANTs oferece as vantagens de não oferecer risco de perda de vidas de tripulantes e de muitas vezes, dependendo do tamanho, as aeronaves serem invisíveis a sistemas de vigilância do espaço aéreo. Além disso, embora os principais projetos de VANTs sejam dispendiosos, ainda assim custam menos que uma aeronave tripulada ou um satélite para os mesmos fins (JENSEN, 2009).

Alguns dos VANTs mais modernos de uso militar para reconhecimento e vigilância 
são demonstrados a seguir.

\section{$\underline{\text { RQ-2 Pionner - Pioneers UAV's Inc }}$}

Peso: $205 \mathrm{~kg}$

Comprimento: $4,27 \mathrm{~m}$

Envergadura: 5,18 m

Carga Útil: 34 kg

Teto: $4575 \mathrm{~m}$

Autonomia: $5 \mathrm{~h}$

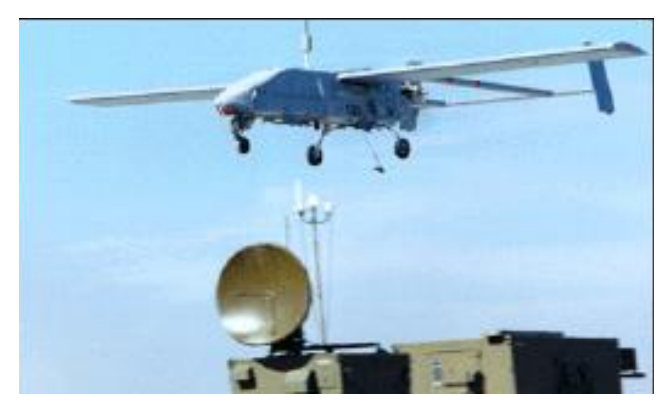

RQ-7 Shadow - AAl

Peso: $148,5 \mathrm{~kg}$

Comprimento: $3,4 \mathrm{~m}$

Envergadura: 2,9 m

Carga Útil: $27,2 \mathrm{~kg}$

Teto: $4575 \mathrm{~m}$

Autonomia de vôo: $4 \mathrm{~h}$

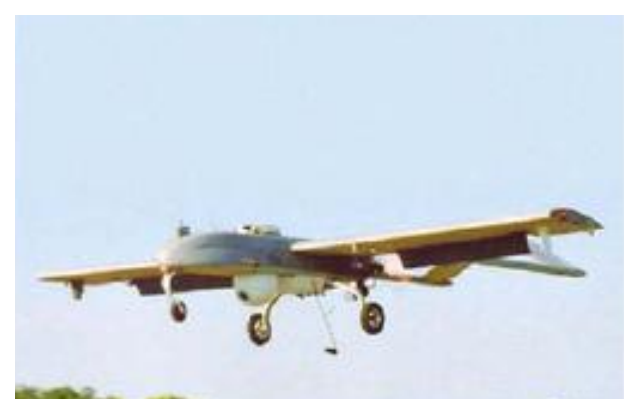

RQ-4 Global Hawk - Northrop Grumman

Peso: $12.144,5 \mathrm{~kg}$

Comprimento: $13,5 \mathrm{~m}$

Envergadura: $35,4 \mathrm{~m}$

Carga Útil: $885,3 \mathrm{~kg}$

Teto: $19825 \mathrm{~m}$

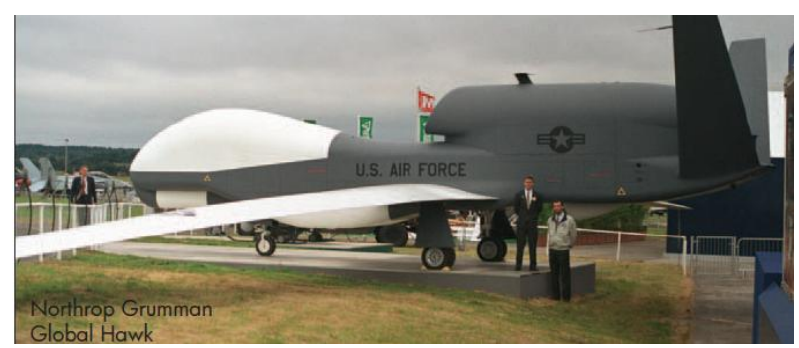

Autonomia de vôo: $32 \mathrm{~h}$

\section{MQ-9 Predator B - General Atomics}

Peso: $4540 \mathrm{~kg}$

Comprimento: $11,4 \mathrm{~m}$

Envergadura: 19,5 m

Carga Útil: 1702 kg (interna + externa)

Teto: $13725 \mathrm{~m}$

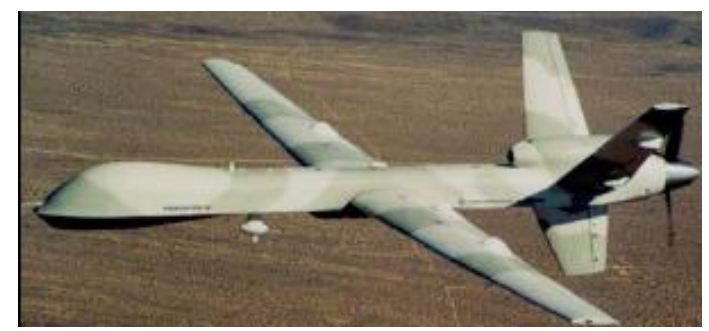

Autonomia de vôo: $>24 \mathrm{~h}$

Figura 2.1.2-5: Exemplos de VANTs militares. Adaptado de DoD (2003) e Armada (2004)

Estes VANTs foram desenvolvidos inicialmente para aplicações militares, mas alguns deles foram adaptados também para aplicações civis. Um exemplo é o 
Global Hawk, que foi utilizado em março de 2010 pela Nasa na primeira missão científica com VANT a atravessar o Oceano Pacífico (FREITAS e COTTET, 2010). A Figura a seguir mostra a evolução cronológica do desenvolvimento de VANTs militares dos EUA.

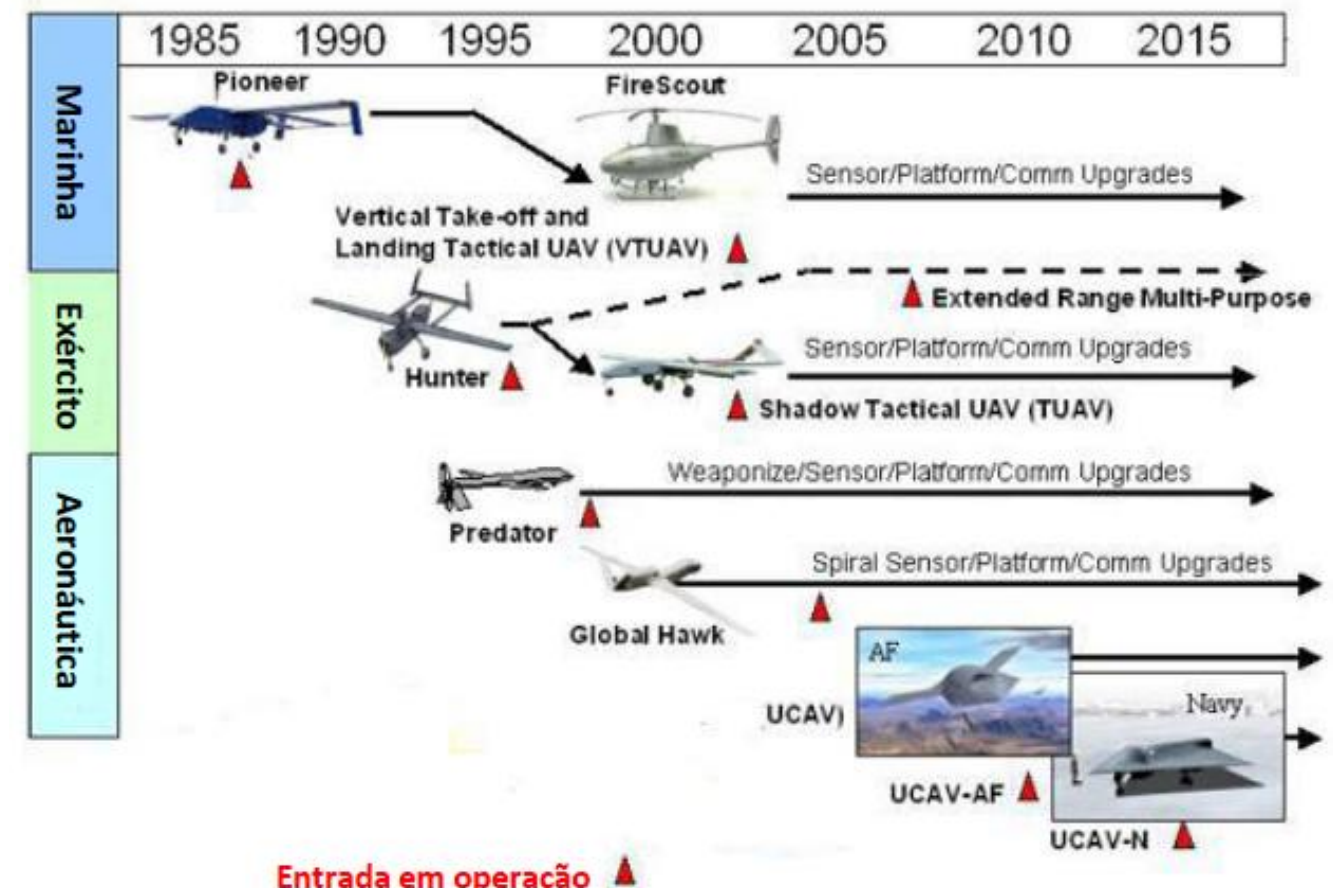

Figura 2.1.2-6: Evolução de VANTs militares nos EUA. Adaptado de http://www.sdauvsi.org/pdfs/uavdod_103101.pdf

Os equipamentos apresentados demonstram o avançado estágio da tecnologia VANT militar.

Embora os investimentos ainda representem uma pequena fatia dos investimentos na área militar, de aviação e de sensoriamento remoto, trata-se de um dos ramos mais dinâmicos e com investimentos crescentes destes setores.

Desde os anos de 1980, o Departamento de Defesa dos Estados Unidos (DOD) investiu bilhões de dólares no desenvolvimento de veículos aéreos não-tripulados para atender aos requisitos de missões específicas táticas ou daquelas que precisem de grande autonomia de vôo para reconhecimento e vigilância. (JENSEN, 2009) 


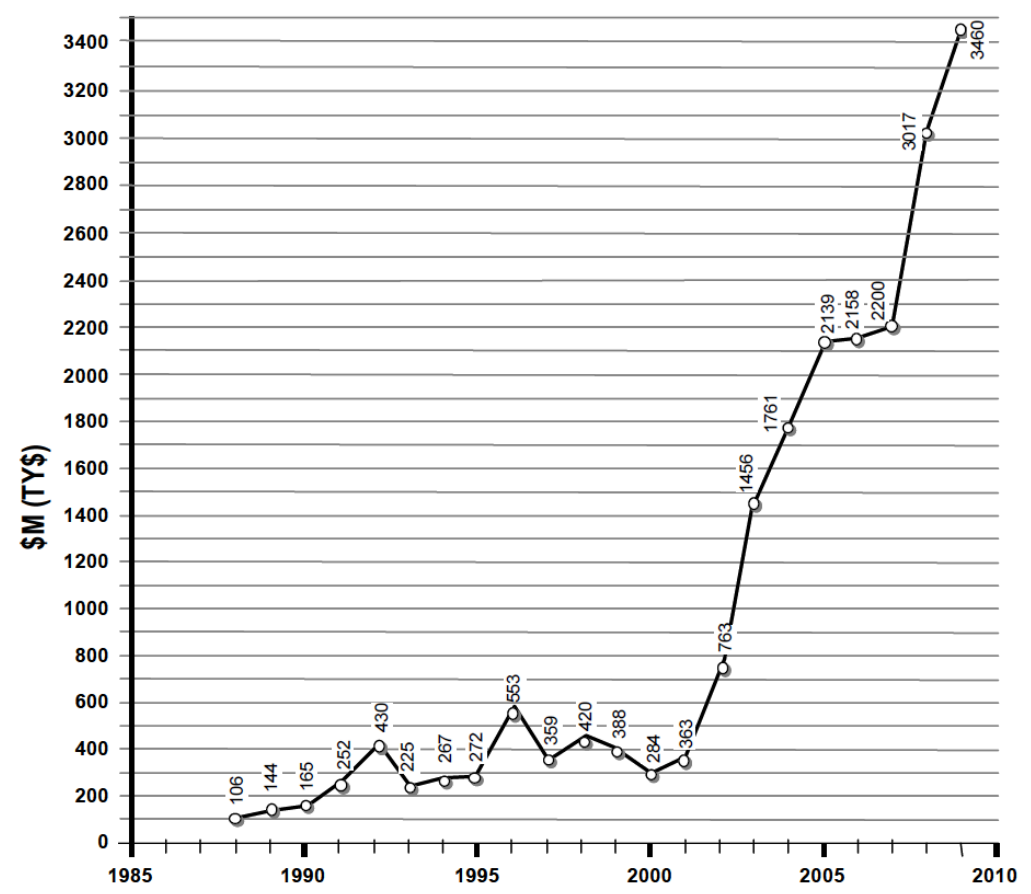

Figura 2.1.2-7: Perfil de fundos anuais (em milhões de dólares) do Departamento de Defesa - DOD dos EUA em VANTs. (DOD, 2003).

Através do perfil apresentado na Figura 2.1.2-7, verifica-se que houve grande aumento dos fundos reservados do DOD para investimentos em VANTs nos últimos anos, principalmente após o ataque de 11 de setembro de 2001.

Além da existência de conflitos militares, como se verificou acima, e pode também ser exemplificado pelo desenvolvimento avançado de VANTs em Israel, onde reconhecidamente há conflito histórico e atual por território, o avanço tecnológico nos setores de processamento de dados e miniaturização de componentes eletrônicos ocorridos nas últimas duas décadas também favoreceram 0 desenvolvimento de diversos VANTs não apenas militares ao redor do mundo, havendo uma proliferação do número de projetos atualmente.

No Brasil, embora ainda muito longe do número de projetos e de quantidade de recursos na área quando comparado aos Estados Unidos, os investimentos em desenvolvimento de VANTs começaram mais marcadamente na última década, sendo que nos últimos anos os projetos de desenvolvimento de VANTs têm se multiplicado, como será apresentado no item 2.1.3 do presente estudo.

Apenas para exemplificar, a Financiadora de Estudos e Projetos (FINEP) destinou em 2009, R\$ 18 milhões para a empresa Avibrás desenvolver um VANT para aplicações militares e civis.

A realização em junho de 2008 do primeiro Seminário Sobre Veículos Aéreos Não- 
Tripulados, organizado pela Organização Brasileira para o Desenvolvimento da Certificação Aeronáutica, também é representativo do crescente interesse pelo assunto no Brasil.

De forma geral, o emprego de VANTs ainda tem se voltado principalmente para áreas de inteligência militar e segurança pública, envolvendo atividades de espionagem, monitoramento de fronteiras, apoio em missões de equipes terrestres, reconhecimento de terreno e obtenção de informações de territórios inimigos ou hostis. O sensoriamento remoto é fundamental para as finalidades referidas.

Entretanto, podem ser citadas outras aplicações de VANTs onde o sensoriamento remoto é uma tecnologia auxiliar, como alvo móvel para testes de armas e treinamentos militares, transporte de suprimentos e armamentos e como veículo de combate, com capacidades de lançar e disparar armas contra inimigos. Estes últimos são os chamados Unmanned Combat Aerial Vehicles - UCAV, o ramo dos VANTs que mais cresce em investimentos militares.

A aeronave a seguir exemplifica um UCAV.

Peso: $13.166 \mathrm{~kg}$

Comprimento: $10,34 \mathrm{~m}$

Envergadura: $15,25 \mathrm{~m}$

Carga Útil: $2500 \mathrm{~kg}$

Teto: $12200 \mathrm{~m}$

Autonomia de vôo: $12 \mathrm{~h}$

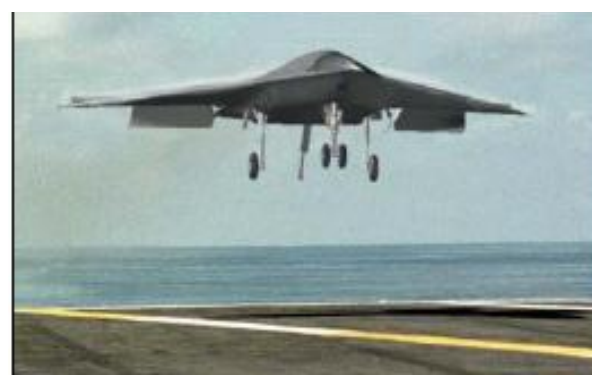

Figura 2.1.2-8: Características do VANT UCAV-N da Pioneers UAV's Inc. (DOD, 2003)

O Brasil, pela Força Aérea Brasileira, tem negociado acordo com a África do Sul para cooperação no desenvolvimento do Denel Bateleur, um VANT MALE (MediumAltitude Long-Endurance) provavelmente de combate (UCAV).

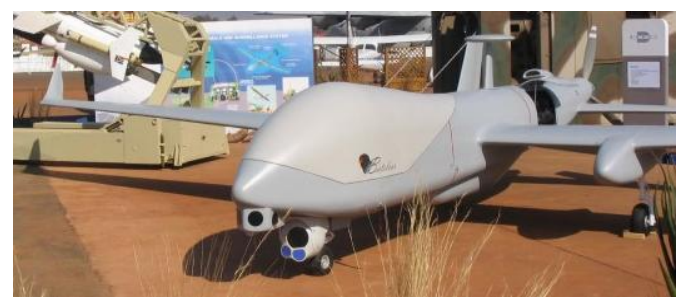

Figura 2.1.2-9: Protótipo do VANT Denel Bateleur. Adaptado de http://www.defesanet.com.br/fab1/bataleur.htm 
Os gráficos a seguir retratam o diagnóstico dos 4600 participantes da Conferência e Exibição AUVSI's Unmanned Systems - North America 2008, a maior do mundo em sistemas de veículos não tripulados.

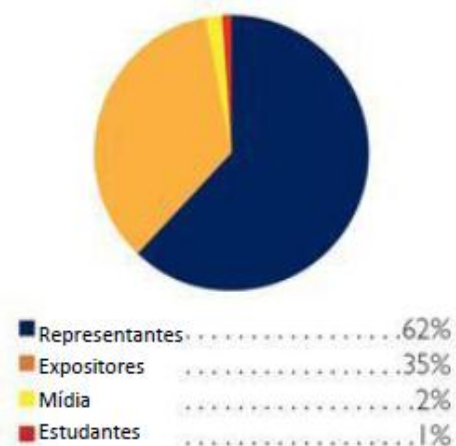

Ocupação

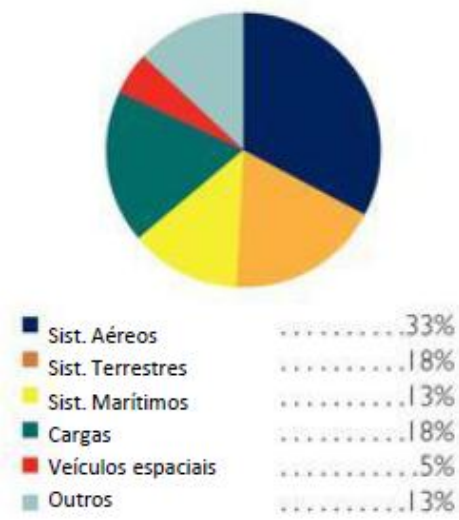

Área de Interesse

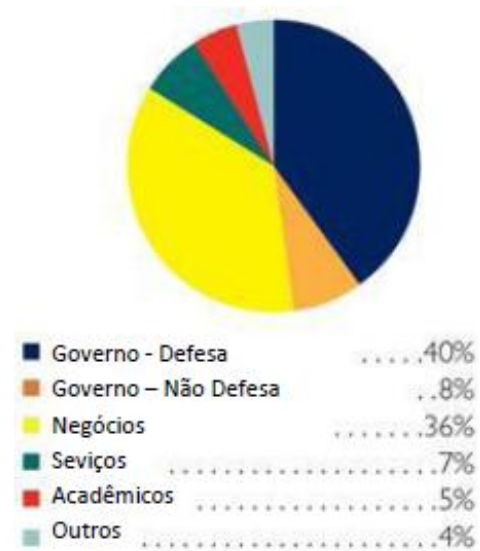

Setor

Figura 2.1.2-10: Diagnóstico dos Participantes da AUVSI's Unmanned Systems - North America 2008. Adaptado de http://symposium.auvsi.org/show/a_demographics.php

Os dados refletem o perfil dos participantes do evento em específico, mas de qualquer forma, podem ser indicativos do perfil dos interessados no assunto.

Embora os números englobem também veículos terrestres e marinhos e sistemas específicos para estas aplicações, verifica-se que a maior parte dos participantes é do setor de defesa público. Outra informação relevante é que estudantes e participantes do setor acadêmico são minoria no evento.

Deve ser observado que o desenvolvimento de tecnologia de VANTs para uso militar envolve montante de recursos financeiros muito superiores do que no setor civil, o que inviabiliza a simples adaptação de sistemas militares para não-militares. Neste sentido, todos os VANTs para uso civil para terem sucesso devem ter custos operacionais e de despesas que devem ser reembolsadas durante o ciclo de vida dos respectivos projetos (KOLDAEV, 2009).

O uso civil desta tecnologia avança mais lentamente, não apenas devido aos recursos investidos serem inferiores ao setor militar, mas também devido às faltas de: aplicações sistemáticas, customização, divulgação e reconhecimento do uso da tecnologia por usuários, capacitação de operadores, segurança no uso e regulamentação para operações no espaço aéreo, conforme afirmado por Nasa (2006) e Gurtnel et al.(2009).

Em diversas nações a regulamentação da operação de VANTs inexiste ou encontra- 
se em elaboração em vários países, inclusive no Brasil. Este tema bastante sensível será melhor abordado posteriormente neste estudo.

$\mathrm{Na}$ abordagem do histórico do desenvolvimento de VANTs na área civil, destacamse iniciativas isoladas de desenvolvimento de VANTs ao redor do mundo por pesquisadores.

Conforme exposto, existem relatos de experimentos com obtenção de fotografias aéreas através de balões não tripulados e pipas desde o século XIX, mas foi a partir da década de 1960 que as pesquisas envolvendo VANTs começaram a aparecer mais constantemente. Em geral, tratava-se da adaptação de aeromodelos rádio controlados para embarcarem câmeras fotográficas de filmes de pequeno formato dotadas de sistemas para acionamento remoto via rádio.

Disperati (1991) destaca em seu livro "Obtenção e uso de fotografias aéreas de pequeno formato" alguns dos autores que desenvolveram pesquisas nesta área. Consta que Bukolt (1969) apud Disperati (1991) utilizou um aeromodelo rádio controlado para obtenção de informações áreas para construção de uma maquete da Universidade de Wiscosin. Przybilla e Ebbinghaus (1979) apud Disperati (1991) descreveram os resultados das imagens obtidas por uma câmara aerofotográfica de 70mm em um aeromodelo. Tomlins e Lee (1983) ) apud Disperati (1991) utilizaram aeromodelos para obtenção de imagens a fim de avaliar os danos florestais. Walker (1988a, 1988b, 1989, 1990) ) apud Disperati (1991) empregou aeromodelo de avião rádio controlado para obtenção de imagens aplicadas em estudos arqueológicos.

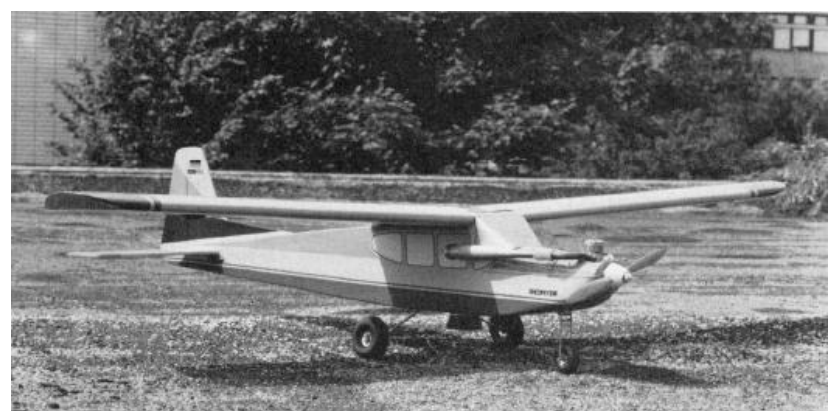

Figura 2.1.2-11: Aeromodelo Rádio-controlado utilizado por Przybilla (1979) para obtenção de fotografias aéreas. (EINSEINBEISS, 2004)

Em 1980, Wester-Ebbinghaus utilizou o primeiro helimodelo para propósitos fotogramétricos, segundo Einseinbeiss (2004). Os helimodelos representam nos dias atuais uma grande parcela das plataformas VANTs utilizadas para sensoriamento remoto (MARTINS, 2008). Uma de suas principais vantagens é a capacidade de 
decolagem e pouso vertical ou VTOL (Vertical Take-Off and Landing).

A NASA realizou diversas pesquisas desde a década de 1960 contendo experimentos que apoiariam futuros pesquisadores da área de Veículos Aéreos Não Tripulados, como por exemplo, testes de aerodinâmica e estruturas dos veículos.

Mas foi apenas na década de 1990 em que houve um maior esforço e volume de pesquisas da NASA neste setor, impulsionado pelo aceleramento no desenvolvimento de tecnologias eletrônicas e computacionais.

Na década de 1990 a NASA conduziu um programa com parceiros da
indústria, para o desenvolvimento de tecnologias para capacitar o mercado
de VANTs, focando o desenvolvimento de um potencial mercado comercial.
Os esforços buscaram a resolução dos principais impedimentos políticos e
tecnológicos que restringem o desenvolvimento destas aeronaves para o
seu pleno potencial. Os nove longos anos do programa da NASA, chamado
Environmental Research Aircraft and Sensor Technology (ERAST),
ajudaram a redefinir a tecnologia dos VANTs, com pesquisas em motores,
sensores e veículos integrados que venceriam os obstáculos de altos
alcances e autonomia (duração de vôos). Os produtos resultantes do
Programa ERAST incluem os SANTs Pathfinder, Helios, Altus, Perseus A e
Be, potencialmente, poderiam ser desenvolvidos ainda veículos com limites
de altitude acima dos 100.000 pés e autonomia de até 6 meses. (NASA,
2006)

Os usos científicos e civis têm sido desenvolvidos em maior quantidade e englobando funções avançadas mais recentemente, nas últimas duas décadas, buscando-se que os veículos aéreos desprovidos de tripulação apresentem vantagens técnicas e/ou econômicas em relação a diferentes campos de atuação.

$\mathrm{Na}$ maioria das aplicações civis desenvolvidas, os VANTs têm sido concebidos como plataforma para embarcar sensores remotos para obtenção de imagens e dados da superfície terrestre.

Destaca-se também o uso significativo de VANTs para estudos da atmosfera terrestre, para medições e coletas de dados de variáveis físicas e de componentes químicos da atmosfera. Como exemplos de equipamentos desenvolvidos nesta área podem ser citados o Atmosfpheric Radiation Measurement (ARM) UAV do Departamento de Energia dos EUA ou ainda os Aerolemma-1 e 2 da Universidade Federal do Paraná - UFPR (MALHEIROS, 2008).

Outros usos são menos comuns, como para aplicação de pesticidas em lavouras, conforme proposto em pesquisa da Universidade Federal de Pelotas (RASI, 2008), plantio por dispersão de sementes ou ainda como provedor de sistemas e acesso de comunicações em áreas específicas.

O documento elaborado pela NASA (2006) denominado "Earth Observations and the Role of UAVs" levanta os potenciais de aplicação de VANTs na área civil, divididos 
em três categorias: Missões para Ciências da Terra, Gestão Costeira e do Uso do Solo e Segurança Pública. Esta listagem é apresentada a seguir na tabela 2.1.2-1:

Tabela 2.1.2-1: Áreas potenciais de emprego de VANTs no setor civil e aplicações ligadas a sensoriamento remoto (em vermelho). Adaptado de Nasa (2006).

\begin{tabular}{|l|l|}
\hline \multicolumn{2}{|c|}{ Missões em ciências da Terra } \\
\hline Interferometria repetida da superfície & Medições de campos magnéticos \\
\hline Medições de nuvens e aerossóis & Propriedades de nuvens \\
\hline Química da camada de ozônio & Descargas fluviais \\
\hline Qualidade do ar e poluição da troposfera & Equivalência de neve com água líquida \\
\hline Medições de vapor de água & Umidade e congelamento do solo \\
\hline Observações costeiras & Microfísica e propriedades de nuvens \\
\hline Incêndios, emissões, dispersão de plumas & $\begin{array}{l}\text { Observações de condições de tempo } \\
\text { extremas }\end{array}$ \\
\hline Medições de fluxo de O2 e CO2 & Investigações iniciais \\
\hline Composição e estrutura da vegetação & Furacões \\
\hline $\begin{array}{l}\text { Distribuição de aerossol, nuvens e } \\
\text { precipitação }\end{array}$ & Oceanografia física \\
\hline Dinâmica de geleiras & Rastreamento de transportes \\
\hline Radiação - perfis verticais de ondas curtas & $\begin{array}{l}\text { Interação entre nuvens / Aerossois/ Gases/ } \\
\text { Radiação }\end{array}$ \\
\hline Espessura e superfície de geleiras & $\begin{array}{l}\text { Perfilamento vertical de longo período da } \\
\text { atmosfera }\end{array}$ \\
\hline Espectroscopia de imageamento & Mapeamentos 3D globais contínuos \\
\hline Mapeamento topográfico & $\begin{array}{l}\text { Evolução química e do transporte de } \\
\text { substâncias na atmosfera }\end{array}$ \\
\hline Medições da aceleração da gravidade & Vigilância para explorações antárticas \\
\hline
\end{tabular}

\begin{tabular}{|l|l|}
\hline \multicolumn{2}{|c|}{ Gestão do território e missões costeiras } \\
\hline $\begin{array}{l}\text { Contagem de população para gestão da vida } \\
\text { selvagem }\end{array}$ & Identificação e rastreamento de vida no mar \\
\hline $\begin{array}{l}\text { Missões de telemetria para gestão da vida } \\
\text { selvagem }\end{array}$ & Fauna bentônica em águas rasas \\
\hline $\begin{array}{l}\text { Detecção de alterações de habitats da vida } \\
\text { selvagem }\end{array}$ & Fluxo de dióxido de carbono \\
\hline Agricultura de precisão & $\begin{array}{l}\text { Comunicação em tempo real de incêndios e } \\
\text { desastres }\end{array}$ \\
\hline Gestão de reservatórios & Predição e medição de incêndios e desastres \\
\hline Gestão de faixas (APP, servidão de LTs, etc) & $\begin{array}{l}\text { Aplicação de substâncias retardantes em } \\
\text { incêndios }\end{array}$ \\
\hline Gestão urbana & $\begin{array}{l}\text { Redução do risco em ações de resposta a } \\
\text { incêndios e desastres }\end{array}$ \\
\hline Qualidade da água costeira & $\begin{array}{l}\text { Avaliação pré e pós-evento de incêndios e } \\
\text { desastres. }\end{array}$ \\
\hline
\end{tabular}

\begin{tabular}{|l|l|}
\hline \multicolumn{2}{|c|}{ Missões para segurança pública } \\
\hline Vigilância marinha & Missões táticas em fronteiras \\
\hline Monitoramento de túneis & Patrulhas costeiras \\
\hline Vigilância de grandes áreas e fronteiras & \\
\hline
\end{tabular}

Legenda:

Setores que podem se utilizar do sensoriamento remoto da superfície terrestre 
Deve ser ressaltado que o presente estudo tem como escopo os VANTs para sensoriamento remoto da superfície terrestre, sendo destacadas as aplicações civis em detrimento às militares. Por isso, no tabela, foram destacados em vermelho os campos em que o uso civil está ligado ao sensoriamento remoto da superfície terrestre.

Conforme levantado na bibliografia, podem ser citadas diversas aplicações dos VANTs para sensoriamento remoto. Análise de recursos terrestres, planejamento urbano, manejo de recursos naturais, agricultura de precisão, monitoramento ambiental, estudos de tráfego e demanda por estacionamento, resposta a emergências em desastres, monitoramento florestal, monitoramento de áreas vulcânicas, monitoramento de obras lineares (oleodutos e linhas de transmissão) e mapeamentos sistemáticos e temáticos em geral, são exemplos de áreas mais citadas em que o sensoriamento remoto por estes veículos pode proporcionar avanços. Esta nova tecnologia, ao ter seus custos reduzidos e a operação mais fácil em relação às plataformas convencionais (avião e satélite), poderá disseminar o sensoriamento remoto para diversos fins, inclusive para atividades ilícitas, como roubo e espionagem industrial, e para grupos armados, como guerrilhas e traficantes.

Como forma de exemplificar alguns dos usos civis citados, temos Araújo (2006), que utilizou-se do VANT AgPlane para inventário de mortalidade de indivíduos, avaliação de uniformidade de plantio, coeficiente de variação de áreas de copas em silvicultura. Barbosa (2007) utilizou-se de VANT de baixo custo para mapeamento de cobertura vegetal. Johnson (2007) integrou no RCATS UAV um espectrômetro imageador e uma câmera RGB para obtenção de imagens sobre áreas agrícolas que combinam alta resolução espacial e espectral. O uso de um VANT para uso em um sistema de avaliação de congestionamentos no trânsito de veículos é proposto por Halem (2007).

Realizado um breve histórico do desenvolvimento dos VANTs, a seguir são apresentadas no próximo item as principais variações tecnológicas e de capacidades de Sistemas Aéreos Não Tripulados modernos através de exemplos dos equipamentos para usos civis mais proeminentes da atualidade. Projetos nacionais serão enfatizados. 


\subsubsection{Tecnologias, Capacidades e Exemplos de Sistemas Aéreos Não Tripulados para Sensoriamento Remoto}

A proliferação do número de projetos e a evolução tecnológica aliadas a diferentes objetivos finais no uso de VANTs trouxeram uma enorme variedade nos equipamentos e em suas capacidades.

As variações já se iniciam no tipo de plataforma VANT. Além de veículos aéreos em forma de pipas, dirigíveis, helicópteros e aviões, há ainda outros equipamentos com formas que não se enquadram em nenhum dos modelos citados, como alguns MAVs (Mini ou Micro UAVs).

Há alguns termos específicos para os tipos de aeronaves, a citar, RPH (Remotely Piloted Helicopter) para helicópteros, DAAV (Dirigible Autonomous Aerial Vehicle) para dirigíveis (FILARDI, 2006), e KAP (Kite Aerial Photography) para obtenção de fotografias aéreas com pipas.

Segundo Martins (2008), em geral, aviões (veículos de asas fixas) atingem maior velocidade e têm maior autonomia de vôo. Dirigíveis são capazes de voar a baixas velocidades e pairar no ar gerando baixos níveis de ruído e vibração, além de possuírem sempre a capacidade de decolar e pousar verticalmente, embora apresentem maior suscetibilidade a ventos. Helicópteros são capazes de voar a baixas velocidades e médias velocidades e decolar e pousar verticalmente também. Entretanto são inerentemente instáveis e com dinâmica de vôo diferente de acordo com o modo de vôo.

Pipas são as mais simples das plataformas. Necessitam de vento, dependem de o operador estar próximo ao local a ser imageado, o alcance em altitude é limitado, a capacidade de carga é pequena, e o controle do local e posicionamento para obtenção de imagens é difícil. Entretanto, são as plataformas mais baratas. Para algumas finalidades, como acompanhamento de obras e fins de registro $e$ modelagem arquitetônica de prédios, estes equipamentos podem ser úteis e suficientes. A empresa brasileira AutoRetrato comercializa este tipo de serviço. A imagem abaixo foi obtida por pipa da AutoRetrato. 


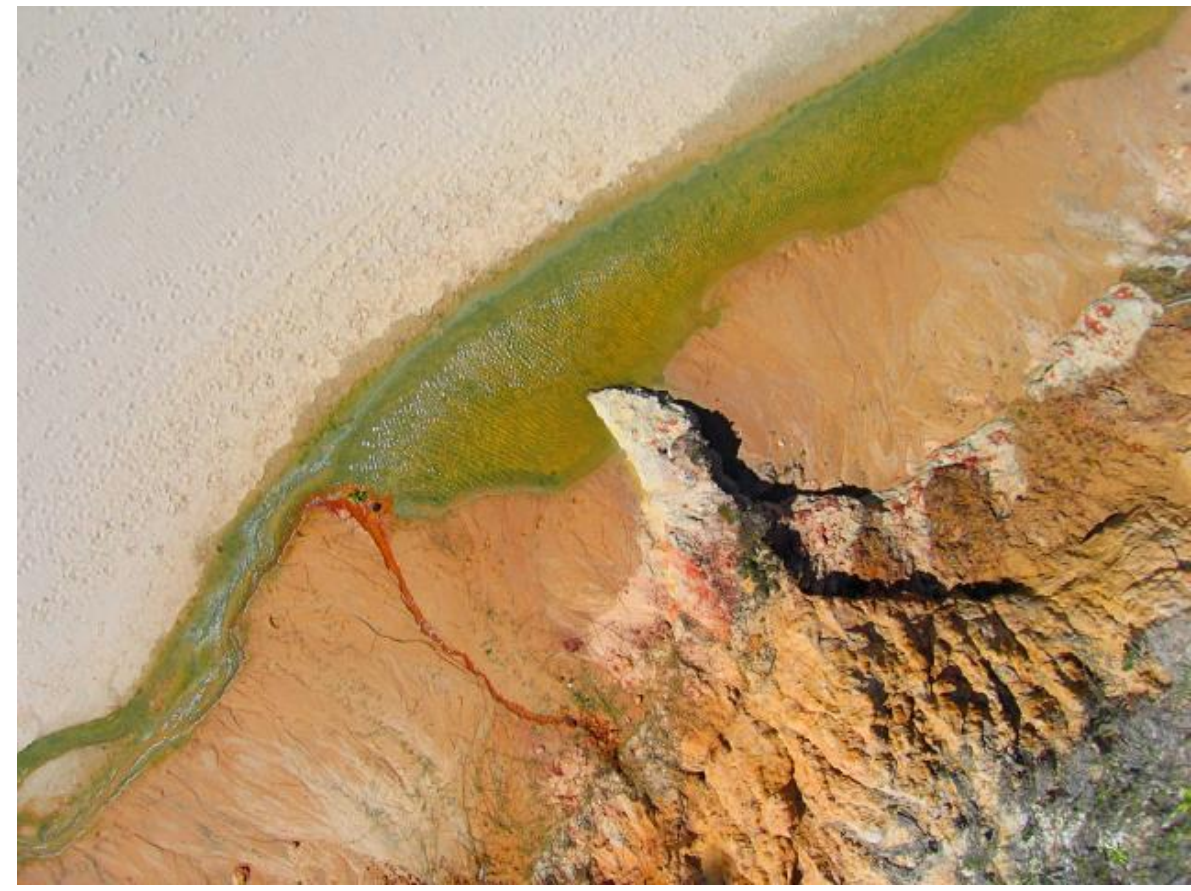

Figura 2.1.3-1: Foto aérea de Praia das Fontes, em Beberibe-CE obtida por pipa. (http://www.altoretrato.com.br/pt-br/empinando_fotografias)

Como exemplos de desenvolvimento de dirigíveis não tripulados para obtenção de imagens aéreas pode ser citado o projeto Aurora do Centro de Pesquisas Renato Archer (CenPRA) de Campinas-SP, que desenvolve, desde 1997 em parceria com diversas instituições nacionais e internacionais, dirigível robótico para aplicações ambientais e agrícolas (GALVES, 2003), além do sistema desenvolvido pela $\mathrm{Hi}$ Shots, citado por Falkner (1994).
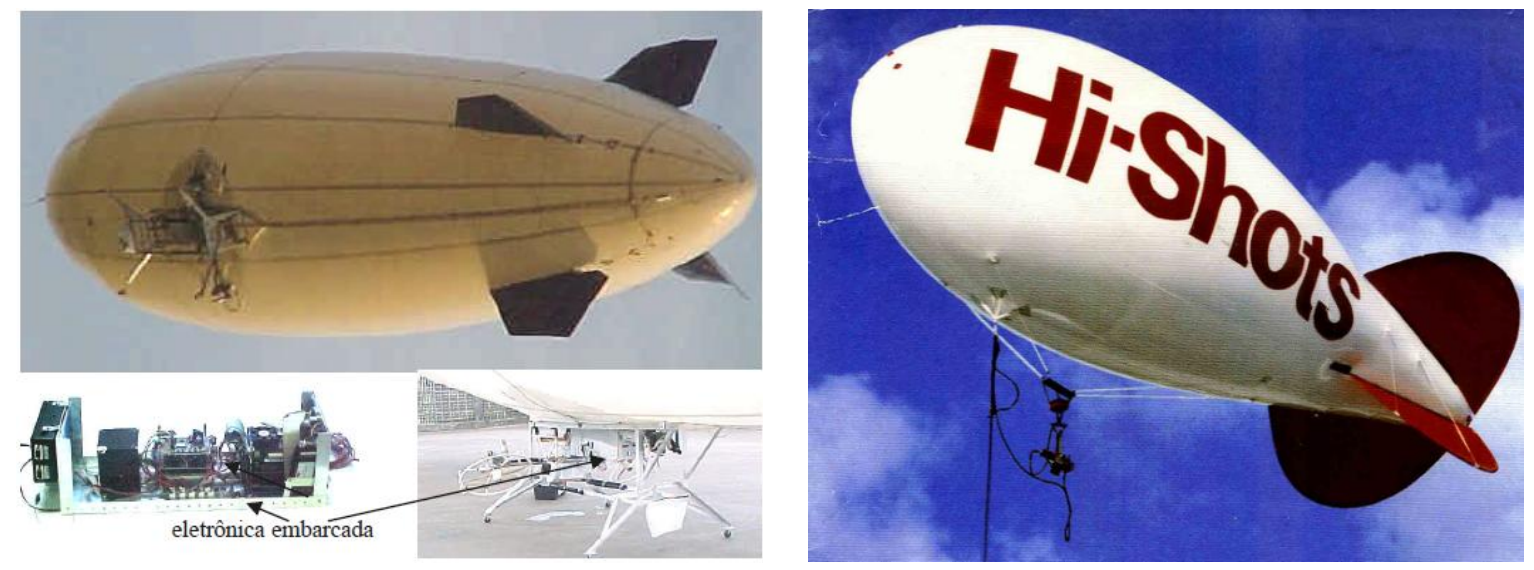

Figura 2.1.3-2: Exemplos de dirigíveis para obtenção de imagens aéreas do Projeto Aurora e HiShots, respectivamente. (GALVEZ, 2003) e (http://hi-shots.biz)

Dentre projetos de desenvolvimento de VANTs baseados em helimodelos, podem ser citados o Avatar desenvolvido pela Universidade do Sul da California, o GTAR 
da Georgia Tech, o projeto Helix da Gyron, CenPRA, Universidade Federal de Santa Catarina e o Projeto CARCARAH da Universidade de Brasília (MARTINS, 2008).

Um dos mais antigos e utilizados VANTs em forma de helicóptero do mundo é o RMAX da Yamaha, sendo utilizado para sensoriamento remoto de áreas agrícolas e vegetadas e vigilância. É capaz de carregar $30 \mathrm{~kg}$, voar por cerca de 90 minutos e tem alcance de $10 \mathrm{~km}$ (NASA, 2006).

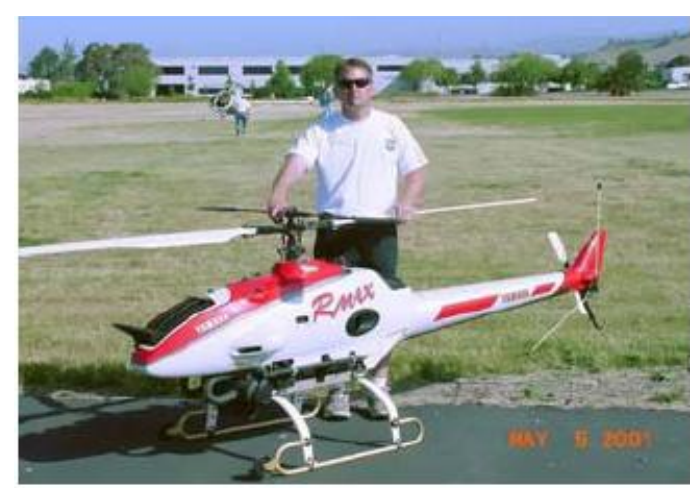

Figura 2.1.3-3: RMAX da Yamaha. (NASA, 2006)

A figura a seguir apresenta alguns mais notáveis projetos de VANTs baseados em helimodelos.

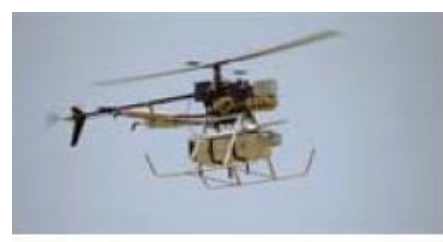

(a) AVATAR - Universidade do Sul da California, EUA

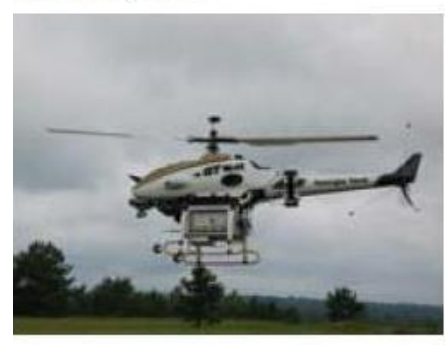

(d) GTAR - Georgia Tech, EUA

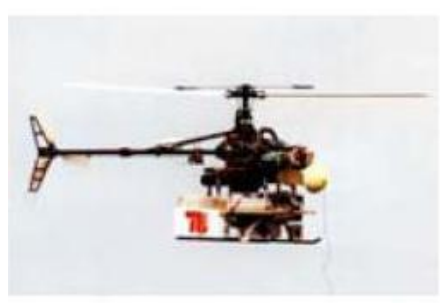

(g) Marvin - Universidade de Berlin, Alemanha

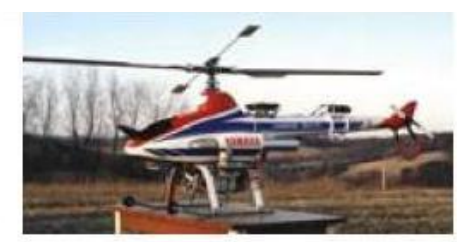

(b) AHP - Universidade Carnegie Mellow, EUA

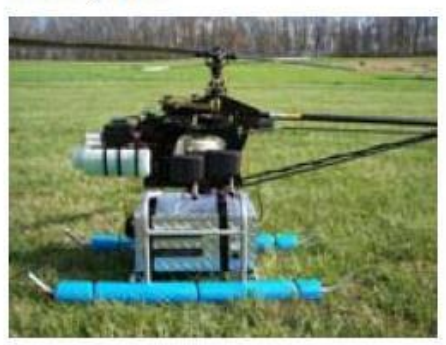

(e) AAVT - Virginia Tech, EUA

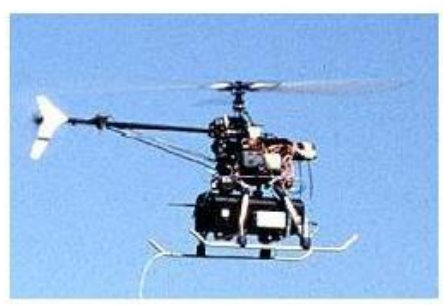

(h) Mantis - CISRO, Austrália

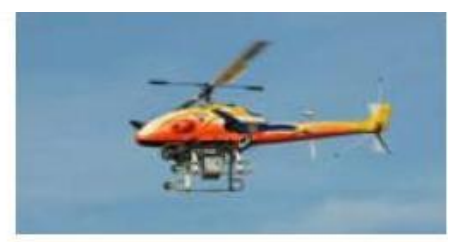

(c) BEAR - Universidade da California, Berkeley, EUA

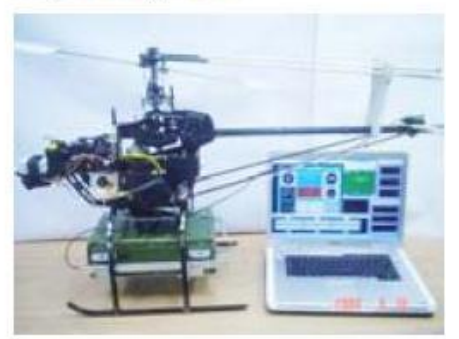

(f) Colibri - Universidade EAFIT, Colômbia

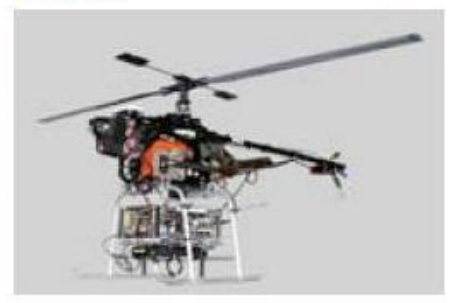

(i) HIROBO - Universidade de Chiba, Japāo

Figura 2.1.3-4: VANTs baseados em helimodelos no mundo. (MARTINS, 2008) 
Alguns dos VANTs mais expressivos e que tiveram mais investimentos foram em forma de avião (asas fixas). Os VANTs Atair e Altus foram adaptados para aplicações civis a partir de projetos militares, sendo construídos pela General Atomics Aeronautical Systems Incorporated de San Diego-EUA como versões para aplicações civis do Predator $B$.

Para operar em altitudes mais elevadas (até 15,2 km) e com maior confiabilidade foi desenvolvido o Altair que é capaz de carregar cargas úteis de $300 \mathrm{~kg}$ internamente e até $1361 \mathrm{~kg}$ na ala externa e realizar vôos de $30 \mathrm{~h}$.

As aeronaves Altus I e // foram projetadas para transportar instrumentos e sensores de investigação científica. O Altus // tem um limite máximo de vôo de cerca de 19,8 km e uma autonomia de vôo de cerca de 24 horas (NASA, 2006).
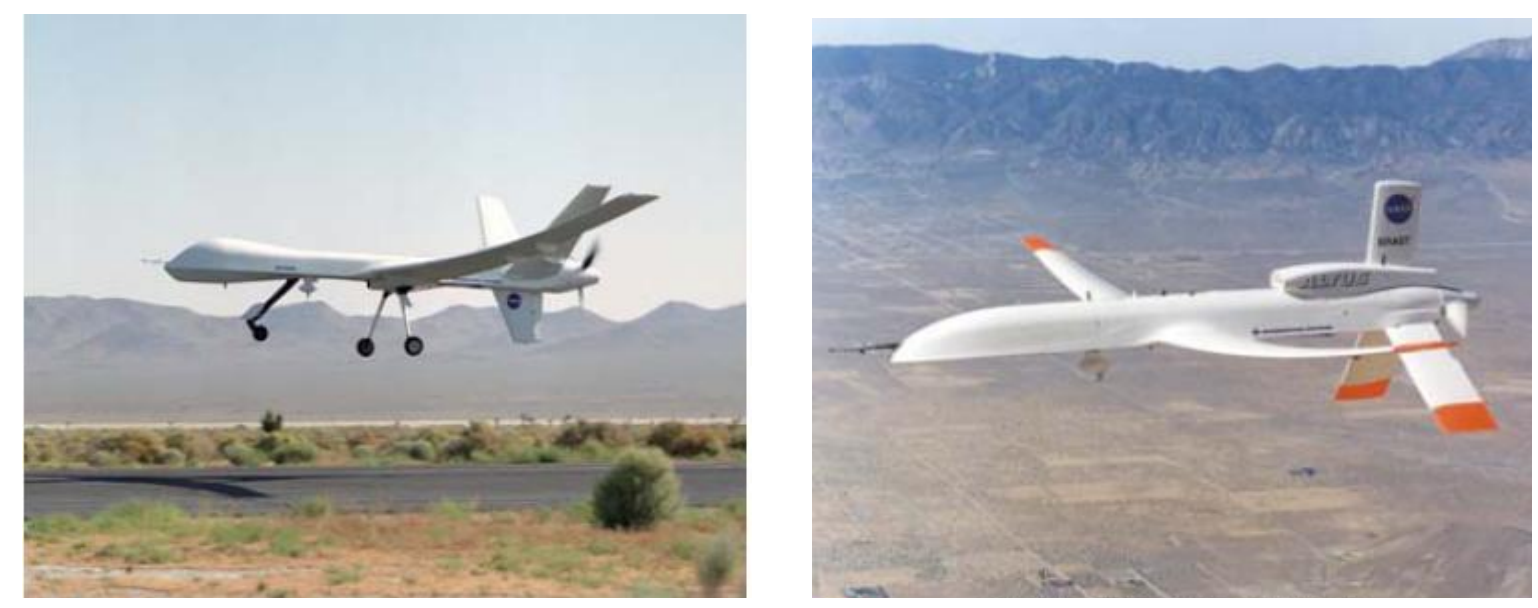

Figura 2.1.3-5: Altair e Altus em vôo, respectivamente. (NASA, 2006)

O UAV Aerosonde foi desenvolvido por em conjunto pelo Enviromental Systems and Services em Melbourne, pelo The Insitu Group no estado de Washington, pelo Australian Bureau of Meteorology na Austrália e a empresa Aerosonde Pty, Ltd. da Austrália, uma das pioneiras e mais reconhecidas mundialmente no desenvolvimento de VANTs para aplicações civis.

Foi originalmente concebido para meteorologia e reconhecimentos ambientais e teve diversas aplicações. Uma das aeronaves da Aerosonde foi a primeira a cruzar o oceano Atlântico de maneira totalmente autônoma (MCGEER e VAGNERS, 1999).

A aeronave Aerosonde apresentada abaixo carrega de 2 a $5 \mathrm{~kg}$, dependendo do tempo de vôo desejado e tem uma duração de vôo de 10 a 30 horas (NASA, 2006). 


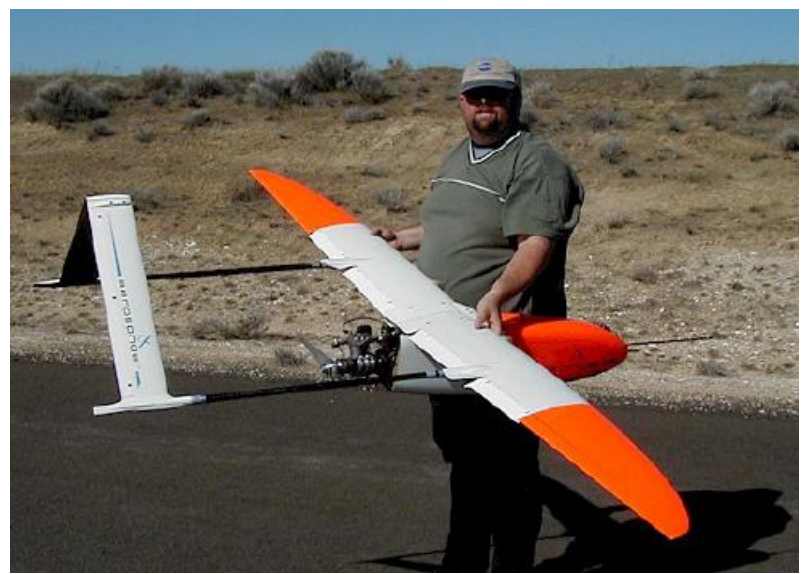

Figura 2.1.3-6: Aeronave Aerosonde. (NASA, 2006)

O Pegasus é um dos mais interessantes VANTs para sensoriamento remoto, sendo desenvolvido pelo VITO - Flemish Institute for Technological Research.

Um dos principais diferenciais é que a plataforma é projetada para funcionar continuamente durante meses e atingir até $20 \mathrm{~km}$ de altitude. "É projetado para utilizar energia solar e voar até $55^{\circ}$ de latitude norte, sendo capaz de cobrir grandes áreas (até 125000 km² por verão), mas também pode ser usado para monitorar pequenas áreas com uma elevada freqüência de revisita” (BIESEMANS, 2005).

O projeto prevê a incorporação de sensor multespectral com 10 bandas no visível e infra-vermelho próximo, laser para altimetria e posteriormente sensores térmicos e um SAR.

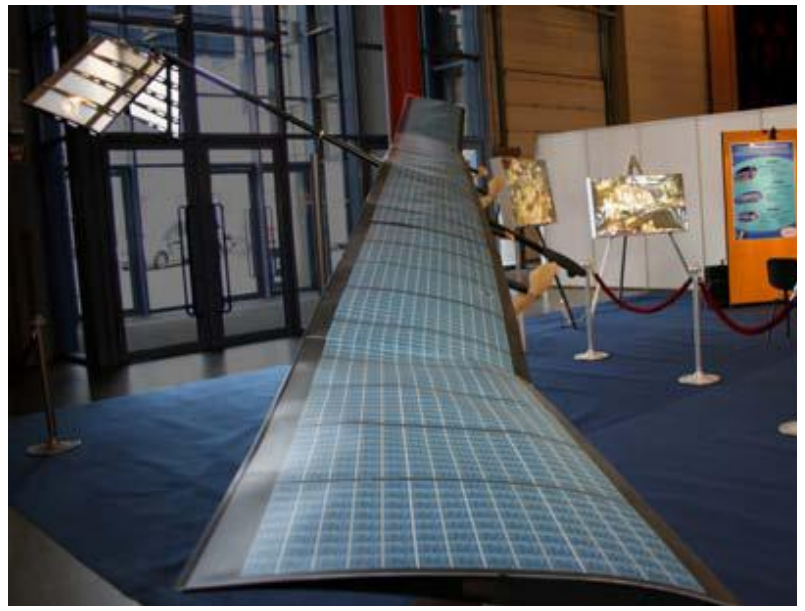

Figura 2.1.3-7: Aeronave Pegasus. Asas cobertas por painéis de captação de energia solar. (EVERAERTS, 2008)

O tamanho das aeronaves não tripuladas pode variar de centímetros, até apresentar muitos metros, assemelhando-se a aviões tripulados. 
Os MAVs por serem VANTs de tamanhos reduzidos, são feitos de componentes tecnológicos em miniatura e apresentam muitas vezes outros conceitos de formato e propulsão para vencerem a gravidade, como quad-rotors, por exemplo. A seguir são apresentados na Figura 2.1.3-8 três modelos de MAVs.

Estes equipamentos apresentados tem autonomia de até $2 \mathrm{~h}$, carregam até $19 \mathrm{~kg}$ (Kestrel) podem voar a altitudes de até 4880 m (iStar).

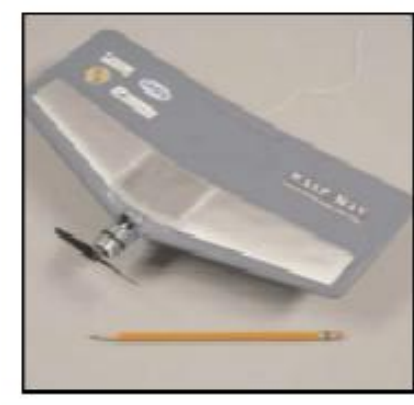

Wasp AeroVironment

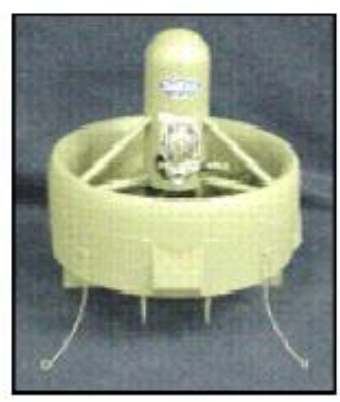

iStar

Allied Aerospace

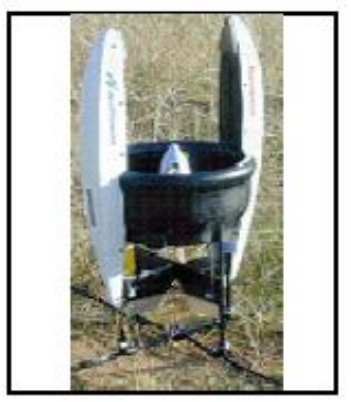

Kestrel Honeywell

Figura 2.1.3-8: Exemplos de MAVs. (DOD, 2003)

Além da própria plataforma, outras tecnologias empregadas em sistemas VANTs variam muito. As aeronaves podem ter estruturas reforçadas, formas de aproveitamento de energia solar, propulsão através de foguetes, além de sistemas de comunicação através de satélite, sistemas de processamento de dados em tempo real, de operação autônomas, de navegação via GPS e detecção e perseguição de objetos, contra colisões e panes, etc.

A enorme variedade de equipamentos levou à criação de algumas classes de VANTs, considerando-se funções e parâmetros como tamanho, autonomia de vôo e altura de vôo.

Uma das classificações mais utilizadas, definida pela UVS International combina as variáveis peso, alcance, altura de vôo e autonomia em horas. A tabela 2.1.3-1 apresenta as especificações desta classificação que divide os VANTs em Micro, Mini (MAVs), Curto Alcance (Close Range), Médio Alcance (Medium Range), Alta Altitude e Longa Autonomia (High Altitude Long Endurance - HALE). 
Tabela 2.1.3-1: Categorias de VANTs definidas pela UVS-International. Adaptado de Einseinbeiss (2004)

\begin{tabular}{|c|c|c|c|c|}
\hline Categoria & Massa (kg) & Alcance $\mathbf{( k m )}$ & Altitude $(\mathbf{m})$ & Autonomia (horas) \\
\hline Micro & $<5$ & $<10$ & 250 & 1 \\
\hline Mini $^{\star}$ & $<25 / 30 / 150$ & $<10$ & $150 / 250 / 300$ & $<2$ \\
\hline Close Range & $25-150$ & $10-30$ & 3000 & $2-4$ \\
\hline Medium Range & $50-250$ & $30-70$ & 3000 & $3-6$ \\
\hline HALE & $>250$ & $>70$ & $>3000$ & $>6$ \\
\hline
\end{tabular}

*Varia de acordo com o escopo dos países

Outros termos comuns sobre classes de VANTs usados no setor militar são os Táticos (Tactical) e Estratégicos (Strategic), respectivamente TUAV e SUAV (SUAV também pode se referir a Small UAV, e por isso não é muito utilizada esta sigla). Ambos possuem como objetivos principais funções de reconhecimento e vigilância do território. Entretanto, Strategic UAVs devem apresentar capacidades superiores de altitude de vôo e autonomia normalmente. Apresentam capacidade de comunicação via satélite e necessitam estrutura aeroportuária, segundo o Centro Tecnológico do Exército (OKAMOTO, 2007). Estão ligados ao conceito de HALE, enquanto os TUAV, de forma mais próxima ao conceito de MALE (Medium Altitude Long Endurance).

Quanto à forma de decolagem (lançamento) e pouso (recuperação), há diferentes tecnologias. VANTs podem decolar de forma convencional, vertical para helimodelos, ou com corrida em local plano até velocidade suficiente para vôo, para aviões. Outras maneiras são através de catapulta, lançamento manual e acoplamento em um carro ou outro veículo terrestre para impulso inicial.

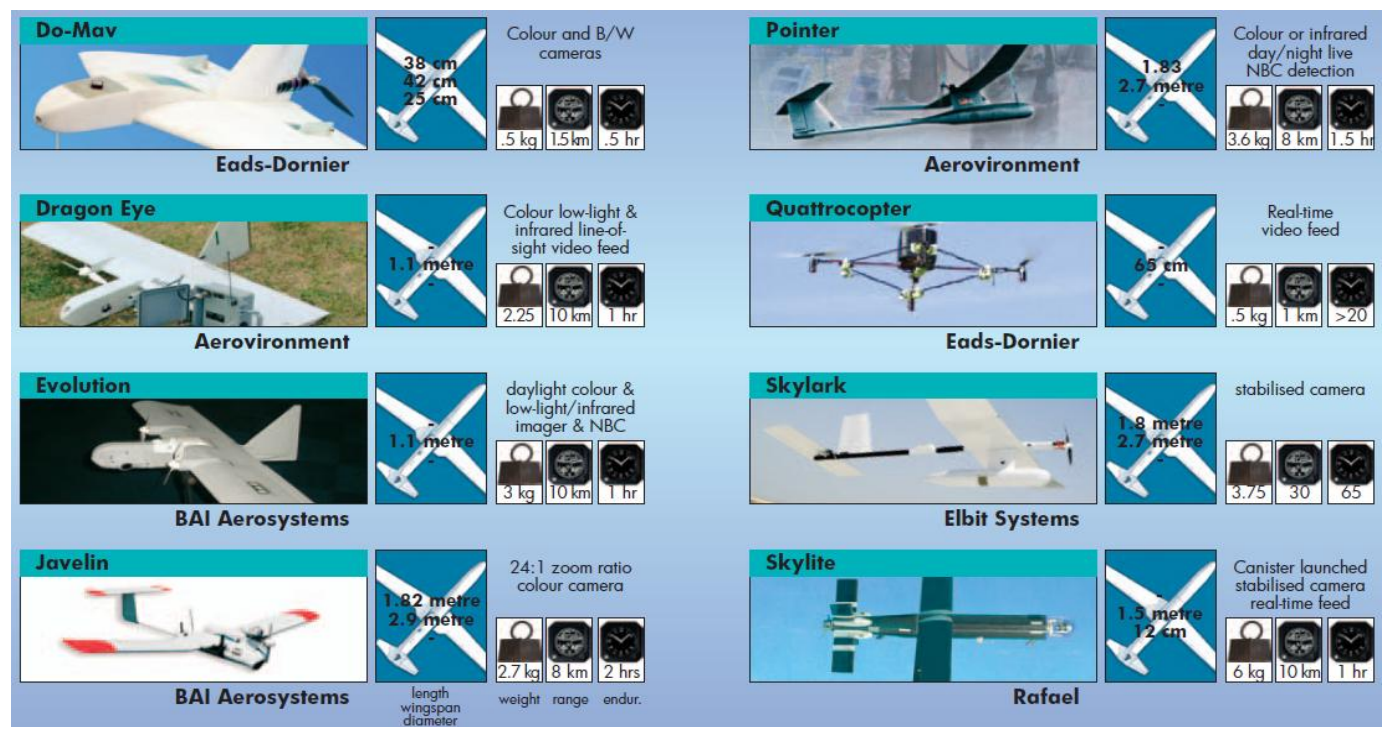

Figura 2.1.3-9: Exemplos de VANTs de lançamento manual. (ARMADA, 2004). 
Para pouso, além dos modos convencionais, os VANTs podem se utilizar de páraquedas, redes ou ganchos.

Em relação às capacidades e funções, estas aeronaves podem diferir em muitos aspectos. As capacidades chaves requeridas paras os VANTs, de acordo com NASA (2006), são apresentadas na figura a seguir, considerando-se a porcentagem de projetos de VANTs levantados que exigem tais capacidades.

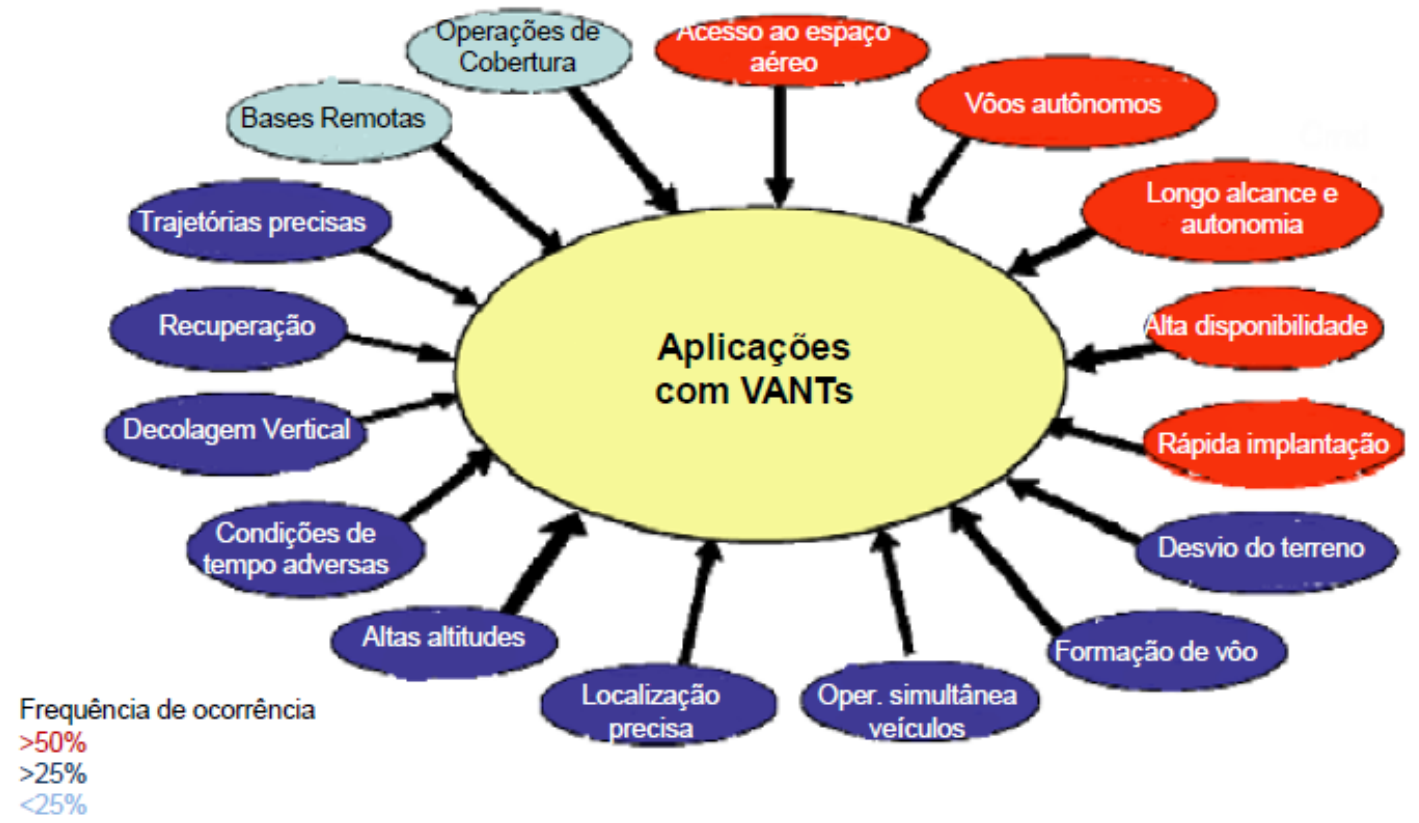

Figura 2.1.3-10: Capacidades chaves exigidas em missões com VANTs. Adaptado de Nasa (2006)

As capacidades chaves apresentadas na figura 2.1.3-10 são aqui explicitadas. A capacidade de acesso ao espaço aéreo diz respeito à capacidade de operar no espaço aéreo coabitado por aeronaves tripuladas. A capacidade de alta disponibilidade é de ter operação disponível na maior parte do tempo, enquanto a de rápida implantação é ligada à velocidade e tempo para o VANT ser colocado em operação. A habilidade de desvio do terreno é relativa ao VANT apresentar sistema automático que evite colisões com o terreno. Sobre a operação simultânea de veículos, seria destinada a operações que necessitassem de mais um VANT operando ao mesmo tempo e em cooperação a outro. O aspecto descrito como bases remotas está ligado à possibilidade do VANT ser operado de bases remotas distantes, enquanto que o aspecto de operações de cobertura está ligado à capacidade do VANT acompanhar e prover cobertura sobre determinados alvos em superfície (NASA, 2006). As outras capacidades são facilmente associáveis e estão abordadas ao longo deste estudo. 
No caso do uso para sensoriamento remoto da superfície terrestre, os sensores embarcados nas plataformas são, obviamente, equipamentos chave nos sistemas VANTs.

Inicialmente, os sensores eram meras câmeras fotográficas de filmes, normalmente de pequeno formato, monocromáticas e depois coloridas. Avançou-se para o uso de filmadoras portáteis e posteriormente de câmeras fotográficas digitais.

Mais recentemente, sensores digitais tem sido desenvolvidos ou adaptados especialmente para VANTs. Ficou comum a geração de imagens nas faixas do espectro eletromagnético correspondentes ao visível e infra-vermelho.

Atualmente, há VANTs que embarcam sensores hyperespectrais, lasers e SARs Synthetic Aperture Radar.

Nos avanços no desenvolvimento da tecnologia de sensores e equipamentos associados para VANTs, destacam-se algumas pesquisas recentes como as destacadas em IEEE (2009).

Wang et al. (2009) sugere o projeto de um sistema imageador SAR para VANT através de técnica denominada waveform-diversity-based. Nagai et al. (2009) propõe um sistema que combina duas câmeras CCD com um scanner laser, uma unidade de medição inercial (IMU) e um aparelho GPS para serem embarcados em pequenos VANTs para aplicação em mapeamentos 3-D de superfícies (MDT). Gurtner et al. (2009) demonstra a obtenção de imagens através de câmera dotada de lentes do tipo olho de peixe a fim de reduzir problemas com as rolagens de ângulos de obtenção de imagens em pequenos UAVs devido à suscetibilidade maior à turbulências. Bernie et al. (2009) demonstra o uso de sensoriamento remoto termal e multiespectral através de sensores de baixo custo para monitoramento agrícola com a extração de índices e parâmetros biofísicos de vegetação.

Nos últimos anos, diversas pesquisas têm sido realizadas envolvendo não apenas o desenvolvimento e aprimoramentos nas plataformas VANTs, nos sensores embarcados e no sistema de transmissão de dados, mas também inovações e experimentações nos procedimentos e técnicas de processamento digital das imagens e dados obtidos pelos equipamentos, a fim de obter produtos de forma mais rápida e de melhor qualidade.

Neste sentido, são citados alguns trabalhos. Através da elaboração de algoritmos, Mukaerjee et al.(2009) extraiu pontos de interesses em diversas escalas de imagens 
hiperespectrais obtidas por UAV. Zhou (2009) apresenta georreferenciamento de vídeo com precisão e quase em tempo real em pequeno VANT desenvolvido para monitoramento de incêndios. Laliberte et al. (2009) determina as melhores formas de medição de texturas associadas a escala de análise em imagens obtidas por VANT que apresentam altíssima resolução espacial em aplicação de monitoramento de vegetação.

Algumas imagens obtidas por diferentes sensores embarcados em VANTs são apresentadas a seguir.

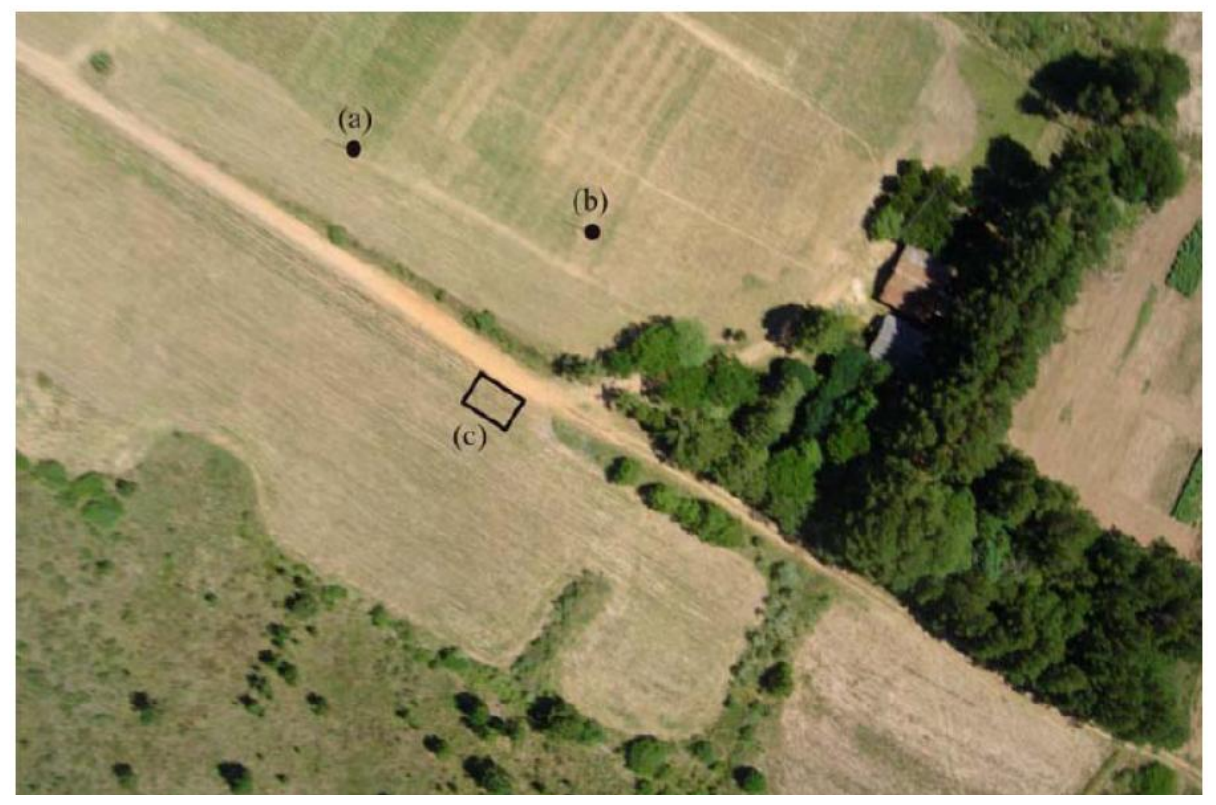

Figura 2.1.3-11: Imagem obtida por VANT construído na UFSM para monitoramento agrícola. (MEDEIROS et al., 2007)

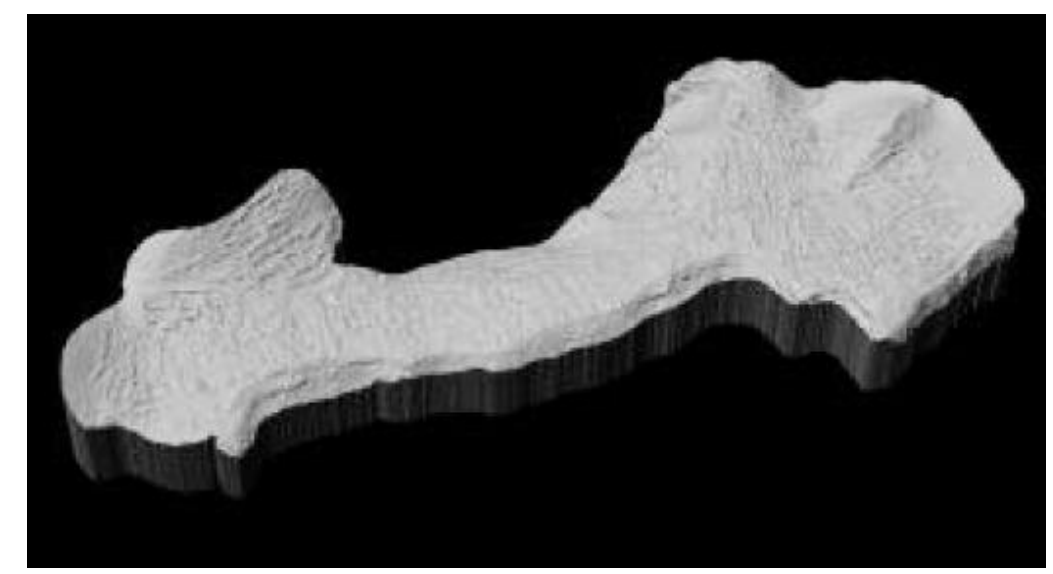

Figura 2.1.3-12: Modelo 3D do terreno obtido por sensor laser embarcado em VANT(EISENBEISS, 2004) 

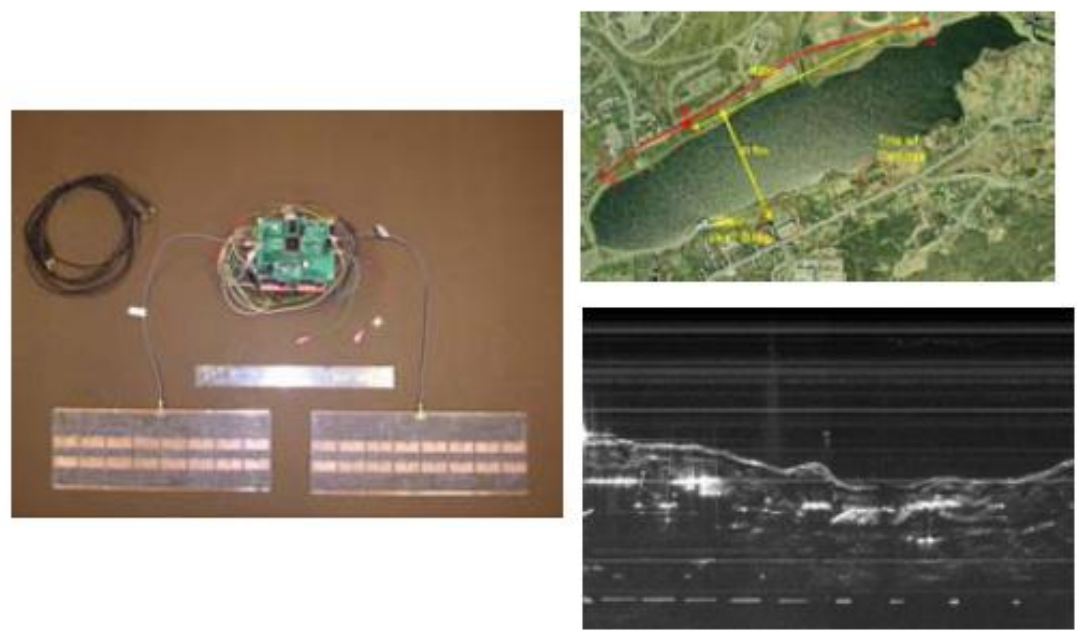

Figura 2.1.3-13: À esquerda, SAR embarcado no VANT Raven, e à direita, fotografia aérea e imagem do radar de uma área com reservatório. (O YOUNG, 2007)
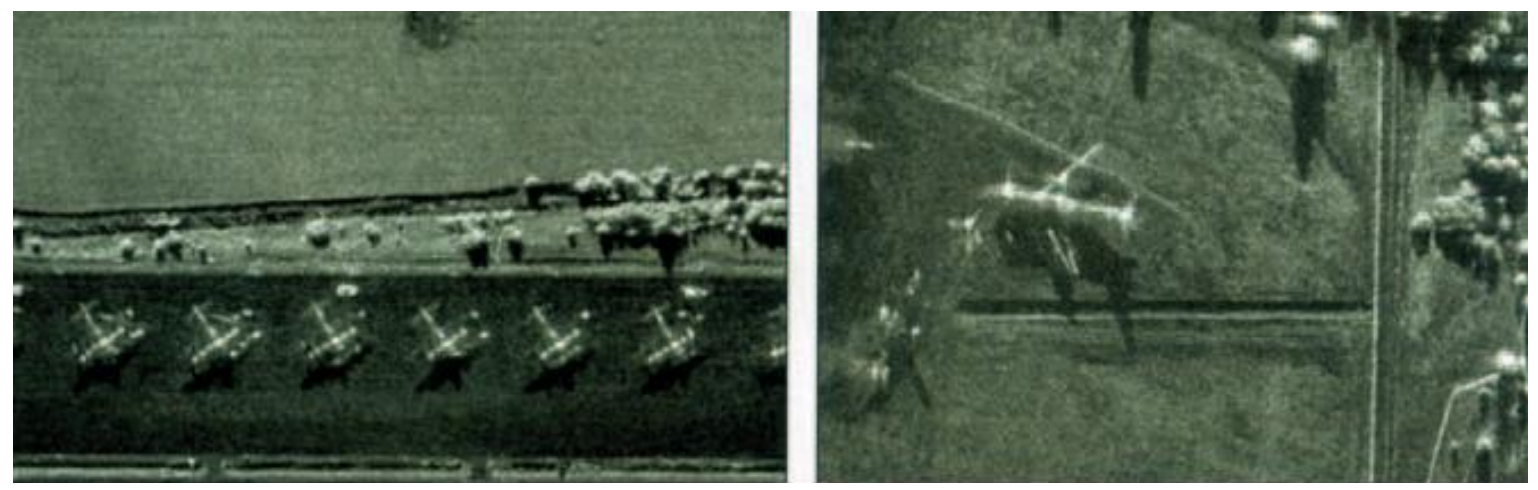

Figura 2.1.3-14: Imagens SAR provenientes do IAI Elta EL/M-2055. Na imagem podem ser identificados aviões. (ARMADA 2004)

Além dos projetos brasileiros anteriormente citados, são expostos aqui outros dos principais projetos de VANTs no Brasil. São destacados os VANTs com capacidades de sensoriamento remoto da superfície terrestre.

Na década de 70, o CTA (Comando-Geral de Tecnologia Aeroespacial situado em São José dos Campos - SP), em conjunto com o IPqM (Instituto de Pesquisas da Marinha) e o CTEX (Centro Tecnológico do Exército) foram os primeiros órgãos brasileiros que tiveram interesse nesta tecnologia. O Centro Técnico Aeroespacial (CTA) desenvolveu o projeto Acauã no ano de 1984, o primeiro projeto de um VANT brasileiro. A aeronave não-tripulada e rádio-controlada tinha como objetivos aplicações militares e civis, como auxiliar estudos ambientais e na inspeção de dutos de gás e óleo, por exemplo. O veículo de $5,1 \mathrm{~m}$ de envergadura tinha a capacidade de alcançar uma velocidade de vôo de cruzeiro de até $100 \mathrm{~km} / \mathrm{h}$, transportar uma carga de 14 kg (BRANDÃO et al., 2007). 


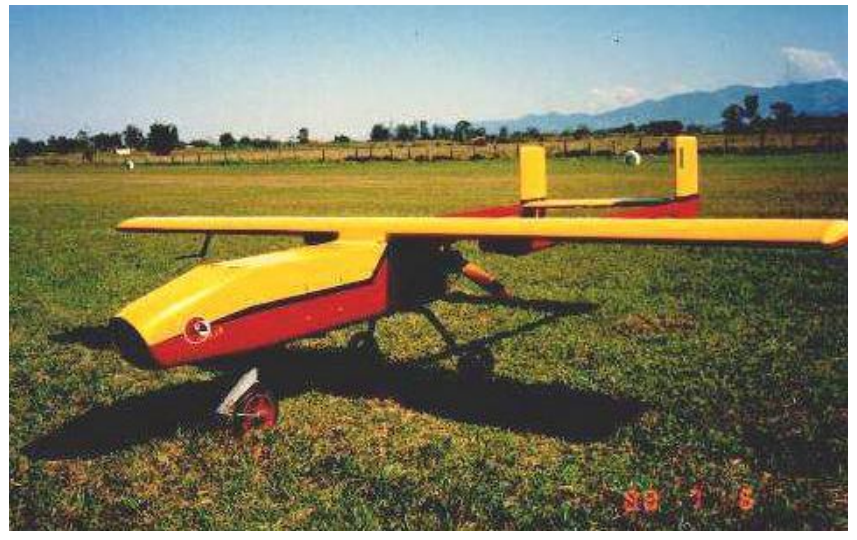

Figura 2.1.3-15: Aeronave ACAUÃ. (FITEC CTA, 2005).

Mais recentemente, em 2004 CTA, IPqM e o CTEx juntamente com empresa Avibras Aeroespacial se engajaram no desenvolvimento do Projeto VANT. Este projeto visa desenvolvimento de VANTs para aplicações civis e militares. Com isso, o Acauã foi retomado como plataforma de testes e aprimoramentos para o projeto. A Avibras visiona ainda a elaboração de um VANT estratégico, denominado de Falcão.

Dentre as iniciativas de desenvolvimento de sistemas completos e componentes integrantes de um SANT, podem ser elencadas diversas instituições.

O SOFIA - Sistema de Obtenção de Fotos e Imagens com Aeromodelo foi desenvolvido pelo Departamento de Cartografia da Faculdade de Ciência e Tecnologia da Universidade Estadual Paulista - UNESP, que de forma simplificada realizou alguns testes obtendo imagens aéreas através de uma câmara de pequeno formato embarcada em aeromodelo (PIOVESAN, 2003). Medeiros (2008) da Universidade Federal de Santa Maria - UFSM , desenvolveu de forma semelhante, pequena aeronave não tripulada e rádio controlada com câmera digital colorida convencional de pequeno formato para fins de agricultura de precisão.

O Projeto Carcarah da Universidade de Brasília - UnB, desenvolve VANT baseado em helimodelo para inspeção de linhas de transmissão (MARTINS, 2008).

O UAV-UFBA da Universidade Federal da Bahia é um projeto que "visa desenvolver um aeromodelo autônomo capaz de monitorar reservas ecológicas e áreas de desmatamento, auxiliar no controle de pragas, além de prover novas bases de conhecimento para a pesquisa científica" (FILARDI, 2006).

Segundo MARANHÃO NETO (2009) o projeto AEROPETRO da Universidade Federal do Rio Grande do Norte visa construir um VANT para tarefas de inspeção e supervisão de instalações da indústria de petróleo e gás. Outro equipamento pela 
UFRN desenvolvido trata-se de um helimodelo rádio controlado (CORDEIRO, 2009). Dentre os projetos acadêmicos mais avançados na área de VANTs, destacam-se o projeto Aurora do CenPRA de Campinas, apresentado na Figura 2.1.3-2, o projeto SiDeVAAN da Universidade Federal de Minas Gerais-UFMG, O APOENA desenvolvido na Escola Politécnica da Universidade de São Paulo (EP-USP) e o projeto A.R.A.R.A. desenvolvido em parceria pelo Instituto de Ciências Matemáticas e Computação da Universidade de São Paulo (ICMC-USP). A maioria destes projetos apresentava parceria com outros órgãos de pesquisas ou empresas privadas.

A UFMG desenvolveu diversos projetos na área de VANTs. Promoveu em outubro de 2000, a conclusão do Projeto "Controle e Implementação de um Dirigível Autônomo" (CIDA). Tratava-se da construção de um pequeno dirigível autônomo, capaz de se movimentar por ambientes fechados, realizando tarefas de navegação por meio de Visão Computacional (CAMPOS e de SOUZA COELHO, 1999 apud ALVES NETO, 2008). No ano de 2003, foi criado na UFMG o Projeto SiDeVAAN, que resultou em aeronave capaz de levar uma carga de até $30 \mathrm{~kg}$, dotada de uma autonomia de vôo de cerca de 4 horas e podendo atingir uma velocidade média de aproximadamente 200 km/h (CAMPOS et al., 2007 apud ALVES NETO, 2008).

Em 2006 teve início, também na UFMG, o Projeto Avião que Voa Sozinho (AqVS), utilizando-se de motoplanador elétrico autônomo de decolagem por arremesso manual (hand-launched) (ISCOLD, 2007 apud ALVES NETO, 2008).

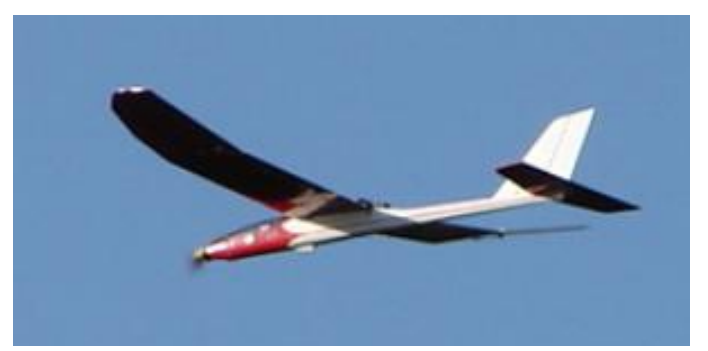

Figura 2.1.3-16: Projeto AqVS. VANT de pequeno porte da UFMG (ISCOLD, 2007 apud ALVES NETO, 2008).

No Departamento de Engenharia Mecatrônica da Escola Politécnica da Universidade de São Paulo - USP há o Laboratório de Veículos Não Tripulados. Fruto do projeto BR-UAV, surgiu a concepção de aeronaves Apoena (AMIANTI, 2005). Seu desenvolvimento teve envolvimento de outras instituições além da USP. CIETEC, CNPq, FAPESP e IPT participaram juntamente com a empresa XMobots que surgiu 
na incubadora de empresas da USP focada no desenvolvimento de Veículos Não Tripulados.

Segundo dados fornecidos pela Xmobots que constrói e opera comercialmente a aeronave Apoena 1000, ela pesa cerca de $32 \mathrm{~kg}$, tem envergadura de 2,52 m e comprimento de $2,62 \mathrm{~m}$. Tem autonomia de $8 \mathrm{~h}$, alcance de $64 \mathrm{~km}$, voa até alturas de $3000 \mathrm{~m}$, tem capacidade de carga útil de $10 \mathrm{~kg}$ ou cerca de $15 \mathrm{l}$. Decola de forma manual em pistas não pavimentadas sendo prevista para 2010 a implantação de catapulta e pára-quedas para decolagem e aterrissagem, respectivamente.

Pode ser controlado remotamente ou operar de forma autônoma e com autotracking, apresentando diversos sistemas embargados, como DGPS e air data computer (mede velocidade e direção do ar, umidade, temperatura e pressão barométrica).

É capaz de adquirir imagens georreferenciadas com resolução de 7 megapixels, na faixa do visível e infra vermelho. Pode obter imagens automaticamente e transmitir vídeo em tempo real. O sensor é dotado de zoom ótico com aproximação de até 22 $x$.

As aplicações iniciais do equipamento visam aerofotogrametria e monitoramento preditivo (linhas de transmissão, oleodutos e rodovias).

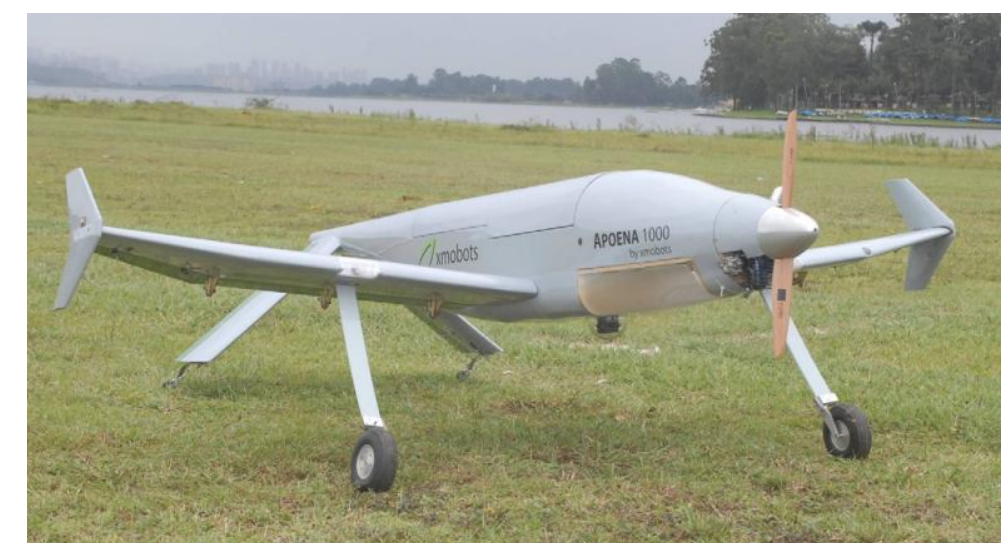

Figura 2.1.3-17: Apoena 1000 (Catálogo Apoena Series - Xmobots, 2009).

A Xmobots atualmente trabalha no desenvolvimento em uma segunda aeronave, a Apoena 3000, que deverá ter maior alcance, autonomia e capacidade de carga útil que a Apoena 1000.

O Projeto A.R.A.R.A. (Aeronaves de Reconhecimento Assistidas por Rádio e Autônomas) foi desenvolvido no Laboratório de Computação de Alto Desempenho do Instituto de Ciências Matemáticas e de Computação da Universidade de São 
Paulo, campus São Carlos, em parceria com a EMBRAPA, Fazenda Campo Bom e AGX Tecnologia Ltda, sob responsabilidade do Professor Dr. Onofre Trindade Júnior.

Teve início há mais de 10 anos e foi dividido em quatro fases. Algumas das pesquisas relacionadas ao seu desenvolvimento são de Souza (1999), Ribeiro (2000) e Jorge (2001).

A AGX Tecnologia opera comercialmente aeronave desenvolvida pelo projeto desde 2005. O AGplane possui capacidades de vôo autônomo e programado. Para lançamento, a aeronave é acoplada a um suporte em cima do veículo e quando este atinge cerca de $60 \mathrm{~km} / \mathrm{h}$, momento em que há força suficiente devido à aerodinâmica, ocorre a decolagem automaticamente. Pode pousar convencionalmente ou via pára-quedas em casos de emergências ou quando o operador desejar. As principais áreas em que vem atuando estão ligadas à agricultura de precisão até o momento, mas outras aplicações têm sido testadas, como para monitoramentos ambientais.
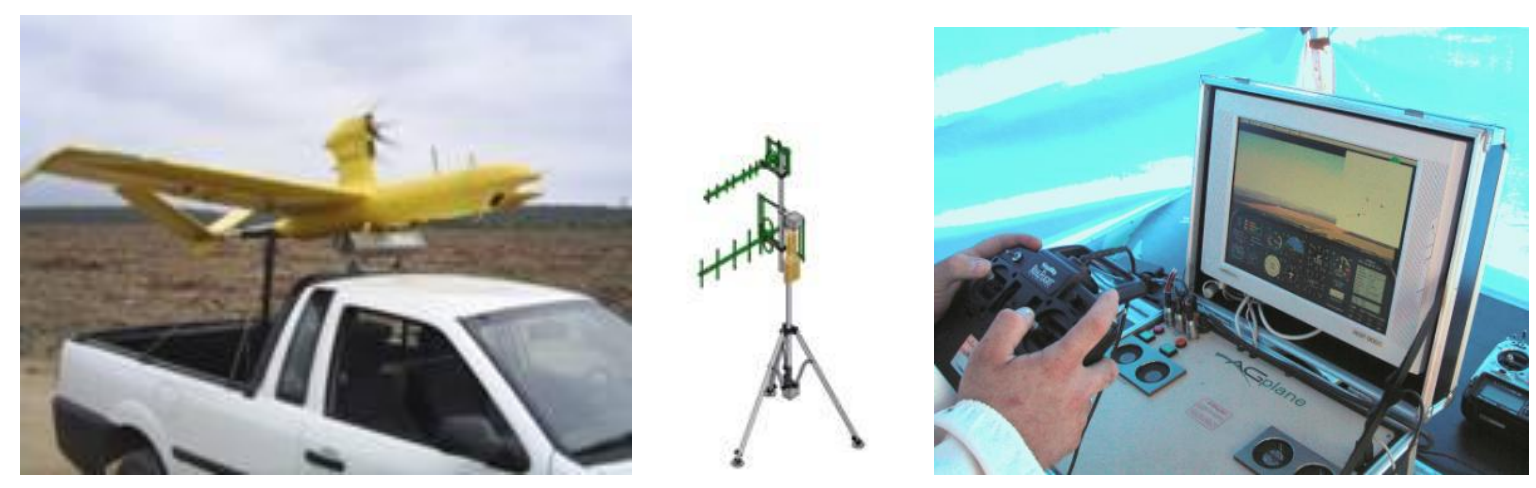

Figura 2.1.3-18: Aeronave acoplada a veículo para decolagem, torre de rastreamento e estação de comando, respectivamente (AGX TECNLOGIA. ORG. LONGHITANO, 2006)

A aeronave AGplane pesa $20 \mathrm{~kg}$ e mede $3,2 \mathrm{~m}$ de envergadura e 2,2 $\mathrm{m}$ de comprimento, tem capacidade de carga útil de até $10 \mathrm{~kg}$, autonomia de vôo 3,5 h e alcance de $8 \mathrm{~km}$. A aeronave pode ser equipada com câmeras digitais convencionais ou outros sensores. Um sensor multiespectral de imageamento das regiões do visível e infra-vermelho próximo (NIR) já foi empregado.

As imagens a seguir demonstram uma imagem obtida com câmera RGB convencional de 8 megapixels. 


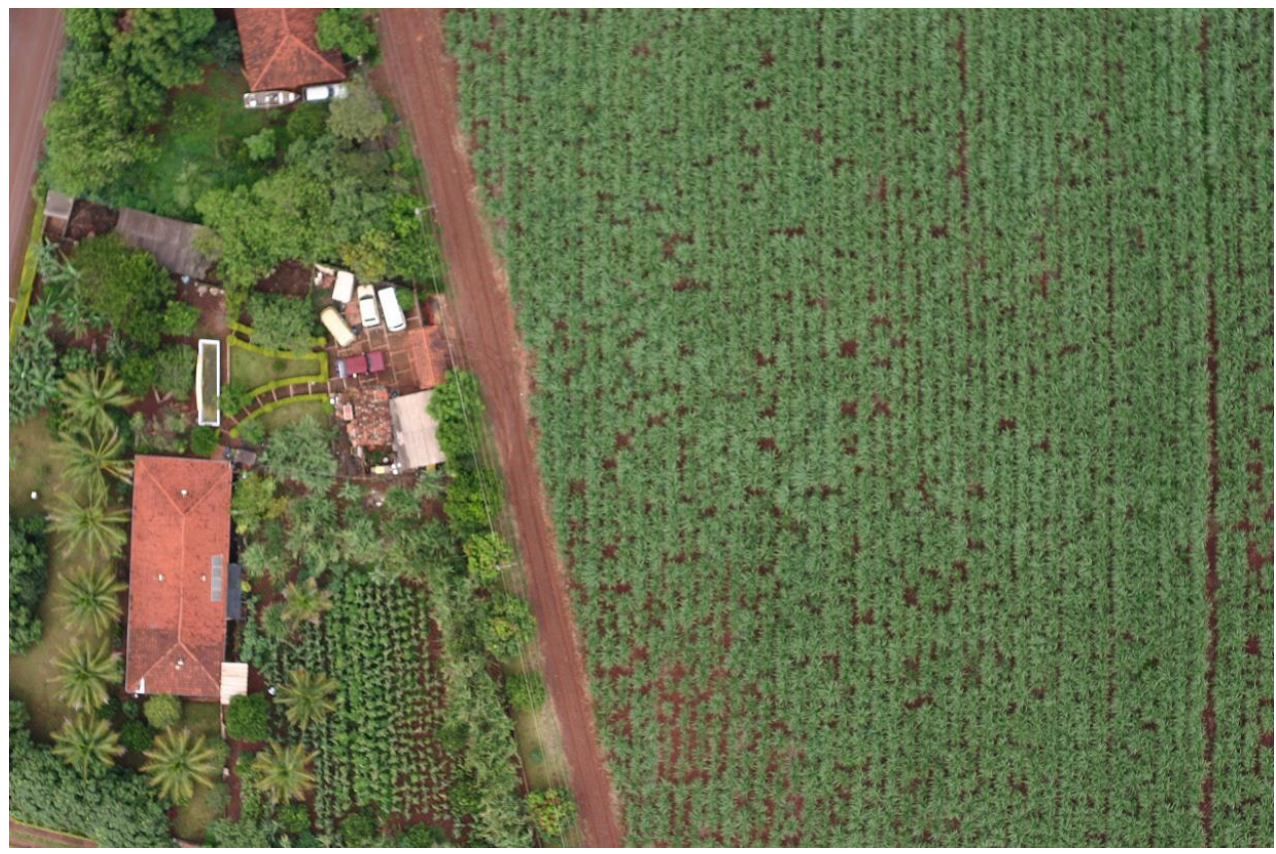

Figura 2.1.3-19: Imagem obtida a 200m de altura com distância focal de $50 \mathrm{~mm}$ - (a área recoberta é de aproximadamente $0,53 \mathrm{ha}$, com pixel de $2,57 \mathrm{~cm}$ em solo). (AGX TECNLOGIA. ORG.

LONGHITANO, 2006)

A AGX Tecnologia está atualmente desenvolvendo um VANT elétrico de baixo custo denominado Tibira. Outro VANT, o SAR-VANT, de maior porte também está em desenvolvimento em parceria com a empresa Aeroalcool que é desenvolvedora de aeronaves. Esta aeronave deverá ter capacidade de 40 horas de vôo e transportar 70 quilos. Foi encomendada pela empresa Orbisat. $O$ intuito é que seja embarcado sistema sensor radar (FREITAS e COTTET, 2010). Ambos VANTs estão previstos para serem concluídos até o final de 2010.

Além das instituições relacionadas, destaca-se que o CEFET-MG Centro Federal de Tecnologia de Minas Gerais e o ITA, Instituto Tecnológico da Aeronáutica, são também duas instituições que tem desenvolvido pesquisas na área de VANTs tanto na concepção de hardware como sistemas e softwares para telemetria, navegação e execução de diversas capacidades, como reconhecimento automático de atributos em solo para navegação (RODRIGUES et al., 2009).

O FITuav foi desenvolvido pela Fitec Inovações Tecnológicas. O projeto tem parceria da CEMIG para aplicação em inspeção de linhas de transmissão de energia elétrica. Trata-se de um pequeno VANT capaz de transportar uma carga paga máxima (payload máximo) de, aproximadamente, $3 \mathrm{~kg}$. 


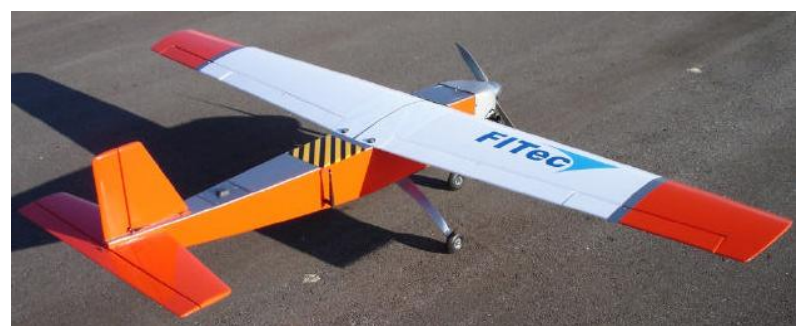

Figura 2.1.3-20: VANT FITuav. (FITEC, 2005).

Outro projeto nacional foi da Gyron Sistemas Autônomos, que lançou em 1991 seu primeiro projeto de aeronave robótica, chamada HELIX. O projeto foi desenvolvido em parceria com a Universidade Federal de Santa Catarina e o CenPRA. "Tratavase da construção de um helicóptero não-tripulado e remotamente controlado para fins de inspeção. O protótipo apresentava uma carga útil de cerca de $10 \mathrm{~kg}$, com uma autonomia de vôo de 1,5 h e raio operacional de 30 km." (Gyron, 1998 apud ALVES NETO, 2008).

A Flight Solutions é uma empresa nacional especializada em desenvolvimento de SANTs. Atualmente conta com três projetos. O FS-02 Avantvision é um projeto de VANT que será lançado manualmente e de curto alcance $(10-15 \mathrm{Km})$ com capacidade de carga paga de $1 \mathrm{~kg}$. Está em fase de desenvolvimento.

O FS-03 Starcopter trata-se de um helimodelo que se encontra em fase de concepção.

Já o Watchdog (FS-01) é um VANT tático de médio alcance $(70 \mathrm{~km})$ com capacidade de carga útil de $10 \mathrm{~kg}$ se encontra desenvolvido e em fase final de ensaios junto ao Comando de Aviação do Exército em Taubaté-SP. A aeronave possui 2,80 m de comprimento e 4,30m de envergadura. Sua autonomia é de $2 \mathrm{~h}$ e o alcance projetado é de $70 \mathrm{~km}$. A altura máxima de vôo é de cerca de 7 mil metros e a capacidade de carga é de $10 \mathrm{Kg}$ ou $2500 \mathrm{~cm}^{3}$. Pode operar de forma autônoma em vôo e rádio assistido para decolagem e pouso. Sua carga pode ser configurada em 2 versões. Payload 1 - Vídeo: é desenvolvida em parceria pela Flight Solutions e o Centro Tecnológico do Exército (CTEX). O Payload 2 - Georreferenciamento: é desenvolvido pela Flight Solutions em parceria com o CENTRAN (Centro de Excelência Engenharia de Transportes) e o IME (Instituto Militar de Engenharia), sendo esta segunda configuração mais voltada para fins civis.

Payload 1 - Vídeo é composto por câmera de vídeo modelo AXIS PTZ (Pan-TiltZoom) comandada via joystick, da estação de solo. Informações de GPS e inercial 
através da unidade de dados de alta precisão. Objetiva o monitoramento de áreas para aquisição de alvos em linha de combate para artilharia.

O Payload 2 - Georreferenciamento é composto por câmera fotográfica Canon EOS 40D (10.1 megapixels), GPS Novatel RTK 20cm precisão RMS, inercial de alta precisão Rockwell Collins (0.2 graus para pitch e roll, 0.6 graus para yaw), sistema de aquisição de dados de georreferenciamento (foto, latitude, longitude, altitude, angulos de pitch, roll, e yaw) e sistema de estabilização da câmera no eixo de rolamento (mantém a câmera sempre apontada para o nadir independentemente da atitude do VANT). As imagens obtidas são armazenadas em cartão de memória, com posterior download através de interface USB, após o pouso do VANT. Este payload visa aplicações em mapeamento aéreo, para operações de mosaicamento e ortorretificação, monitoramento de estradas e demais obras públicas para fins de fiscalização. Tais aplicações devem ser testadas pelo CONTRAN e IME.

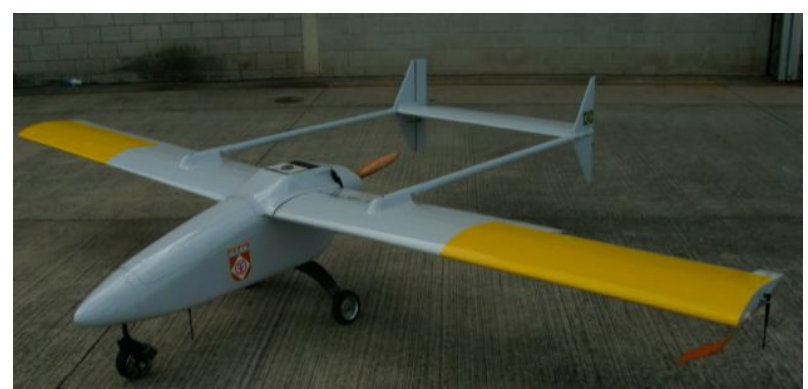

Figura 2.1.3-21: FS-01 - Watchdog da Flight Solutions. Imagem gentilmente cedida (FLIGHT SOLUTIONS, 2009)

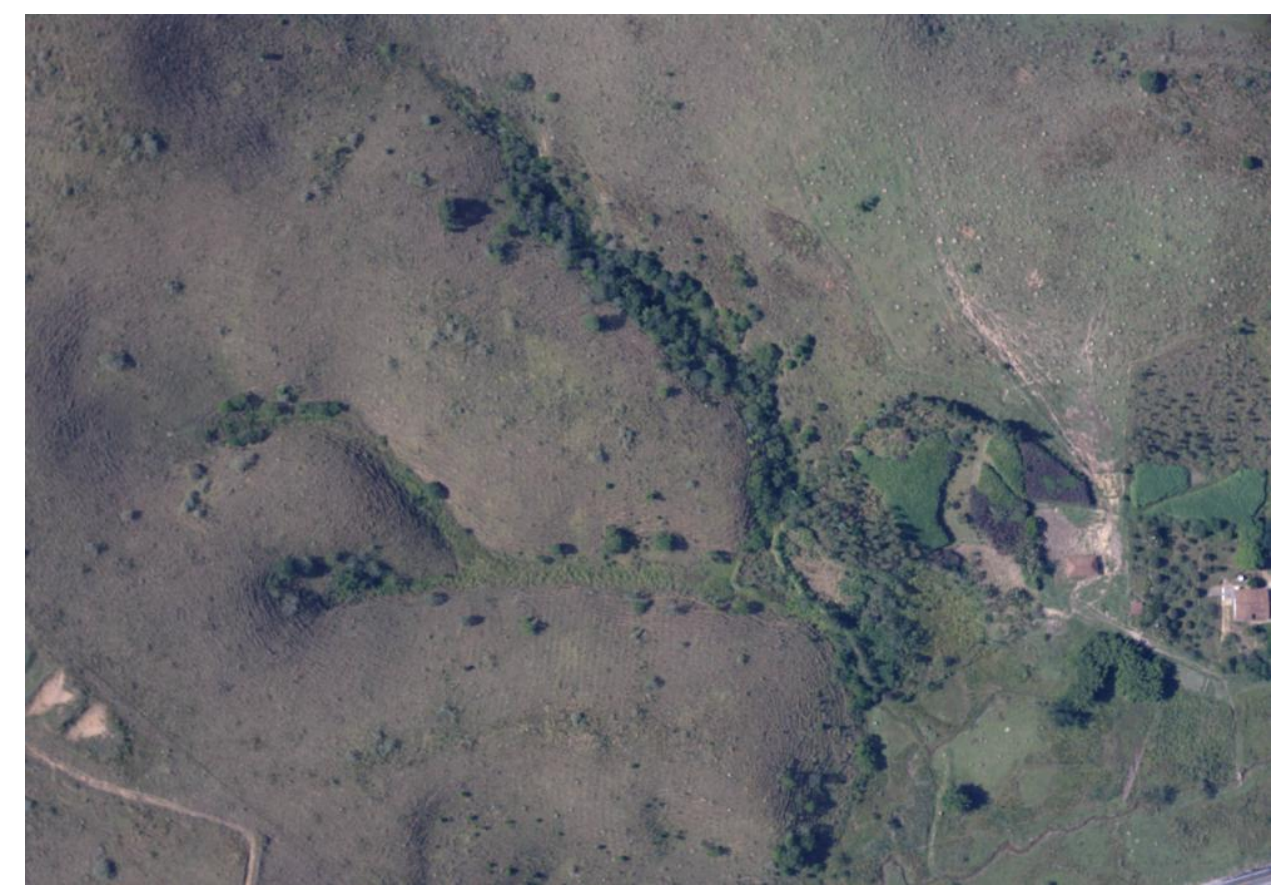

Figura 2.1.3-22: Exemplo de Imagem aérea obtida pelo FS-01 Imagem gentilmente cedida (FLIGHT SOLUTIONS, 2009) 
A Santos Lab é outra empresa nacional que tem atuado no mercado de VANTs. Desenvolveu o Carcará, veículo aéreo de 1,6 m de envergadura com decolagem manual ou por catapulta. Tem autonomia de 60 a 95 min e pode ser provido com câmera móvel com zoom ou sensor infra-vermelho.

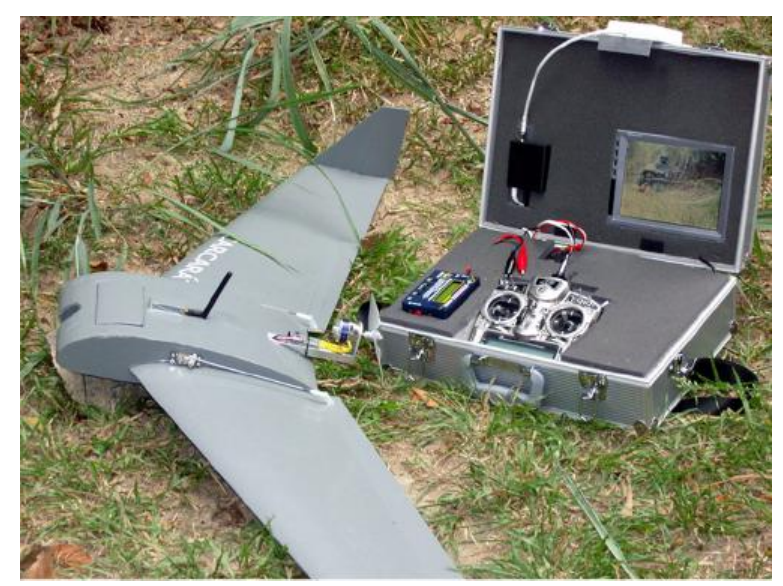

Figura 2.1.3-23: VANT Carcará. Santos Lab, 2009

O VANT é utilizado desde 2006 pela Marinha Brasileira, integrando o Batalhão de Controle Aerotático e Defesa Antiaérea do Corpo de Fuzileiros Navais, em funções de reconhecimento.

Outro VANT criado pela Santos Lab é o Jabiru, uma plataforma aérea de reconhecimento tático de média altitude e média duração. Tem envergadura de $5 \mathrm{~m}$ e comprimento de $2,4 \mathrm{~m}$, pode ser lançado por teto de viatura ou catapulta. Sua autonomia é de $12 \mathrm{~h}$ e tem carga paga de $6 \mathrm{~kg}$.

A FlyBR UAV Solutions é representante da Swissteps no Brasil. De forma semelhante a Rotomotion Brasil, representa a Rotomotion. Ambas visam comercializar e prestar serviços com helimodelos voltados para aplicações diversas com sensoriamento remoto. Outra empresa que visa revender VANTs importados de acordo com a necessidade do cliente é a AeroCamera.

A Empresa Brasileira de Veículos Aéreos Não Tripulados (EMBRAVANT) visa desenvolver e produzir VANTs para aplicações civis. O primeiro projeto encontra-se em desenvolvimento e é batizado de Gralha Azul. Possuirá mais de 4 metros de envergadura e capacidade de transportar uma carga de até 40 quilos e autonomia de 3 horas.

Outra empresa nova é a Gyrofly Innovations, que tem como objetivo a elaboração, 
construção e comercialização de Mini VANTs. Seu projeto Gyro 500, em fase de desenvolvimento, deverá utilizar propulsão elétrica, sistema inercial, GPS e um sistema de pouso e decolagem vertical.

Recentemente, em julho de 2009, a polícia federal brasileira realizou alguns testes sobre a tríplice fronteira para atividades de vigilância com um modelo do VANT Heron, da Israel Aerospace Industries Ltd. (IAI)'s. Trata-se de um VANT MALE e a princípio, a polícia federal estuda a aquisição de três unidades para operações diversas em território nacional.

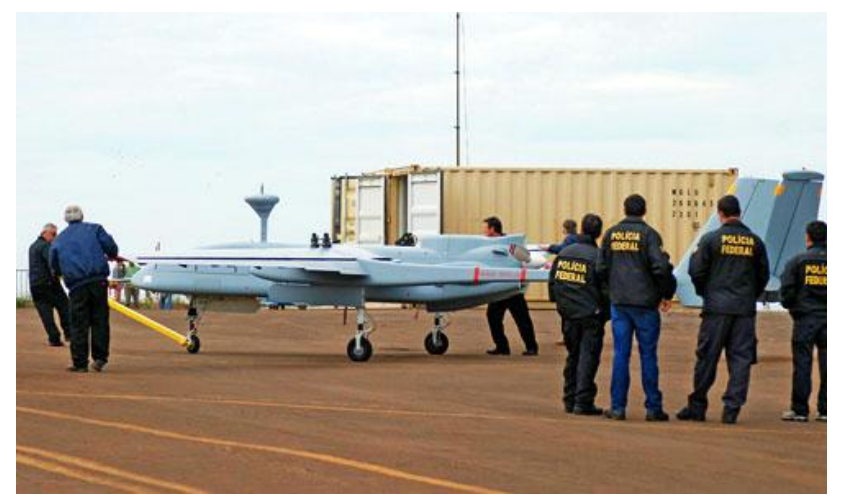

Figura 2.1.3-24: Aeronave Heron em teste pela polícia federal no Paraná. (http://www.paranaonline.com.br/editoria/cidades/news/384669/)

O VANT Hermes 450 desenvolvido pela Elbit Systems, companhia israelense, envolvendo a participação de sua subsidiária no Brasil, a empresa Aeroeletrônica, está no Brasil desde dezembro de 2009 e está em testes pela Força Aérea Brasileira. O equipamento mede 10 metros de comprimento e seis de envergadura, voa a 110 quilômetros por hora e pode atingir cerca de cinco mil metros de altitude, com autonomia de mais de 15 horas em vôo (FREITAS e COTTET, 2010).

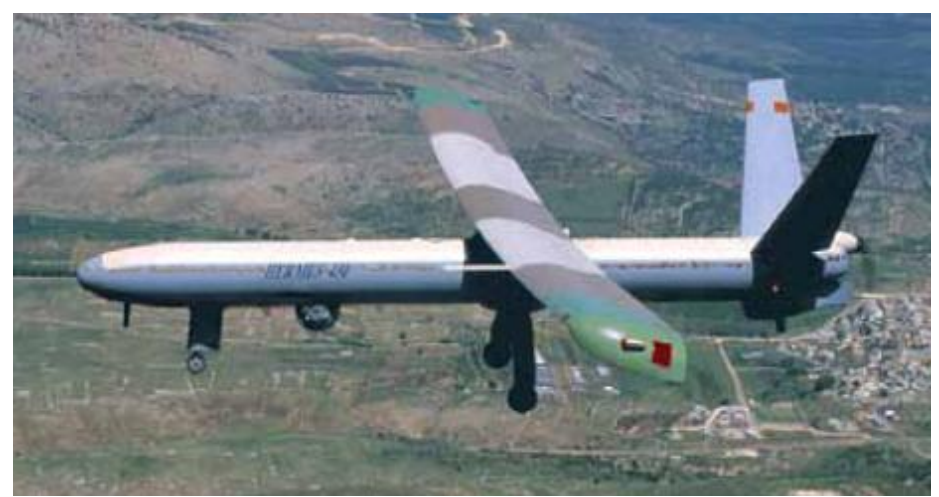

Figura 2.1.3-25: Aeronave Hermes 450. (FREITAS e COTTET, 2010) 
As aeronaves Harpia da empresa Avibras e K1AM da Aeromot são outros VANTs nacionais, entretanto, voltadas para o objetivo de servirem como alvos para treinamento militar e por isso não foram mais detalhados. Outro VANT nacional desenvolvido pela Prince Air Models é o Agro Robot, para pulverização em agricultura (RASI, 2008).

\subsection{AVALIAÇÃO E MONITORAMENTO DE IMPACTOS AMBIENTAIS EM ACIDENTES COM TRANSPORTE DE CARGAS PERIGOSAS EM RODOVIAS}

Em todas as operações que envolvem produtos perigosos há probabilidade de ocorrência de acidentes, entretanto, as atividades de transporte são as mais suscetíveis. Falhas humanas e tecnológicas nas atividades e equipamentos utilizados podem ocasionar acidentes. Mas além deste, há outros diversos fatores externos e que fogem ao controle dos responsáveis pelo transporte, que podem ocasionar os acidentes, independentemente de avanços e melhorias na prevenção destes.

\footnotetext{
É no transporte desses materiais que a exposição ao risco de acidentes é ainda maior, devido ao contato com outros fatores externos tais como: condições de sinalização das vias, geometria, clima, falhas humanas, irregularidades nos veículos, nas cargas transportadas, nas fichas de emergência, na formação dos motoristas, em certificados, em documentos fraudados, entre outros. (ALVES et al, 2003)
}

O transporte de produtos perigosos pode ser aéreo, marítimo, fluvial ou terrestre e nenhum dos meios está imune a riscos de acidentes.

Os acidentes com transporte aéreo de cargas perigosas podem ocorrer durante 0 vôo, com vazamento do produto por exemplo, em solo e durante a decolagem ou aterrissagem. Em vôos, a bordo das aeronaves, e nas dependências aeroportuárias devem sempre estar presentes profissionais treinados para proceder adequadamente se ocorrerem situações emergenciais com substâncias perigosas, seguindo-se as normas vigentes (no Brasil a Instrução de Aviação Civil IAC 1531001 é a que trata da normatização para o transportes de artigos perigosos).

Situação mais grave acontece quando a aeronave cai ou explode no ar. Nestes 
casos, a localização da emergência muitas vezes é de difícil acesso. Acidentes aéreos com transporte de cargas perigosas são raros e pelas suas características não favorecem a sistematização de procedimentos para atendimentos.

Acidentes com o transporte fluvial e, principalmente, marítimo têm o potencial de liberar grandes volumes de material. Em geral, são derrames de óleo, os quais podem provocar vários impactos ambientais.

Impacto ambiental, segundo Sánchez (2008), "é qualquer alteração da qualidade ambiental que resulta da modificação por processos naturais ou sociais provocada por ação humana."

A identificação e quantificação dos impactos provocados por estes acidentes representam um grande desafio, pois há uma série de dificuldades operacionais e metodológicas a serem vencidas, quando acidentes acontecem sobre a água. Tipo e quantidade do material, época do ano, a dinâmica e os processos fluviais, marinhos e costeiros, e outras variáveis ambientais, como a comunidade biológica que existe na região, influenciam e determinam uma grande variedade de cenários para 0 atendimento de uma emergência. Pode haver também contaminações de áreas terrestres de interface com as águas fluviais ou marinhas, como margens de rios ou costas litorâneas (LOPES, 2009).

Devido à possibilidade de grandes dispersões nas manchas de derramamentos e alterações na forma de deslocamento e comportamento do óleo na água, o monitoramento das áreas é um procedimento imprescindível para o planejamento das ações necessárias para responder a desastres no transporte fluvial e marinho de cargas perigosas.

Tratando-se de transporte terrestre de substâncias perigosas, ele pode ocorrer por dutos, ferrovias ou rodovias.

De acordo com Lainha et al. (2003), dutos servem em geral para transporte de petróleo e derivados, gás, álcool, e outros produtos em distâncias longas e onde há constante demanda por estes. São equipados com dispositivos de segurança e construídos com materiais e métodos construtivos que visam prover o maior nível de segurança possível. Por serem caracterizados por uma estrutura fixa de transporte, de maneira geral, diminuem os riscos de acidentes ambientais no transporte de grandes montantes de fluido.

Porém, a existência de uma malha de dutos em regiões ambientais relevantes e 
áreas povoadas exigem identificação e ações rápidas e eficientes em caso da ocorrência de vazamentos. Estas ações, muitas vezes encontram barreiras para execução, como terrenos acidentados e de difícil acesso.

O modal ferroviário, mesmo que carente de investimentos nas últimas décadas, ainda é um importante meio de transporte de cargas. Dentre os produtos perigosos mais transportados no Brasil, estão o álcool, coque, diesel e a gasolina.

O atendimento a acidentes ferroviários tem algumas peculiaridades quando comparado aos acidentes rodoviários. O acesso viário às áreas atingidas muitas vezes inexiste e é necessária a abertura de acessos (LAINHA et al., 2003). A ferrovia não raramente é danificada pelo acidente e, pela capacidade de carga de uma composição, a quantidade de produto derramado normalmente é maior que em acidentes rodoviário, embora tenha ocorrência muito menos freqüente (LOPES, 2009). Pode ocorrer até o espalhamento de mais de um tipo de produto.

Em diversos países do mundo, como os Estados Unidos, o transporte rodoviário é o principal em termos de fluxo. Mesmo na Europa onde há apoio governamental de incentivo à intermodalidade, dados da International Road Transport Union (IRU) demonstram que as rodovias ganham cada vez mais espaço (TEIXEIRA, 2005).

No Brasil, a priorização pelo transporte rodoviário é histórica. Trata-se do modal de transporte que recebeu maior atenção e investimentos no último século. É o que apresenta maior fluxo de cargas e de passageiros dentre todos os modais.

O transporte de produtos dos setores químicos, petroquímico, de refino de petróleo, e outras cargas perigosas, também é realizado em sua maior parte por rodovias. Embora faltem dados. O transporte destes por rodovias é estimado em cerca de $70 \%$, de acordo com Alves et al. (2009).

Segundo a Norma NFPA (2002), produto perigoso é qualquer substância (sólido, líquido ou gás) que quando exposta é capaz de provocar riscos às pessoas, ao meio ambiente e à propriedade.

No Brasil os riscos inerentes ao transporte rodoviário são amplificados pelas situações das estradas. De acordo com Teixeira (2005), dados oficiais demonstram que o país apresenta quase 1,8 milhão de quilômetros de estradas, dos quais somente $10 \%$ são pavimentados. Mas apesar da precariedade, a malha rodoviária brasileira é a segunda maior do mundo, e perde apenas para os Estados Unidos. Outros dados apresentados pelo autor mostram que o número de mortes nas 
estradas por $1000 \mathrm{~km}$ de rodovias são de 10 a 70 vezes superiores no Brasil do que em outros países (Canadá, França, Alemanha, Japão, Reino Unido, EUA e Itália).

Deve-se destacar que, segundo Alves et al. (2009):

Existe uma carência de estudos, pesquisas, banco de dados e informações
disponíveis sobre os acidentes envolvendo o transporte de produtos
químicos e perigosos. Esse fato, muitas vezes, dificulta a análise mais
detalhada da situação no Brasil, tornando-se um obstáculo para as
pesquisas e possíveis intervenções com vistas na redução dos impactos
causados por esse tipo de atividade.

A CETESB, como uma das exceções, é órgão público que provém informações sobre os acidentes, sendo a seguir apresentados alguns dados referenciados por esta instituição.

No estado de São Paulo, a maior parte do total dos acidentes ambientais atendidos entre 1978 e 2008 pela CETESB (CETESB, 2009), foram provocados por transporte de cargas perigosas em rodovias. Nos últimos cinco anos, entre 2004 e 2008, a média foi de 216 atendimentos por ano, ou aproximadamente 0,6 atendimentos por dia pela CETESB a este tipo de emergência.

Os dados de atendimento da CETESB serão utilizados como exemplo, uma vez que no Estado de São Paulo é onde se concentra a maior parte de produtores e consumidores de produtos químicos do país e o maior fluxo no transporte destes produtos. Além disso, o órgão é reconhecidamente uma referência no cenário nacional no atendimento de emergências químicas e dispõe de base de dados atualizada.

A tabela 2.2-1 apresenta a distribuição dos atendimentos a emergências químicas realizadas pela CETESB por tipos de ocorrência e o número total de atendimentos realizados a acidentes com transporte rodoviário de cargas perigosas pela CETESB.

Tabela 2.2-1: Distribuição dos acidentes químicos por atividade no Estado de São Paulo - 1978 a maio de 2009. (CETESB, 2009)

\begin{tabular}{|c|c|c|c|c|c|}
\hline \multirow[t]{2}{*}{ PERÍODO: } & 1978 & até maio de & 2009 & TOTAL DE ACIDENTES: & 7754 \\
\hline & & & & & $\%$ \\
\hline \multicolumn{5}{|c|}{ Armazenamento } & 2,5 \\
\hline \multicolumn{5}{|c|}{ Descarte } & 5,2 \\
\hline \multicolumn{5}{|c|}{ Indústria } & 7,1 \\
\hline \multicolumn{5}{|c|}{ Mancha Órfã } & 1,6 \\
\hline \multicolumn{5}{|c|}{ Nada Constatado } & 9,2 \\
\hline \multicolumn{5}{|c|}{ Não Identificada } & 5,1 \\
\hline \multicolumn{5}{|c|}{ Outras } & 11,4 \\
\hline \multicolumn{5}{|c|}{ Postos e Sistemas Retalhistas de Combustíveis } & 8,9 \\
\hline \multicolumn{5}{|c|}{ Transporte Ferroviário } & 1,2 \\
\hline \multicolumn{5}{|c|}{ Transporte Maritimo } & 4,7 \\
\hline \multicolumn{5}{|c|}{ Transporte por Duto } & 2,6 \\
\hline \multicolumn{5}{|c|}{ Transporte Rodoviário } & 40,5 \\
\hline
\end{tabular}


Os dados mostram que o transporte rodoviário é o que gera a maior parte de acidentes químicos com 40,5\% das ocorrências. Em relação a outros modais de transporte terrestre, o transporte ferroviário e por dutos representam apenas 1,2 e $2,6 \%$, respectivamente, dos acidentes.

Deste modo, embora o potencial de volume de substâncias a serem emitidas para o ambiente por meio de um acidente com transporte rodoviário de cargas perigosas seja inferior a um acidente com transporte ferroviário ou por dutos, há um número muito maior de acidentes neste modal. Assim os impactos ambientais causados por acidentes rodoviários são em geral localizados, mas em número e freqüência de ocorrência muito superior que as outras formas de emergências químicas.

Este caráter reforça a importância de melhorias na velocidade, segurança e qualidade das informações ambientais a serem obtidas na avaliação e monitoramento de impactos ambientais causados especificamente por transporte rodoviário de cargas perigosas.

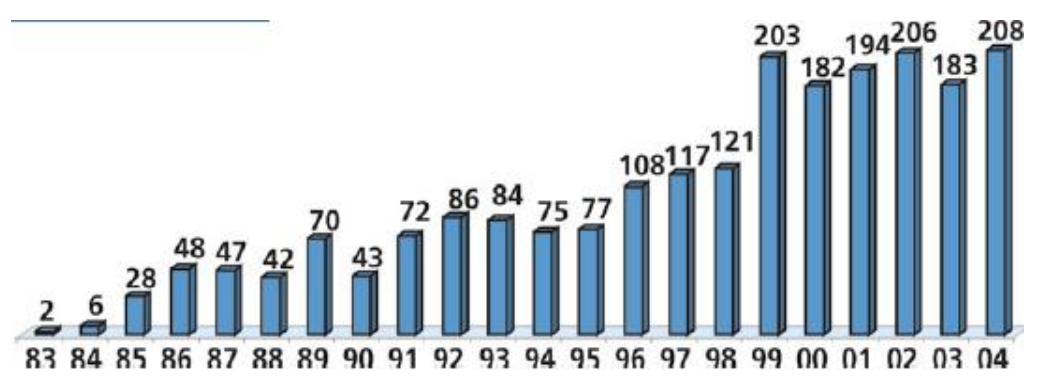

Figura 2.2-1: Número de atendimentos emergenciais realizados pela CETESB a acidentes com transporte rodoviário de carga perigosa - 1983 a 2004. (TEIXEIRA, 2005)

Dados mais atuais mostram a continuidade da tendência de aumento de ocorrências de acidentes rodoviários com cargas perigosas atendidos pela CETESB. Nos anos de 2005, 2006, 2007 e 2008, foram realizados respectivamente 197, 198, 244 e 233 atendimentos (CETESB, 2009). Cabe mencionar, que os dados são referentes aos atendimentos, portanto não correspondem ao número de acidentes, sendo que este pode ser consideravelmente maior.

Teixeira (2005) apresenta os dados de acidentes atendidos pela CETESB no estado de São Paulo regionalizados e com dados temporais, conforme apresenta-se a seguir. 


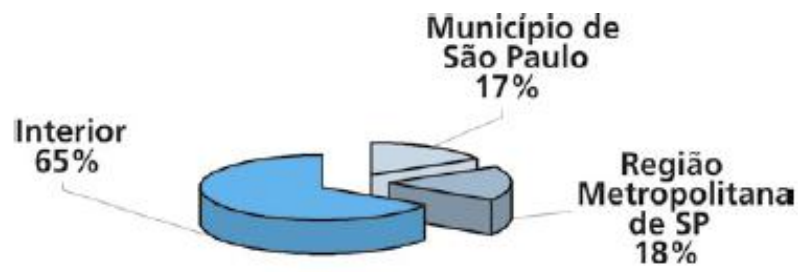

Figura 2.2-2: Distribuição regional dos acidentes com transporte rodoviário de cargas perigosas no Estado de São Paulo - 1978 a 2004. (TEIXEIRA, 2005)

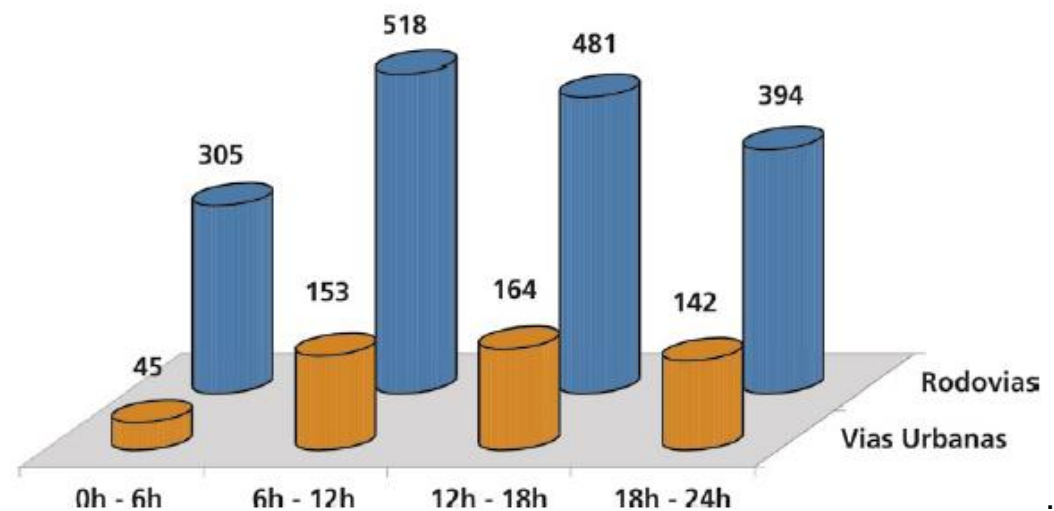

Figura 2.2-3: Distribuição horária dos acidentes com transporte rodoviário de cargas perigosas no Estado de São Paulo - 1978 a 2004. (TEIXEIRA, 2005)

A partir dos dados, confirma-se que as áreas em que mais ocorrem acidentes são aquelas com maior fluxo do transporte rodoviário, pois embora com apenas $6 \%$ dos municípios que compõem o estado de São Paulo, A RMSP por ter uma grande malha viária e concentrar grande parte do setor produtivo do estado, apresenta cerca de $35 \%$ do total dos acidentes em seu território. Cabe, porém, destacar que os $65 \%$ dos acidentes que ocorrem no interior apresentam-se relativamente bem distribuídos no estado (TEIXEIRA, 2005).

Em relação aos dados horários dos acidentes, estes ocorrem em maior parte no horário comercial, das 6 às 18h, quando as atividades de transporte ocorrem em maior fluxo. Dados também mostram que a grande maioria dos acidentes ocorrem em rodovias em comparação com as vias urbanas.

Tendo em vista a periculosidade e riscos que a atividade de transporte rodoviário de cargas perigosas traz, segundo Alvim e Amorim (2010), ela é altamente regulamentada com o objetivo de agregar-se o maior grau de segurança, confiabilidade e profissionalismo:

O transporte rodoviário e ferroviário de produtos perigosos, no âmbito nacional e por vias públicas, é disciplinado, respectivamente, pelos Decretos no. 96.044/88 e 98.973/90 e complementados pelas instruções da Resolução ANTT no. 420/04 e suas alterações, sem prejuízo da legislação e disciplina peculiar a cada produto.

A Resolução ANTT no. 420/04 especifica exigências detalhadas aplicáveis ao transporte terrestre de produtos perigosos. Tal regulamento está 
elaborado com base na décima primeira e décima segunda edições das Recomendações para o Transporte de Produtos Perigosos das Nações Unidas, conhecido como Orange Book, e na edição de 2001 do Acordo Europeu para o Transporte de Produtos Perigosos - ADR.

$O$ documento, além de trazer uma lista de aproximadamente 3000 produtos perigosos, os mais comumente transportados, dispõe sobre as exigências relacionadas à classificação dos produtos; embalagens e tanques; marcação e rotulagem; identificação de unidades de transporte e de carga; documentação; prescrições especiais relativas às operações de transporte. (ALVIM e AMORIM, 2010)

Esta parametrização, entretanto, não elimina a possibilidade de acidentes, embora seja importantíssima para que os riscos sejam reduzidos e auxilie nas operações de atendimento quando da ocorrência destes.

Segundo Lainha et al. (2003), "excluindo os eventos naturais, hoje em dia, os acidentes com produtos químicos são os mais significativos". Os acidentes com transportes de cargas perigosas podem causar diversos impactos ambientais, como por exemplo, contaminação do solo, águas superficiais e subterrâneas, impactos à fauna e vegetação, prejuízos ao patrimônio público e privado e às atividades econômicas como a agropecuária, impactos aos meios físico, biótico e socioeconômico. Podem, inclusive, ocasionar danos à saúde e bem estar do homem. Outro aspecto negativo que pode ocorrer é a interdição do trecho rodoviário onde houve o acidente até que este seja atendido e liberado para rodagem.

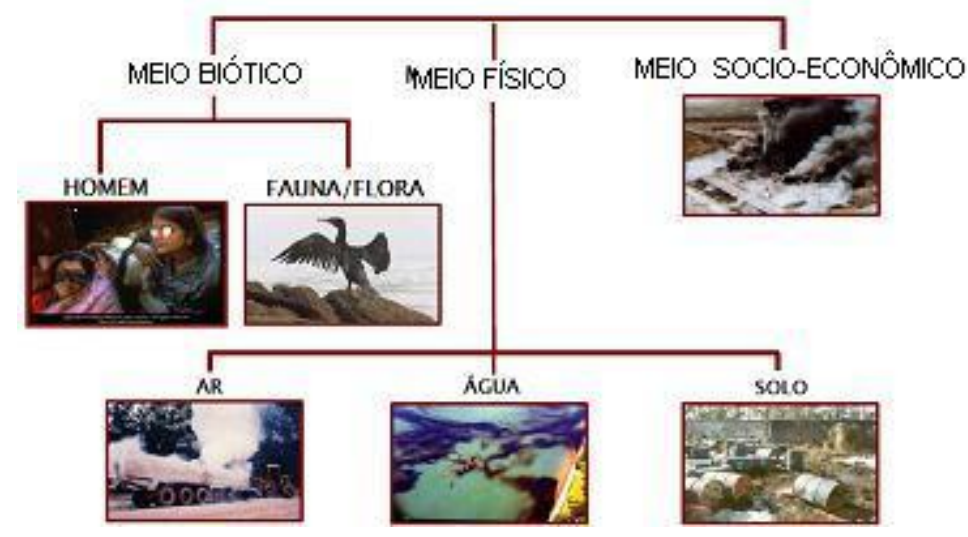

Figura 2.2-4: Aspectos ambientais suscetíveis a acidentes químicos (Adaptado de CETESB, 2009)

A tabela 2.2-3 apresenta a porcentagem das características de risco dos produtos perigosos transportados nos acidentes atendidos pela CETESB entre 2003 e maio de 2009 de acordo com a classificação da Resolução ANTT no. 420/04. Acidentes das classes 1 - Explosivos e 7 - Material radioativo, não ocorreram no período.

A tabela 2.2-3 mostra os tipos de contaminação que os acidentes entre 2005 e maio de 2009 ocasionaram ao meio ambiente. 
Tabela 2.2-2: Distribuição das classes de risco dos produtos perigosos transportados nos acidentes atendidos pela CETESB entre 2003 e maio de 2009 (CETESB, 2009)

\begin{tabular}{|c|c|c|c|c|c|}
\hline \multicolumn{6}{|c|}{ CLASSE DE RISCO } \\
\hline \multirow[t]{2}{*}{ PERIOODO: } & 1983 & até maio de & 2009 & TOTAL DE ACIDEN & 3141 \\
\hline & & & & & $\%$ \\
\hline \multicolumn{4}{|l|}{ Gases } & & 8,6 \\
\hline \multicolumn{4}{|c|}{ Líquidos Inflamáveis } & & 37,3 \\
\hline \multicolumn{4}{|c|}{ Sólidos Inflamáveis } & & 2,9 \\
\hline \multicolumn{4}{|c|}{ Oxidantes / peróxidos } & & 2,2 \\
\hline \multicolumn{4}{|c|}{ Tóxicas / infectantes } & & 3,9 \\
\hline \multicolumn{4}{|c|}{ Corrosivas } & & 19,6 \\
\hline \multicolumn{4}{|c|}{ Substâncias perigosas diversas } & & 5,5 \\
\hline \multicolumn{4}{|c|}{ Diversas } & & 3,2 \\
\hline \multicolumn{4}{|c|}{ Năo Identificadas } & & 4,2 \\
\hline \multicolumn{4}{|c|}{ Não classificados } & & 12,6 \\
\hline
\end{tabular}

Tabela 2.2-3: Tipos predominantes de contaminação que os acidentes entre 2005 e maio de 2009 ocasionaram ao meio ambiente (CETESB, 2009)

\begin{tabular}{|c|c|c|c|c|c|}
\hline \multicolumn{6}{|c|}{ CONTAMINAÇÄO } \\
\hline PERÍODO: & 2005 & até maio de & 2009 & TOTAL DE ACIDE| & 939 \\
\hline & & & & & $\%$ \\
\hline \multicolumn{5}{|l|}{ Solo } & 39,5 \\
\hline \multicolumn{5}{|l|}{$\mathrm{Ar}$} & 12,6 \\
\hline \multicolumn{5}{|l|}{ Fauna } & 1,2 \\
\hline \multicolumn{5}{|l|}{ Flora } & 4,0 \\
\hline \multicolumn{5}{|c|}{ Água } & 13,5 \\
\hline \multicolumn{5}{|c|}{ Não houve cont aminaçäo } & 29,2 \\
\hline
\end{tabular}

Verifica-se através dos dados mostrados na tabela 2.2-2 a divisão das classes de risco que das substâncias químicas transportadas. Todas elas apresentam grande potencial de gerar impactos ambientais e/ou danos à saúde humana, mas especial atenção deve ser dada a aquelas que podem ocasionar incêndios ou explosões, uma vez que tais fenômenos apresentam poder de amplificar os efeitos negativos de tais acidentes consideravelmente. Ainda sobre os acidentes ocorridos entre 2005 e maio de 2009 , em menos de $30 \%$ apenas não foram constatadas contaminações algumas, sendo maior parte delas ocorridas sobre o solo e as águas.

Destaca-se que a maioria das ocorrências registradas no estado de São Paulo envolve líquidos inflamáveis (37,3\%). As fotos a seguir ilustram a situação de alguns acidentes, incluindo incêndios ocasionados por acidentes rodoviários no transporte de líquido inflamável. 


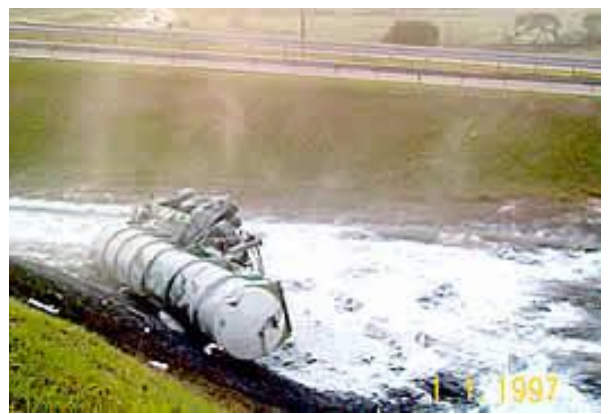

Acidente envolvendo derramento de ácido sulfúrico.

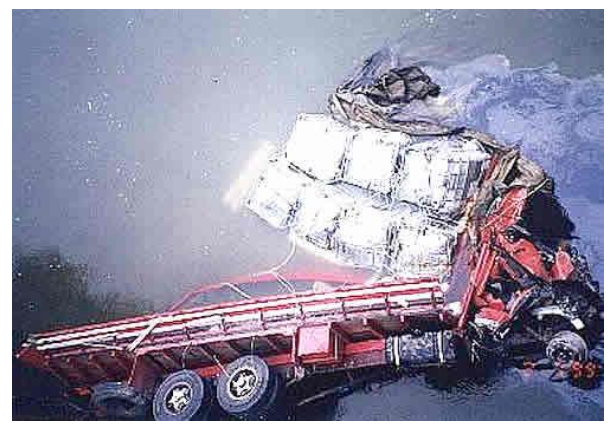

Caminhão com diversas substâncias em corpo d'água.

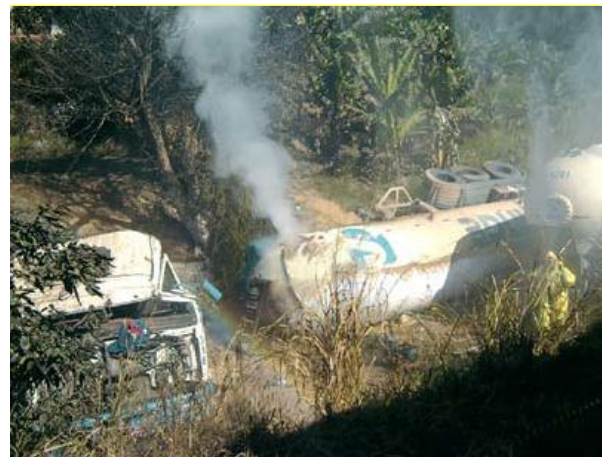

Acidente com transporte de amônia anidra

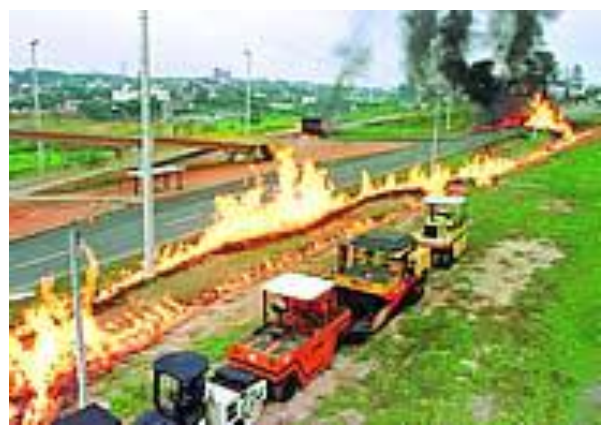

Acidente com derramamento de combustível seguido de incêndio.

Figura 2.2-5: Exemplos de acidentes com transporte de cargas perigosas por rodovias. (VASCONCELLOS e LAINHA, 2006) e (CETESB, 2009) 
Além de riscos de incêndios e explosões, a contaminação de mananciais de abastecimento público, contaminação do ar e radiação ionizante são alguns dos mais graves riscos de acidentes no transporte de cargas perigosas.

Mesmo em caso de acidentes com cargas gasosas, embora estas ocorram em menor número, podem ocorrer impactos mais graves em superfície. Gases podem se dispersar rapidamente na atmosfera dependendo dos ventos e de sua densidade, se for menos denso que o ar no local. Mas um gás pode também se concentrar em áreas, se houver relativa calmaria de ventos, o gás for mais denso que o ar no local, e o relevo for favorável a esta acumulação, como fundos de vales, por exemplo.

Deve ser considerado ainda, segundo Lopes (2009) que:

Muitos produtos químicos transportados não são classificados como
perigosos. Isto não significa que não possam comprometer o equilíbrio do
meio. Exemplo disso são produtos orgânicos como óleo vegetal,
concentrado cítrico, chorume, entre outros, que apresentam elevada DBO -
demanda bioquímica de oxigênio. Por serem orgânicos, se atingirem corpos
d'água com baixa capacidade de diluição da carga, estes produtos podem
ocasionar a depleção de oxigênio dissolvido.

Em função do exposto, sobre os impactos ambientais associados a acidentes com transporte de cargas perigosas, deve haver um sistema de procedimentos de atendimento emergencial.

Há diversas instituições que são responsáveis pelo atendimento emergencial a acidentes rodoviários no transpor de cargas perigosas. Corpo de Bombeiros, Polícia Rodoviária Estadual e Federal, Coordenadoria Estadual e Municipal de Defesa Civil, Departamento de Estradas de Rodagem, concessionárias de rodovias, órgãos ambientais públicos e as empresas responsáveis pelo transporte do produto (fabricante, transportador, expedidor e receptor).

No âmbito federal, destaca-se o papel do P2R2 - Plano Nacional de Prevenção, Preparação e Resposta Rápida a Emergências Ambientais com Produtos Químicos Perigosos, que está vinculado ao Departamento de Qualidade Ambiental da Secretaria de Mudanças Climáticas e Qualidade Ambiental do Ministério do Meio Ambiente. Criado pelo Decreto do Presidente da República no 5.098 de 2004, tem o objetivo de prevenir a ocorrência de acidentes com produtos químicos perigosos e aprimorar o sistema de preparação e resposta a emergências químicas no País.

O plano visa a promover a articulação e a integração dos vários níveis de governo, do setor privado, das representações da sociedade civil e das demais partes interessadas prevenção e resposta a emergências ambientais com produtos 
químicos.

As ações emergenciais devem ser coordenadas e integradas entre todas estas entidades de forma rápida e eficiente. Por isso, em situações ideais, estas entidades devem estar articuladas previamente em um PAE - Plano de Atendimento Emergencial, "o qual deve reunir as diretrizes e informações sobre os procedimentos técnicos e administrativos destinados a atender rapidamente situações de emergência" (LAINHA et al., 2003), e que conforme a Resolução SMA n.ำ 81, de 01 de dezembro de 1998, é documento obrigatório de ser elaborado pelos responsáveis pelas rodovias.

As estratégias de ação e combate empregadas durante o atendimento a acidentes com produtos químicos variam de acordo com o produto, características do acidente e do local atingido, mas os procedimentos envolvidos no atendimento de emergências com acidentes com transporte de cargas perigosas, em relação à componente ambiental, de acordo com os procedimentos da CETESB e preconizados por Lainha et al. (2003), podem ser resumidos em:

- Acionamento: ocorrido o acidente, as instituições responsáveis pelo atendimento devem ser acionadas. Para isso, devem possuir um sistema eficiente e bem divulgado de meios de comunicação de acidentes incluindo, por exemplo, telefones de emergência ao longo das rodovias, ou números de telefone gratuitos com atendentes $24 \mathrm{~h}$.

- Avaliação da ocorrência: Na avaliação da ocorrência são identificados os impactos ocorridos e outros potenciais de risco. Esta fase é de grande importância por determinar quais deverão ser as ações iniciais para evitar ou mitigar impactos causados pelo acidente.

Deve ser realizada uma avaliação prévia da ocorrência, antes mesmo do deslocamento das primeiras unidades de atendimento. Estas informações poderão propiciar às equipes de atendimento, informações preciosas, mesmo que secundárias, para dimensionar o episódio e elaborar previamente algumas diretrizes para o atendimento emergencial. Informações obtidas pela pessoa que acionou a equipe e de um banco de dados sobre a rodovia do Plano de Atendimento Emergencial - PAE poderão ser utilizadas nesta primeira etapa.

Destaca-se que atualmente para o licenciamento de rodovias, os empreendedores devem apresentar mapas de sensibilidade ambiental das áreas situadas no entorno 
destas, sendo definidas zonas de sacrifício e prioritárias para proteção. Estes mapeamentos também podem auxiliar bastante na avaliação prévia do local do acidente, principalmente se estiverem disponíveis em um Sistema de Informações Geográficas, juntamente com outros dados como, imagens aéreas (podem até terem sido obtidas previamente por um VANT) ou orbitais.

A avaliação da ocorrência in loco deve envolver a avaliação dos impactos diretos e indiretos já desencadeados pelo acidente. A observação de pessoas e áreas atingidas (solos, corpos hídricos, etc) e de morte de animais e plantas, por exemplo é importante para adoção de medidas mitigadoras em resposta aos impactos ambientais ocorridos.

Simultaneamente, deve haver a identificação do produto perigoso transportado, sua classe de risco e características físico-químicas e as condições em que se encontram armazenados.

Também deve ser realizado um diagnóstico ambiental do local do acidente. Condições do tempo, tipo de solo, relevo, proximidade a corpos hídricos e uso destes, a presença de unidades de conservação ambiental, locais de armazenamento de substâncias inflamáveis, além de identificação de áreas sensíveis, como áreas habitadas (em especial com escolas, hospitais, asilos), por exemplo, devem ser levantados juntamente com as informações obtidas do tipo e classe de risco do produto transportado. Estas deverão subsidiar a identificação de potenciais impactos diretos e indiretos a serem ocasionados ao meio ambiente e aos seres humanos, incluindo os profissionais envolvidos no atendimento.

Desta forma, estes procedimentos deverão subsidiar a tomada de decisões, estratégia e o planejamento das medidas de controle a serem executadas, o que implicará numa série de fatores a serem considerados, como os requisitos humanos, técnicos e materiais que serão necessários para os trabalhos e os riscos inerentes a estes.

É importante enfatizar que esta etapa deve ser realizada com a maior rapidez possível, dado o caráter emergencial e o tempo ser um fator importantíssimo para evitar e diminuir riscos.

- Ações de gestão: realizada a avaliação da ocorrência, as ações de gestão são planejadas e executadas, com a finalidade de diminuir os riscos e impactos provocados pelo acidente da forma mais adequada e eficiente. 
As ações de gestão podem ser divididas, de acordo com informações da CETESB e Sánchez (2008) em:

Acões de mitigação dos impactos ambientais: São as medidas que visam eliminar ou minimizar os impactos ambientais já ocorridos ou em ação.

No caso de acidentes químicos, envolvem a remoção do produto, como por técnicas de absorção ou sucção do produto e/ou descontaminação do local e procedimentos para atenuar os impactos com técnicas de neutralização do produto derramado ou diluição com água deste, por exemplo.

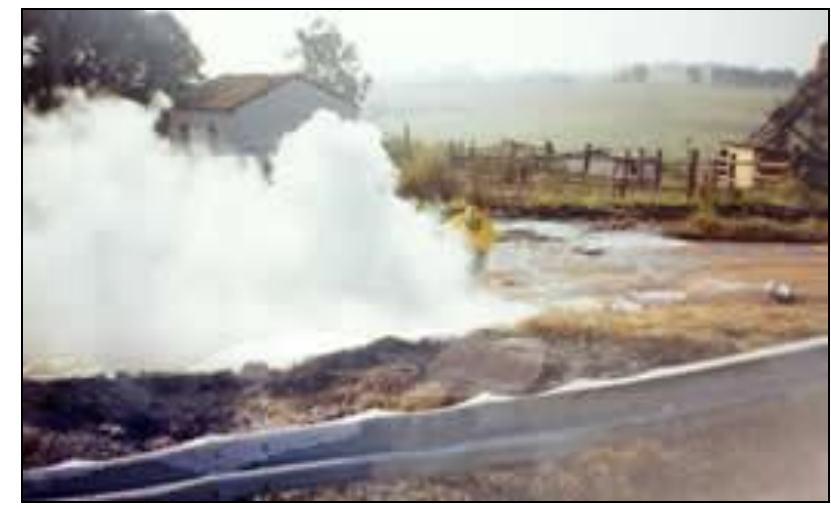

Figura 2.2-6: Neutralização de área atingida por acidente (CETESB, 2009)

Acões de controle dos impactos ambientais: São ações empregadas para controlar os aspectos ambientais visando à prevenção ou redução dos potenciais impactos ambientais futuros em decorrência do acidente.

Podem ser estabelecidas zonas de restrição de trabalho no entorno do acidente e operações de evacuação e abandono para resguardar os seres humanos da equipe de atendimento e circunvizinhos ao acidente.

Para evitar e conter vazamentos decorrentes de avarias nos veículos envolvidos nos acidentes, medidas de controle podem ser adotadas como, destombamento de veículos, transbordo de cargas, estancamento do vazamento e contenção do produto vazado com diques, barreiras e neblinas d'água, por exemplo. Novamente, deve ser reforçada a importância da avaliação da ocorrência e todos seus aspectos para a definição da técnica mais adequada na ação de gestão. Os resíduos gerados devem ser coletados, tratados e encaminhados para disposição final adequada.

Medidas para prevenção e combate a incêndios também são importantíssimas, face ao risco que tais incidentes podem provocar e à quantidade de produtos inflamáveis que é transportada pelo modal rodoviário, conforme anteriormente exposto. 


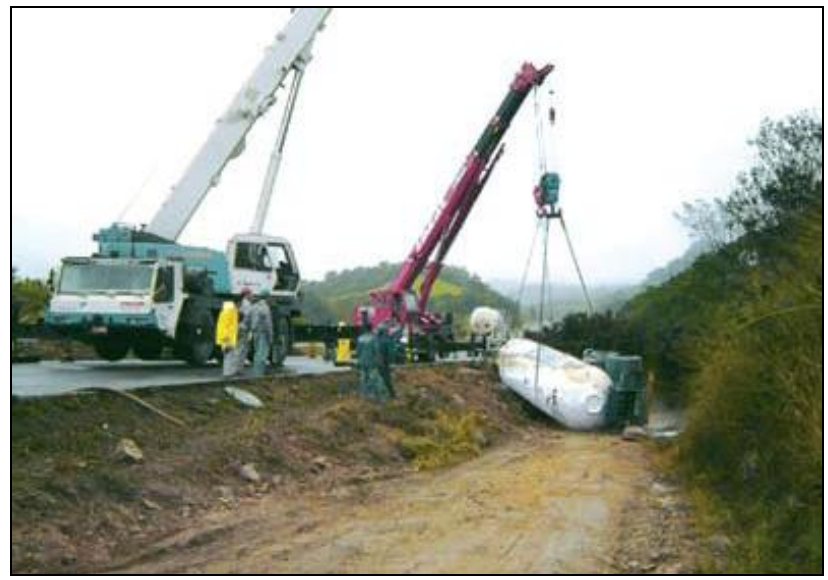

Figura 2.2-7: Destombamento de veículo em acidente com amônia anidra. (VASCONCELLOS e LAINHA, 2006)

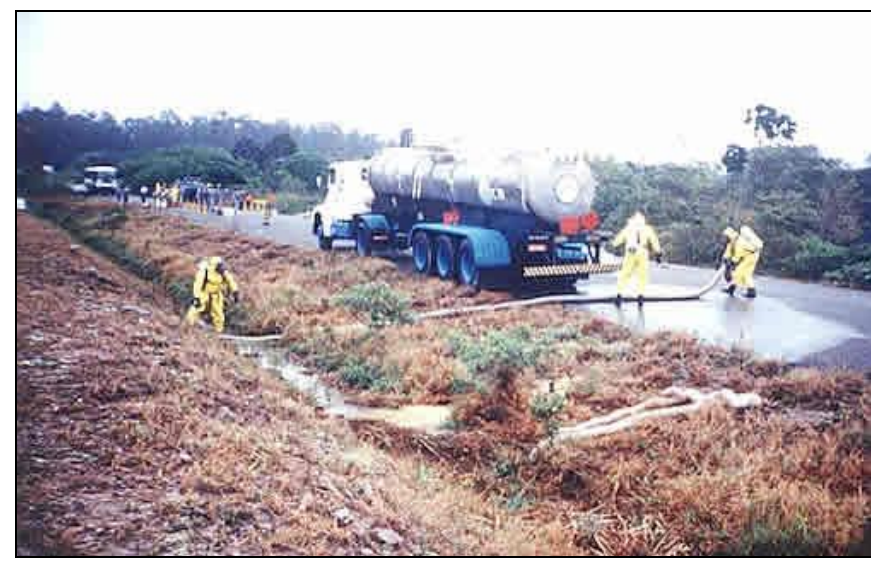

Figura 2.2-8: Contenção de substância derramada com barreiras e recolhimento. (CETESB, 2009)

Ações de remediação ou recuperação ambiental: tratam-se de ações para a recuperação ambiental ou restabelecimento de condições ambientais próximas às anteriores ao acidente.

Podem incluir medidas como a revegetação de áreas e recomposição das características físico-químicas de um solo contaminado.

Ações de monitoramento: São ações que visam avaliar a ocorrência de impactos anteriormente identificados como potenciais, os resultados e a eficácia das medidas de mitigação e recuperação de impactos que ocorreram e a forma de reação natural do meio afetado.

Devem ser monitoradas as concentrações de substâncias químicas no solo e água em locais atingidos e o efeito de possíveis contaminações no meio ambiente como na vegetação por exemplo. 
Ressalta-se que novas medidas de mitigação e de recuperação podem ser definidas de acordo com os resultados do monitoramento realizado.

Acões de compensação ambiental: aplicáveis aos impactos ambientais efetivamente ocorridos. No caso de acidentes, cabe às entidades responsáveis, a aplicação de multas.

Outros procedimentos também são adotados com outros objetivos, que não o de avaliação de impactos e adoção de ações de gestão ambientais, como o conhecimento das causas que geraram os acidentes e verificação de irregularidades no cumprimento da legislação vigente. Estas não foram tratadas, considerando-se o escopo do presente trabalho.

Cada uma das entidades citadas como responsáveis pelo atendimento a emergências com acidentes com transporte de cargas perigosas possui competências específicas.

Para as atividades de identificação e avaliação da ocorrência em relação aos danos ambientais e planejamento e execução das medidas de controle, mitigação e monitoramento das áreas atingidas, destaca-se o papel do Corpo de Bombeiros, órgãos ambientais públicos e empresas privadas de atendimento a desastres ambientais, embora todos eles tenham relação direta ou indireta a estas atividades, no sentido de prover esforços e suporte pessoal e material quando possível.

A etapa de avaliação da ocorrência foi destacada em relação às outras quanto às atividades necessárias por ser onde se encontram os maiores potenciais do uso do sensoriamento remoto por VANTs, a fim de avaliar com melhor precisão os impactos ocorridos e os potenciais, assim como o nível de risco associados a eles.

\subsection{SENSORIAMENTO REMOTO PARA AVALIAÇÃO DE IMPACTOS AMBIENTAIS EM EMERGÊNCIAS}

O sensoriamento remoto é reconhecidamente uma ferramenta muito útil em estudos ambientais, inclusive de avaliação de impactos.

A avaliação de impactos por imagens de sensores remotos pode ser vantajosa 
quando comparada por métodos de avaliação em solo, pois permite obter informações de áreas impactadas sem a necessidade da presença humana nos locais de acidente, uma vez que na maioria das vezes pode haver riscos à saúde humana de acordo com a situação.

A figura a seguir mostra duas imagens de uma mesma área antes e após se atingida por tsunami, exemplificando o uso de sensoriamento remoto para avaliação de impactos pós desastre.
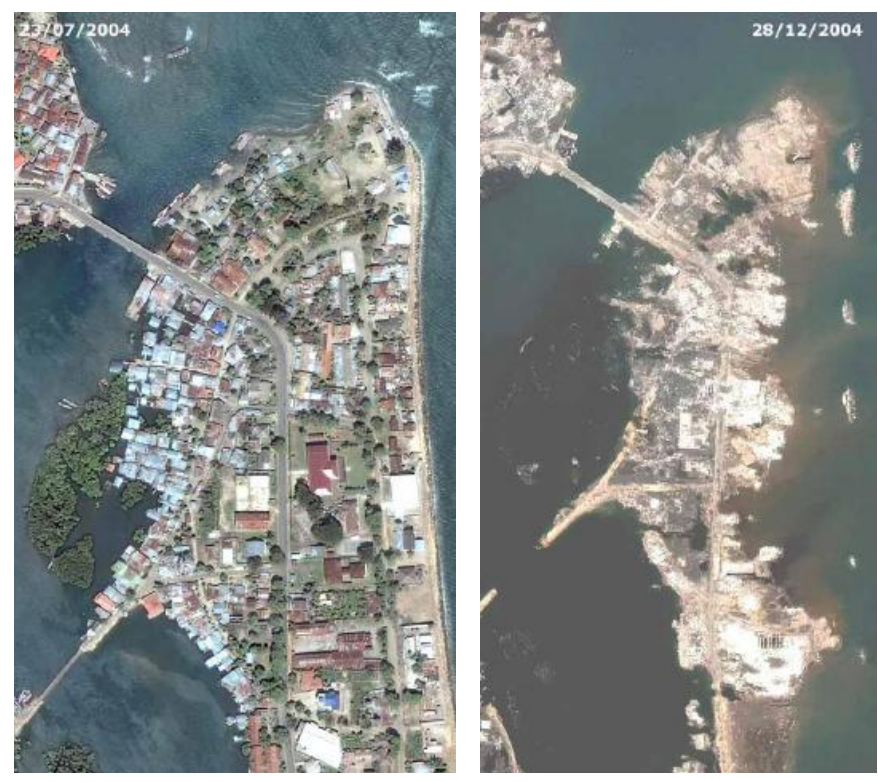

Figura 2.3-1: Uso do sensoriamento remoto para avaliação de impactos ambientais causados por desastres, no caso um tsunami. (LUCHIARI e MORATO, 2009)

Para acidentes químicos, é possível detectar, localizar e determinar a extensão de contaminações em solos, drenagens, na vegetação, assim como o grau de alteração provocado por impactos. Imagens de sensoriamento remoto podem ser utilizadas também no diagnóstico ambiental do entorno do acidente para a previsão de potenciais impactos.

$\mathrm{Na}$ etapa de execução das ações de gestão, o sensoriamento remoto pode ser utilizado no monitoramento ambiental das áreas atingidas.

A possibilidade da obtenção de imagens de sensoriamento remoto em meio digital, como ocorre com a maioria dos sensores embarcados em VANTs, e muitas vezes com geração de imagens já georreferenciadas, mesmo que imprecisamente, permite que estas sejam integradas de forma mais rápida a Sistemas de Informações Geográficas - SIG ou GIS. Os SIGs, segundo Silva (2003), são sistemas que usam intensivamente da informática e permitem o armazenamento de informações 
georreferenciadas e funções de análises que variam de álgebra cumulativa até não cumulativa destes dados.

Os SIGs são, hoje, recursos poderosos de ampla utilização em pesquisas e trabalhos que facilitam a visualização de informações espaciais, bem como o cruzamento e análise destas. Portanto, tratam-se de ferramentas que auxiliam na identificação e previsão de impactos ambientais, uma vez que uma enorme quantidade de variáveis ambientais influencia na dinâmica da ocorrência de impactos diretos e indiretos de um acidente.

O sensoriamento para identificação e monitoramento de impactos causados por desastres de grande magnitude e de abrangência regional tem sido utilizado amplamente. Áreas atingidas por terremotos, tsunamis, tempestades, tornados, grandes inundações e erupções vulcânicas, por exemplo, tem sido imageadas por diferentes formas de sensoriamento remoto, tanto aéreo, como orbital (JENSEN, 2009).

Os acidentes em rodovias, em geral apresentam impactos de pequena extensão em áreas (<10ha). Como não é possível prever onde e quando ocorrerão acidentes e a avaliação de impactos destes tem caráter emergencial, as imagens de sensoriamento remoto para este fim devem ser dotadas de altíssima resolução espacial e necessitam ser obtidas em momentos determinados, sem possibilidade de planejamento prévio.

As principais capacidades desejadas do sensoriamento remoto de áreas atingidas por qualquer desastre é o provimento de imagens que combinem alta resolução temporal (tempo de revisita de poucas horas) com alta resolução espacial (preferencialmente sub-métrica), para avaliação dos impactos ocorridos e planejamento das ações de resposta. (MEULEMAN et al., 2007)

Segundo Jensen (2009) sistemas sensores para situações emergenciais em caso de acidentes e desastres ambientais devem ser capazes da obtenção de imagens em até $12 \mathrm{~h}$ pós evento.

Imagens que preencham os requisitos de alta resolução são provenientes de aerofotogrametria convencional ou de sensores orbitais de alta resolução, como os dos satélites Quick Bird, Geoeye-I e Wordview-Il. Porém, os sensores orbitais dependem da órbita dos satélites para gerarem imagem de certo local e em momento específico. São dependentes também das condições atmosféricas para gerarem boas imagens.

Os sensores embarcados em aviões convencionais utilizados em aerofogrametria 
dependem de condições logísticas, como existência de aeroportos próximos para decolar, e também de autorizações do DAC - Departamento de Aviação Civil.

Além disto, ambas as opções de aquisição de imagens são onerosas e de elevado custo financeiro.

Por estes motivos não tem sido utilizados para aplicações em desastres ambientais localizados. Neste tipo de aplicação, é feita avaliação terrestre em campo, conforme exposto.

Uma opção que possui flexibilidade para obtenção de imagens em momentos específicos é através de helicóptero tripulado. É onerosa e normalmente sem parâmetros técnicos adequados para sensoriamento remoto, mas pode se justificar seu uso dependendo da necessidade.

Em função disto, entende-se que há a opção de aquisição das imagens da superfície terrestre com as características pretendidas através de Veículos Aéreos Não Tripulados (VANTs), pois sistemas sensores embarcados nestes podem apresentar grande flexibilidade temporal para aquisição imagens e a baixos custos em relação aos métodos supracitados.

Trata-se de uma tecnologia para uso civil ainda incipiente e em fase de consolidação, mas com diversas aplicações potenciais. Algumas plenamente operacionais e outras em fase experimental.

Dentre as aplicações em situações emergenciais, um dos principais usos é em detecção, monitoramento e registro incêndios, tanto em áreas vegetadas, como em áreas urbanas. Exemplos de VANTs empregados para os fins citados são o AIRDAS - Airbone Infrared Disaster Assessment System e o ALTUS II (WEGENER, 2003) e o ALTAIR (AMBROSIA et al., 2005).

Freire (2009) descreve o desenvolvimento de um sistema que inclui o EINFOREXUAV, para auxílio de bombeiros ao combate a incêndios em áreas florestadas. Outra experiência de emprego de VANT para serviços dos Bombeiros de West Midland, no Reino Unido, também é demonstrada por Mika (2009).

Bowman et al.(2006) demonstra o desenvolvimento pelo U.S. Department of Homeland Security de um sistema de comunicação móvel disposto em um veículo utilitário esportivo do tipo SUV. O sistema desenvolvido é denominado de Manportable and Interoperable Tactical Operations Center - MITOC para gestão de emergências e aponta como pesquisa futura para incorporação ao projeto, de um 
experimento de integração ao MITOC de um UAV de baixo custo para vigilância por vídeo e provimento de comunicação via wireless a locais específicos. Maleman et al.(2007) destaca o desenvolvimento recente de VANTs para obtenção de dados de sensoriamento remoto para gestão pós-desastres de forma rápida.

Em muitos aspectos, a tecnologia VANT oferece a perfeita visão do estadoda-arte no que diz respeito ao sensoriamento remoto em tempo real. Uma recente iniciativa neste sentido é o Projeto Pegasus Hale-UAV que visa obter dados quase em tempo real com observações em alta resolução espacial.

No Simpósio de Aplicações Civis de SANTs, realizado em outubro de 2007, Argrow et al.(2008) pesquisou com o público quais seriam as aplicações civis que mais se desenvolveriam e seriam mais importantes na próxima década. Os dados levantados mostram que a maioria indicou a aplicação para resposta a desastres ambientais.

A bibliografia e a opinião das pessoas inseridas na área demonstram o grande potencial de aplicação nesta área, mas o único uso operacional dentre as diversas possibilidades levantadas para impactos localizados, é no auxílio à detecção e monitoramento de queimadas e incêndios.

Para resposta a desastres, os VANTs já demonstraram a sua eficácia no
acompanhamento incêndio (...). Estes vôos auxiliaram na extinção de
incêndios, poupando custos de vida (...). VANTs também podem ser
utilizados para o levantamento de áreas atingidas para prestar informações
imediatas para salvar vidas e bens. (ARGROW et al., 2008) Em desastres, naturais ou de origem antrópica, de grande magnitude os VANTs podem e têm sido utilizados como plataformas de obtenção de dados através de sensoriamento remoto.

Um exemplo é o UAVSAR, Veículo Não Tripulado com Radar de Abertura Sintética do Laboratório de Propulsão a Jato da Nasa, que foi utilizado para obter imagens após o terremoto de 12 de janeiro de 2010 que ocorreu no Haiti para medir os deslocamentos da superfície terrestre (FREITAS e COTTET, 2010).

Este mesmo VANT está em uso, de acordo com a NASA para identificação, avaliação e monitoramento de impactos ambientais gerados em áreas litorâneas dos Estados Unidos pela a explosão plataforma de exploração de petróleo da empresa britânica BP e vazamento de enorme quantidade de petróleo no Golfo do México. O acidente ocorrido em 20 de abril de 2010 é considerado um dos maiores acidentes ambientais da história. Na figura 2.3-3 são apresentadas áreas atingidas pelo petróleo em imagem obtida pelo UAVSAR. 


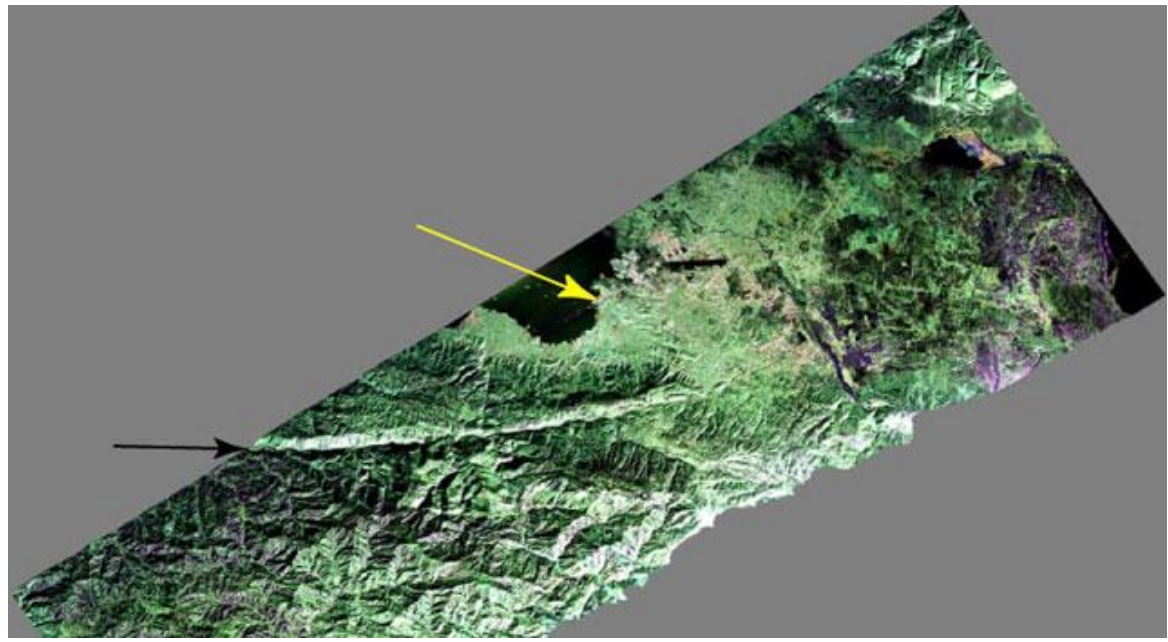

Figura 2.3-2: Imagem gerada pelo UAVSAR após terremoto no Haiti - falha geológica que gerou o abalo (seta preta) e a cidade de Porto Príncipe (seta amarela). (NASA, 2010)

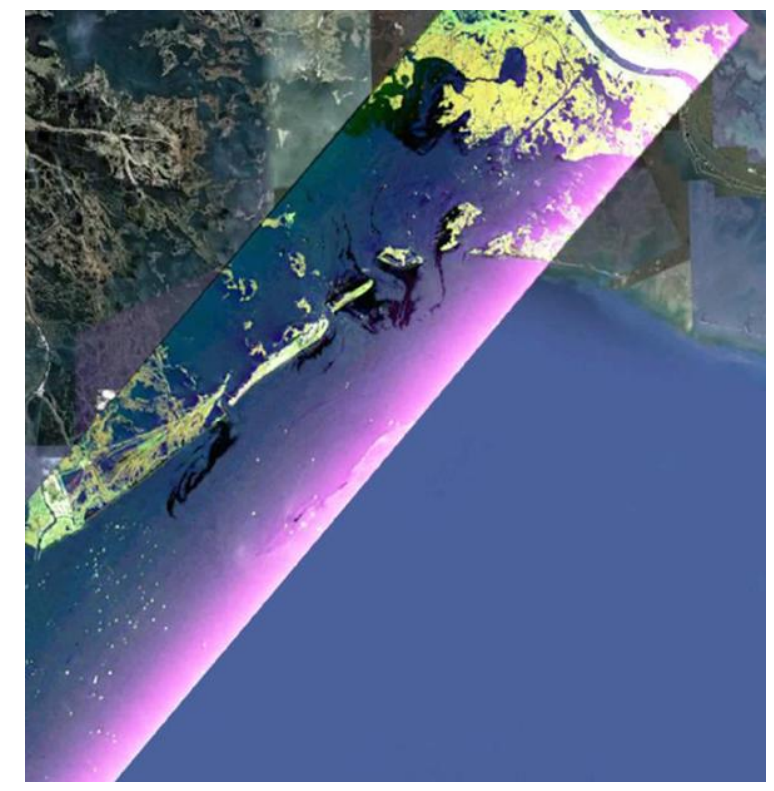

Figura 2.3-3: Litoral da Louisiana com faixa imageada pelo UAVSAR em junho de 2010 - manchas de óleo em preto. (NASA, 2010)

Observa-se que o uso de VANTs em atendimentos emergenciais em desastres ambientais é uma das aplicações civis mais indicadas pela bibliografia e há órgãos de atendimento a situações emergenciais que tem utilizado esta técnica com sucesso nos últimos anos, de acordo com os dados levantados, principalmente em grandes desastres ambientais ou incêndios.

Destaca-se, porém, que embora citada como uma possibilidade de aplicação, não foi verificada na bibliografia um estudo ou caso do uso de sensoriamento remoto por VANTs para avaliação de impactos ambientais em acidentes com transporte rodoviário de cargas perigosas, em específico. 
Um exemplo de imagem aérea obtida por aeronave tripulada em um caso de acidente com transporte rodoviário de combustível pode ser observado em Jensen e Cowen (1999) apud Jensen (2009).

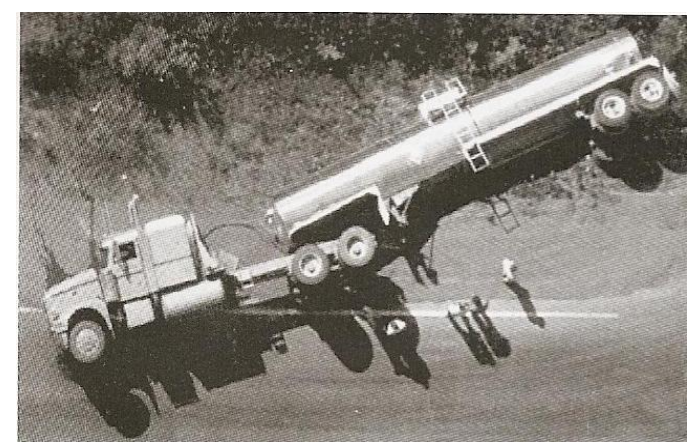

Figura 2.3-4: Caminhão de Combustível Tombado em imagem aérea. (JENSEN e COWEN, 1999 apud JENSEN, 2009). 


\section{METODOLOGIA}

Para atingir o objetivo principal da pesquisa que é o de verificação da aplicabilidade de sensoriamento remoto por VANTs para avaliação e monitoramento de impactos ambientais causados por acidentes envolvendo transportes de cargas perigosas em rodovias, se fez necessária a identificação dos benefícios que a tecnologia pode trazer referentes aos procedimentos técnicos usuais. Estas hipóteses de melhorias, embora citadas algumas preliminarmente na justificativa da presente pesquisa, foram refinadas, com base nas informações levantadas na revisão bibliográfica e do entendimento das principais questões e dificuldades envolvidas no processo de avaliação dos impactos ambientais.

Foram identificados os procedimentos que podem ser beneficiados em velocidade, segurança e incremento de qualidade e eficiência através do uso de imagens da superfície terrestre obtidas por sensores remotos transportados por VANT.

A partir desta identificação, foram definidos os melhores parâmetros e capacidades mais adequadas de VANTs, buscando-se o provimento das informações com a qualidade e dentro do tempo necessário para a avaliação de impactos ambientais de forma emergencial.

Uma vez definidos os aspectos técnicos de um VANT modelo para aplicação, foi possível realizar um estudo de viabilidade da aplicação deste para sensoriamento remoto de acidentes com cargas perigosas.

A viabilidade está ligada à capacidade técnica, ao custo financeiro da aquisição e ou operação do VANT e a questões legais que podem restringir a atividade deste equipamento.

Para verificação da viabilidade do uso de um VANT específico para a aplicação, é preciso que as capacidades do VANT supram as necessidades impostas face ao maior número de cenários ambientais e técnicos possíveis.

O método para se chegar às respostas de viabilidade foi a pesquisa de um grande número de cenários hipotéticos passíveis de ocorrência de acidentes com transporte de cargas perigosas, com posterior dedução hipotética da operação do VANT nestas 
condições, avaliando-se se ele seria capaz de gerar as informações requeridas no tempo necessário e a custos acessíveis.

Para que este mecanismo funcione da forma mais próxima da realidade, dados de detalhes operacionais sobre as atividades de sensoriamento remoto por VANTs e de avaliação de impactos ambientais em acidentes com transporte por cargas perigosas foram obtidos.

A maior parte destes dados, que são muito específicos, não está disponibilizada na bibliografia especializada, ou ainda em documentos públicos.

Para a obtenção destes dados e informações foram aplicados questionários com empresas de VANTs nacionais, conforme modelo anexo ao final do volume. Apenas representantes das empresas AGX tecnologia, Xmobots e Flight Solutions responderam os questionários e os dados relevantes obtidos sobre os VANTs destas foram incorporados no item 2.1.3.

Também foram feitas solicitações de informações por e-mail e entrevistas com profissionais experientes nas áreas ligadas ao escopo da pesquisa. Estes procedimentos foram realizados com gerentes técnicos da AGX Tecnologia e da Xmobots, duas empresas nacionais que desenvolveram VANTs e atualmente operam comercialmente no setor civil, oferecendo o serviço de sensoriamento remoto por VANTs

Outras solicitações de informações e entrevistas foram realizadas, para obtenção de informações específicas sobre o atendimento emergencial em acidentes com transporte de cargas perigosas e a avaliação e monitoramento de impactos ambientais, com técnicos do setor de atendimento a emergências químicas da CETESB, de empresas habituadas às atividades de avaliação de impactos ambientais e à remediação, recuperação e monitoramento ambiental de áreas contaminadas, a AMPLA - projetos e serviços em meio ambiente e a BTX - geologia e meio ambiente.

A partir destes dados coletados, foram realizadas considerações utilizando-se de raciocínio lógico dedutivo para compreensão do comportamento de um VANT modelo com características determinadas previamente, frente às diversas situações hipotéticas, sendo levantadas as possibilidades de atendimento ou não dos requisitos técnicos, econômicos e legais impostos à aplicação.

O fluxograma a seguir apresenta resumidamente e de forma esquemática os 
procedimentos realizados na presente pesquisa.

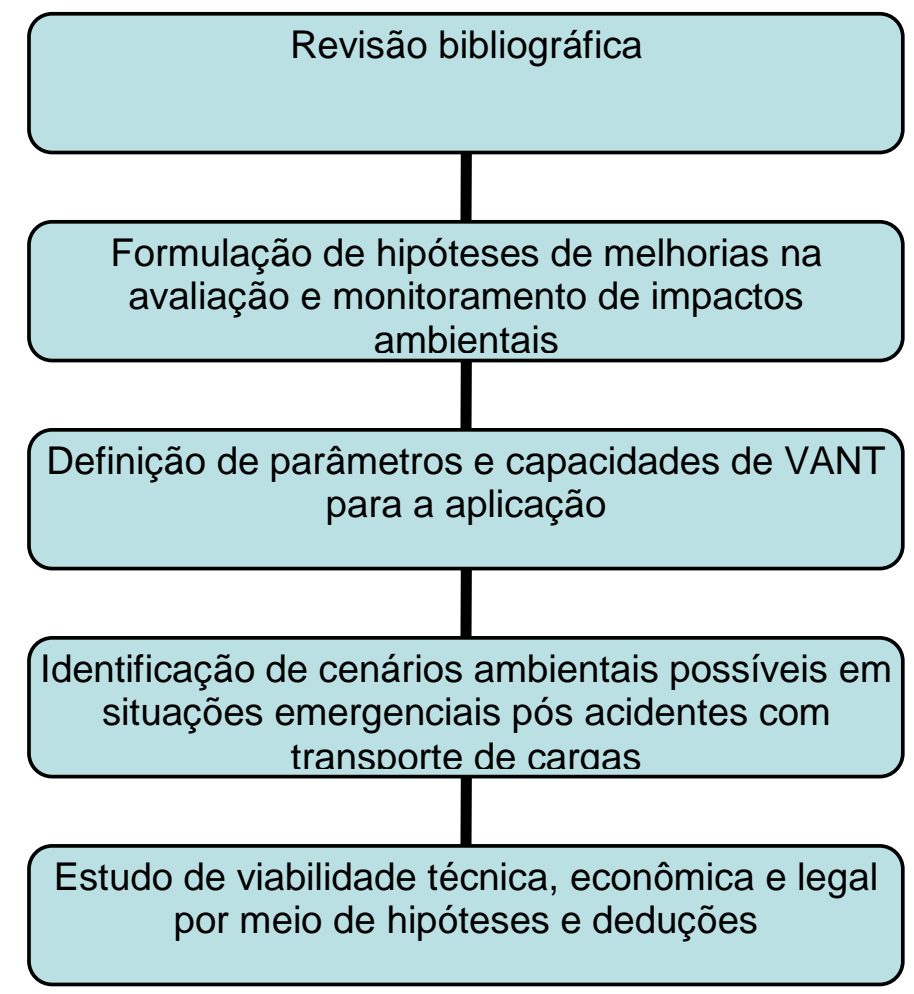

Figura 3-1: Procedimentos Metodológicos da Pesquisa

\subsection{HIPÓTESES DE MELHORIAS NA AVALIAÇÃO E MONITORAMENTO DE IMPACTOS AMBIENTAIS ATRAVÉS DO USO DE VANTS}

Considerando-se o apresentado na justificativa e na revisão bibliográfica da presente pesquisa, entende-se que o sensoriamento remoto por VANTs tem potencial de ser aplicado nas etapas de avaliação da ocorrência e na adoção de ações de gestão, em específico na avaliação de impactos ambientais e no monitoramento ambiental, respectivamente. Isto se deve ao fato de ser nestas etapas em que informações ambientais sobre as áreas atingidas e no entorno devem ser coletadas diretamente em campo.

$\mathrm{Na}$ avaliação de um acidente com transporte de carga perigosa, ocorre a avaliação de impactos ambientais.

As áreas e objetos atingidos (solos, vegetação, corpos hídricos, etc) são 
identificados e os impactos ambientais diretos e indiretos são avaliados. Como anteriormente citado no item 2.2, deve também ser realizado o diagnóstico ambiental do local do acidente e seu entorno para auxiliar a previsão de novos impactos ou, ainda, do comportamento dos impactos identificados.

Neste sentido, imagens obtidas por VANTs podem auxiliar estas atividades, uma vez que uma imagem aérea possibilita visualizar áreas de uma posição estratégica, permitindo ao analista ambiental identificar e quantificar áreas atingidas e visualizar relações topológicas e de proximidade com elementos e objetos do entorno (MARCHETTI e GARCIA, 1977). Imagens aéreas podem facilitar a identificação de substâncias e áreas atingidas que sejam de difícil visualização a olho nu, principalmente se forem imagens que aliem alta resolução espacial e espectral.

As imagens aéreas também permitem o diagnóstico ambiental e a identificação de áreas atingidas sem a necessidade de presença humana direta nestas. Há casos em que as substâncias derramadas são tóxicas ou corrosivas, por exemplo, o que pode desencadear riscos à equipe de atendimento do acidente.

Dependendo das condições de acesso às localidades afetadas, a imagem área pode também tornar mais rápida esta avaliação. Se o terreno for de várzea (brejo) ou muito declivoso, o acesso às áreas potencialmente atingidas é dificultado, tornando a avaliação de impactos ambientais mais lenta. Situações de acidentes em terrenos de fundos de vales, com derramamento de substâncias em corpos d'água, também são mais difíceis e demoradas de serem avaliadas. Se imagens aéreas forem rapidamente obtidas, pode ser viável observar estas áreas e avaliar os impactos ambientais com maior agilidade.

Numa etapa posterior, há o monitoramento ambiental de áreas atingidas, quando ocorre o acompanhamento do desenvolvimento de impactos ambientais, bem como a verificação da eficiência das ações de mitigação e recuperação destas áreas. Este monitoramento, se realizado com o auxílio de imagens aéreas, pode ser beneficiado com os aspectos supracitados, facilitando também a comparação evolutiva da área ao longo do tempo, que é o escopo do monitoramento ambiental.

Imagens aéreas podem ser úteis na documentação da ocorrência, auxiliando as empresas ambientais a produzir relatórios de acompanhamento da recuperação ambiental e os órgãos fiscalizadores a verificar se a ações de gestão realizadas estão resultando em melhorias ambientais buscadas. Neste sentido, imagens aéreas 
podem facilitar a confecção de mapas e geração de informações georrefenciadas. Isto deve ocorrer principalmente se o sistema VANT for capaz de gerar imagens automaticamente georreferenciadas.

Realizadas tais considerações, de forma objetiva, as imagens aéreas obtidas por VANT apresentam os seguintes potenciais de beneficiar a avaliação e monitoramento de impactos ambientais.

- Melhorar a qualidade e quantidade de informações ambientais de áreas atingidas e seu entorno (identificação e quantificação de áreas impactadas pelo acidente e do uso do solo no entorno);

- Prover maior segurança às equipes de atendimento ao acidente e avaliação de impactos ambientais;

- Tornar mais rápido o processo de avaliação da ocorrência;

- Facilitar a avaliação da eficiência das ações de gestão, o acompanhamento e a evolução de áreas atingidas ao longo do tempo e o monitoramento ambiental, de modo geral;

- Incrementar, por meio de imagens aéreas, a documentação de atendimento à ocorrência e do monitoramento ambiental.

- Proporcionar vantagens econômicas nas atividades envolvidas na avaliação e monitoramento de impactos ambientais.

Cabe destacar que tais melhorias no processo são aqui apresentadas como hipóteses.

Embora o uso pós desastres ambientais seja uma das áreas de potencial aplicação mais indicadas para sensoriamento remoto por VANTs, de acordo com Argrow et al.(2008), não se verificou atualmente na prática, esta função para desastres em áreas reduzidas (em geral, inferiores a 10ha), como o propõe-se neste estudo.

Levanta-se, ora, questionamentos de ordem técnica, sobre a capacidade de estes sistemas sensores adquirirem imagens das áreas atingidas em tempo hábil, com a qualidade desejada e com custos não proibitivos.

Deste modo, o estudo de viabilidade tratado no item 4.2 visa auxiliar a verificação das possibilidades listadas, com comprovação ou negação destas. Tem também como objetivo, além da avaliação da viabilidade técnica da aplicação de VANTs para sensoriamento remoto na avaliação e monitoramento de impactos ambientais 
causados por acidentes com cargas perigosas, a avaliação econômica.

Para ser realizada a simulação com maior probabilidade de sucesso e viabilidade técnico-econômica na busca pelas melhorias elencadas na avaliação e monitoramento de impactos ambientais causados por acidentes com transporte rodoviário de cargas perigosas, foram definidos parâmetros e capacidades chave dos VANTs que devem ser empregados. Tais aspectos são apresentados no próximo capítulo. 


\section{RESULTADOS E DISCUSSÃO}

\subsection{PARÂMETROS TÉCNICOS DE VANTS PARA A APLICAÇÃO}

Os VANTs, conforme pode ser observado na no capítulo 2, apresentam enorme variedade de características técnicas e funcionalidades. Neste sentido, estas necessitam ser definidas e especificadas em função das melhorias buscadas e da melhor relação custo-benefício na avaliação e monitoramento de impactos ambientais causados por acidentes com transporte de cargas perigosas.

A identificação dos parâmetros técnicos e capacidades dos VANTs e dos sistemas sensores embarcados deve buscar atender as especificidades e possibilidades existentes no cenário de avaliação de impactos ambientais em atendimentos emergenciais a acidentes.

Impactos gerados por estes acidentes normalmente são de curto prazo, em relação ao critério de avaliação de prazo de ocorrência, e são locais, em relação à abrangência. Para melhor entendimento e padronização, estas características são tratadas em mais detalhes a seguir.

A maioria dos impactos ambientais gerados por um acidente ocorre de forma imediata, em eventos, com o vazamento da carga. A substância que vaza, em contato com o ar, solos, corpos d'água, vegetais, animais e seres humanos, pode provocar uma série de danos imediatamente, em instantes, minutos, ou ainda em questão de poucas horas após o acidente. Por isso, estes impactos ambientais são classificados como de curto prazo de ocorrência (SÁNCHEZ, 2008) ou ainda são chamados de impactos agudos. Impactos de médio prazo para ocorrência também podem existir, mas são mais raros. Alguns exemplos são a contaminação de aqüíferos, onde é necessária a percolação de substâncias no solo, e a contaminação indireta e morte de espécimes da fauna por meio da cadeia alimentar, em que indivíduos se alimentaram de vegetação ou animal contaminado. Ambos impactos podem demorar alguns dias ou até meses para ocorrer. Tais impactos 
podem continuar se manifestando ao longo do tempo, caso não seja realizada a recuperação destas áreas.

Com isto em vista, é extremamente importante que o sistema sensor seja capaz de obter imagens pouco tempo depois de ocorrido um acidente, e logo após a chegada da equipe de avaliação ambiental da ocorrência, para que as ações de gestão para controlar e mitigar o impacto e para recuperar as áreas atingidas sejam realizadas com maior agilidade e eficiência possível.

Sobre a abrangência destes impactos, é necessário que se estime o tamanho das áreas que normalmente são afetadas por acidentes com transporte rodoviário de cargas perigosas para parametrização do recobrimento que uma imagem área deve apresentar.

De acordo com Queiroz Filho (2005), o entendimento da escala do fenômeno, que diz respeito ao tamanho da manifestação do fenômeno geográfico sobre a superfície terrestre,

é essencial para que o pesquisador compreenda a relação de seu trabalho com a complexidade, as inter-relações e a abrangência do fenômeno; para que possa entender e delimitar a contribuição do seu trabalho face à magnitude do objeto de estudo.

Com base em informações da CETESB, órgão que apresenta equipes que procedem a avaliação de impactos em acidentes com transporte de cargas perigosas, as áreas atingidas variam normalmente entre dezenas de metros quadrados a 10ha (informação verbal) ${ }^{1}$. Em geral, as áreas atingidas diretamente apresentam algumas centenas de metros quadrados. Os volumes de substâncias que podem ser derramadas variam, mas pode-se considerar que um caminhão tanque carrega atualmente volumes de até $50 \mathrm{~m}^{3}$, de acordo com informações do SINDICOM (2004).

Por isso pode se afirmar que os impactos ambientais decorrentes de acidentes com cargas perigosas apresentam geralmente manifestação em áreas pequenas, se comparado a outros modais de transporte. Entretanto, cabe distinguir que a forma de manifestação destes impactos pode variar entre pontual, linear e areal no espaço geográfico. Quando o produto derramado chega a drenagens superficiais, a área de contaminação pode se estender de forma linear por mais de quilômetros, com o transporte do produto pelo fluxo do rio. Há exemplos de que as margens de rios

\footnotetext{
1 Dados fornecidos pelo técnico Marco Antonio Lainha do Setor de Operação de Emergências da CETESB em junho de 2010.
} 
contaminadas se estendem $5 \mathrm{~km}$ a jusante do acidente (informação verbal) 1 . Quando isto ocorre, determinar a extensão do impacto requer a necessidade de deslocamentos maiores por parte da equipe de atendimento da ocorrência, complicando a avaliação, dependendo das características e situações ambientais das áreas.

Deve ser ressaltado que as extensões e áreas atingidas por acidentes com transporte rodoviário de cargas perigosas podem ser maiores que as tomadas como referências, embora em raros casos. A situação ideal seria o dimensionamento dos parâmetros de acordo com as possibilidades de extensão máximas específicas calculadas de acordo com às características ambientais (piores cenários ambientais) do entorno da(s) rodovia(s) onde efetivamente o VANT seria empregado. Estas informações podem ser obtidas no PGR - Programa de Gerenciamento de Riscos e no PAE - Plano de Ação de Emergências da(s) rodovia(s). De qualquer modo, no presente estudo, para a definição de parâmetros técnicos genéricos para aplicação dos VANTs, foram adotados valores de referência com base na vasta experiência de profissionais da CETESB na atividade de atendimento a acidentes rodoviários com cargas perigosas.

Além das áreas propriamente atingidas, também devem ser caracterizadas as áreas no entorno destas para prever impactos de vizinhança, se o impacto continuará a ocorrer ou ainda se novos impactos podem ser gerados.

Por exemplo, substâncias poder ser voláteis e tóxicas e caso existam moradias ou outras estruturas habitadas, pode haver transporte pelo ar destas substâncias e a população vizinha pode ser afetada se respirar ou entrar em contato com o produto. Determinar o tipo de solo do local e se há corpos d'água para onde a substância está escoando é importante para saber dimensionar a magnitude do impacto e determinar medidas de controle.

Dadas estas circunstâncias, deve ser realizado um diagnóstico no entorno das áreas atingidas. As áreas a serem levantadas no entorno destas, variam, mas normalmente não passam de 200m de distância.

A área varia de acordo com a forma de manifestação geográfica dos impactos e das características locais, variando ainda, em orientação. Áreas de jusante em derramamentos são mais importantes de serem diagnosticadas que áreas de montante, por exemplo, pois devido à ação da gravidade são mais suscetíveis de 
serem contaminadas.

Desta forma, as áreas de levantamento ambiental nestes casos, dificilmente ultrapassam os 10ha. Em casos extremos podem chegar a distâncias lineares de da ordem de quilômetros, quando há transporte fluvial de substâncias derramadas.

Conhecendo-se as especificidades e circunstâncias da avaliação de impactos ambientais em caráter emergencial, abordadas acima e no item 2.2 do presente estudo, o sistema sensor e a plataforma embarcada para obtenção de imagens aéreas, no caso um VANT, deve aliar facilidade e rapidez na operação e, ao mesmo tempo, geração de imagens com resolução espacial e espectral que permitam a identificação de áreas afetadas e quantificação destas.

A seguir, são realizadas as apreciações e definições mais detalhadas sobre os aspectos técnicos e capacidades requeridas para um modelo de VANT de sensoriamento remoto para a aplicação em evidência.

\subsubsection{Plataforma VANT}

Em relação à plataforma VANT, que pode ser pipa, dirigível, helicóptero e avião, além de MAVs (Mini ou Micro UAVs) que podem não se enquadrar em nenhuma das anteriores, ela deve oferecer principalmente facilidade na decolagem, operação e aterrissagem para tornar mais rápida a obtenção das imagens. Com estas premissas, são preferíveis VANTs com plataformas mais estáveis e capazes de operar em condições de adversidades climáticas e capacidade de decolagem e aterrissagem em curtos espaços. Há modelos em forma de avião, helicópteros e ainda outras formas não convencionais como alguns MAVs que atendem tais requisitos. Assim a plataforma em si não é tão importante de ser determinada, mas sim suas capacidades.

\subsubsection{Alcance}

Como se prevê que os VANTs devem ser operados em conjunto com a equipe que realizará o atendimento à ocorrência e a avaliação de impactos ambientais em campo, o alcance não necessita ser grande. Alcances de até $8 \mathrm{~km}$ são suficientes para enorme maioria dos casos, baseando-se nas informações obtidas de extensão 
de áreas atingidas.

A opção de operação remota, de bases distantes, exigiria maiores requisitos do alcance do VANT e também de seu sistema de transmissão de dados, o que o encareceria. Eventuais solicitações e instruções da equipe de avaliação de impactos ambientais para a cobertura por imagens de áreas específicas também seriam dificultadas e menos flexíveis.

\subsubsection{Autonomia de vôo}

Como destacado para o alcance dos VANTs, o local de decolagem e aterrissagem deve ser próximo ao local do acidente com o transporte de cargas perigosas. Como as áreas a serem recobertas pelo imageamento também devem ser pequenas, normalmente da ordem de 10ha, não é necessária grande autonomia de vôo. Em pouco tempo é possível realizar as missões de aquisição de imagens destas áreas. Apenas para rastrear e monitorar possíveis processos em andamento, como vazamentos em corpos d'água, seria indicada uma maior autonomia. Mas como o lançamento e pouso deverá ser realizado nas proximidades, o veículo aéreo poderá pousar e decolar quantas vezes forem necessárias e com grande frequência. Dados estes aspectos, a autonomia deve ser superior a 30 minutos e pode ser inferior a duas horas, tempos de vôos suficientes para as finalidades desejadas e totalmente compatíveis com o alcance determinado anteriormente.

\subsubsection{Altura do vôo}

A altura de vôo máxima está vinculada ao tamanho máximo necessário da área a ser levantada principalmente, e esta depende além da altura do vôo, do tamanho físico do sensor e da distância focal do instrumento. Como as áreas a serem recobertas devem ser pequenas e os sensores aerotransportados pelos VANTs apresentam normalmente pequenas distâncias focais, não se necessita que estes atinjam grandes alturas de vôos. Para exemplificar, considera-se a fórmula a seguir (FALKNER,1994) para cálculo de área de recobrimento de uma imagem obtida por aerofotogrametria: 


$$
a c=(a v / d f \times l s) \times(a v / d f \times c s)
$$

$\mathrm{ac}=$ área coberta

av = altura do vôo em relação ao solo

$\mathrm{df}=$ distância focal

Is = largura do sensor

$\mathrm{cs}=$ comprimento do sensor

Tomando-se como exemplo, temos que para um sensor de 22,7 x 15,1 mm e distância focal de $28 \mathrm{~mm}$ (câmera digital convencional de pequeno formato), voando a $1000 \mathrm{~m}$ de altura em relação ao solo, a área recoberta por imagem será de $792,86 \mathrm{~m} \times 528,57 \mathrm{~m}=41,91$ ha.

Esta área de cerca de 40 ha seria suficiente para recobrir a grande maioria dos impactos gerados um acidente com transporte rodoviário de cargas perigosas e o entorno imediato. Esta área pode não ser suficiente apenas em caso da atuação de agentes de transporte ou dispersão da carga, como por exemplo, ventos ou drenagens e corpos hídricos superficiais, ou ainda quando da ocorrência de explosões, ou incêndios, em que os danos se espalhem por áreas maiores.

Nestes casos, mais de uma imagem seria necessária para recobrimento das áreas atingidas e do entorno destas, mas de qualquer forma, poucas imagens.

Realizadas as apreciações, VANTs que operem a alturas de até $2000 \mathrm{~m}$ são adequados para o uso estudado.

Sobre a altura do vôo, ressalta-se ainda que em caso de nebulosidade sobre a área a ser imageada, os VANTs devem ser capazes de obterem imagens abaixo das nuvens, as quais, dependendo do tipo, como as nuvens baixas, apresentam suas bases a poucas centenas de metros do solo. Assim, é importante que o VANT seja habilitado a voar a pequenas alturas, da ordem de $100 \mathrm{~m}$, de forma segura para gerar imagens sob nuvens baixas.

\subsubsection{Classe de VANT}

Para aplicação desejada, entende-se que os VANTs devem ser pequenos para poderem ser transportados com maior facilidade até o local do desastre. Estes VANTs também deverão possuir futuramente, quando da regulamentação plena da atividade, menores restrições em relação ao uso do espaço aéreo e oferecem 
menores riscos em caso de acidentes, em relação aos aspectos de dimensões e massas. Os aspectos de viabilidade legal para a operação de VANTs são tratados no item 4.2 .

Desta forma, e considerando-se os aspectos descritos nos itens anteriores, os VANTs das classes Mini ou Close Range são mais indicados para a aplicação desejada.

A maioria dos VANTs para aplicação civil é do tipo Mini ou Close Range, sendo estes também, em geral, menos custosos para aquisição e operação.

\subsubsection{Decolagem e aterrissagem}

Recomenda-se que os VANTs apresentem capacidade de decolagem vertical, via lançamento manual ou via acoplamento em veículo terrestre e capacidade de aterrissar verticalmente. Entretanto, como o atendimento a acidentes com transporte de cargas perigosas ocorrerá necessariamente próximo a rodovias, há a possibilidade de uso destas como pistas para decolagem e aterrissagem, desde que o VANT em questão seja capaz de realizar as ações em curtos espaços, de dezenas de metros. Caso contrário, seria necessário interditar trecho da rodovia para decolagem e aterrissagem.

\subsubsection{Operações programadas e autônomas}

Recomenda-se que o VANT embarque GPS e possibilite a aquisição de imagens de pontos e altitudes conhecidas para facilitar o georreferenciamento das imagens.

É desejável que o VANT apresente capacidade de realização de missões programadas ou autônomas de obtenção de imagens aéreas, com possibilidade de programação dos pontos georreferenciados de aquisição. Este método deve, porém, ser mais rápido e seguro em relação às operações manuais, realizadas por operador humano, com sistema autônomo consolidado.

\subsubsection{Transmissão e armazenamento de dados}

A função de transmissão de informações e imagens em tempo real, principalmente 
através de vídeo, é recomendada para que sejam visualizados elementos ambientais importantes em tempo real através do vídeo, o que pode inclusive determinar a obtenção de imagens de áreas específicas anteriormente o pouso do VANT, gerando agilidade para a obtenção de imagens relevantes. A capacidade de armazenamento das informações é imprescindível, para casos de falha na transmissão (NASA, 2006).

\subsubsection{Condições de tempo}

Recomenda-se que o VANT apresente capacidade de vôo diurno e noturno e principalmente, capacidade de operar sob condições atmosféricas adversas, como sob chuva e ventos moderados. A operação em tempestades, com chuvas e ventos fortes é difícil de ser realizada com VANTs do tipo Mini e Close Range. Além disso, estas ocorrências meteorológicas são mais raras e normalmente duram tempo restrito, da ordem de poucas horas.

\subsubsection{Segurança}

Há alguns riscos da adoção desta tecnologia para a aplicação ora abordada que podem ser visualizados desde o início e devem ser considerados. Um acidente com o transporte rodoviário de produtos perigosos, por sua definição, envolve trânsito de veículos e pessoas. Mesmo pequenos VANTs, caso atinjam seres humanos, podem ser capazes de provocar sérios danos e inclusive a morte. O VANT deve prover segurança em sua operação para não oferecerem riscos de agravarem a situação em desastres e os profissionais operadores devem ser capacitados para a atividade. O VANT deve ter um nível de Confiabilidade e Segurança Crítica (Safety) adequados e estudos para integração segura de VANTs no espaço aéreo tem sido realizados (FURTADO et al, 2008).

\subsubsection{Tempo para provimento de informações}

Os sistemas VANTs a serem utilizados devem ser capazes de chegarem ao local da ocorrência e de obterem imagens de forma muito rápida, juntamente com a equipe 
de atendimento. Devem ter implantação e operação ágil para fornecer respostas em pouco tempo. Após chegar a um local para decolagem, a implantação, operação e geração de imagens pelo sistema, não deve demorar mais que uma hora.

\subsubsection{Capacitação profissional}

Profissionais capacitados devem estar sempre disponíveis para operação do sistema VANT, aquisição das imagens, processamento e análise delas. Estes profissionais normalmente são engenheiros mecânicos, aeronáuticos e elétricos especializados na operação de VANTs.

\subsubsection{Sensores a serem embarcados}

O sensoriamento remoto para respostas a emergências, de acordo como Jensen (2009), necessita de imagens de alta resolução espacial e temporal. A figura a seguir apresenta esta relação para diversas aplicações, entre elas, a para resposta a emergências (elipse vermelha).

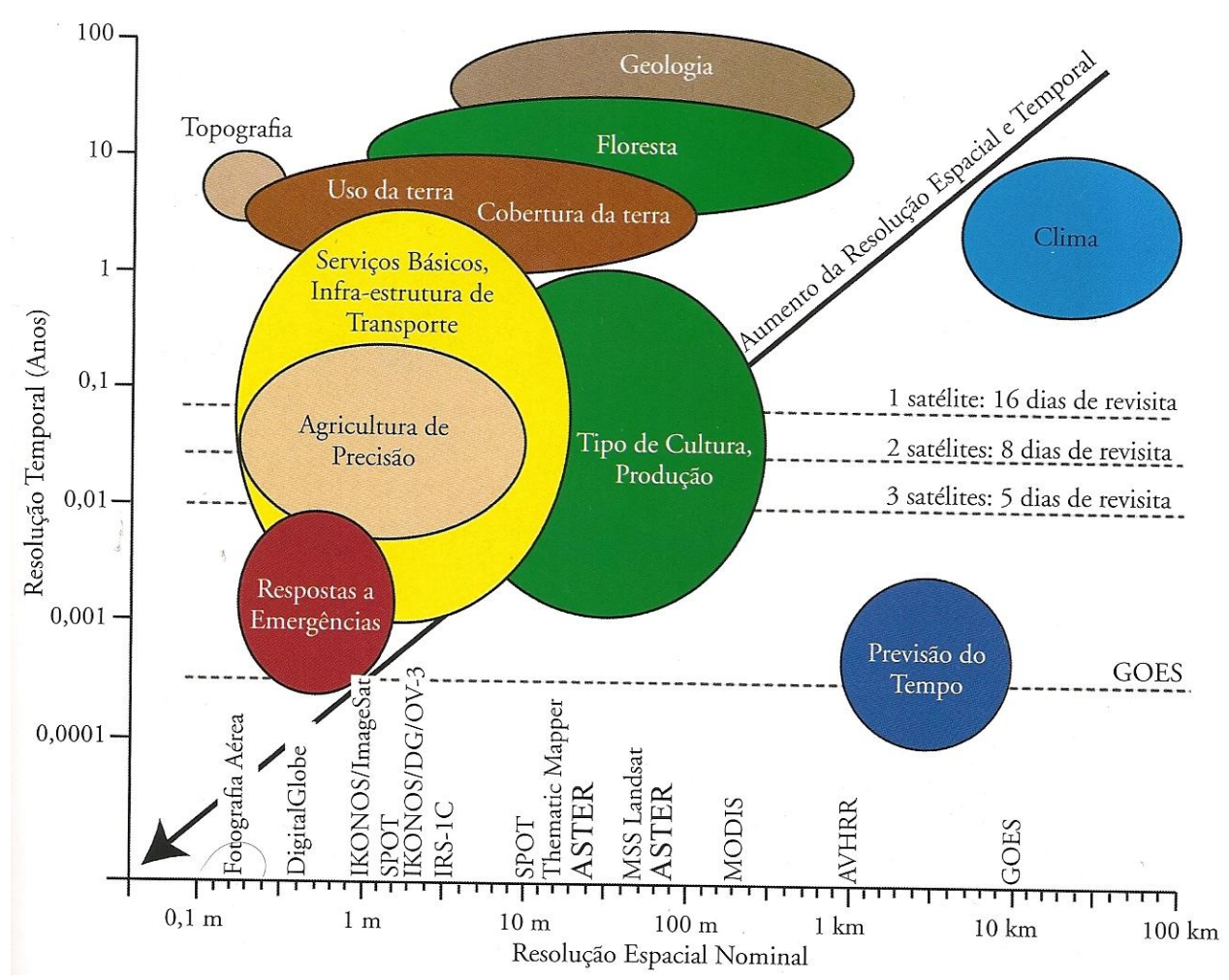

Figura 4.1.13-1: Resolução espacial e temporal de dados de sensoriamento remoto para diversas aplicações. (JENSEN, 2009). 
Segundo Jensen (2009), normalmente quanto maior o requisito de resolução temporal, menor o requisito de resolução espacial, e vice versa, sendo a aplicação em respostas a emergências, uma exceção. "Aplicações de respostas a emergências podem necessitar de coletas de dados com resoluções espaciais e temporais muito altas, que geram uma enorme quantidade de dados." (JENSEN, 2009). O autor recomenda para respostas a emergências, resoluções temporais de $12 \mathrm{~h}$ a dois dias e resoluções espaciais iguais ou superiores que $1 \mathrm{~m}$. Para resposta especificamente a acidentes com transportes de cargas perigosas, de acordo com as características levantadas, estas resoluções necessitam ser ainda melhores.

O sistema sensor necessita apresentar resolução temporal alta e flexibilidade para atender ao registro por imagens das áreas potencialmente afetadas logo após o acidente e monitorá-las em seguida. Plataformas VANTs, de maneira geral, apresentam esta característica, de permitir resolução temporal flexível e alta, sendo possível gerar imagens de uma mesma área com resolução temporal até de segundos.

É importante salientar que o caráter emergencial para obtenção das imagens não exige grandes exatidões geométricas destas ou necessidades de georreferenciamento preciso.

Em relação à resolução espacial, como as áreas atingidas e seu entorno a serem aerolevantados normalmente são inferiores a 10 ha, e os alvos a serem identificados podem ser muito reduzidos, se faz necessária que esta resolução seja altíssima, com pixels representando $0,5 \times 0,5 \mathrm{~m}$ ou menos, em solo.

É interessante que a resolução radiométrica seja boa para auxiliar na identificação e diferenciação de substâncias que despejadas no ambiente e nas áreas afetadas. Resoluções de 8bit (256 níveis de brilho) por banda são suficientes para a aplicação. Sobre a resolução espectral, devem ser realizadas várias considerações e podem ser determinadas algumas opções.

Como as substâncias transportadas e seus efeitos quando em contato com a superfície podem ser os mais diversos, há uma grande dificuldade de se definir com precisão que faixas do espectro eletromagnético um sensor deve captar para a melhor eficiência da utilização em questão. Ressalta-se que seria necessária uma biblioteca de assinaturas espectrais de substâncias perigosas passiveis de transporte rodoviário para o aprimoramento da identificação destas e melhor 
definição de sensores para a aplicação em estudo.

Feitas as devidas ressalvas, pode se afirmar que um sensor multispectral, com pelo menos quatro bandas divididas nas faixas do espectro de comprimentos de ondas referentes ao visível (RGB) e ao infravermelho próximo seria adequado inicialmente para a aplicação. A informação do infravermelho justifica-se pela sua importância na diferenciação de objetos na superfície terrestre, sendo ótima para extração de dados biofísicos. Trata-se de uma das faixas espectrais com maior número de estudos no sensoriamento remoto, sendo a sua utilização bastante consolidada por profissionais que trabalham com sensoriamento remoto (JENSEN, 2009). Prova disto, é que os sensores imageadores passivos da superfície terrestre embarcados em satélites de alta e media resolução espacial, quase sempre apresentam, além das bandas pancromáticas e RGB, pelo menos uma banda no infra-vermelho próximo.

Obviamente que quanto mais informações espectrais, melhor para distinção de objetos em superfície, de acordo com a assinatura espectral destes. Nesta ótica, sensores hiperespectrais que aliam a alta resolução espacial à espectral seriam muito úteis, fornecendo maior quantidade de informação espectral para identificação de substâncias derramadas e áreas atingidas. Exemplo pode ser observado em Longhitano et al. (2009), que se utilizou de imagens do sensor hiperespectral aerotransportado CASI-1500 para identificação de pigmentos foliares e variação da diversidade vegetal.

Sensores SAR poderiam ser úteis, principalmente na ocorrência de nevoeiros ou fumaça sobre as áreas a serem imageadas, ou em operações do VANT durante a noite. Um sensor laser, tipo LIDAR, teria sua utilidade na análise do relevo da área para melhor entendimento da dinâmica de escoamento superficial da área.

Entretanto, deve se considerar que quanto mais bandas são adquiridas por um sensor, maior a lentidão para análise e processamento destas e que sensores hiperespectrais, SAR e lasers são mais caros comparados aos multiespectrais que imageam o visível, de modo geral.

Informações geradas por estes sensores também exigiriam que os profissionais responsáveis pelo tratamento e análise destas possuíssem mais e profundos conhecimentos em processamento imagens e no comportamento espectral das cargas perigosas e áreas afetadas.

Em contrapartida, uma composição colorida com cores associadas às bandas na 
faixa do visível, gerando cores próximas às reais, é fácil de ser fotointerpretada por analistas ambientais, mesmo que estes não sejam muito familiarizados com produtos de sensoriamento remoto, em oposição a composições em falsa-cor e com uso de bandas de faixas espectrais fora do visível.

Assim deve se considerar que o sistema sensor embarcado no veículo aéreo seja capaz ao menos de gerar composições coloridas associadas às reais. Este sensor pode ser inclusive uma câmera digital colorida de pequeno formato adaptada ao sistema VANT, gerando nada mais do que fotografias aéreas coloridas digitais.

Desta forma, recomenda-se que o sensor gere imagens coloridas ao menos da região do visível, embora um sensor multiespectral com a informação do infravermelho próximo seria bem vindo para identificar com maior acuidade danos ambientais sobre a vegetação e áreas afetadas. As outras opções de sensores não devem ser descartadas para a aplicação, mas nesta análise não apresentam a princípio um custo-benefício técnico e econômico justificável para a aplicação em foco.

Destaca-se que independentemente destas duas opções recomendadas, a altíssima resolução espacial das imagens deve permite a identificação de fenômenos e objetos na superfície com maior facilidade. Rocchini (2007), por exemplo, demonstrou a eficiência tanto das melhores resoluções espectrais como espaciais, em estudos de vegetação ao comparar o uso de dados de diferentes sensores.

\subsubsection{Modelo de VANT adequado à aplicação}

De acordo com os requisitos e capacidades levantadas, e dentro dos VANTs nacionais atualmente operacionais, o VANT AGplane é o que apresenta características mais adequadas para a aplicação, sendo utilizado como referência no item que segue, sobre a viabilidade da aplicação.

A aeronave pesa $20 \mathrm{~kg}$ e mede $3,2 \mathrm{~m}$ de envergadura e 2,2 $\mathrm{m}$ de comprimento, tem capacidade de carga útil de até $10 \mathrm{~kg}$, autonomia de vôo $3,5 \mathrm{~h}$ e alcance de $8 \mathrm{~km}$. Atinge alturas de até $3 \mathrm{~km}$. Pode ser classificada como um VANT Close Range. Decola acoplado em automóvel, que é o mesmo de seu transporte e pousa em áreas curtas, de poucos metros, ou ainda através de pára-quedas de forma assistida. A obtenção de imagens e o plano de vôo podem ser realizados de forma 
autônoma, por meio de programação prévia. A aeronave pode ser equipada com câmeras digitais convencionais (atualmente câmeras com 10 a 21 megapixels) ou outros sensores. A AGX possui um sensor multiespectral de imageamento das regiões do visível e infra-vermelho próximo (NIR) que pode ser embarcado.

A aeronave fornece imagens georreferenciadas automaticamente, com precisão de GPS de navegação (aproximadamente 15m), transmite vídeo e imagens em tempo real para estação de comando em solo e pode voar sob condições de chuva e ventos moderados, bem como durante a noite. Um piloto de solo e um assistente/piloto reserva são suficientes para operação.

Para locomoção, todos os equipamentos do VANT podem ser transportados por um automóvel pick-up, do tipo Saveiro.

Este VANT cumpre os requisitos dimensionados para a aplicação, inclusive com algumas capacidades extras.

\subsection{VIABILIDADE DA APLICAÇÃO}

Para a verificação da viabilidade do uso de sensoriamento remoto por VANT em avaliação e monitoramento de impactos ambientais causados por acidente com transporte rodoviário de cargas perigosas, foram pesquisados os diversos cenários que podem ocorrer na realidade quando da ocorrência de acidentes com transporte de cargas perigosas em rodovias.

A partir destas situações, foi simulado por meio de hipóteses, como seria utilizado um VANT com características dentro dos parâmetros definidos no item 4.1 para buscar as melhorias buscadas e elencadas no item 3.1.

A simulação envolveu a avaliação técnica e econômica da aplicação, sendo também comparadas com o sensoriamento remoto obtido de outras plataformas.

\subsubsection{Viabilidade Técnica}

Para o levantamento de informações representativas da realidade de acidentes com transporte de cargas perigosas, apoiou-se em casos de acidentes que tenham 
gerado impactos ambientais distintos e que tenham atingido áreas de tamanhos diversos. Dados sobre tempo de atendimento e de características ambientais dos locais também foram pesquisados.

Desta forma, buscou-se por cenários ambientais diversos onde a avaliação de impactos ambientais pode ser realizada muito facilmente ou ser de alta complexidade.

O VANT a ser utilizado nesta simulação de hipóteses apresenta as características previamente determinadas.

Para que o VANT esteja sempre à disposição das equipes de atendimento a acidentes, é preferível que o ele seja adquirido por esta equipe e que incorporem na equipe de atendimento, profissionais capacitados à operação. Destaca-se que a operação do VANT deve ainda estar vinculada e articulada às etapas contidas no fluxograma de acionamento de emergências do Plano de Atendimento Emergencial PAE da rodovia.

Este seria o modelo de operação ideal do ponto de vista técnico.

Utilizou-se como referências os procedimentos determinados pelas leis e normas que são válidas para o estado de São Paulo. Em outros países e estados, o atendimento a emergências de maneira geral segue procedimentos semelhantes, mas há casos de locais onde não existem legislação e normas específicas para estes casos de atendimento acidentes com transporte de cargas perigosas.

As características acima descritas são tomadas como premissas para as informações apresentadas a seguir.

\subsubsection{Acionamento}

Ocorrido o acidente, o transportador, as concessionárias de rodovias privatizadas, a polícia, o corpo de bombeiros ou a defesa civil solicitam à CETESB ou a uma empresa especializadas em tais atendimentos que realizem as medidas de caráter ambiental.

Qualquer uma das entidades citadas e envolvidas no atendimento emergencial poderia interessar-se pelo uso de VANTs para sensoriamento remoto após um acidente. Entretanto, de acordo com a demanda de informações, entende-se que os maiores favorecidos com a tecnologia para avaliação e monitoramento de impactos 
ambientais podem ser os órgãos públicos ambientais responsáveis pelo atendimento a emergências químicas, grandes transportadoras que possuam equipe própria para acidentes e empresas especializadas em adoção de ações de gestão para acidentes ambientais.

Após acionada, normalmente através do telefone, segundo informações da CETESB, uma equipe responsável pela avaliação ambiental da ocorrência demora, em geral, menos de 20 minutos para obter algumas informações prévias antes do acidente e partir para o local (informação verbal) ${ }^{2}$. As informações podem ser obtidas no Plano de Atendimento Emergencial da rodovia, que deve possuir informações ambientais das áreas adjacentes a esta e os procedimentos de avaliação a serem tomados em situações de acidentes com cargas perigosas, conforme determina Resolução SMA n. 81, de 01 de dezembro de 1998.

Embora não faça parte do escopo e da presente pesquisa, há a possibilidade, inclusive, de previamente VANTs serem empregados para obtenção de imagens de faixas no entorno das rodovias em estudos ambientais prévios à obtenção da licença prévia e de instalação destas. Deste modo, o próprio PAE poderia apresentar imagens obtidas por VANTs dos locais antes de serem atingidos, para diagnóstico preliminar das equipes de apoio e comparação futura da situação ambiental da área após o acidente e após a adoção das ações de gestão.

Normalmente a equipe de atendimento é composta de três profissionais, como engenheiros químicos e ambientais e biólogos.

Os equipamentos transportados com as equipes são EPls, Equipamentos de Proteção Individual para os profissionais envolvidos e outros para realização das primeiras medidas de controle e mitigação do impacto, além de sensores para medição da concentração de gases no ar. Estes equipamentos são normatizados pela norma ABNT NBR 9735, que trata do "Conjunto de equipamentos para emergências no transporte terrestre de produtos perigosos".

Um VANT do tipo Mini ou Close Range, com as características previstas é capaz ficar previamente preparado para emergência.

Para operação, uma ou duas pessoas, dependendo do VANT, são suficientes para operação do equipamento. Consideramos duas, para sempre haver uma pessoa reserva que seja capaz de operar o equipamento também, caso ocorra algum

\footnotetext{
2 Dados fornecidos pelo técnico Marco Antonio Lainha do Setor de Operação de Emergências da
} CETESB em junho de 2010. 
imprevisto com uma delas. É importante que o VANT e profissionais que devem operá-lo, estejam sempre disponíveis para operação.

Deve haver sempre uma equipe composta por dois profissionais de plantão e o VANT deve ser mantido sempre em ordem, através de procedimentos de manutenções periódicas.

Uma vez acionados, profissionais e o VANT podem imediatamente partir para a obtenção de imagens aéreas para avaliação da ocorrência ou podem se locomoverem juntamente com a equipe que irá realizá-la.

\subsubsection{Transporte para o local do acidente}

A locomoção para as áreas atingidas ocorre por rodovias. O tempo para chegar-se ao local do acidente varia em decorrência da localização deste e da base onde se instalam as equipes para a avaliação ambiental. No caso da CETESB, a equipe se localiza no município de São Paulo. Mesmo empresas particulares, também em geral possuem apenas um local utilizado como base, e não vários situados ao longo do estado.

Os profissionais responsáveis pela operação e o próprio VANT, portanto, devem ficar junto a estas equipes preferencialmente.

Os equipamentos utilizados na avaliação da ocorrência são normalmente transportados juntamente com a equipe em veículos dotados de pequenos furgões, como vans por exemplo.

O VANT com as especificações determinadas ocupa pouco espaço. Com isto, a equipe de avaliação da emergência poderia transportá-lo juntamente com os outros equipamentos ou em um automóvel, como uma pick-up, no caso do AGplane.

Desta forma, o tempo para transporte dos equipamentos seria o mesmo que para a locomoção da equipe de avaliação da ocorrência, podendo estes inclusive, viajarem juntos.

É necessário lembrar que a viabilização plena da aplicação depende de uma organização e inteligência pronta, vinculada à rotina e metodologia de atendimento das equipes e vinculada ao fluxograma das etapas de acionamento dos PAEs das rodovias e dos responsáveis pelo transporte de cargas perigosas. 


\subsubsection{Avaliação da ocorrência no local}

Uma equipe de atendimento, mesmo antes de chegar ao local do acidente, coleta informações prévias, via telefone durante a locomoção.

Ao chegar ao local, em geral, são coletadas informações sobre o acidente com as pessoas que chegaram previamente na área, como policiais, bombeiros, funcionários da concessionária da rodovia, etc. Estes procedimentos duram poucos minutos.

Realizada esta primeira etapa, a equipe irá avaliar as áreas potencialmente atingidas através de inspeção visual, explorando a área.

Esta avaliação, de modo geral, dura de poucos minutos a dois dias, dependendo da quantidade e tipo da substância vazada, além das características físicas das áreas atingidas (informação verbal) ${ }^{3}$.

Em função disto, a obtenção das imagens, deve ocorrer o quanto antes e preferencialmente em até uma hora, após a chegada da equipe de avaliação da ocorrência, para que esta possua as imagens, anteriormente ou simultaneamente à necessidade de explorar o local.

A determinação da área a ser imageada dependerá das características da área e do acidente. Inicialmente, uma área padrão recobrindo o entorno de $300 \mathrm{~m}$ ao redor do ponto exato do acidente pode ser obtida, pois segundo dados de atendimentos, em geral as áreas de levantamento de informações são restritas a este raio. As áreas podem ser maiores de acordo com as condições de relevo do local, condições atmosféricas (chuva) e transporte dos materiais pela água, em rios, represas ou lagos. Ainda, em caso de incêndios gerados pelo acidente, onde o fogo pode se alastrar, as áreas afetadas podem ser consideravelmente maiores.

É interessante que o VANT transmita um vídeo link em tempo real, das áreas por onde ele sobrevoa. Assim os operadores e técnicos ambientais podem iniciar imediatamente a avaliação de impactos ambientais por meio do vídeo e determinar outras áreas para aquisição de imagens aéreas. No caso do AGplane, esta opção está presente.

Caso a equipe de avaliação possua alguma dúvida em relação da extensão das áreas atingidas, ela poderá solicitar aos profissionais imagens de determinadas

\footnotetext{
${ }^{3}$ Dados fornecidos pelo técnico Marco Antonio Lainha do Setor de Operação de Emergências da CETESB em junho de 2010.
} 
áreas que não foram recobertas, ou ainda, imagens mais detalhadas, obtidas com zoom ótico ou de forma mais próxima das áreas contaminadas. Por exemplo, em um caso que a substância derramada atinja um córrego e é necessário determinar até onde houve contaminação de suas margens e qual é melhor local para serem colocadas barreiras de contenção.

Há diversos VANTs do tipo Mini e Close Range que possuem esta capacidade de obtenção de imagens rapidamente, que não demoram em ser montados e testados no local antes de operarem, ou já chegam prontos para decolarem. Como irão decolar de áreas muito próximas ao acidente, não gastam tempo de locomoção à área a ser imageada. Também não necessitam atingir grandes altitudes, inferiores a $2000 \mathrm{~m}$, como anteriormente afirmado. Assim, o tempo gasto para decolagem, chegada ao local e altitude para obtenção da imagem, retorno e pouso, dura poucos minutos.

Para descarregar as imagens obtidas pelo VANT em um Notebook, os procedimentos são rápidos também. Normalmente, as imagens ficam gravadas em cartões de memórias flash convencionais existentes no mercado. Portanto, os procedimentos são semelhantes aos realizados para descarregar fotos obtidas por uma câmera digital e devem durar poucos minutos.

O AGplane, de acordo com informações da AGX tecnologia, pode gerar e fornecer as imagens para os analistas em cerca de 30 minutos após a chegada ao local (informação verbal) ${ }^{4}$. Estima-se que um VANT do tipo Mini pode gerar informações de forma ainda mais rápida. Além disso, a imagem de vídeo do AGplane pode ser observada em tempo real, durante o vôo.

Em relação ao tratamento digital destas imagens, normalmente ele não é necessário, se os sensores embarcados forem câmeras digitais RGB configuradas para obtenção de imagens no VANT. O aumento de contraste para facilitar a fotointerpretação pode ser necessário, mas este procedimento é muito rápido, leva poucos minutos, e pode ser realizado inclusive em softwares convencionais de tratamento de fotografias digitais. A velocidade de processamento é rápida, ainda mais se as imagens forem geradas em formato JPEG (Joint Photographic Experts Group) como em câmeras digitais convencionais, arquivos compactos que são da ordem de poucos megabytes, em geral inferiores a $15 \mathrm{MB}$.

\footnotetext{
${ }^{4}$ Dados fornecidos pelo diretor da AGX tecnologia, Adriano Kancelkis, em junho de 2010.
} 
Imagens multiespectrais, geradas com bandas separadas proveriam mais informações espectrais sobre a área imageada, entretanto demandariam tempo um pouco maior para processamento e geração de composições coloridas, bem como técnicos com maiores conhecimentos em interpretação de dados de sensoriamento remoto para analisar as imagens, como anteriormente previsto.

O registro preciso das imagens não é necessário para a avaliação da ocorrência, onde o importante é a obtenção de imagens rapidamente, sem maiores preocupações com a precisão. Como os técnicos ambientais estarão nas proximidades da área atingida, pode se associar elementos visíveis em campo aos mesmos nas imagens. Assim podem ser obtidas informações básicas de orientação e localização de elementos identificados apenas na imagem, mesmo que ela não esteja georreferenciada.

A AGplane gera imagens georreferenciadas, através de sistema de posicionamento embarcado, com precisão de aproximadamente $15 \mathrm{~m}$, sendo esta suficiente para a destinação.

Se houvesse necessidade de precisão, seria necessário o georreferenciamento através de procedimentos convencionais com uso de Modelo Digital do Terreno ou aquisição de vários pontos de controle em campo ou com cartografia de apoio. Trata-se de um processo que levaria tempo que poderia inviabilizar uma situação emergencial. Este procedimento, portanto, é desnecessário e desconsiderado.

Pode ser necessário o mosaico de imagens, quando a área a ser estudada não pode ser coberta por uma única foto, conforme anteriormente explicitado. Entretanto, não são previstas muitas imagens para cobertura de áreas a serem diagnosticadas. $O$ mosaico poderia ser gerado a partir do georreferenciamento automático das imagens ou através do encaixe manual das fotos ou ainda por interpolação via software. Os três procedimentos podem ser realizados rapidamente em minutos.

Deste modo, as imagens são viáveis de serem geradas para os analistas ambientais envolvidos na avaliação ambiental da ocorrência em até uma hora, utilizando-se do AGplane e considerando-se os processos descritos, após a chegada do equipamento e dos profissionais na área. Este tempo de resposta está dentro do requisito de imagens que sejam geradas rapidamente para as equipes de atendimento.

Deve ser ressaltado que as condições meteorológicas podem prejudicar a aquisição 
de imagens aéreas.

A existência de nebulosidade na área a ser recoberta pelo sensoriamento remoto sempre se constituiu um grande problema para obtenção de fotografias aéreas pelo método convencional em aviões tripulados e de imagens orbitais. As nuvens impedem que parte da radiação eletromagnética refletida/emitida pela superfície terrestre chegue ao filme ou sensor.

VANTs, entretanto, podem voar a baixas altitudes até a dezenas de metros da superfície, abaixo das bases das nuvens, e podem imagear mesmo em condições de muita nebulosidade e sob os mais diversos tipos de nuvens.

O VANT AGplane apresenta capacidade de voar em condições de precipitação e ventos moderados. A precipitação de neve e de chuva são eventos meteorológicos que podem atrapalhar na geração de imagens nítidas. Mas uma vez que o VANT apresente capacidade de operação nessas condições, recomenda-se que sejam obtidas imagens mesmo assim, pois, principalmente a chuva, também muito mais comum que a neve no Brasil, potencializa o escoamento de águas superficiais. A água pode transportar por distâncias muito maiores as substâncias derramadas. Mesmo imagens com menor nitidez geradas sob chuva moderada podem auxiliar na avaliação de impactos. Sob chuvas e ventos fortes, VANTs do tipo Mini e Close Range dificilmente apresentam capacidade de vôo e as imagens poderiam ser geradas apenas após a melhora do tempo.

Outro cenário que pode ocorrer é a existência de fumaça na área causada por incêndios que podem ter sido gerados pelo acidente. Se o VANT obtiver imagens em meio à fumaça, estas não serão nítidas. Com isto em vista o VANT a ser utilizado para a avaliação deve ser capaz de voar em alturas superiores a $1000 \mathrm{~m}$, onde a fumaça pode ser detectada, mas não atrapalhe muito a visualização da área a ser estudada. A aplicação em resposta a incêndios é inclusive uma das encontradas na literatura para respostas a desastres ambientais, como em Mika (2009) e Freire (2009).

Caso o acidente ocorra durante a noite, as equipes de atendimento se deslocam para área mesmo sem a luz solar. Para auxiliar na visualização da área, normalmente são utilizados holofotes ligados a geradores. Estes podem ser providos pelas entidades diversas envolvidas no atendimento.

Deve ser destacado que as equipes de atendimento nos casos em que chegam ao 
local pela noite, apenas irão ter uma avaliação completa da situação ambiental do desastre, com a luz do dia, mesmo com o uso de holofotes, em casos que a carga transportada se espalhe, entrando nas áreas apenas com a luz solar, para segurança na operação.

É importante mencionar também que tanto nas rodovias como nas vias urbanas os acidentes com transporte de cargas perigosas em rodovias acontecem entre às 06h00min e 18h00min, em horário comercial de atividades industriais, que coincide o fotoperíodo natural diurno de forma aproximada, segundo Teixeira (2005) e Alves et al. (2009).

Há VANTs do tipo Mini ou Close Range, como o AGplane, que possuem capacidade de operação noturna. Entretanto, as imagens da região do visível do espectro eletromagnético obtidas provavelmente não ficariam com uma boa qualidade, mesmo com a iluminação artificial por holofotes. Neste caso, mesmo um VANT com estas capacidades, provavelmente teria que aguardar até o nascer do sol e boa incidência de iluminação natural, o que ocorre cerca de trinta minutos após o nascer do sol, para adquirir imagens melhores. Em casos de incêndios noturnos, até mesmo a obtenção de imagens da região do visível poderiam auxiliar a dimensionar o incêndio e as áreas atingidas, devido à luminosidade emitida pelo fogo.

VANTs providos de sensores imageadores na faixa do infravermelho termal ou com SAR poderiam auxiliar na identificação de áreas atingidas por acidentes. Entretanto, isto encareceria o VANT e os profissionais que iriam analisar estas imagens deveriam ser capacitados a interpretar dados destes tipos de sensores também.

Portanto, são necessários requisitos que dificultariam esta aplicação durante a noite. Há de se considerar ainda, que mesmo com o uso dos holofotes, não apenas a identificação das áreas atingidas e do uso do solo do entorno, mas a adoção de ações de contenção e retirada das substâncias, também é dificultada. Caso o VANT possua sensores que apresentem as características acima descritas, que possibilitem a identificação de substâncias derramadas sobre a superfície e o uso do solo desta, muitas vezes não seria possível adotar as ações de gestão cabíveis sem a luz do dia.

Testes empíricos necessitariam ser realizados para mensurar a real eficácia destes procedimentos durante a noite, entretanto, de acordo com o apresentado, são de difícil viabilidade técnica e as informações geradas poderiam não ter uso imediato. 
Cabe aqui mencionar que a presente pesquisa não elimina a necessidade testes e treinamentos empíricos pelos interessados em uso da tecnologia. Estes devem ocorrer antes da operação sistemática de VANTs para sensoriamento remoto em situações emergenciais e envolver todos os procedimentos de avaliação de impactos ambientais aqui identificados como passíveis de melhoria técnica.

Não foram encontrados casos da aplicação proposta na pesquisa. Somente com testes empíricos, os procedimentos e parâmetros de vôo poderão ser padronizados e especificados em detalhe visando a eficiência da operação destes. Estes testes e treinamentos devem ser realizados de forma coordenada entre os técnicos ambientais envolvidos no atendimento de acidentes e os operadores de VANTs. Desta forma os procedimentos de uso de VANTs podem ser inclusive incluídos nos Planos de Atendimento Emergencial - PAE de rodovias, pelos responsáveis destas. Feitas tais considerações sobre a operação de um VANT e considerando-se que há viabilidade técnica de obtenção de imagens aéreas de áreas atingidas rapidamente e no tempo necessário para a avaliação de impactos ambientais da ocorrência, se tratará a seguir sobre as informações que podem ser geradas pelas imagens e como estas podem auxiliar na avaliação de impactos ambientais.

\subsubsection{Geração de informações para avaliação imediata da ocorrência}

Metodologicamente, é importante distinguir a avaliação de impactos ambientais já ocorridos em função de um acidente, bem como outros impactos futuros, que poderão ser desencadeados por alguma atividade ou evento humano ou ambiental no local, como a chuva, por exemplo.

Neste sentido, cabe aqui realizar algumas considerações acerca da avaliação de impactos ambientais. Segundo Sánchez (2008):

O caráter prévio e preventivo da avaliação de impactos ambientais predomina na literatura, mas também se pode encontrar referências à avaliação de impactos de ações ou eventos passados, por exemplo, depois de um acidente envolvendo a liberação de alguma substância química. Embora a noção de impacto ambiental envolvida em tais avaliações seja fundamentalmente a mesma daquela da AIA preventiva, o objetivo do estudo não é mesmo, nem o foco das investigações. Nesse caso, a preocupação é com os danos causados, ou seja, impactos negativos (...). Trata-se de tentar medir o dano ambiental e, ocasionalmente, de valorar economicamente as perdas.

Para ambos os olhares, para o passado e futuro, há um exercício que é comum, que é a comparação entre duas situações, passada e presente e presente e futura, 
respectivamente. Desta forma, o diagnóstico das condições no presente de certa área serve para ser comparada com suas condições passadas e entender quais impactos poderão ocorrer no futuro.

As imagens aéreas são úteis para o diagnóstico de situações ambientais após desastres, servindo, portanto aos dois aspectos, de caracterização dos impactos já ocorridos e prevenção da amplificação destes ou ainda da ocorrência de novos impactos.

As imagens aéreas geradas seriam entregues para os analistas ambientais pelo sistema do VANT definido como modelo para a aplicação, com as seguintes características: obtidas dentro de uma hora após chegada da equipe ao local, seriam coloridas (composição RGB - Red Green Blue associada às reais) ou multiespectrais, de resolução espacial altíssima (pixels representando menos que 0,5x05m de superfície), georreferenciadas com precisão de $15 \mathrm{~m}$ e mosaicadas (se necessário).

Com base em imagens com estas características, serão aqui analisadas quais informações poderiam ser obtidas rapidamente pelos técnicos envolvidos na avaliação ambiental da ocorrência.

As imagens devem ser fotointerpretadas por estes profissionais, visando a identificação de informações espaciais relevantes para atividades de avaliação dos impactos ambientais, que deverão subsidiar a tomada de decisões para adoção de ações de gestão.

A fotointerpretação é "a arte de examinar as imagens dos objetos nas fotografias e de deduzir a seu significado" (MARCHETTI e GARCIA, 1977). Estes autores definem, para a fotointerpretação, que a seqüência de aquisição e análise dos dados da fotografia é feita por: objeto - filtro - imagem - olhos - identificação reconhecimento - descrição - dados - análise - interpretação - significância.

É importante que os técnicos sejam capacitados e familiarizados com a fotointerpretação, para conseguirem extraírem o máximo de informações através da técnica.

Os profissionais deverão realizar a leitura da imagem área, que trata da observação geral e análise das imagens, sendo definidas as categorias gerais.

Nesta leitura, deverão ser identificadas, além das superfícies contaminadas, o uso do solo destes locais impactados e do entorno. Segundo Clawson e Stewart (1965) 
apud Anderson et al. (1979) uso da terra é a "atividade do homem na terra, que se acha diretamente relacionada com a terra". O revestimento do solo também pode ser entendido como "a vegetação e construções artificiais, que recobrem a superfície da terra" (BURLEY, 1969 apud ANDERSON et al., 1979). A expressão "uso da terra" pode ser compreendida, portanto, como a forma pela qual o espaço está sendo ocupado pelo homem, sendo de significativa importância para verificação do contexto ambiental em que se insere uma área atingida.

Atividades agropecuárias, possíveis receptores sensíveis a contaminação e a vegetação da área poderão ser identificadas. Um bom fotointérprete pode com a imagem aérea localizar e identificar as áreas contaminadas e extrair informações ambientais importantes sobre o entorno destas rapidamente, em poucos minutos.

Em avaliações de impactos ambientais nestas circunstâncias, normalmente o mais importante é detectar o que há e onde, sem necessidade de quantificar precisamente as áreas (informação verbal) ${ }^{5}$.

Embora, em hipótese inicial tal procedimento não se faz necessário, se for preciso imediatamente, na imagem, delimitar as áreas atingidas ou as classes de uso do solo da área através de polígonos, existe a possibilidade de esta ser realizada através de fotointerpretação, com desenho manual dos polígonos através de vetorização sobre a imagem, ou por classificação digital, através de processamentos da imagem.

O processamento digital da imagem para realização de classificações, sejam supervisionadas ou não-supervisionadas, requer a definição e escolha de parâmetros, além de alguns procedimentos técnicos mais complexos. Como as áreas a serem identificadas são de forma geral, pequenas, e inicialmente não deve ser necessária a identificação e classificação de todos os usos existentes na área, a fotointerpretação e desenho de polígonos sobre a imagem deve ser o recurso utilizado. Assim pode se delimitar as áreas com a substância perigosa e outras classes ou objetos importantes sobre a superfície de acordo com a necessidade e interesse da equipe de avaliação ambiental. Este procedimento também pode ser realizado em softwares convencionais de tratamento de imagens e com capacidade de desenho sobre imagens.

A realização de classificações digitais será abordada no item a seguir, que trata da

\footnotetext{
${ }^{5}$ Dados fornecidos pelo técnico Marco Antonio Lainha do Setor de Operação de Emergências da CETESB em junho de 2010.
} 
avaliação de impactos ambientais em etapa posterior, para documentação da ocorrência.

Caso seja necessário realizar medições imediatas sobre as imagens, estas podem ser realizadas diretamente na tela, através de uma régua, desde que conhecida a escala, ou por softwares de mapeamento ou geoprocessamento.

A partir da fotointerpretação das imagens, os locais contaminados pela carga perigosa podem ser identificados, uma vez que o solo normalmente fica mais escuro em contato com substâncias líquidas. Se a substância apresenta comportamento espectral diferenciado da água em corpos hídricos, também poderão ser identificados. Exemplos são os óleos combustíveis que não se misturam facilmente com a água, ficam sobrepostos na parte superior da água e podem ser visualizados facilmente.

Deste modo, as áreas contaminadas e extensão destas, além de tipo de solo, relevo, vegetação, hidrografia, uso e ocupação e a proximidade de pontos receptores sensíveis, podem ser extraídas das imagens.

Estas informações deverão subsidiar a identificação e a avaliação de impactos ambientais ocorridos e potenciais, além da vulnerabilidade e sensibilidade ambiental das áreas diretamente afetadas e do entorno.

A imagem a seguir foi obtida pelo AGplane em 2006, e mostra uma boa diversidade de usos do solo. Nela é destacada uma área de mancha de umidade no solo, que pode ser facilmente identificada. Um vazamento de substância líquida em caso de acidente sobre o solo poderia apresentar elementos visuais de fotointepretação semelhantes a esta mancha. 


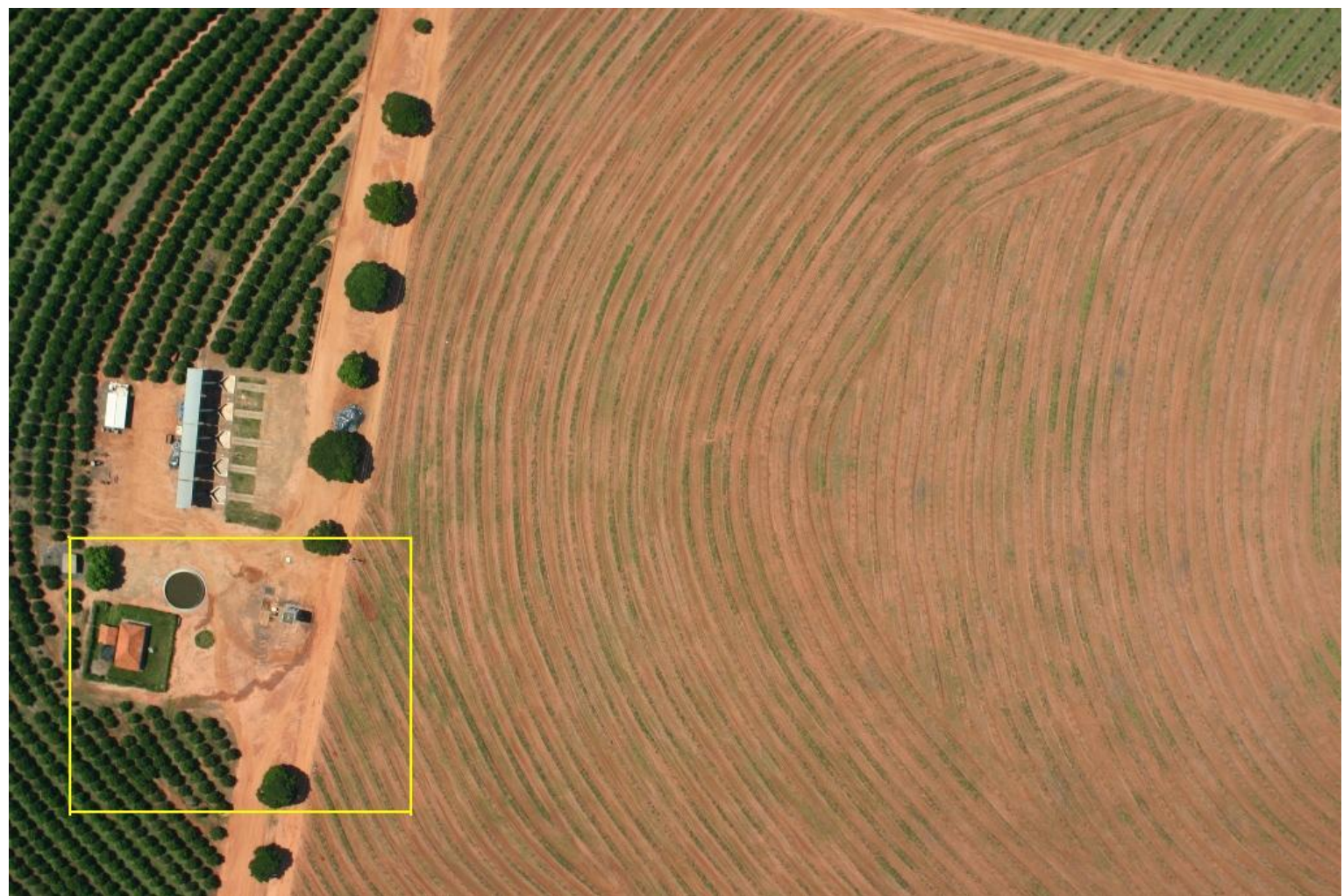

Figura 4.2.1.4-1: Imagem obtida a cerca de 600m com área recoberta de 15,09 ha (pixel corresponde a 13,76 x 13,76cm em solo). (AGX TECNOLOGIA org LONGHITANO, 2006)

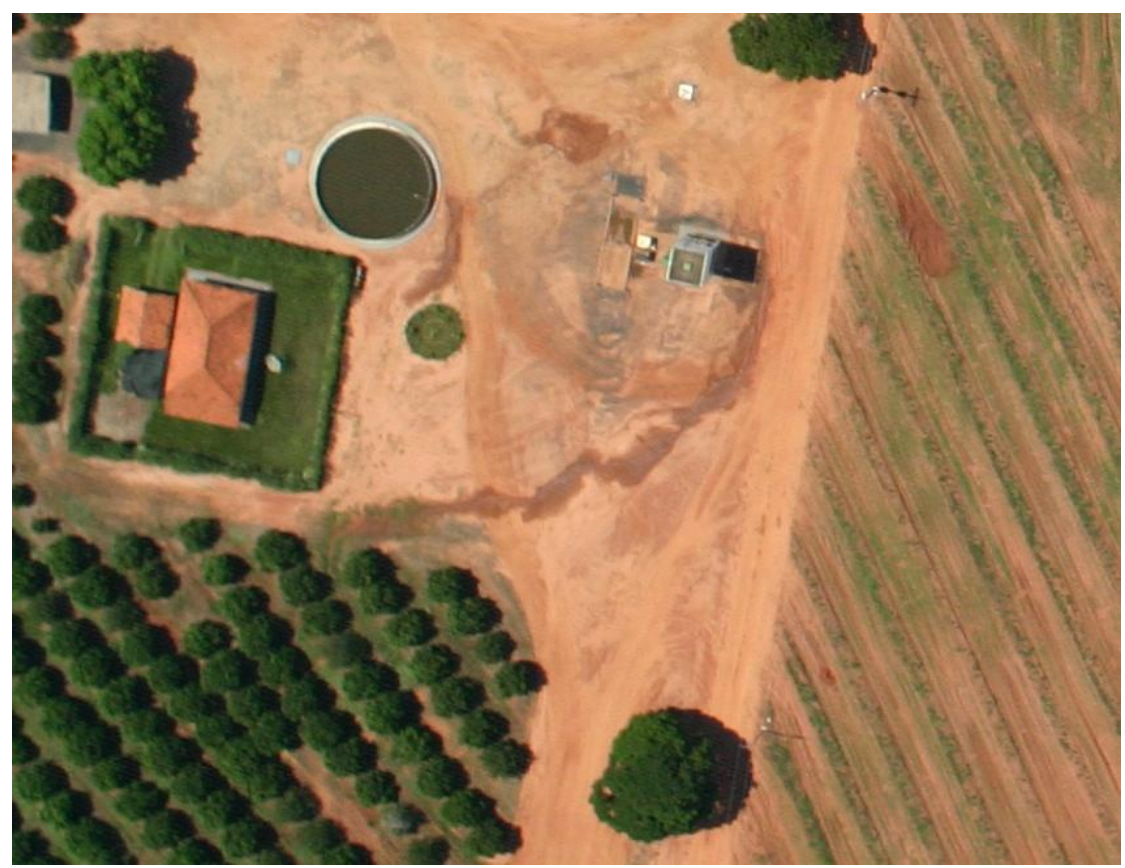

Figura 4.2.1.4-2: Ampliação do retângulo demarcado na Figura 4.2.1.3-1. (AGX TECNOLOGIA org LONGHITANO, 2006)

Muitas vezes o levantamento das informações supracitadas pode ser dificultado da forma convencional pela equipe em terra, devido às características topográficas do local, que não permitem a visualização do entorno ou dificultam a locomoção pelos 
locais, como vertentes íngremes. Situações onde o impacto pode abranger áreas maiores, como em incêndios ou quando há derramamento de carga sobre rios, também podem ser avaliadas mais rapidamente e facilmente com o sensoriamento remoto.

De qualquer forma, uma imagem área provém uma visão privilegiada do terreno, facilitando a avaliação. A obtenção de fotos aéreas "tendo uma visão panorâmica, dá condições (...) de obter os elementos de interesse de uma vista aérea, em pouco tempo, comparando-o com os métodos de campo" (LOCH e LAPOLLI, 1998).

As equipes especializadas nestes atendimentos, a partir desta avaliação ambiental da ocorrência, devem determinar as melhores ações de gestão imediatas para controle e mitigação dos impactos

Durante a intervenção emergencial, as atividades de recuperação do contaminante do meio através de procedimentos de limpeza, visam minimizar os efeitos nocivos do produto, bem como propiciar 0 restabelecimento do equilíbrio das comunidades atingidas. As atividades de limpeza têm que ser escolhidas e postas em prática com critério, caso contrário podem ampliar as conseqüências do acidente. A limpeza dos ambientes atingidos visa ainda, o restabelecimento estético do meio com o intuito de diminuir os impactos sociais e econômicos. (LOPES, 2009).

Deste modo, com informações mais precisas sendo geradas pelas imagens, as ações de gestão podem ser planejadas com maior eficiência, sendo determinadas as técnicas e os pontos mais adequados para adoção destas.

Os impactos ambientais diretos que podem ser gerados através de acidentes com transporte de cargas perigosas em rodovias são: contaminação do solo, contaminação das águas superficiais, contaminação das águas subterrâneas, contaminação de seres humanos, contaminação da fauna terrestre, contaminação da fauna aquática, contaminação e morte da vegetação, queima da vegetação, perda de atividades agropecuárias, perda de patrimônio público ou particular.

Há ainda a possibilidade de impactos ambientais indiretos, como a paralisação do abastecimento de água de um município, devido à contaminação de fontes de água superficiais ou subterrâneas, por exemplo.

Destes impactos listados, o sensoriamento remoto das áreas pode gerar informações úteis para a previsão e/ou detecção e/ou combate de todos, uma vez que há elementos envolvidos no desencadeamento destas ações para os impactos relacionados que podem ser visualizados em superfície.

Exceção se faz apenas para a identificação e comprovação da contaminação de águas subterrâneas, quando são necessários poços para amostragem de água e 
análise laboratorial. Mas mesmo para a adoção destes procedimentos, a imagem aérea pode ser útil, como está apresentado posteriormente.

Mas deve ser destacado que pode haver casos em que as imagens não apresentariam boa eficácia.

Há substâncias que são extremamente voláteis e evaporam rapidamente, sem deixar em superfície, vestígios observáveis. Também há possibilidade do escoamento de substâncias para áreas vegetadas que apresentem dossel fechado, impossibilitando a visualização das áreas atingidas através das imagens aéreas.

Quando a carga atinge corpos d'água, se a vazão ou fluxo for muito rápido (ambiente fluvial lótico), a substância pode ser misturada rapidamente na água, sendo detectada apenas através de análises laboratoriais. Se a substância for mais densa que a água, esta submergirá e dificilmente poderá ser detectada via o processo de sensoriamento remoto proposto. Segundo Lopes (2009), "produtos solúveis também não são possíveis de serem contidos ou recolhidos como acontece com produtos oleosos".

A eficiência técnica obviamente vai depender do cenário ambiental da área das características do acidente e da carga transportada e em hipótese alguma a obtenção de imagens via sensoriamento remoto de áreas atingidas substitui a necessidade da avaliação de impactos ambientais pelos técnicos em campo. Ela deve sim auxiliar, com a possibilidade de geração de mais informações, e de forma mais rápida e segura, como será analisado nos próximos dois itens.

\subsubsection{Redução do tempo da avaliação ambiental}

A geração de informações ambientais úteis através do sensoriamento remoto por VANTs para avaliação dos impactos imediatos se mostra viável tecnicamente, desde que realizada com VANT de parâmetros definidos para a aplicação.

Entretanto, em casos emergenciais, é de fundamental importância que os procedimentos sejam realizados rapidamente.

A redução do tempo para a avaliação ambiental da ocorrência é um aspecto relativo. Esta redução do tempo está vinculada a quão difícil seria a avaliação sem a obtenção das imagens aéreas. E como os aspectos ambientais podem variar enormemente, bem como a forma de ocorrência do acidente e as características 
físico-químicas das cargas perigosas transportadas, este tempo de avaliação pode ser reduzido ou ampliado.

Em casos onde a avaliação é complexa, devido a diversos elementos anteriormente levantados, o uso da tecnologia deve agilizar a obtenção de dados relevantes.

Em acidentes onde os impactos são bastante restritos e podem ser visualizados facilmente por analistas ambientais em solo, o procedimento de obtenção de imagem e análise desta, deve aumentar o tempo para realização da avaliação.

Deste modo, deve ser repetido que a avaliação de impactos ambientais no local não deve depender da obtenção das imagens, pois há casos em que a avaliação em solo é muito mais rápida e eficiente.

Entretanto, conforme maior a complexidade do acidente, maior a aplicabilidade das imagens obtidas e maior economia de tempo elas deverão trazer na avaliação de impactos. O uso destas imagens pode ser justificado também se houver riscos à vida ou saúde das equipes de atendimento, o que é discutido a seguir.

\subsubsection{Segurança das equipes de avaliação}

Considerando-se que há substâncias altamente tóxicas que podem gerar inúmeros prejuízos à saúde dos técnicos evolvidos na avaliação dos impactos ambientais e adoção das medidas de controle, mitigação dos impactos e recuperação ambiental das áreas afetadas, certamente a obtenção de imagens aéreas pode prover maior segurança a estes profissionais.

Há diversas substâncias tóxicas que podem causar danos à saúde em caso de inalação ou contato físico. Podem ser substâncias tóxicas ou corrosivas, por exemplo.

Existe a possibilidade de incêndios em caso de acidentes com cargas inflamáveis, deixando as equipes de atendimento a perigos ligados à exposição ao calor do fogo. Há ainda fatores ambientais das áreas afetadas que podem potencializar ou expor as equipes a novos perigos.

Exemplos são áreas declivosas, onde há perigo de quedas dos profissionais ao andarem sobre estas áreas, além do risco de deslizamentos de encostas e de blocos rochosos. Áreas de brejo e várzea, ou de mangue, onde o solo é altamente instável e encharcado, também são de difícil acesso e caminhar e podem expor as 
equipes a contato a substâncias que estejam derramadas sobre tais áreas.

Há áreas potencialmente afetadas ainda onde pode haver animas peçonhentos, como cobras, aranhas, carrapatos e abelhas que podem apresentar riscos aos seres humanos.

Uma vez que acidentes ocorrem de forma imprevisível e em locais imprevisíveis, todas as situações acima descritas são passíveis de ocorrerem.

Portanto, o sensoriamento remoto de áreas atingidas por acidentes com transporte de cargas perigosas, além de permitir a avaliação das áreas remotamente, também auxilia na tomada de decisões para a adoção das ações de gestão mais seguras.

\subsubsection{Monitoramento ambiental das áreas afetadas}

O monitoramento ambiental das áreas afetadas e do entorno pode ser considerado em duas escalas de tempo diferentes.

O monitoramento pode ser realizado pela equipe de atendimento ao acidente, de forma imediata e simultânea à adoção das medidas de controle e mitigação (imediatas), para avaliação de como os impactos ambientais estão se comportando, previsão de novos impactos e observação da eficácia das ações adotadas.

Pode ser realizado também posteriormente a estas ações imediatas, o monitoramento da área através de diagnósticos periódicos que podem durar mais de uma dezena de anos (informação verbal) ${ }^{6}$.

Para estes dois tipos de monitoramento, deve ser considerado o uso da tecnologia de sensoriamento remoto por VANTs.

O primeiro tipo ocorre em seguida da avaliação ambiental da ocorrência. Os impactos e a manifestação destes ocorrem basicamente da mesma forma.

Neste sentido, informações que podem ser extraídas através da observação da superfície terrestre, podem auxiliar no monitoramento.

Desta forma, o sensoriamento remoto por VANTs pode continuar auxiliando nesta atividade da mesma forma que a descrita para a avaliação da ocorrência, podendo ser realizado a partir de imagens aéreas obtidas de 30 em 30 minutos, por exemplo, um quadro evolutivo dos impactos ambientais, considerando-se a adoção das ações de gestão.

\footnotetext{
${ }^{6}$ Dados fornecidos pelo técnico Marco Antonio Lainha do Setor de Operação de Emergências da CETESB e por BTX - geologia e meio ambiente em junho de 2010.
} 
Caso sejam verificadas que as ações não estejam apresentando a eficácia desejada, estas ações podem ser revistas e alteradas, ou ainda serem executadas outras ações com técnicas diferentes.

Para o monitoramento ambiental posterior da área, que normalmente é determinado pelo órgão ambiental, ele segue uma série de procedimentos previstos, no caso do estado de São Paulo pelo documento "Decisão de Diretoria n 103/2007/C/E, de 22 de junho de 2007" da CETESB, que dispõe sobre os procedimentos para gerenciamento de áreas contaminadas, e pela Lei Estadual 13577 que trata da:

da proteção da qualidade do solo contra alterações nocivas por contaminação, da definição de responsabilidades, da identificação e do cadastramento de áreas contaminadas e da remediação dessas áreas de forma a tornar seguros seus usos atuais e futuros.

Os procedimentos de avaliações confirmatórias e detalhadas, dispostos nas regulamentações acima previstas, para verificar se efetivamente há contaminantes na área, se baseiam basicamente na amostragem de solos e de águas superficiais e subterrâneas para geração de níveis de concentração de substâncias e valores de parâmetros físico-químicos, os quais são referenciados por legislação específica.

Os impactos antes visíveis na superfície normalmente desapareceram através da adoção das medidas de controle, mitigação ou regeneração das áreas, que pode ser inclusive, natural.

Assim, neste momento as imagens aéreas obtidas por VANTs pouco poderiam acrescentar nestas avaliações. Além disso, nestes casos, este monitoramento é periódico e planejado, portanto a aquisição de imagens de alta resolução da área pode ser obtida também através da programação de satélites.

Uma possível vantagem nesta fase seria que, através da análise das imagens obtidas anteriormente na avaliação da ocorrência e no monitoramento ambiental imediatamente pós desastre, possam ser otimizados e determinados dos melhores pontos de monitoramento da qualidade do solo, águas superficiais e subterrâneas.

Principalmente no que diz respeito ao monitoramento de águas subterrâneas, é necessária a implantação de poços de monitoramento, antes das amostragens de materiais. Através de imagens que retratem a situação do acidente, podem ser reduzidos o número de pontos de amostragem e estes podem ser locados de forma mais eficiente para o monitoramento. 


\subsubsection{Documentação da avaliação e do monitoramento de impactos ambientais}

De acordo como as diretrizes legais previstas no Brasil, em caso de ocorrência de emergências com contaminação de áreas, os responsáveis, no caso os transportadores, os remetentes e os destinatários da carga, devem ser solidários à adoção de procedimentos para controlar e minimizar os impactos. Assim os responsáveis pelo transporte da carga sinistrada devem prover esforços nesta direção.

Grandes transportadoras possuem equipe de atendimento emergencial a acidentes. Outras podem contratar empresas especializadas em prestar estes serviços. Nestes casos, conforme previsto na Decisão de Diretoria no 103/2007/C/E, a CETESB por meio de suas diferentes atribuições e setores técnicos, além de acompanhar e orientar as ações de gestão, pode solicitar a emissão de relatórios de avaliação, documentando a ocorrência e as atividades de avaliação ambiental. Nestes relatórios, devem ser avaliados e descritos os impactos identificados, bem como as medidas de controle e mitigação adotadas.

Estes documentos servem para o órgão o ambiental avaliar se foram tomadas as medidas adequadas e determinar a solicitação de outras medidas de recuperação e monitoramento das áreas afetadas e do entorno.

Neste sentido, é importante que este relatório apresente as informações mais precisas possíveis, pois quanto mais dúvidas a respeito da efetividade das medidas, provavelmente mais informações serão solicitadas pelo corpo técnico da CETESB, como maior número de amostragens e freqüência num eventual monitoramento ambiental da área.

Há casos que devido a gravidade da ocorrência a CETESB é obrigada a imediatamente tomar ações emergenciais. Ela age também efetivamente na adoção de medidas de controle e mitigação em casos em que o responsável não é capaz de disponibilizar equipe para atendimento ambiental da ocorrência.

A CETESB também realiza relatórios de atendimento para controle interno e para subsidiar autos de infração ambientais a serem gerados para os responsáveis pelo transporte da carga perigosa.

Os tipos de impactos, abrangência e magnitude destes são levados em 
consideração para a determinação dos valores.

Deste modo, imagens aéreas geradas na avaliação da ocorrência e monitoramento imediato, podem auxiliar na geração de informações para esta série de documentos obrigatórios de registro e descrição do caráter ambiental da ocorrência.

Não apenas as imagens podem ser utilizadas, mas também representações visuais ou cartográficas obtidas através destas seriam úteis.

Uma vez que nesta etapa, as informações não necessitam ser geradas tão rapidamente, podem ser realizados procedimentos mais demorados, com vistas de obter informações mais precisas ou melhores representações dos impactos e características ambientais das áreas.

Além da determinação das áreas impactadas, é interessante que se conheça o uso do solo do entorno destas áreas, para o planejamento das medidas de remediação, recuperação e monitoramento da área. Como definido na avaliação de impactos ambientais em campo, imediata, após ocorrência do acidente, esta identificação de áreas atingidas e uso do solo pode ser feita por fotointerpretação.

Entretanto, nesta fase posterior, pode ser indicado o mapeamento de uso do solo através de classificações das imagens obtidas por VANT. "Um mapa de uso e cobertura da terra de um determinado território é um dos mais importantes para diversos estudos e aplicações porque faz a ligação entre os elementos físicos e sociais" (LOCH, 2006).

Para efetuar um mapeamento através de imagens é necessária a identificação, divisão e agrupamento (classificação) de classes correspondentes às existentes na superfície terrestre. Para isto existem diferentes métodos e técnicas, analógicas ou digitais.

A mais tradicional é através da fotointerpretação, já abordada, que pode proporcionar a delimitação de classes do uso do solo de forma analógica sobre papel ou em meio digital. Esta técnica pode ser considerada a mais importante, pois é através dela e do controle em campo que mesmo as classificações realizadas através do processamento digital das imagens podem ser avaliadas e otimizadas para atingirem o melhor resultado. "É preciso saber interpretar uma imagem, até mesmo para poder avaliar o resultado de uma classificação ou interpretação automática" (FLORENZANO, 2002).

O processamento digital "trata especificamente das técnicas utilizadas para 
identificar, extrair, condensar e realçar a informação de interesse para determinados fins, a partir de uma enorme quantidade de dados que usualmente compõem essas imagens" (CRÓSTA, 1992).

Existem diversas técnicas de processamento digital de imagens. Deve se buscar aquelas que são melhores de acordo com as características das imagens e de acordo com a aplicação. Assim, a escolha das técnicas e procedimentos do processamento digital das imagens é um dos pontos cruciais para determinação da qualidade das informações a serem obtidas de certa área.

Em específico para imagens de VANTs, em trabalho prévio a este, foram executados três diferentes métodos de classificação em imagens obtidas pelos equipamentos do VANT AGplane (anteriormente denominado A.R.A.R.A), da AGX, a fim de testar, avaliar e comparar seus resultados (LONGHITANO, 2006). Os métodos testados foram a fotointerpretação e vetorização sobre a imagem, por classificação digital supervisionada por máxima verossimilhança e por segmentação seguida de classificação supervisionada, respectivamente.

As imagens utilizadas foram obtidas com câmeras digitais de resoluções de 6 e 8 megapixels, sendo resoluções inferiores às câmaras atualmente embarcadas no AGplane. As imagens foram obtidas a alturas de 500 a $600 \mathrm{~m}$ de altura em relação ao solo, recobrindo áreas por foto, entre 10 e 15 ha aproximadamente. A resolução espacial destas imagens é de $13 \mathrm{~cm}$. Tratam-se, portanto, de imagens dentro das especificações determinadas previamente no item 4.1, e servem como referência para tecer algumas considerações sobre a aplicação destas para mapeamento de uso do solo e áreas atingidas por impactos ambientais.

Para o desenho da classificação por fotointerpretação foi adotado o software Autocad Map 2004, para a classificação supervisionada o software Ilwis 3.2 e para classificação utilizando-se de segmentação, foi empregado o Spring 4.3.1.

O método de classificação supervisionada aplicado foi o de MaxLikehood (máxima verossimilhança), que utiliza parâmetros estatísticos e é o método mais comum que considera a ponderação das distâncias das médias dos níveis digitais das classes (CRÓSTA, 1993).

A segmentação foi obtida por crescimento de regiões. O classificado escolhido foi o Battacharya que mede a distância média entre as distribuições de probabilidades de classes espectrais (INPE, 2006). 
Para cada uma das classificações foram associadas cores às classes criadas, as quais apresentam maior eficácia para manifestações zonais (MARTINELLI, 2003), onde a "correspondência gráfica entre o fenômeno no terreno e a representação cartográfica é realizada por meio de um colorido" (LIBAULT, 1975).

De acordo como os resultados obtidos em Longhitano (2006), por fotointerpretação e delimitação de classes via vetorização, as classes foram delimitadas com limites bem definidos e se referindo às tipologias de uso da terra predominantes. A falta de normalização das tonalidades das imagens é menos sentida, pois a interpretação é visual. Apresentou-se como um método consistente, porém é mais trabalhoso e demorado para áreas maiores e que apresentem muitas classes distintas, de formas irregulares e divididas em áreas muito pequenas.

Os resultados do método pixel a pixel por máxima verossimilhança foram interessantes, mas apresentaram algumas áreas de confusão. O método se destacou pela agilidade e maior leque de opções de classificação digital. Troncos de árvores secas, por exemplo, foram bem detectados.

Por segmentação, os resultados foram melhores do que os obtidos pela máxima verossimilhança. As classes foram corretamente associadas e bem delimitadas em sua maioria. Necessita de tempo um pouco maior de processamento, por possuir mais procedimentos que a anterior realizada pixel a pixel.

Em Longhitano, (2005a) também foram efetuadas classificações de imagens de VANTs por meio de método não supervisionado (clusters), entretanto, os resultados foram inferiores aos das classificações supervisionadas.

As imagens das Figuras 4.2.1.8-1 e 3, apresentadas a seguir, demonstram que houve incêndio há algum tempo em certas glebas vegetadas, com parcela da vegetação queimada ou seca (classe Vegetação predominantemente seca ou queimada - em amarelo), o que pode ser identificado por áreas com troncos de eucalipto e mata natural que estão secos, sem folhagens e dossel.

Incêndios podem ocorrer em acidentes com cargas inflamáveis, gerando situações de vegetação queimada, semelhantes a esta. Desta forma, observa-se que imagens deste tipo e classificações digitais podem ser utilizadas para avaliação deste impacto. A partir da classificação obtida pode ser possível até a contagem e indivíduos arbóreos secos de forma automática.

Na Figura 4.2.1.8-4 que apresenta a classificação de uso do solo da imagem da 
Figura 4.2.1.8-3, observa-se, além de vegetação seca, também identificada, áreas úmidas (classe Solo exposto encharcado). Esta condição, embora natural na área imageada, assemelha-se a condições de solo atingido por derramamento de substâncias líquidas. Outro exemplo é a representação temática (Figura 4.2.1.8-6) da classificação da imagem apresentada na Figura 4.2.1.4-1 do presente estudo, onde pode ser verificada uma mancha de área úmida (em marrom e bem delimitada na imagem classificada), gerada por derramamento ou vazamento de água, em local próximo a uma caixa d'água.

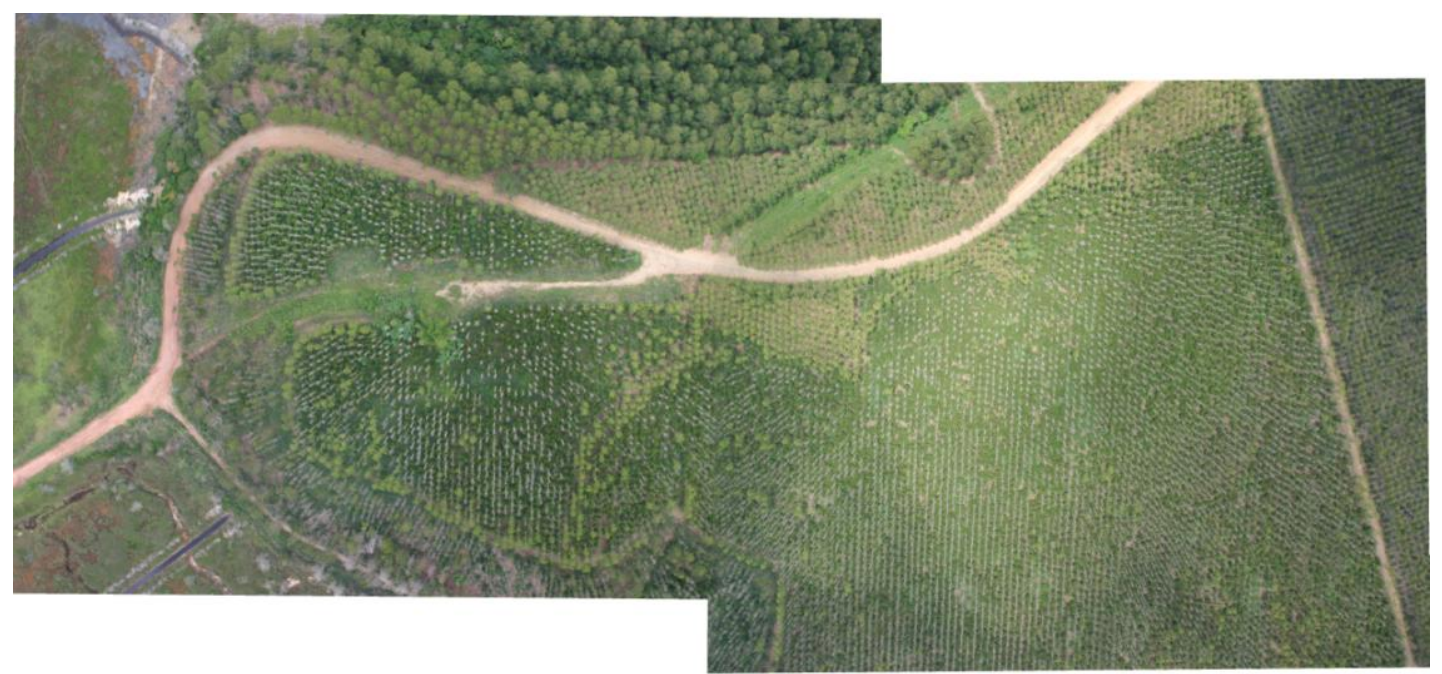

Figura 4.2.1.8-1: Mosaico da área teste 1- Pixel da imagem original corresponde a cerca de $13 \times 13$ $\mathrm{cm}$ em solo (LONGHITANO, 2006).

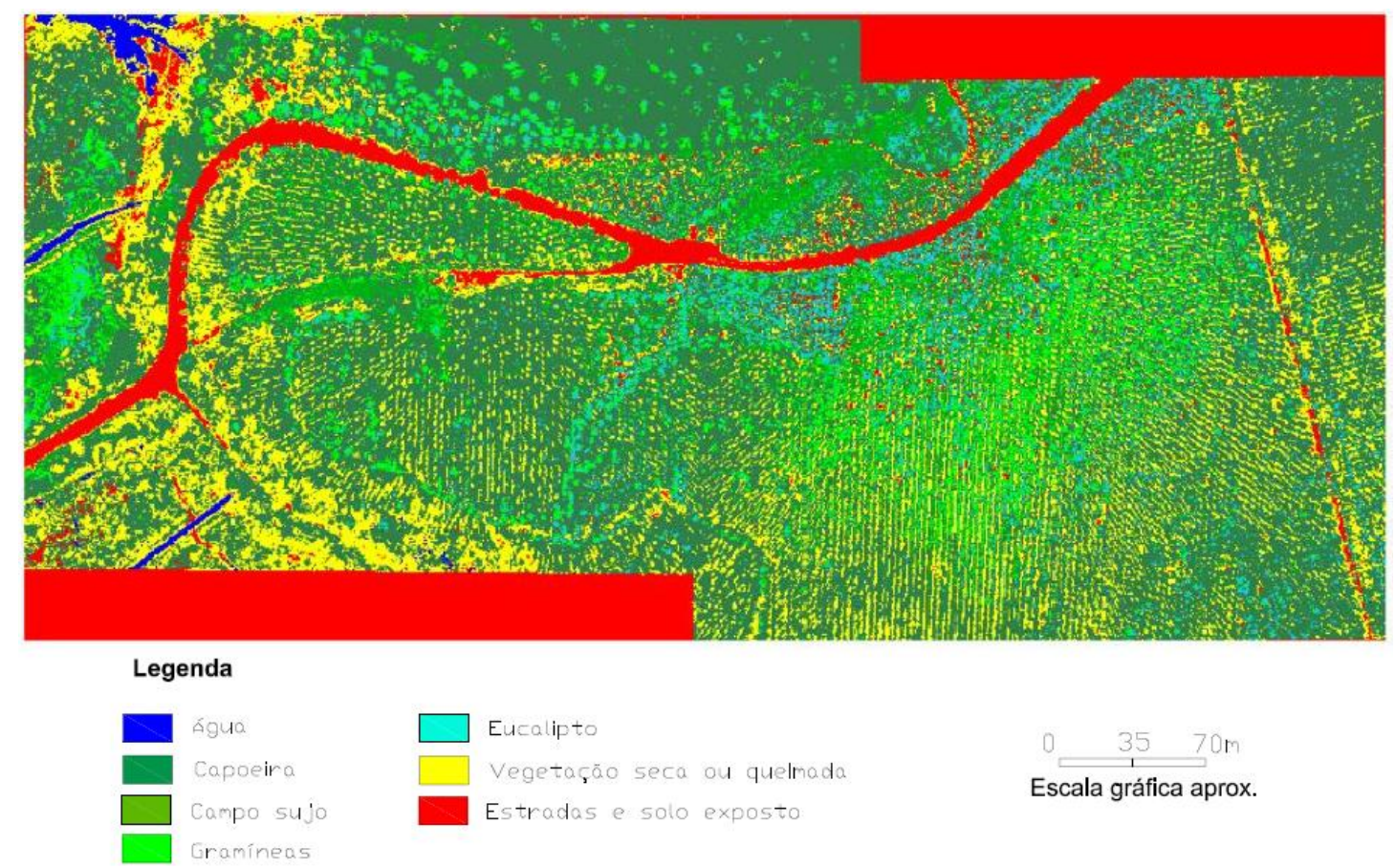

Figura 4.2.1.8-2: Classificação por máxima verossimilhança da área 1. (LONGHITANO, 2006). 


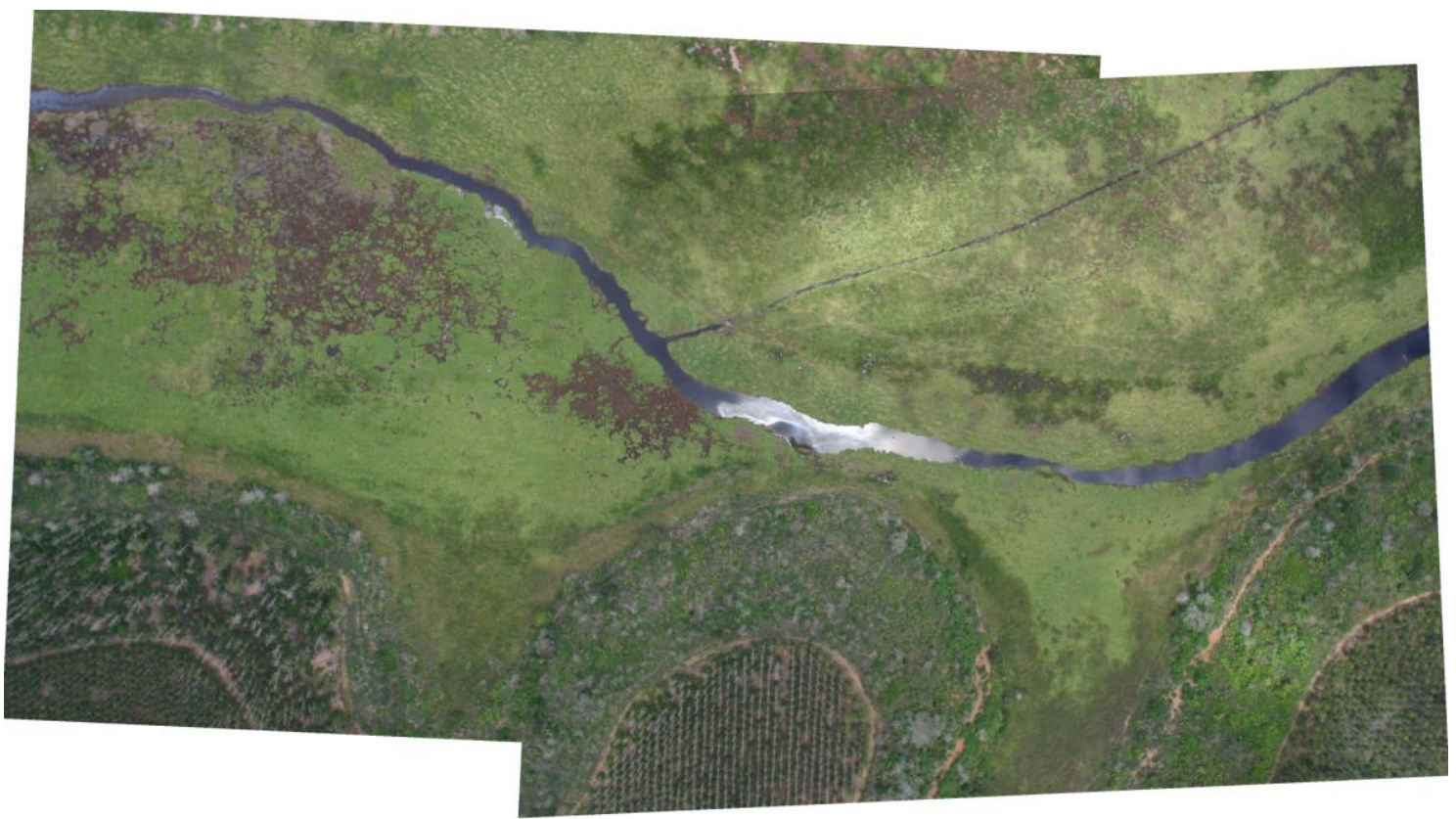

Figura 4.2.1.8-3: Mosaico da área teste 2- Pixel da imagem original corresponde a cerca de $13 \mathrm{x}$ $13 \mathrm{~cm}$ em solo. (LONGHITANO, 2006).

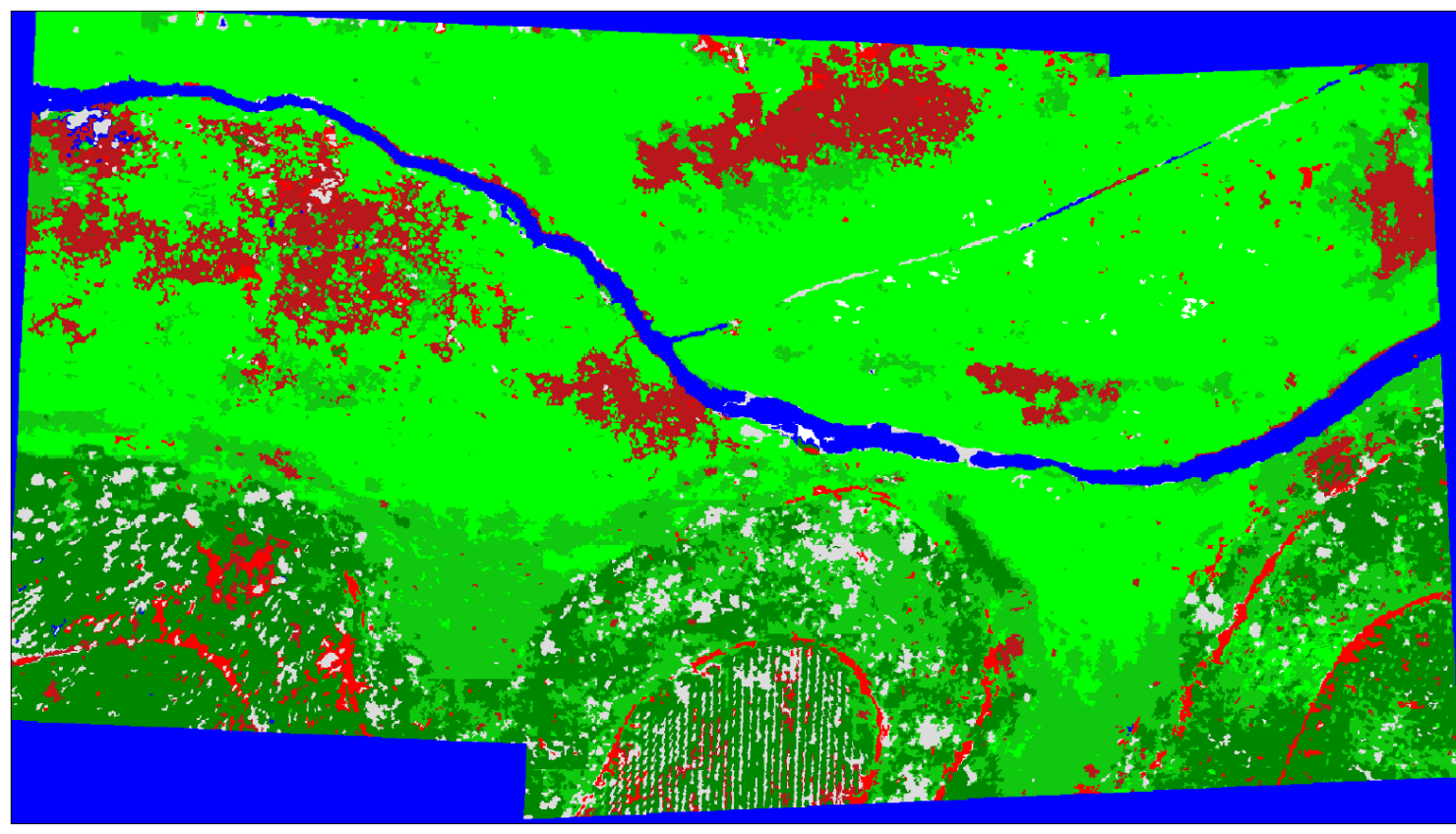

Legenda

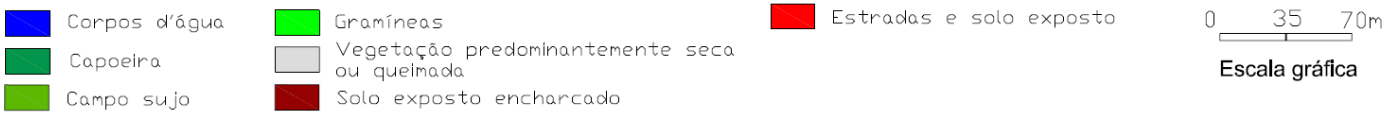

Figura 4.2.1.8-4: Classificação por segmentação da área 2. (LONGHITANO, 2006). 




Figura 4.2.2.8-5: Resultado da segmentação da imagem da área 3. (LONGHITANO, 2006).
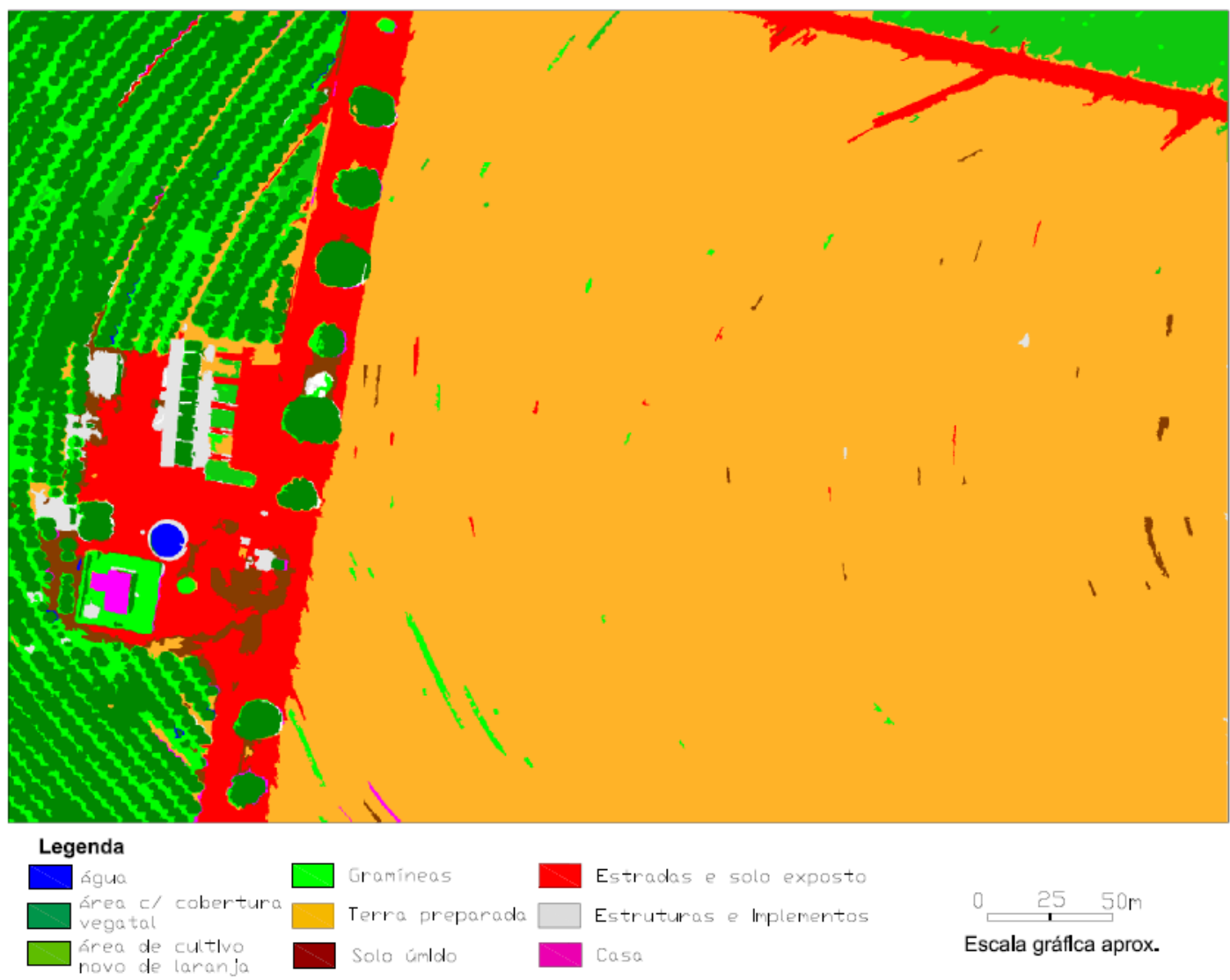

Figura 4.2.2.8-6: Classificação por segmentação - área 3. (LONGHITANO, 2006). 
Através destas classificações obtidas em Longhitano (2006), demonstra-se, por corolário, que através de imagens obtidas por VANTs, áreas com vegetação seca e áreas com líquidos derramados sobre o solo podem ser identificadas e classificadas. Estes padrões identificados são semelhantes a impactos que podem ser gerados por acidentes com transporte de cargas perigosas.

Considerando-se as especificidades de imagens obtidas por sensores embarcados em VANTs, a enorme diversidade de sensores que podem ser embarcados e que a tecnologia é relativamente recente, devem ser testados diferentes métodos de classificação além dos descritos, dependendo das características das imagens e objetivos do classificador. Pode se afirmar que comparado ao sensoriamento remoto de nível aéreo convencional e orbital, as imagens obtidas por sensores de VANTs ainda apresentam poucos estudos de técnicas e métodos de processamento digital específicos.

Há de se considerar que futuramente, se consolidada a tecnologia para a aplicação estudada, outros testes de processamento e classificação digital de imagens obtidas por VANTs com as características de altíssima resolução espacial com detecção de faixas do visível e do infravermelho podem ser realizados e apontar formas e métodos mais eficientes para detecção de áreas.

Para aplicação, de acordo as características de altíssima resolução espacial das imagens a serem obtidas, indica-se atualmente a realização de classificações voltadas a objetos.

As elevadas resoluções (dos novos sistemas sensores) exigem um novo tipo de processamento, que ultrapassa a observação de pixels unitários. No processamento digital de dados de sensoriamento remoto está ocorrendo uma grande revolução. Ao invés de classificar os pixels individualmente quanto às suas características espectrais, os novos procedimentos consideram a delimitação de objetos homogêneos como a base para o processamento posterior. (BLASCHKE; GLASSER e LANG, 2005 apud BLASCHKE e KUX, 2005)

A segmentação e posterior classificação podem ser consideradas procedimentos de classificação orientada aos objetos simplificada, conforme realizado em Longhitano (2006), e que apresentou bons resultados para as imagens geradas por um VANT. Pesquisas recentes, por exemplo, têm destacado o emprego do software Definiens para classificação orientada a objetos de imagens de alta resolução espacial, como em Nóbrega (2007) e Pinho et al (2007).

A partir dos dados levantados em campo no atendimento da ocorrência, através de pesquisa em dados secundários e trabalho de gabinete, onde as imagens de 
sensoriamento remoto realizado por VANT podem ser empregadas para obtenção e consolidação de informações ambientais, conforme se demonstrou, deve ser realizada uma avaliação de impactos ambientais.

A magnitude do impacto e o tempo de recuperação do ambiente estão associados a muitos fatores como o tipo e quantidade do produto envolvido, as características físicas do ambiente, as comunidades biológicas incluindo suas características reprodutivas e a presença de espécies sensíveis, condições climáticas, época do ano e o procedimento de limpeza aplicado. (LOPES, 2009)

Para cada um dos impactos identificados, deve ser realizada a avaliação através de critérios (SÁNCHEZ, 2008), os quais devem auxiliar na mensuração qualitativa destes e na determinação das ações de gestão que devem ser tomadas para cada um deles. Estes parâmetros normalmente são utilizados para previsão de impactos, entretanto, entende-se que alguns podem ser utilizados para avaliação impactos ocorridos.

Dentre os critérios de avaliação de importância de impactos ambientais definidos por Erickson (1994) apud Sánchez (2008), por Sánchez (2008), pela resolução CONAMA 1/86 e por Ampla (2008), considerando-se os potenciais impactos causados por acidentes com transporte de cargas perigosas, podem ser aplicados os seguintes: reversibilidade, abrangência, relevância, magnitude, duração, ocorrência, incidência e prazo de ocorrência

Com o uso dos critérios elencados, a empresa responsável pela elaboração do relatório, ou a CETESB, pode avaliar a importância dos impactos ambientais ocasionados pelo acidente com maior clareza, o que deverá subsidiar também a escolha e decisão pelas possíveis medidas de monitoramento, remediação e reabilitação da área, além das medidas de compensação dos impactos.

Em geral, a descrição das áreas atingidas e do entorno é realizada por meio de texto, acompanhada por vezes por fotos e croquis ilustrativos (informação verbal) ${ }^{7}$. As fotografias aéreas iriam melhorar e facilitar esta descrição.

(...) a carência de dados estatísticos sobre acidentes no transporte rodoviário de produtos perigosos no âmbito nacional constitui fator limitante para o diagnóstico e o planejamento de ações corretivas e preventivas. Isso significa que, sem indicativos da sinistralidade desse segmento de transporte e suas eventuais conseqüências ao homem e ao meio ambiente, corre-se o risco de mensurar e aplicar recursos de forma equivocada, dificultando o desenvolvimento de ações prioritárias, principalmente das políticas públicas voltadas ao tema 'Transporte Rodoviário de Produtos Perigosos. (TEIXEIRA, 2005)

\footnotetext{
${ }^{7}$ Dados fornecidos pelo técnico Marco Antonio Lainha do Setor de Operação de Emergências da CETESB em junho de 2010.
} 
A citação acima demonstra a importância da geração de dados de impactos ambientais das ocorrências.

Assim como para esta primeira avaliação de impactos ambientais, as imagens aéreas serviriam para documentar posteriormente as ações de gestão. Poderiam ser utilizadas na composição de relatórios de acompanhamento da adoção das ações de gestão.

As imagens aéreas poderiam ser utilizadas deste modo, para obtenção de um quadro evolutivo da área impactada e entorno, considerando-se a adoção das ações de gestão. Entretanto, nesta fase de monitoramento, para composição de relatórios de diversos de avaliação ou de monitoramento, as imagens teriam utilidade apenas quando há intervenções que sejam observáveis em superfície, como remoção e remediação de solos ou ainda recomposição e enriquecimento vegetal. Caso estas não ocorram, as informações relevantes são obtidas através de análises laboratoriais de águas superficiais, subterrâneas ou do solo em relação à concentração de parâmetros físico-químicos alteráveis pela carga acidentada, conforme anteriormente afirmado.

\subsubsection{Viabilidade legal}

Por coabitar o espaço aéreo utilizado por aeronaves tripuladas e poder sobrevoar áreas povoadas, a atividade de VANTs deve ser regulamentada, uma vez que ela pode provocar sérios riscos e danos à aviação e à população. Seu constante crescimento tem provocado pressão sobre os órgãos responsáveis para certificação da atividade.

Encontra-se em discussão as diretrizes e regras para certificação legal da atividade em diversos locais do mundo. Na Europa e em alguns países como, Canadá, E.U.A. e Austrália, a atividade já possui regulamentação.

No Brasil, levantamentos aerofotogramétricos realizados através de aviões convencionais tripulados dependem de autorização do DAC - Departamento de Aviação Civil, e o próprio DAC realizou alguns esforços em avançar na questão de falta de regulamentação da atividade de VANTs, uma vez que tem ocorrido aumento 
de instituições de pesquisas e empresas brasileiras interessadas nestes. Recentemente, o DCEA - Departamento de Controle do Espaço Aéreo Brasileiro apresentou o primeiro documento que prevê e regulamenta a atividade no país. A Circular de Informações Aeronáuticas (AIC) 29/09 de 19/11/2009 tem por finalidade, apresentar as informações necessárias para o uso de veículos aéreos não tripulados no espaço aéreo brasileiro e reconhece a aplicação da tecnologia no Brasil.

\begin{abstract}
Já está em curso, na maioria dos países do mundo, um aumento gradual e significativo do uso de VANT, tanto no meio civil, quanto no militar, em especial devido às suas inúmeras funções e aplicabilidades. O Brasil, com as suas dimensões continentais e características geográficas, apresenta um grande potencial de aplicação para VANT, atividade essa já em andamento e com sua intensidade crescendo notoriamente.
\end{abstract}

Esta circular determina provisoriamente, enquanto não há legislação e regulamentação específica, que para operação, VANTs no Brasil necessitam de uma autorização NOTAM, a ser emitida pelos órgãos da Aviação Civil e Militar. O item 3.4 da AIC 29/09 determina que para autorização NOTAM, deve ser analisado caso a caso a solicitação e impõe algumas diretrizes:

3.4 Considerando as reais e futuras necessidades do uso do Espaço Aéreo Brasileiro por VANT e o fato da OACI não ter publicado legislação que aborde o emprego desses aparelhos em espaço aéreo compartilhado, as necessidades de voo de VANT serão analisadas caso a caso, em função das particularidades do pedido e levando em conta todos os aspectos concernentes à segurança dos usuários do SISCEAB, entre eles:

a) a operação de qualquer tipo de VANT não deverá aumentar o risco para pessoas e propriedades (no ar ou no solo);

b) a garantia de, pelo menos, o mesmo padrão de segurança exigido para as aeronaves tripuladas;

c) a proibição do voo sobre cidades, povoados, lugares habitados ou sobre grupo de pessoas ao ar livre;

d) os VANT deverão se adequar às regras e sistemas existentes, e não o ATM se ajustar às necessidades e equipamentos em operação; $e$

e) o voo somente poderá ocorrer em área restrita (espaço aéreo segregado), definida por NOTAM e em condições visuais. Cabe ressaltar o impedimento para a autorização de voos de VANT em espaço aéreo compartilhado com aeronaves tripuladas.

De acordo esta circular e informações obtidas com algumas empresas que operam VANTs de uso civil no Brasil, não têm sido autorizados vôos sobre áreas de segurança e áreas habitadas. Além disso, para obtenção da autorização, a demora média é de quarenta dias após o envio da solicitação ao DAC, o que tem se apresentado com um grande empecilho para estas empresas (FREITAS e COTTET, 2010).

Como rodovias são áreas ocupadas por definição, atualmente, a autorização de vôos sobre estas áreas seria dificultada. Vôos sobre acidentes ocorridos em áreas 
urbanas, independentemente do tipo e porte do VANT, certamente não seriam autorizados.

O item 3.9 desta AIC, determina:

3.9 No caso de utilização de VANT por organizações militares e órgãos públicos de segurança, como Polícias e Receita Federal, as restrições descritas no item 3.4 poderão ser reavaliadas pelo Órgão Regional e, subsequentemente, pelo DECEA, considerando as peculiaridades da missão requerida. No entanto, todos os outros itens deverão ser observados, em especial com relação ao trâmite e prazo dos pedidos.

A interpretação deste item pode ser utilizada como um caminho legal para o uso de VANTs para sensoriamento remoto em situações emergenciais e de interesse público, mas ainda assim não há garantias desta aplicação ser autorizada atualmente, principalmente se a área a ser sobrevoada for urbana.

Este quadro somente poderá ser alterado quando for gerada uma resolução mais completa que regulamente a atividade de VANTs no Brasil.

Neste sentido, esforços devem ser providos para apresentar os possíveis benefícios técnicos que os VANTs podem trazer na avaliação e monitoramento ambiental de situações emergenciais, para que a regulamentação considere estas opções.

A recomendação por VANTs do tipo Mini e Close Range para a aplicação foco da presente pesquisa envolve os aspectos técnicos antes mencionados, mas a opção por estes proporciona também menores restrições legais para aplicação, uma vez que são equipamentos que devido ao porte e alcance, apresentam menores potenciais de causar acidentes graves, caso colidam em solo ou em ar.

A operação a pequenas alturas em relação ao solo, de poucas centenas de metros também pode auxiliar como argumento de segurança, uma vez que aeronaves tripuladas normalmente voam em altitudes maiores.

\subsubsection{Viabilidade econômica}

Além das características técnicas das imagens geradas por VANTs, para a viabilidade de aplicação, deve ser levantado o custo para aquisição das imagens. Há duas opções de operação dos VANTs para o uso em avaliação de impactos ambientais em acidentes com cargas perigosas. O órgão ambiental responsável pelo atendimento emergencial em caso de acidentes com transportes de cargas 
perigosas, ou a empresa privada que realiza estes atendimentos, poderia adquirir um ou mais VANTs para a aplicação e ter em seu quadro técnico, profissionais habilitados para operá-los. Esta opção do ponto de vista técnico é a mais indicada.

Outra opção seria a contratação dos serviços de empresa especializada em obtenção de imagens aéreas por VANT em cada acidente.

No primeiro caso, a entidade interessada nesta aplicação deveria realizar um investimento inicial para compra de um VANT. Para a aquisição de um VANT AGplane que tenha as características sugeridas neste estudo, o valor é de aproximadamente $\mathrm{R} \$ 90.000,00$.

A própria AGX está desenvolvendo um novo VANT do tipo Mini, elétrico e de baixo custo, o qual deverá apresentar características adequadas para aplicação, inclusive com lançamento manual. Este equipamento deverá estar comercialmente a disposição em setembro de 2010, a valores de aproximadamente $R \$ 30.000,00$ (FREITAS e COTTET, 2010).

Os custos operacionais envolveriam o pagamento de salário de quatro operadores da tecnologia, que deveriam se revezar em duplas em esquema de plantão para atender a emergências, e com possíveis manutenções do equipamento. O custo operacional dos equipamentos em si é muito reduzido. Os gastos de operação de um VANT são baseados praticamente na locomoção até o local e no consumo de combustível da aeronave, que é baixo. As imagens são geradas praticamente em todos os VANTs atuais em meio digital, que dispensa filmes e gastos com a revelação.

Para a avaliação da segunda opção, foi solicitada uma informação de valor à empresa AGX, que atualmente opera VANTs comercialmente no setor civil e oferece o serviço de sensoriamento remoto com o AGplane. O valor seria por volta $\mathrm{R} \$ 600,00$ por hora de vôo para realização do serviço de obtenção das imagens, excluindo-se os gastos com o deslocamento para área, mas que são realizados por um automóvel, portanto não são altos (informação verbal) ${ }^{8}$.

O valor apresentado serve apenas como uma referência para conhecimento da ordem de grandeza dos custos. Outro fato que deve ser lembrado, é que esta empresa não apresenta corpo técnico de plantão e a legislação não permite vôos sem autorização. Trata-se de um orçamento para um serviço hipotético.

\footnotetext{
${ }^{8}$ Valores estimados, fornecidos pelo diretor da AGX tecnologia, Adriano Kancelkis, em junho de 2010.
} 
Para empresas ou órgãos ambientais que apresentam grande volume de atendimento a ocorrências de acidentes, a primeira opção é mais viável economicamente. Caso contrário, a segunda é mais indicada em relação à economia.

De qualquer forma, os custos não são proibitivos, sendo bastante atraentes para os possíveis interessados. A avaliação de impactos ambientais e principalmente a adoção de ações de gestão, podem envolver grandes montantes financeiros.

A avaliação de impactos ambientais exige técnicos especializados, que atendam em plantão, envolvendo pagamentos adicionais de horas extras de trabalho, além de equipamentos de segurança e sensores específicos para identificação de contaminações. Como exemplos destes equipamentos, temos detectores de gás sulfídrico, amônia, cloro, monóxido de carbono e fotoionizador (FERRANTE et al, 2010).

Para efeito comparativo, uma empresa pode ser autuada pelos danos ambientais em valores de 4 (quatro) a 4.000 .000 (quatro milhões) de vezes o valor da Unidade Fiscal do Estado de São Paulo - UFESP ${ }^{9}$, de acordo com a Lei Estadual (São Paulo) $n^{\circ} 13577$. Assim as multas podem chegar a valores muito altos. Segundo a lei, os valores dependem da intensidade do dano, efetivo ou potencial, das circunstâncias atenuantes ou agravantes e dos antecedentes do infrator.

A adoção de medidas de remediação e reabilitação de áreas também podem envolver facilmente valores significativos.

No monitoramento de águas subterrâneas, é necessária a abertura de poços e amostragem de água periódica. O valor para construção de cada poço varia de acordo com a profundidade, pois necessita chegar até um metro abaixo do nível de água do lençol freático. Mas para um poço de poucos metros de profundidade, o valor é de aproximadamente $R \$ 1.000,00$. Cada amostragem e análise de água subterrânea tem este custo aproximado também, de $\mathrm{R} \$ 1.000,00^{10}$. As análises de águas superficiais e de solos também apresentam valores de mesma ordem. Para elaboração de relatórios e acompanhamento destes dados, também há custos que dependem da quantidade de pontos de amostragem. Assim, para um acompanhamento periódico e durante alguns anos de uma área atingida, são gastas quantias que podem chegar a valores altos também. Caso estes pontos sejam

\footnotetext{
${ }^{9}$ O valor da UFESP é de R\$16,42 em junho de 2010.

${ }^{10}$ Valores estimados, providos pela BTX - geologia e meio ambiente.
} 
otimizados em relação à quantidade e localização, estes custos podem sofrer reduções significativas.

Deste modo, a quantia a ser investida na tecnologia de VANTs para sensoriamento remoto é relativamente pequena para o universo em análise e para os possíveis interessados. Ela pode ser justificada pelas melhorias técnicas e de segurança que pode trazer.

Além disso, considerando-se todas as etapas envolvidas na avaliação de impactos ambientais e recuperação de áreas atingidas, o uso de VANTs para sensoriamento remoto poderia até trazer economia de recursos, uma vez que melhor e mais rapidamente avaliado um impacto ambiental, as ações de gestão podem ser determinadas com maior velocidade e melhor ajustadas ao caso, visando a eficiência destas e a redução dos impactos ambientais. Reduzidos os impactos, as autuações ambientais tendem a serem menores e os custos com a recuperação e monitoramento das áreas também.

A possibilidade de otimizar e reduzir o número de pontos de monitoramento da qualidade das águas superficiais e subterrâneas e do solo, também poderia trazer vantagens econômicas a médio e longo prazo.

\subsubsection{Comparação entre VANTs e outras plataformas de sensoriamento remoto}

\subsubsection{Parâmetros técnicos}

\subsection{Resolução temporal}

VANTs em geral apresentam maior flexibilidade de resolução temporal que o sensoriamento remoto de nível orbital, ou realizado através da aerofotogrametria convencional, pois não necessitam de dias sem nebulosidade para a realização de missões e não dependem da órbita, como no caso do primeiro, ou de aeroportos, caso da aerofotogrametria convencional. Mas deve ser novamente frisado que no Brasil, a operação de VANTs depende de autorização que leva em média 40 dias para ser obtida, portanto, embora tecnicamente flexível, esta plataforma de 
sensoriamento atualmente encontra sua resolução temporal e disponibilidade vinculadas à obtenção desta autorização. Deve ainda ser mencionado, que embora mais flexível quanto à resolução temporal de uma mesma área, a locomoção de um VANT com as especificações definidas no estudo não se dá na mesma velocidade que a de um avião de porte normal ou que as das órbitas de satélites. Isto dificulta a obtenção de imagens de grandes áreas ou áreas distantes entre si, mas não é o caso da aplicação em vista.

Há constelações de satélites atualmente, como do RapidEye, que apresentam freqüência de revisita muito boa, da ordem de horas. Entretanto, dependem das condições atmosféricas da localidade para gerar boas imagens e estas também não possuem resolução espacial suficiente para a aplicação.

Do ponto de vista prático, para obtenção de imagens de programação dos satélites GeoEye-I e WordView-II que apresentam as resoluções espaciais melhores para o setor civil, uma vez encomendadas, o prazo para obtenção de imagens é de 40 dias, sem garantia de $100 \%$ de ausência de nuvens.

Imagens ou fotografias aéreas convencionais, obtidas por equipamentos profissionais e empresas de aerofotogrametria, dependem de autorização de vôo, que não é imediata. Depende de autorização do DAC.

Deste modo, ambas opções descritas são inviáveis para a aplicação desejada.

Uma opção que pode apresentar a mesma flexibilidade que um VANT, é a contratação de helicóptero para obtenção de imagens aéreas. Este precisaria estar de plantão e sempre preparado para execução do serviço, assim como o VANT. O principal limitante é que os custos para isso são relativamente elevados, como será demonstrado.

Um aspecto positivo das imagens obtidas com VANTs é que a atividade de trabalho de campo pode ser integrada/realizada juntamente com a missão aerofotogramétrica, com isto, é possível dar mais ênfase na captura de imagens de certas áreas de interesse, ou então, a partir das imagens vistas em tempo real, ir aos locais que chamem a atenção por algum aspecto. As condições observadas em campo também seriam exatamente as mesmas das registradas nas imagens. Estes aspectos são interessantes para aplicação proposta. 


\subsection{Resolução espacial e área de recobrimento}

Considerando-se que para a aplicação desejada seja minimamente necessária uma câmera digital convencional e que os VANTs de sensoriamento remoto mais simples embarcam sensores deste tipo, serão realizadas algumas comparações com base nestas.

As imagens de satélites apresentam resoluções espaciais para uso civil de no máximo 0,5m atualmente, para os satélites WorldView-II e GeoEye-I. As áreas

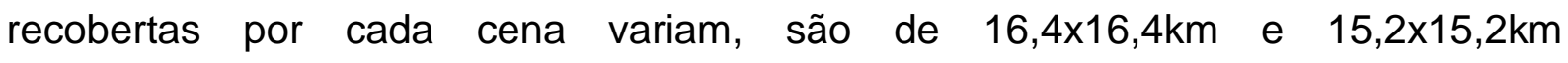
respectivamente. Tratam-se áreas relativamente grandes, se comparadas com as imagens obtidas em nível aéreo.

Para comparação de imagens de VANTs com a fotogrametria convencional, é necessária uma estimativa baseada na representação da área real no solo por pixel. A resolução de uma fotografia aérea obtida por uma câmara aerofotogramétrica convencional com negativo de 23 x 23cm é estimada em 85 Megapixels (RUY et al., 2005).

A figura 4.2.4.1.2-1 apresenta uma comparação entre a área coberta por uma câmera aerofotogramétrica convencional analógica e as áreas cobertas por diferentes câmeras digitais, para um mesmo tamanho de pixel em solo.

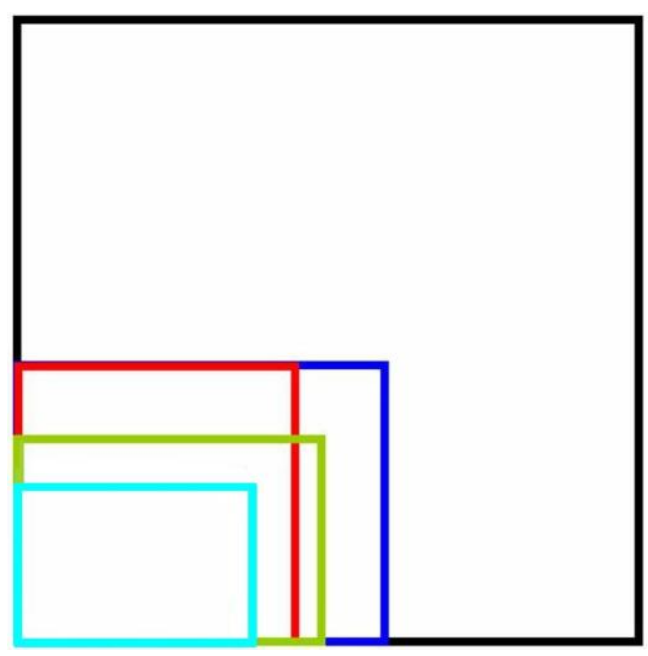

Analógica $230 \times 230 \mathrm{~mm}-$ (85 Megapixels)

Phase One P25 - (5440 x $4080=22$ Mpix $)$

Kodak Pro 14n - $(4080 \times 4080=16$ Mpix $)$

Phase One P20 - (4500 x $3000=14$ Mpix $)$

Canon EOS 350D - (3456 x 2304= 8 Mpix $)$

Figura 4.2.4.1.2-1: Comparação entre áreas cobertas por diferentes câmeras Adaptado de RUY et al., 2005

Segundo Ruy et al (2005), "com os modelos de câmaras digitais disponíveis no mercado, a área de cobertura no terreno obtida pelas câmaras analógicas convencionais é bem superior às câmaras digitais. Neste sentido, o número de imagens e pontos de apoio necessários ao projeto com câmaras digitais é bem superior. Em contrapartida, a tecnologia digital 
oferece a vantagem da rapidez na obtenção dos dados digitais, que agiliza o projeto fotogramétrico e reduz os custos. Mesmo com o aspecto da resolução limitada, as vantagens de utilização das câmaras digitais sobressaem em algumas aplicações que requeiram resposta rápida, como monitoramento ambiental, e em projetos de estradas e linhas de transmissão, onde são realizadas faixas isoladas".

Fica clara a importância das técnicas de confecção de mosaicos, georreferenciamento e correção geométrica para a aplicação deste tipo de imagens em áreas maiores, pois estas influenciariam fortemente no tempo de execução de um mapeamento e na qualidade geométrica do produto final.

Para áreas pequenas, da ordem de até centenas de hectares, a serem recobertas por sensoriamento remoto, como é o caso de áreas para aplicação aqui estudada, entretanto, as imagens geradas por VANTs não apresentam estas necessidades e podem apresentar resoluções espaciais altíssimas.

A tabela 4.2.4.1.2-1 expressa os tamanhos de pixels em solo e área abrangida por fotografia para aquisição em diferentes alturas para uma Câmera Canon EOS350D de apenas 8 megapixels (atualmente há celulares com câmeras com resoluções semelhantes), sensor de tamanho 22,2 por 14,8mm, com emprego de distância focal de $28 \mathrm{~mm}$.

Tabela 4.2.4.1.2-1: Tamanho de pixel e área imageada para diferentes alturas de vôo - Distância focal de 28mm. (AGX TECNOLOGIA org LONGHITANO, 2010)

\begin{tabular}{|c|c|c|c|c|}
\hline \multirow{2}{*}{ Altura (m) } & \multirow{2}{*}{ Pixel (cm) } & \multicolumn{2}{|c|}{ Tamanho da Projeção no Solo (m) } & Área Imageada (ha) \\
& & $\mathbf{X}$ & $\mathbf{Y}$ & \\
\hline 50 & 1,15 & 39,64 & 26,43 & 0,10 \\
100 & 2,29 & 79,29 & 52,86 & 0,42 \\
200 & 4,59 & 158,57 & 105,71 & 1,68 \\
300 & 6,88 & 237,86 & 158,57 & 3,77 \\
500 & 11,47 & 396,43 & 264,29 & 10,48 \\
800 & 18,35 & 634,29 & 422,86 & 26,82 \\
1000 & 22,94 & 792,86 & 528,57 & 41,91 \\
1500 & 34,41 & 1189,29 & 792,86 & 94,29 \\
2000 & 45,88 & 1585,71 & 1057,14 & 167,63 \\
2500 & 57,35 & 1982,14 & 1321,43 & 261,93 \\
3000 & 68,82 & 2378,57 & 1585,71 & 377,17 \\
\hline
\end{tabular}

Conclui-se que o tamanho da área imageada por uma fotografia digital de pequeno formato é bem menor do que a imageada por câmeras aerofotogramétricas e sensores de satélites, necessitando de muito mais imagens para cobrir uma mesma 
área, além da confecção do mosaico desta, sendo que esta característica torna o uso inadequado para certas aplicações

Entretanto, para áreas pequenas, da ordem de até algumas centenas de hectares, VANTs mesmo equipados com meras câmeras digitais, podem gerar imagens com resoluções espaciais altíssimas, inferiores a $1 \mathrm{~cm}$, dependendo da resolução da câmera e da altura do vôo.

A opção de gerar imagens aéreas por helicóptero pode ser considerada com os mesmos parâmetros de resolução espacial descritos para um VANT, pois em geral, este serviço é realizado com câmeras digitais convencionais, inclusive muitas vezes carregadas e disparadas de forma manual.

\subsection{Resolução espectral}

A resolução espectral de sensores aerotransportados varia muito. Pode captar apenas imagens pancromáticas ou hiperespectrais, como permite o sensor CASI 1500. Sensores laser (LIDAR) e SARs também podem ser utilizados.

A resolução espectral de câmeras digitais que geram imagens apenas na região do visível é muito menor se comparada com o sensor mencionado.

Se comparada com os sensores de satélites de recursos terrestres, esta também será menor.

Mesmo os satélites de alta resolução espacial apresentam de 4 a 8 bandas espectrais, envolvendo a região do visível e do infra-vermelho, enquanto que o sensor da câmera digital registra apenas as bandas RGB - red, green e blue.

Com mais bandas seria possível detectar melhor as diferentes substâncias sobre a superfície do solo ou da água e também variações destas.

Entretanto, a análise destas informações requer profissionais capacitados e maior tempo de análise e processamento das informações. A altíssima resolução espacial, como anteriormente exposto, também contribui na identificação dos alvos sobre a superfície terrestre em contrapartida à baixa resolução espectral. Desta forma, para a aplicação emergencial, as informações de mais regiões além do visível e do 
infravermelho próximo, não apresentam custo-benefício a princípio interessante para o uso estudado.

\subsection{Resolução radiométrica}

A resolução radiométrica de câmeras convencionais digitais é normalmente de 8 bits.

A resolução dos sensores orbitais e aerotransportados mais recentes chega a 11 bits.

Embora a resolução radiométrica seja importante para detectar variações mais tênues da resposta espectral de alvos, a resolução das câmeras convencionais digitais é boa e não constitui fator limitante para a aplicação em avaliação de impactos ambientais. Além disso, a proximidade com os alvos no caso dos VANTs, permite que a energia eletromagnética chegue com maior intensidade aos sensores aerotransportados, que podem registrar a variação da intensidade desta energia com maiores contrastes, se comparado ao sensoriamento de nível orbital.

\subsection{Qualidade geométrica}

VANTs geralmente possuem menor estabilidade quanto a processos atmosféricos por possuírem massa reduzida, ficando mais suscetíveis a turbulências. Com isso normalmente há maior variação da angulação para a obtenção de imagens aéreas, o que compromete a qualidade geométrica das imagens.

Há distorção geométrica muito maior também em imagens obtidas em câmeras digitais de pequeno formato, do que as obtidas por câmeras métricas e sensores de satélites. Câmeras de pequeno formato normalmente não são calibradas e por isso não têm determinados parâmetros como "valor de distância focal de grande precisão, posição do ponto principal com relação às marcas fiduciais, distorção radial e tangencial da lente e posição relativa das, ou da distância entre as marcas fiduciais" (DISPERATI, 1995). 
Entretanto, para a aplicação desejada, os dados geométricos a serem extraídos não são muito importantes, predominando a obtenção de informações temáticas. Portanto, as imagens geradas por VANTs mesmo quando geradas por câmeras digitais de pequeno formato, servem ao propósito.

\subsubsection{Aspectos legais de operação}

Um empecilho para a operação de VANTs em áreas habitadas, é que na atualidade, ela não é autorizada, de acordo com lei. Quando permitida a operação, ela demora cerca de quarenta dias para sair, o que inviabiliza o uso em situações emergenciais, como a proposta.

Para as plataformas orbitais, não há restrições legais. Para aerolevantamentos convencionais, também são demoradas as autorizações para execução dos serviços de aquisição de imagens ou fotos aéreas.

O uso de helicópteros neste sentido é mais flexível e poderia obter autorizações rápidas e passíveis para execução de vôos emergenciais.

\subsubsection{Aspectos de custos de obtenção de imagens}

A cotação para aquisição de fotografias aéreas convencionais foi realizada com empresa especializada em serviços aerofotogramétricos no mês de junho de 2010 .

Para novos levantamentos aéreos, o valor da bandeirada (valor incial, apenas para o vôo ser realizado) varia entre cerca de $R \$ 25.000,00$ e $R \$ 35.000,00{ }^{11}$.

No caso das imagens de satélite, foram consultadas duas empresas, uma distribuidora oficial no Brasil das imagens obtidas pelo satélite WordView-II e a outra do satélite GeoEye-I.

O satélite WordView-II foi desenvolvido pela DigitalGlobe e teve seu lançamento em outubro de 2009. O sistema produz imagens multiespectrais em oito bandas diferentes, com resolução espacial de 1,8 m no nadir, além da banda pancromática, que apresenta resolução de 0,46 m no nadir. A resolução radiométrica das imagens

${ }^{11}$ Como referência para conversões monetárias de valores apresentados, o dólar é cotado em $\mathrm{R} \$ 1,80$ em 14 de junho de 2010. 
é de 11 bits. Cada cena compreende uma área de 16,4×16,4km da superfície terrestre, adquiridas em revisitas que podem variar entre 1,1 e 3,7 dias, dependendo do ângulo de visada do satélite.

De acordo com cotação realizada em junho de 2010 com empresa brasileira distribuidora oficial das imagens do Worldview II, o preço da imagem por $\mathrm{km}^{2}$ para imagens a serem obtidas varia de acordo com opção de produto.É de no mínimo $\mathrm{R} \$$ 72,00 para imagem colorida RGB fusionada e no máximo $R \$ 138,00$, para as bandas separadas (PAN 50cm + 8 MULTI 1,84m). A área mínima para pedido é de $90 \mathrm{~km}^{2}$ para imagens de programação. Ou seja, para imagens a serem adquiridas por programação do satélite, o preço mínimo é de $90 \mathrm{~km}^{2} \times \mathrm{R} \$ 72,00=R \$ 6.480,00$,e o máximo, de $90 \mathrm{~km}^{2} \times \mathrm{R} \$ 138,00=\mathrm{R} \$ 12.420,00$.

Sobre o satélite GeoEye-I, ele foi lançado pela GeoEye em 6 de setembro de 2008, é capacitado para produção de imagens multiespectrais (4 bandas) e pancromática. A resolução espacial das imagens é de $0,41 \mathrm{~m}$ para a banda pancromática e de 1,65 $\mathrm{m}$ para as bandas multiespectrais, e a radiométrica é de 11 bits também. Cada cena abrange 15,2kmx15,2km no terreno, sendo revisitada a mesma área em pouco menos de 3 dias.

A cotação para aquisição de imagens obtidas por este satélite também foi realizada junto à empresa distribuidora oficial destas imagens no Brasil. Para imagens de programação do satélite o valor é de $R \$ 89,00$ por $\mathrm{km}^{2}$. A área mínima para pedido é de $100 \mathrm{~km}^{2}$ para imagens de programação. Desta forma, o valor mínimo para imagens brutas obtidas por programação do referido satélite é de $R \$ 89,00 \times 100=$ $\mathrm{R} \$ 8.900,00$.

Os valores descritos não garantem imagens livres de cobertura de nuvens e é importante mencionar e o prazo de entrega varia, mas fica em torno de 40 dias.

Para obtenção de imagens aéreas com helicóptero tripulado, foram consultadas duas empresas de São Paulo-SP que prestam serviço de obtenção de imagens. Entretanto, o serviço inclui na realidade apenas o taxi aéreo e sobrevôo do local desejado, sendo que a obtenção de imagens fica a cargo do interessado que deve realizá-la pessoalmente ou contratar um terceiro. Trata-se da forma menos custosa para obtenção de imagens aéreas por helicópteros.

Os valores ficam em torno de $\mathrm{R} \$ 2.500,00$ para a hora de vôo. Para uma estimativa, um vôo que saia de São Paulo e parta para um local distante $300 \mathrm{~km}$, irá levar cerca 
de 4 horas no total, envolvendo o tempo para chegar, sobrevoar o local, obter as imagens, pousar para fornecer as imagens, decolar e retornar ao ponto de partida. Para um serviço destes, o valor cobrado seria de $R \$ 10.000,00$. Para distâncias mais longas, o custo cresce de acordo com a quantidade de horas de voo. Não foram contabilizadas as horas de trabalho do profissional que operaria a câmara fotográfica ou sensor neste cálculo.

Para que o helicóptero fique sobrevoando a área ou pousado em local próximo à área à disposição para obtenção de novas imagens de acordo com a necessidade da equipe de atendimento e para monitoramento dos impactos, este valor também deve aumentar consideravelmente em função da ampliação do tempo de aluguel.

A tabela 4.2.4.3-1 traz uma síntese dos custos para aquisição de imagens dos sistemas sensores descritos.

Tabela 4.2.4.3-1: Custos para aquisição de aerofotografias/imagens de alta resolução - junho de 2010

\begin{tabular}{|c|c|}
\hline Sistema Sensor & Valor mínimo aproximado para imagens a serem obtidas \\
\hline VANT AGplane & $\begin{array}{l}\text { - Para contratação = R } \$ 600,00 \text { a hora de operação de VANT + custos de } \\
\text { locomoção. } \\
\text { - Custos operacionais em caso de propriedade do VANT, são } \\
\text { praticamente os de locomoção do equipamento e dos profissionais para } \\
\text { a área. }\end{array}$ \\
\hline $\begin{array}{l}\text { Aerofotogrametria } \\
\text { convencional }\end{array}$ & $\mathrm{R} \$ 25.000,00$ \\
\hline WorldView II & $\begin{array}{c}\text { De } \mathrm{R} \$ 6.480 \text { a } \mathrm{R} \$ 12.420,00 \text { - Valor incluindo área mínima de } 90 \mathrm{~km}^{2} \\
\text { para aquisição }\end{array}$ \\
\hline Geoeye I & $\mathrm{R} \$ 8.900,00$ - Valor incluindo área mínima de $100 \mathrm{~km}^{2}$ para aquisição \\
\hline Helicóptero & $\mathrm{R} \$ 2.500$ por hora de voo, \\
\hline
\end{tabular}

A análise dos valores, mostra que para pequenas áreas que necessitam de imagens novas, os custos de imagens geradas por VANTs são mais atraentes, mesmo 
considerando-se valores de uso de VANT mais sofisticado que o necessário e a contratação de serviço terceirizado.

A obtenção de imagens aéreas através de helicópteros tripulados é a única opção dentre as plataformas levantadas que é capaz de gerar imagens as características requisitadas para a aplicação e próximas daquelas do VANT especificado. Entretanto, a atividade envolve custos muito superiores de operação comparados aos de VANTs.

Portanto, além das vantagens técnicas, para aplicação em avaliação de impactos ambientais causados por acidentes com transporte de cargas perigosas, o sensoriamento remoto por VANT apresenta vantagens econômicas quando comparado a outros métodos.

Por último, ainda sobre o aspecto econômico, cabe ressaltar que VANTs de modo geral, apresentam maior facilidade na incorporação de novas tecnologias de sensoriamento remoto, já que na aerofotogrametria convencional e no sensoriamento remoto de nível orbital, as mudanças requerem investimentos de ordem muito maior.

\subsubsection{Viabilidade do uso da tecnologia em acidentes com transporte de cargas perigosas em ferrovias e dutos}

De acordo com as informações levantadas, o uso do sensoriamento remoto por VANTs pode ser utilizado para avaliação e monitoramento de impactos ambientais causados por acidente com transporte ferroviário e por dutos de cargas perigosas.

Entretanto, devem ser alterados alguns dos parâmetros definidos na pesquisa para um VANT aplicado a acidentes com transporte rodoviário.

Um acidente ferroviário pode trazer a mesma tipologia de impactos ambientais que um acidente com cargas perigosas, sendo os procedimentos de avaliação e monitoramento de impactos ambientais muito semelhantes.

Entretanto, um acidente ferroviário pode provocar impactos em extensões maiores, pois composições ferroviárias possuem maior capacidade de carga. Além disso, o acesso das equipes de atendimento às áreas atingidas pode ser mais difícil se não 
houver vias de acesso próximas ao local. Deste modo, recomenda-se que os parâmetros do VANT para aplicação nestes acidentes tenham ampliadas as capacidades de alcance e autonomia de vôo. Estes dependerão da malha viária existente na região de atuação deste VANT. Para isso, um estudo específico, necessitaria ser realizado a partir do cruzamento de buffers da manha ferroviária, com a malha rodoviária da região, para determinação de valores adequados de alcance e autonomia.

Para a avaliação e monitoramento de impactos ambientais causados por acidentes com transporte de cargas perigosas por dutos, as considerações são praticamente as mesmas para a aplicação de sensoriamento remoto por VANTs em acidentes ferroviários.

Há a possibilidade de acidentes de proporções maiores, com maior volume de substâncias e dificuldade de acesso por vias. Além disso, pode não se conhecer a localização do vazamento, e a identificação ter de ser realizada através de vistoria. Assim, o alcance e a autonomia de vôo do VANT devem ser definidos considerandose a extensão dos dutos a serem cobertos pelo imageamento.

Para a definição do uso VANT em acidentes rodoviários, diferentemente, parte-se da premissa que é conhecida a localização do acidente e o acesso ao local pelas equipes de atendimento é possibilitado por rodovias. 


\section{CONCLUSÕES}

A pesquisa atingiu seus objetivos e conclui-se que atualmente as plataformas VANTs e sensores passíveis de serem transportados por elas são aplicáveis e podem servir adequadamente de tecnologia para sensoriamento remoto, com foco para o emprego em avaliação de impactos ambientais ocasionados por acidentes com transporte de cargas perigosas em rodovias.

As conclusões, considerando-se os objetivos específicos propostos para a pesquisa são apresentadas a seguir:

\subsection{LEVANTAMENTO E CARACTERIZAÇÃO DE VANTS}

A revisão bibliográfica realizada no capítulo 2 não esgota o levantamento de projetos no assunto, mas apresenta vários elementos do histórico de desenvolvimento de VANTs para sensoriamento remoto e o estado da arte atual da tecnologia, principalmente em relação aos projetos brasileiros.

Deste modo, os principais projetos de sensoriamento remoto por VANTs, em especial os nacionais, foram caracterizados na pesquisa.

\subsection{EVOLUÇÕES E TENDÊNCIAS DE APLICAÇÕES DE VANTS}

A variedade de plataformas e sensores embarcados nos dias de hoje é enorme, assim como as capacidades de cada um dos sistemas.

Nos últimos anos vem ocorrendo uma explosão do número de projetos ao redor do mundo e o desenvolvimento de VANTs pode ser considerado como um setor dinâmico e em franco crescimento da aviação e do sensoriamento remoto no mundo, sendo realizados aprimoramentos tecnológicos constantes.

A princípio, os veículos aéreos embarcavam simples câmeras de pequeno formato adaptadas, que normalmente registravam apenas a faixa do espectro eletromagnético correspondente ao visível (RGB) em filmes. 
Os avanços da tecnologia que proporcionaram a possibilidade de desenvolvimento de VANTs a baixo custo, quando comparados a outros tipos de sistemas sensores, e de aplicações em diversas áreas, levou à proliferação destes.

Atualmente há inclusive o desenvolvimento de sensores específicos para VANTs. Sensores com capacidade de gerar imagens com banda do infravermelho próximo se tornaram comuns mesmo em sistemas de baixo custo. Diversos projetos ao redor do mundo tem ainda incorporado sensores laser, SAR, multi e hiperespectrais e enriquecem as capacidades de obtenção de informações das imagens e de aplicações.

Além de aplicações militares, que predominam ainda no universo dos VANTs, nos últimos tempos, várias aplicações no setor civil tem sido desenvolvidas, como por exemplo, em mapeamentos diversos, monitoramento ambiental, agricultura de precisão e segurança pública.

O uso de VANTs em atendimentos emergenciais em desastres ambientais é uma das aplicações civis mais indicadas pela bibliografia e há órgãos de atendimento a situações emergenciais que tem utilizado esta técnica com sucesso nos últimos anos. Exemplos são em geração de informações para combate a incêndios e em resposta a grandes desastres, como terremotos.

Mas destaca-se que, embora citada como uma possibilidade de aplicação, não foi verificada na bibliografia um estudo ou caso do uso de sensoriamento remoto por VANTs para avaliação de impactos ambientais em acidentes com transporte de cargas perigosas em rodovias, em específico.

No Brasil, atualmente, cerca de 10 empresas particulares desenvolvem e ou operam VANTs. Há ainda diversos outros projetos em desenvolvimento em instituições públicas, como universidades e a Força Área Brasileira, por exemplo.

Pode-se afirmar, que os VANTs para sensoriamento remoto, como uma aplicação civil comercial no Brasil, são de desenvolvimento recente, com usos incipientes. Dentre as empresas levantadas, destacam-se a Xmobots, AGX Tecnologia, Flight Solutions, Santos Lab e Gyrofly Innovations, as quais apresentam os VANTs mais avançados.

A maior parte dos VANTs construídos por estas empresas são classificados como Mini e Close Range, possuem sistemas de navegação, controle e transmissão de dados relativamente sofisticados e carregam sensores de imageamento da região do 
visível (RGB). Poucas experiências foram realizadas com outros tipos de sensores embarcados, como multiespectrais. Entretanto, há projetos de VANTs nacionais de porte maior e para embarcarem sensores desenvolvidos especialmente para a plataforma, como o SAR-VANT, que deverá embarcar um SAR.

Dentre os empregos da tecnologia no Brasil destacam-se as aplicações voltadas para agricultura de precisão e monitoramento ambiental, como de linhas de transmissão de energia, por exemplo. O governo também tem demonstrado interesse, principalmente para aplicações militares, de vigilância do território e de segurança pública, para a qual foram adquiridos VANTs israelenses.

Deste modo, no Brasil, observam-se interesses e investimentos crescentes na tecnologia, com grande potencial de desenvolvimento do setor, frente às necessidades de geração de informações espaciais do território nacional, para as mais diversas aplicações.

Conclui-se, desta forma, que as principais evoluções e tendências de aplicações de VANTs no Brasil foram diagnosticadas no estudo.

\subsection{PARÂMETROS TÉCNICOS DE VANTS PARA A APLICAÇÃO}

Os parâmetros técnicos de VANTs adequados para aplicação em vista foram definidos, conforme proposto, e o VANT AGplane foi reconhecido como o VANT de uso civil nacional atualmente mais adequado a estes requisitos. Em breve, outra opção que deve atender tais requisitos e a um custo menor, será o VANT Tibira em desenvolvimento pela AGX tecnologia.

\subsection{VIABILIDADE TÉCNICA, LEGAL E ECONÔMICA DA APLICAÇÃO}

O estudo leva à conclusão de que há VANTs na atualidade que apresentam os parâmetros desejáveis para aplicações emergenciais e são tecnicamente capazes de gerar imagens rapidamente para avaliação de impactos ambientais pós-acidentes com transporte de cargas perigosas.

Sobre a melhoria da qualidade e quantidade de informações ambientais de áreas atingidas e seu entorno (identificação e quantificação de áreas impactadas pelo acidente e do uso do solo no entorno), o estudo indica que: 
- As imagens podem auxiliar na identificação de áreas contaminadas e do uso do solo do entorno através de fotointerpretação ou processamento digital de imagens.

- Imagens aéreas iriam auxiliar principalmente em cenários ambientais complexos, onde a extensão dos impactos é maior, o acesso às áreas é difícil ou a visibilidade do terreno em solo seja difícil.

- As imagens aéreas podem tornar mais rápido o processo de avaliação da ocorrência, principalmente quando da existência de cenários ambientais complexos, conforme os descritos.

- A avaliação ambiental de uma área através de sensoriamento remoto provém maior segurança às equipes de atendimento ao acidente e avaliação de impactos ambientais.

- Sobre a aplicação no monitoramento ambiental, de modo geral, as imagens podem ser utilizadas no acompanhamento das ações de gestão imediatas, para identificação da eficiência destas.

- Para o monitoramento de médio a longo prazo, as imagens não apresentam vantagens significativas, pois normalmente nesta fase, as contaminações não podem ser detectadas em superfície do solo. As imagens geradas quando do atendimento da ocorrência podem auxiliar na programação mais eficiente de pontos de amostragem de solo e águas superficiais e subterrâneas.

- Em relação ao auxílio na documentação de atendimento à ocorrência, avaliação de impactos ambientais e do monitoramento ambiental, as imagens podem ser utilizadas, trazendo informações da avaliação de impactos ambientais mais precisas e melhor representadas espacialmente e visualmente, o que auxilia no planejamento de ações de gestão de remedição e monitoramento da área. Desta forma, autuações econômicas às empresas responsáveis também podem ser calculadas com maior eficiência.

Sobre a viabilidade econômica, conclui-se, através da pesquisa, que os valores atuais para compra e operação ou contratação de serviços de VANTs para sensoriamento remoto demonstram viabilidade econômica para a aplicação, sendo que as imagens podem inclusive gerar informações que contribuam com a redução de gastos com ações de gestão, podendo gerar economia. Os resultados da comparação com outros métodos de sensoriamento remoto permitem afirmar que 
uma plataforma de sensoriamento remoto VANT com as características indicadas pela presente pesquisa se mostra como a tecnicamente mais adequada e a de melhor custo-benefício para aplicação desejada.

Entretanto, de acordo com a normatização atual, o uso abordado, em avaliações ambientais em situações emergenciais, não é considerado, e é ilegal operar VANTs no espaço aéreo brasileiro sem autorização prévia do órgão regional que regulamenta o espaço aéreo e que analisa caso a caso. As principais restrições previstas para atividade de VANTs são para vôos sobre áreas urbanas, onde há grande concentração de pessoas.

Portanto, conclui-se que a viabilidade de uso da tecnologia esbarra nos aspectos legais.

Para aplicação em avaliação e monitoramento de impactos provocados por acidentes em ferrovias e dutos, a tecnologia também pode ser utilizada de forma semelhante, entretanto, o alcance e a autonomia de vôo do VANT devem ser definidos caso a caso, com pesquisas específicas a partir de informações sobre a região de atuação proposta para o VANT. 


\section{CONSIDERAÇÕES FINAIS}

A aplicação estudada é técnica e economicamente viável, porém, do ponto de vista legal, atualmente existem restrições para a atividade de VANTs no Brasil e não é possível afirmar se as entidades interessadas obteriam autorização para os vôos, principalmente sobre áreas urbanizadas. Assim, a viabilidade legal da aplicação depende da possível regulamentação ou autorização dos órgãos regulamentadores do espaço aéreo brasileiro, sendo que não há estimativa de quando isto deverá ocorrer, ou ainda, se efetivamente irá ocorrer.

Neste sentido, as informações geradas no estudo podem auxiliar com subsídios à normatização do uso de VANTs para esta aplicação, uma vez que determina uma série de parâmetros técnicos e capacidades de VANTs para obtenção de imagens aéreas pós-acidentes com cargas perigosas e apresenta as vantagens que imagens aéreas poderiam apresentar para a avaliação e monitoramento de impactos em desastres ambientais.

Embora possam ocorrer variações de alguns parâmetros a serem envolvidos e estudos detalhados de viabilidade devem ser realizados para cada caso e uso específico, os VANTs podem ser aplicados de forma semelhante ao proposto na presente pesquisa para avaliação e monitoramento ambiental de forma emergencial após outros desastres ambientais de abrangência espacial semelhante, como em movimentos de massa em encostas (deslizamentos) ou enchentes. Entende-se que as informações geradas podem servir inclusive de subsídio para usos e pesquisas futuras de VANTs para sensoriamento remoto em situações emergenciais diversas. Deste modo, para prover a divulgação e conhecimento dos resultados da presente pesquisa por parte de órgãos públicos atuantes em respostas a acidentes ambientais, propõe-se a apresentação destas informações, através de uma nota técnica, ao P2R2 - entidade de âmbito federal, e à CETESB - de âmbito estadual.

Em especial o P2R2, apresenta condições de viabilizar a aplicação em nível nacional, uma vez que tem dentro de seus objetivos gerais oficiais, a "implementação de sistemas, ações e procedimentos que visam responder de forma 
rápida e eficaz às ocorrências de acidentes, assim como preparar, capacitar recursos humanos disponíveis nas esferas federais, estaduais e municipais."

Uma vez que a discussão sobre o uso de VANTs para sensoriamento remoto de áreas atingidas por acidentes com transporte de cargas perigosas entre em grupos de trabalho do P2R2 e da CETESB, profissionais que trabalham nos segmentos responsáveis pelo controle e atendimento a emergências poderão tomar conhecimento da tecnologia e atuar para que o modelo de operação de VANTs para a aplicação seja definido e consolidado e, ainda, seu uso seja solicitado legalmente, por meio da incorporação da tecnologia nas etapas do fluxograma e na metodologia de atendimento a emergências contido em PAEs.

Estas entidades possuem expressão e poder político de negociação e articulação com os órgãos públicos, incluindo os responsáveis pela regulamentação da operação de VANTs, e por isso são um caminho para pressionar a certificação da atividade. Também auxiliariam na justificativa e busca por investimentos financeiros diversos para pesquisas em desenvolvimento e aplicações da tecnologia e em sistemas de segurança para incorporação de VANTs ao espaço aéreo brasileiro. Estas instituições poderiam futuramente também articular e coordenar uma rede de VANTs de diversos proprietários e operadores para usos em avaliação de impactos ambientais em situações emergenciais para otimizar o uso desta tecnologia e tornar a aplicação mais eficiente.

Por último, recomenda-se a inserção, acompanhamento e provimento de informações e pesquisas por parte de todos órgãos ambientais públicos, comitês de defesa civil e empresas privadas interessadas na aplicação de VANTs em situações de desastres ambientais, na discussão e elaboração de regulamentação para a atividade no Brasil. Os deveres, obrigações, limites, responsabilidades, especificações técnicas e procedimentos de operação de VANTs em geral precisam ser melhor definidos e o quanto antes.

Desta forma, as demandas por esta aplicação poderão ser previstas e atendidas pela legislação, sendo seus benefícios aproveitados e com a garantia de condições de segurança à aviação e à população. 


\section{REFERÊNCIAS BIBLIOGRÁFICAS}

ABIQUIM - Departamento Técnico, Comissão de Transportes. Manual de Atendimento de Emergências com Produtos Perigosos. $4{ }^{a}$ ed. São Paulo: 2002.

AGX TECNOLOLOGIA. São Carlos. Disponível em: <http://www.agx.com.br> Acesso em 10 de jul. 2009.

ALMEIDA, E.E.R. de. A organização espacial do setor metropolitano de São Paulo. B. Geogr. Rio de Janeiro, 36(256): 5-73, jan./mar., 1978.

ALVES, P. et al. Análise do transporte rodoviário de produtos perigosos no estado de São Paulo suas conseqüências no meio ambiente. In: Anais do VI Congresso de Meio Ambiente da AUGM. São Carlos, 2009

ALVES NETO, A. Geração de trajetórias para veículos aéreos autônomos nãotripulados. Dissertação (mestrado). Pós-graduação em Ciência da Computação da Universidade Federal de Minas Gerais. Belo Horizonte, 2008.

ALVES NETO, A. Identificação de Estradas em Imagens para uma Aeronave em Ambiente Simulado. Belo Horizonte, 2007.

ALVIM, T. F.; AMORIM R. L. O sistema globalmente harmonizado de classificação e rotulagem de substâncias químicas - GHS e a legislação brasileira de transporte terrestre de produtos perigosos. In: Revista ANTT v. 2. São Paulo, 2010.

AMBROSIA Vincent G.; SCHOENUNG, Susan M., WEGENER, Steven S. e ENOMOTO, Francis. The 24-Hour Western States UAV Fire Mission: Sensor and Intelligent Management Systems. Arlington, 2005.

AMIANTI, G Projeto aviônico de um vant. Dissertação de Mestrado apresentada à Escola Politécnica da Universidade de São Paulo 2005 
AMPLA, Complexo Argileiro de Santa Gertrudes - Aspacer, Estudo de Impacto Ambiental apresentado à Secretaria de Meio Ambiente em 07/2008.

ANDERSON, J. R. et al. Sistema de Classificação do uso da terra e do revestimento do solo para a utilização com dados de Sensores Remotos. Rio de Janeiro: IBGE, 1979.

ARAÚJO, G. M. Regulamentação do Transporte Terrestre de Produtos Perigosos. Rio de Janeiro, 2001.

ARAÚJO, Márcio Rodrigo Vieira de. Projeto, simulação e controle de veículo aéreo não-tripulado tail-sitter. Dissertação (mestrado). Departamento de engenharia mecânica da Universidade de Brasília. Brasília, 2007.

ARAÚJO, Marcelo Antunes; CHAVIER, Fernando e DOMINGOS, Jocival Luiz. Avaliação do Potencial de Produtos Derivados de Aeronaves Não Tripuladas na Atividade Florestal. In: Ambiência Guarapuava, PR v.2 p. 69-82, 2006.

ARMADA. The Growing World of Unmanned Airborne Spies. IN: Armada International, vol.28, № 3, 2004.

ASSOCIAÇÃO BRASILEIRA DE NORMAS TÉCNICAS NBR 9735. Conjunto de equipamentos para emergências no transporte terrestre de produtos perigosos. Rio de Janeiro. 2004.

BARBOSA, Humberto Alves e ROANHORSE, Abigail Stella. Mapeamento da cobertura vegetal por meio de aeronave não tripulada na estação experimental de Santa Rita em Arizona: estudo de caso. In: Anais XIII Simpósio Brasileiro de Sensoriamento Remoto, Florianópolis, Brasil, 21-26 abril 2007, INPE, p. 63236328.

BERNI, Jose A. J. et al. Thermal and narrowband multispectral remote sensing for vegetation monitoring from unmanned aerial vehicle. In: IEEE Transactions on Geoscience and Remote Sensing, vol 47, n. 3, 2009.

BIESEMANS, J; EVERAERTS, J; LEWYCKYJ, N.; Pegasus: Remote Sensing from Hale-UAV IN: ASPRS annual convention, Baltimore, 2005. 
BLAND, G.; CORONADO, P.; MILES, T.; BRETTHAUER, P.; LUNSFORD, A.; BOGNAR, J.: Sensors with Wings - Small UAVs for Earth Science, American Institute of Aeronautics and Astronautics, 2004.

BLASCHKE, T. e KUX, H. Sensoriamento Remoto e SIG Avançados - Novos Sistemas Sensores: Métodos Inovadores. São Paulo: Oficina de Textos, 2005

BOWMAN, Michael; GRAHAM JR, James H. e GANTT James. A Robust and Affordable Mobile Communications System for Emergency Management and Crisis Response. In: Fourth Annual Conference on Telecommunications \& Information Technology, 19-20. Las Vegas, 2006.

BRANDÃO, Maurício Pazini et al. UAV activities in Brazil. First Latin-American UAV Conference. Panama, 2007.

BRASIL. Agência Nacional de Transportes Terrestres. Aprova as Instruções Complementares ao Regulamento do Transporte Terrestre de Produtos Perigosos. Resolução ANTT no. 420 de 12 de Fevereiro de 2004 D.O.U. de 31 de mai. 2004.

BRASIL. Conselho Nacional do Meio Ambiente Dispõe sobre procedimentos relativos a Estudo de Impacto Ambiental. Resolução CONAMA 1/86, de 23 de janeiro de 1986. Publicado no D.O.U. de 17 de fev. 86 - págs. 2548 e 2549

CALVO, A. B; FULLERTON, A.V.; VETTER, M.F. Information Technology and Emergency Response. 1997.

CAPITAN, J., MANTECON, D., SORIANO, P. and OLLERO, A. Autonomous perception techniques for urban and industrial fire scenarios. Anais... International Workshop on Safety, Security and Rescue Robotics. Roma, 2007.

CARNI, Johnny. New developments in the Field of UAS Imaging Sensors. International Conference \& Exhibition on Unmanned Aircraft Systems. Paris, 2009.

CETESB - Companhia de Tecnologia e Saneamento Ambiental - Emergências Químicas - Acidentes Rodoviários. Disponível em: http://www.cetesb.sp.gov.br/emergencia/acidentes/rodoviarios/introducao.asp

Acesso em 26 de jan. 2009. 
CETESB - Companhia de Tecnologia e Saneamento Ambiental. Relatório de estatísticas de atendimentos a acidentes ambientais. 2009.

CETESB - Companhia de Tecnologia e Saneamento Ambiental. Relatório de emergências químicas do estado de São Paulo São Paulo: CETESB, 2008. 88 p.

CORDEIRO, Natal Henrique. Environmental Monitoring using Small Format Aerial Image Mosaics. In: Anais XIV Simpósio Brasileiro de Sensoriamento Remoto, Natal, Brasil, 25-30 abril 2009, INPE, p. 1763-1770.

COTON, Frank. UAV Technology Challllenges and Opporttuniittiies: a Uniiversiitty Perspecttiive.

CRÓSTA, A. P. Processamento Digital de Imagens de Sensoriamento Remoto. Campinas-SP, IG/UNICAMP, 1992-3.

DEPARTMENT OF THE ARMY - U.S. Army Corps of Engineers. Engineering and Design: adsorption design guide. 2001

DERMENTZOUDIS, Marinos. Establishment of models and data tracking for small UAV reliability. Dissertação (mestrado). Monterey, 2004.

DIGITAL GLOBE. Disponível em: <http://www.satimagingcorp.com/satellitesensors/worldview-2.html> Acesso em 03 de jun. 2010.

DISPERATI, A. A. Fotografias aéreas inclinadas. Curitiba: Editora da UFPR, 1995.

DISPERATI, A. A. Obtenção e uso de fotografias aéreas de pequeno formato. Curitiba: UFPR, FEPEF, 1991.

DOD - SECRETARY OF DEFENSE. Unmanned Aerial Vehicles (UAV) Roadmap. Washington, 2003. 195p.

DUARTE, P. A. Fundamentos de Cartografia. Florianópolis, Ed. da UFSC. 2002.

EIFES, A. et al. Project AURORA: Development of an Autonomous Unmanned Remote Monitoring Robotic Airship. J. Braz. Comp. Soc. vol. $4 n^{\circ} .3$ Campinas, 1998. 
EISENBEISS, H. A Mini Unmanned Aerial Vehicle (UAV): System Overview and Image Acquisition IN: International Workshop on "Processing and Visualization Using High-Resolution Imagery. Pitsanulok, Thailand, 2004.

EUGENE, M. Chemistry of Hazardous Materials. USA, 1990. HARWOOD, D., et al. Characteristics of Accidents and Incidents in Highway Transportation of Hazardous Materials, Transportation Research Record. 1989.

EVERAERTS, J.. PEGASUS - HALE UAV for Remote Sensing and Security. In: Boeretang 200, B-2400 Mol, Belgium, 2008

FALKNER, E. Aerial Mapping: Methods and Applications. St. Louis, Missouri: Lewis Publishers, 1994

FERRANTE, A. et al Métodos Informais para Identificação de Produtos Químicos nas Emergências. São Paulo, CETESB, 2010.

FILARDI, Vitor Leão. Desenvolvimento de um sistema para navegação e telemetria de aeronaves não-tripuladas. Dissertação (mestrado). Universidade Federal da Bahia. Salvador, 2006.

FILIPPI, A. M. Remote Sensing-Based Damage Assessment for Homeland Security IN: SUI, D. Z. Geospatial Technologies and Homeland Security: Research Frontiers and Future Challenges. Springer Netherlands, 2008.

FITEC, 10. Seminário Intern. de VANT - CTA, 2005

FLIGHT SOLUTIONS Disponível em: <http:// www.flightsolutions.com.br/port/index.html> Acesso em 15 de jul. 2009.

FLORENZANO, T. G. Imagens de satélite para estudos ambientais. São Paulo: Oficina de Textos, 2002.

FREIRE, Ladilas. Einforex-UAV: a uas solution to help firefighters. In: International Conference \& Exhibition on Unmanned Aircraft Systems. Paris, 2009. 
FREITAS, E. e COTTET, F. A invasão dos VANTs: Veículos aéreos não tripulados já são realidade no setor de sensoriamento remoto In: INFOGEO $n^{\circ} 60$. MundoGeo. Curitiba-PR: 2010.

FROST e SULLIVAN. UAV Remote Sensors - Proven Performance Boosts Market Growth. 2005

FURTADO, V. H. et al Aspectos de Segurança na Integração de Veículos Aéreos Não Tripulados (VANT) no Espaço Aéreo Brasileiro. VII Simpósio Brasileiro de Transporte Aéreo. Rio de Janeiro, 2008.

GALVES, Miguel; SHIROMA, Pedro; SILVEIRA, Geraldo F. e RAMOS Josué J. G. Infra-estrutura para o controle servo visual de um dirigível robótico. VI Simpósio Brasileiro de Automação Inteligente. Bauru, 2003.

GAMBA, P., DELL'ACQUA, F. e DASARATHY, B. V. Urban remote sensing using multiple data sets: past, present, and future. Information Fusion 6 (2005) 319-326.

GEOYE. Disponível em: <http://www.geoeye.com/CorpSite/products/imagerysources/Default.aspx\#orbview2> Acesso em 03 de jun. 2010.

GONZALES, R. C.; WOODS, R.E.; Processamento de imagens digitais. São Paulo: Editora Edgard Blücher Ltda., 2000.

GOUVEIA, Jorge Luiz Nobre. Atuação de equipe de atendimento emergencial em vazamentos de combustíveis em postos e sistemas retalhistas. Dissertação (mestrado). Faculdade de Saúde Pública da Universidade de São Paulo. São Paulo, 2004.

GURTNER, Alex et al. Investigation of fish-eye lenses for small-UAV aerial photography. In: IEEE Transactions on Geoscience and Remote Sensing, vol 47, n. 3, 2009.

HALEM, M., PATWARDHAN, A., YESHA Y e DORNBUSH S. Sensor Web Design Studies For Real-time Dynamic Congestion Pricing (DCP). In: Pertran Workshop. 2007.

HAUSCHILD, M.; HALL, H. W. C. Environmental Assessment of Products. 1998. IEEE Transactions on Geoscience and Remote Sensing, vol 47, n. 3, 2009. 
JENSEN, J. R. Sensoriamento Remoto do Ambiente: Uma perspectiva sobre recursos terrestres. São José dos Campos, SP. Ed. Parêntese, 2009.

JOHNSON, L.F. et al. Collection of Ultra High Spatial and Spectral Resolution Image Data over California Vineyards with a Small UAV. In: Int'I Symposium on Remote Sensing of Environment, 2003.

JOLY, F. A Cartografia. São Paulo: Editora Papirus, 1990.

JORGE L. A. de C. Determinação da cobertura do solo em fotografias aéreas do Projeto ARARA (Dissertação de Mestrado em Ciências de Computação e Matemática Computacional). São Carlos. USP, Dezembro de 2001.

KAMRANI, Farzad. Using On-line Simulation in UAV Path Planning. Licentiate Thesis in Electronics and Computer Systems. Stockholm, 2007.

KOLDAEV, Alexander. Basic principals for UAS development for non-military applications. International Conference \& Exhibition on Unmanned Aircraft Systems. Paris, 2009.

LAINHA, M. A. J. et al Sistema integrado de gestão para prevenção, preparação e resposta aos acidentes com produtos químicos: manual de orientação . São Paulo: CETESB, 2003.

LALIBERTE, A. S. e RANGO, Albert. Texture and scale in object-based analysis of subdecimeter resolution Unmanned Aerial Vehicle (UAV) imagery. In: IEEE Transactions on Geoscience and Remote Sensing, v. 47, n. 3, 2009.

LESAK, D. M. Hazardous Materials: strategies and tactics. Brady/Prentice Hall, USA, 1999.

LEWIS, G. et al. Evaluating the Use of a Low-Cost Unmanned Aerial Vehicle Platform in Acquiring Digital Imagery for Emergency Response IN: LI, J et al Geomatics Solutions for Disaster Management. Springer Berlin Heidelberg, 2007.

LIBAULT, A. Geocartografia. São Paulo: Ed. Nacional, Ed. Da Universidade de São Paulo, 1975. 
LIU, C. C. e RODRIGUES, J. E. Sensores fotográficos: conceitos básicos. São José dos Campos. INPE, 1986.

LOCH, C. e LAPOLLI, E. M. Elementos básicos da fotogrametria e sua utilização prática. Florianópolis: Editora da UFSC, 1998.

LOCH, R. E. N. Cartografia: representação, comunicação e visualização de dados espaciais. Florianópolis: Ed. da UFSC, 2006.

LONGHITANO, G. A.; AMARAL, C. H. ; ALMEIDA, T. I. R. Detecção da biodiversidade de coberturas vegetais secundárias pela resposta espectral de pigmentos e água foliar em imagens do sensor hiperespectral CASI-1500. In: Anais do XIV Simpósio Brasileiro de Sensoriamento Remoto. Natal-RN, 2009.

LONGHITANO, G. A. Imagens aéreas Obtidas por aeronave do Projeto A.R.A.R.A.: Testes para mapeamento de uso da terra e potenciais aplicações em Geografia. (Trabalho de Graduação Individual em Geografia). São Paulo. USP, 2006.

LONGHITANO, G. A.; LUCHIARI, A.; TRINDADE JUNIOR, O. Algumas considerações acerca da aplicabilidade de fotografias aéreas digitais de pequeno formato obtidas por aeromodelo do Projeto A.R.A.R.A. ao mapeamento de uso e cobertura da terra. In: Anais do XI - Simpósio Brasileiro de Geografia Física Aplicada - Geografia, Tecnociência, Sociedade e Natureza, São Paulo. p. 28792892, 2005.

LONGHITANO, G. A.; LUCHIARI, A. Classificação de imagens obtidas por aeromodelo do Projeto A.R.A.R.A.. In: Anais... XIII SIICUSP - Simpósio de Iniciação Científica da USP, 2005, São Paulo.

LONGHITANO, G. A.; LUCHIARI, A. Comparação entre classificação digital supervisionada e fotointerpretação de imagens obtidas pelo A.R.A.R.A.. In: Anais... XIV SIICUSP - Simpósio de Iniciação Científica da USP. São Paulo. 2006.

LOPES, C. F. Aspectos Ambientais nas Emergências Químicas. São Paulo: CETESB, 2009.

LUCHIARI, A. e MORATO, R. G. Fundamentos de Sensoriamento Remoto apresentação componente do material didático da disciplina de Sensoriamento Remoto aplicado à Geografia do curso de graduação Geografia da Universidade de São Paulo, 2009. 
MEDEIROS, Fabrício Ardais. Desenvolvimento de um veículo aéreo nãotripulado para aplicação em agricultura de precisão. Dissertação (mestrado). Universidade Federal de Santa Maria. Santa Maria, 2007.

MALHEIROS, André Luciano. Monitoramento de Perfil Atmosférico com Veículo Aéreo Não Tripulado e Calibração de Modelos Matemáticos de Camada-Limite Atmosférica. Tese (doutorado). Pós-graduação em Métodos Numéricos em Engenharia - UFPR, 2008.

MARANHÃO NETO, Djalma Teixeira. Projeto de uma Arquitetura de Hardware e Software para um Veículo Aéreo Não-Tripulado para Supervisão de Instalações de Petróleo. Relatório de estágio supervisionado. Natal, 2009.

MARCHETTI, D.A.B.; GARCIA, G.J. Princípios de fotogrametria e fotointerpretação. São Paulo: Livraria Nobel, 1977.

MARTINELLI, M. Cartografia Temática: Caderno de Mapas. São Paulo: EDUSP, 2003.

MARTINS, Alexandre Simões. Instrumentação e controle de altitude para helimodelo montado em uma plataforma de testes. Dissertação (mestrado). Departamento de engenharia elétrica da Universidade de Brasília. 2008.

MCGEER, T. and VAGNER, J. Wide-scale use of long-range miniature aerosondes over the world's oceans. Proceedings of the AUVSI 26th Annual Symposium, Association for Unmanned Vehicle Systems International. Baltimore: 1999.

MEDEIROS, Fabrício Ardais et al. Utilização de um veículo aéreo não-tripulado em atividades de imageamento georeferenciado. Ciência Rural, Santa Maria, v 38, n. 8, p. 2375-2378, 2008.

MEULEMAN, Koen et al. Seveseo: eo-based services in support to industrial and technological risk management. In: Proc. 'Envisat Symposium 2007, 23-27. Montreux, 2007.

MIKA, Pat. Emergency Service Use of UAS. In: International Conference \& Exhibition on Unmanned Aircraft Systems. Paris, 2009. 
MUKHERJEE, A., VELEZ-REYES, M. e ROYSAM, B.. Interest points for hyperspectral image data. In: IEEE Transactions on Geoscience and Remote Sensing, vol 47, n. 3, 2009.

MULHOLLAND, K. L..; DYER, J. A. Pollution Prevention: Methodology, Technologies and Practices. American Institute of Chemical Engineers, New York, 1999.

NAGAI, Masahiko et al. UAV-Borne 3-D Mapping System by Multisensor Integration. In: IEEE Transactions on Geoscience and Remote Sensing, vol 47, n. 3, 2009.

NASA. A report overview of the Civil UAV capabilities assessment. 2005. 7p.

NASA. Civil UAV capabilities assessment: Interim Status Report. 2005. 31p.

NASA. Earth Observations and the Role of UAVs. 2006.

NASA - USA - Disponível em <http://www.nasa.gov/topics/earth/features/oilspill/ index.html> Acesso em 28 de jun. 2010.

NASA - USA - UAVSAR Disponível em: <http://uavsar.jpl.nasa.gov/> Acesso em 28 de jun. 2010.

NEWMAN, P. A. et al. Uninhabited Aerial Vehicles: Current and Future Use IN: VISCONTI, G. Observing Systems for Atmospheric Composition Satellite, Aircraft, Sensor Web and Ground-Based Observational Methods and Strategies. Springer New York, 2007.

NFPA - National Fire Protection Association. Recommended Practice for Responding to Hazardous Materials Incidents. In: NFPA 471. 2002

NOBREGA, R. A. A. Detecção da malha viária na perifeira urbana de São Paulo utilizando imagens orbitais de alta resolução espacial e classificação orientada a objetos. 2007. 157 f. Tese (Doutorado) - Escola Politécnica, Universidade de São Paulo, São Paulo, 2007.

NOVO, E.M.L.M. Sensoriamento Remoto: Princípios e Aplicações. São José dos Campos: Edgard Blücher, 1989. 
OKAMOTO, Renato Massayuki. Incorporando inteligência: o diferencial invisível. Informativo do centro tecnológico do exército, n. 6. Rio de Janeiro, 2007.

OLIVEIRA, M. Emergências com Produtos Químicos - Manual Básico para Equipes de Primeira Resposta. Diretoria Estadual de Defesa Civil Florianópolis, 2000.

OLIVEIRA, Thomas David Serafini de e BARROS, Ettore Apolonio de. Utilização de técnicas de identificação de sistemas aplicadas a veículos aéreos não tripulados (VANTs).

O'YOUNG Siu and HUBBARD Paul. RAVEN: A Maritime Surveillance Project Using Small UAV. 2007

PETTY, Rickey. ARM Unmanned Aerial Vehicles (UAV). Washington.

PINHO, C. M. D. et al Classificação de Cobertura do Solo de Ambientes Intraurbanos Utilizando Imagens de Alta Resolução Espacial e Classificação Orientada a Objetos In: MONTEIRO. A. M. et al Geoinformação em Urbanismo: cidade real x cidade virtual. São José dos Campos: Oficina de Textos, 2007.

PIOVESAN, E. C. et al. SOFIA - Sistema de Obtenção de Fotos e Imagens com Aeromodelo In: Anais... XXI Congresso Brasileiro de Cartografia, 2003, Belo Horizonte. XXI Congresso Brasileiro de Cartografia/CD-ROM.

PROJETO AURORA. Campinas. Disponível em: <http://www.aurora.aero/Aerostructures/Index.aspx> Acesso em 10 de jul. 2009.

POFFO, I. R. et Acidentes Ambientais e Comunicação de Riscos In: Anais do II Congresso Brasileiro de Comunicação Ambiental. São Paulo, 2005.

QUEIROZ FILHO, A. P. A escala nos trabalhos de campo e laboratório. In: VENTURI, L.A.B. Praticando Geografia. São Paulo: Oficina de Texto. 2005, p.55-67

RAFFO, J. G. da G. Retificação virtual de fotografias de pequeno formato e sua aplicação para vôos aerofotográficos (Tese de Doutorado em Geografia Humana), São Paulo: USP, 2000. 
RASI, José Roberto. Desenvolvimento de um veículo aéreo não-tripulado para aplicação em pulverização agrícola. Monografia (especialização). Departamento de engenharia rural da Universidade Federal de Pelotas. Pelotas, 2008.

RIBEIRO, R.E. Um Sistema de Telemetria e Telecomando de Aeronaves do Projeto A.R.A.R.A. (Dissertação de Mestrado defendida no ICMC-USP), São Carlos: USP, 2000.

ROBERTS, A. e GRISWOLD, L. Practical Photogrammetry from 35-mm Aerial Photography In: Photogrammetric Engineering and Remote Sensing Vol, 52, no 4, pg. 501 a 508, Abril de 1986.

ROCCHINI, D. Effects of spatial and spectral resolution in estimating ecosystem $\alpha$ diversity by satellite imagery. In: Remote Sensing of Environment v.111 (2007) 423-434. 2007.

RODRIGUES, R. C. B. Color and Texture Features for Landmarks Recognition on UAV Navigation. In: Anais XIV Simpósio Brasileiro de Sensoriamento Remoto, Natal, Brasil, 25-30 abril 2009, INPE, p. 7111-7118.

RUY, R. da S.; TOMMASELLI, A. M. G.; LOPES, R. F.; MENOSSI. R. C. Um estudo comparativo entre câmaras digitais não métricas e câmaras analógicas IN: Anais... Congresso Brasileiro de Cartografia, 2005, Macaé.

SALE, Tom. Answers to Frequently Asked Questions About Managing Risk at LNAPL Sites. In: API Soil and Groundwater Research Bulletin Number 18. 2003. $20 \mathrm{p}$.

SÁNCHEZ, L. E. Avaliação de impacto ambiental: conceitos e métodos. São Paulo: Oficina de Textos, 2008.

SANTOS R. B. dos. Geração Automática de Mosaicos de Fotos Aéreas no Projeto ARARA. (Dissertação de Mestrado em Ciência da Computação) São Carlos. USP, 2004.

SÃO PAULO (ESTADO) Companhia de Tecnologia de Saneamento Ambiental. Dispõe sobre o procedimento para gerenciamento de áreas contaminadas. Decisão de Diretoria no 103/2007/C/E, de 22 de jun. de 2007. 
SÃO PAULO (ESTADO). Secretaria do Meio Ambiente. Dispõe sobre o licenciamento ambiental de intervenções destinadas à conservação e melhorias de rodovias e sobre o atendimento de emergências decorrentes do transporte de produtos perigosos em rodovias. Resolução SMA $\mathbf{n} . \mathbf{0} \mathbf{8 1}$, de 01 de dezembro de 1998.

SÃO PAULO (ESTADO) Lei № 13.577, de 8 de julho de 2009 de São Paulo. Dispõe sobre diretrizes e procedimentos para a proteção da qualidade do solo e gerenciamento de áreas contaminadas, e dá outras providências correlatas. Publicado em: D.O.E. de 09 de jul. 2009 - Seção I - pág. 01.

SHIROMA, Pedro M., CARVALHO, José R. H. e SILVEIRA, Geraldo F. Controle servo visual para o rastreamento de trajetória definida por retas: teoria e resultados experimentais. VI Simpósio Brasileiro de Automação Inteligente. Bauru, 2003.

SILVA, A. de B. Sistemas de Informações Geo-referenciadas: conceitos e fundamentos. Campinas, SP: Editora da Unicamp, 2003.

SINDICOM Anuário - Combustíveis \& Lojas de Conveniência do Sindicato Nacional das Empresas Distribuidoras de Combustíveis e Lubrificantes. 2004.

SOUZA N. P. Sistemas Alternativos para Obtenção de Imagem Aérea e sua Aplicação na Agricultura (Dissertação de Mestrado em Ciências de Computação e Matemática Computacional). São Carlos: USP, 1999.

TEIXEIRA A. L. A.; CHRISTOFOLETTI A. Dicionário de Informação Geográfica. São Paulo: Ed. Hucitec, 1997.

TEIXEIRA, M. S. Relatório de atendimento a acidentes ambientais no transporte rodoviário de produtos perigosos 1983 a 2004. São Paulo: CETESB, 2005.

TELLES, M. No piloto automático. In: Inovação em pauta. p. 44- 46.

UNITED STATES GOVERNMENT. Unmanned Aircraft Systems: Federal Actions Needed to Ensure Safety and Expand Their Potential Uses within the National Airspace System GAO-08-511, Report to Congressional Requesters, 2008.

VAN DER MEER, F.; GORTE, B. Spatial statistics for remote sensing. Kluver Academic Pub. Netherlands, 1999. 
VASCONCELLOS, Agnaldo Ribeiro de e LAINHA, Marco Antonio José. Acidente rodoviário envolvendo carreta transportando amônia anidra. In: Revista Meio Ambiente Industrial. 2006. p. 46-50.

VERGARA, O. R. Avaliação de produtos de sensoriamento remoto para fins de atualização cartográfica (Dissertação de Mestrado em Sensoriamento Remoto). São José dos Campos: INPE, 1994.

WANG, Wen-Qin, PENG, Qicong e CAI, Jingye. Waveform-diversity-based millimeter-wave UAV SAR Remote Sensing. In: IEEE Transactions on Geoscience and Remote Sensing, vol 47, n. 3, 2009.

WEIBEL, R. E. Safety consideration for operation of different classes Unmanned Aerial Vehicles in the National Airspace System. Massachusetts, 2005.

WILSON, John T. e ADAIR, Cherri. Monitored Natural Attenuation of Tertiary Butyl Alcohol (TBA) in Ground Water at Gasoline Spill Sites. In: EPA: United States Environmental Protection Agency. 2007. 39p.

YOUNG, S. O.; HUBBARD, P. RAVEN: A Maritime Surveillance Project Using Small UAV. IEEE, 2007.

ZHOU, G. Near real-time orthorectification and mosaic of small UAV video flow for time-critical even response. In: IEEE Transactions on Geoscience and Remote Sensing, vol 47, n. 3, 2009. 


\section{Anexo A}

Questionário - Levantamento de VANTs para Sensoriamento Remoto 
Mestrado em Geoprocessamento - Escola Politécnica da USP Aluno: George Alfredo Longhitano Orientador: Prof. Dr. José Alberto Quintanilha

\section{Questionário - Levantamento de VANTs para Sensoriamento Remoto}

Nome e contato do responsável pelas informações:

Nome do VANT:

Instituições envolvidas no desenvolvimento:

Fabricante:

Data de início do desenvolvimento:

Medidas (altura, comprimento, envergadura):

Peso:

Autonomia:

Alcance:

Altura máxima de vôo:

Capacidade de carga (em peso e volume):

Formas de decolagem e pouso:

Sistema e forma de Controle:

Sistemas sensores embarcados:

Forma de aquisição de imagens (Ex: obtenção autônoma ou programada, transmissão em tempo real ou armazenamento, etc):

№ de linhas e colunas ou megapixels das imagens:

Medidas dos sensores e distância focal:

Resolução radiométrica:

Bandas (faixas do espectro imageadas):

Aplicações iniciais visadas:

Aplicações testadas:

Aplicações potenciais:

Valor estimado do VANT completo:

Estimativa de valor médio para execução de missões para obtenção de imagens (Ex: em $\mathrm{R} \$$ / área ou por execução de missão): 
Fase do projeto (o VANT está em desenvolvimento ou já opera?):

Capacidades (execução de missões autônomas, georreferenciamento automático de imagens, etc):

Outras informações relevantes:

Se possível, favor enviar foto do veículo aéreo e exemplos de imagens obtidas pelo sistema sensor do VANT, bem como eventuais artigos ou reportagens publicadas sobre o VANT.

Obrigado!

George Alfredo Longhitano

Mestrando em Geoprocessamento pela EP-USP

georgelonghitano@yahoo.com.br

11-81557872 